[DIITIE:NATURE· LIBRARY

BUTTERELIES

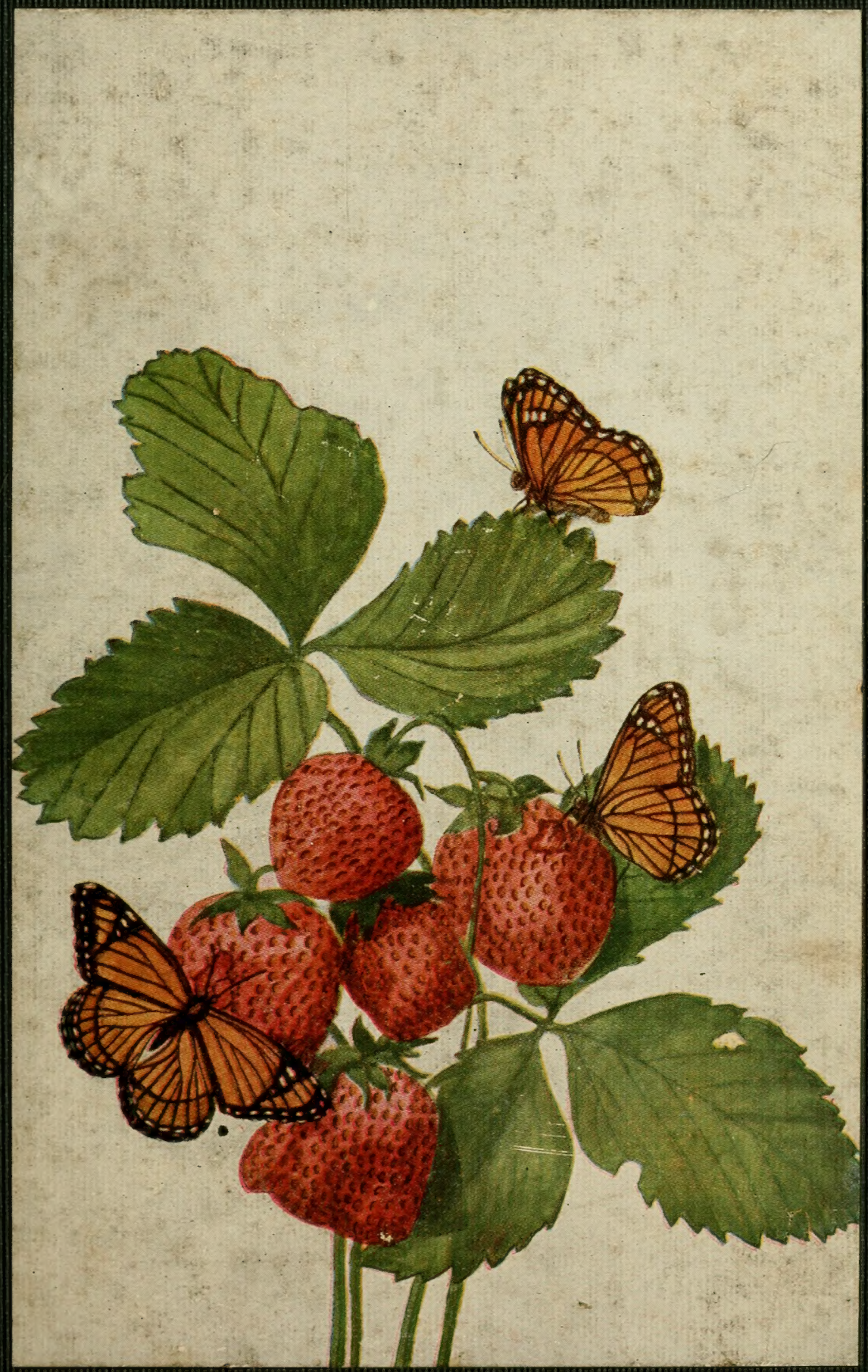

CLARENCE M. WEED 







\section{BUTTERFLIES WORTH KNOWING}






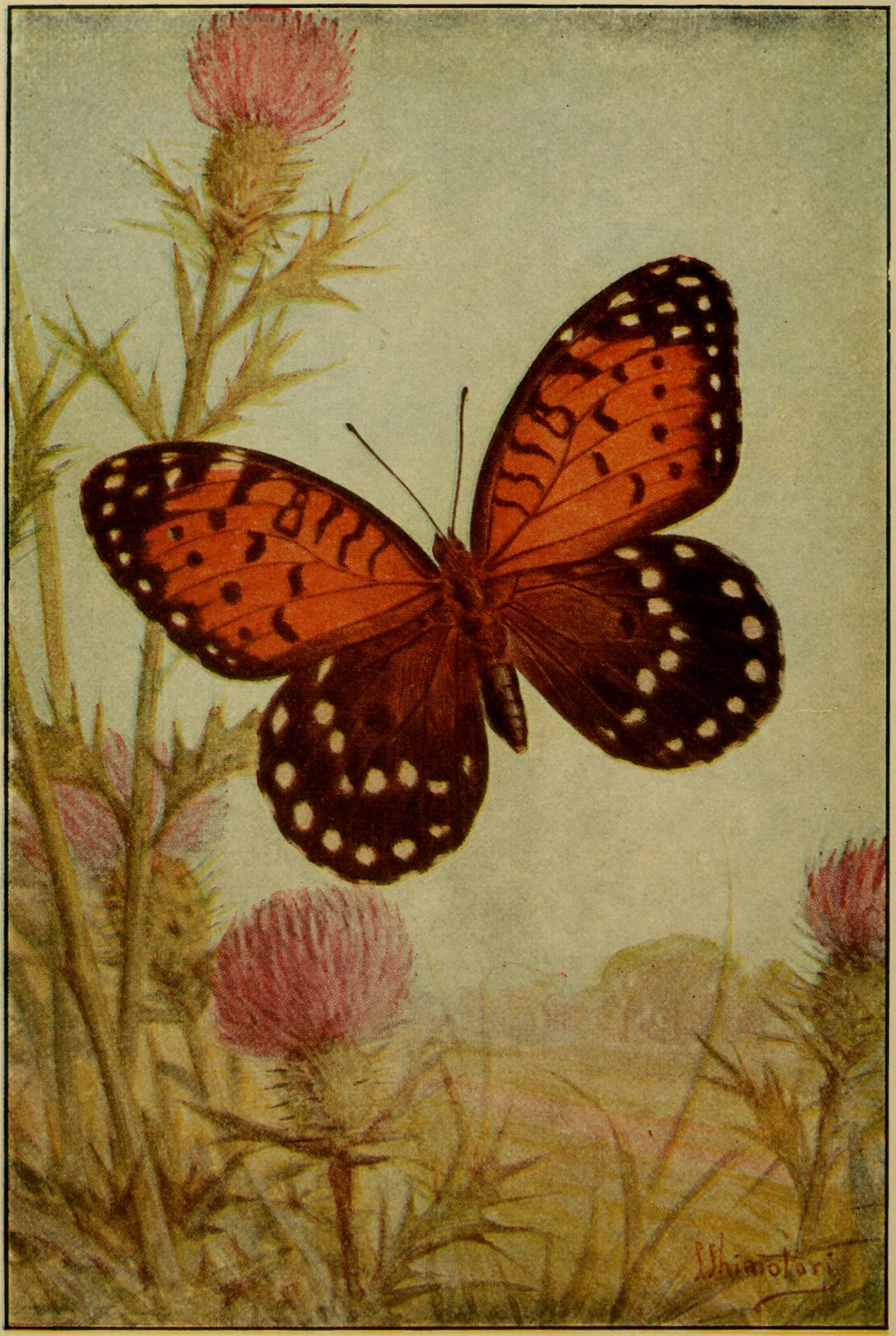

From a drawing by S. Shimotori

See page 120

THE REGAL FRITILLARY, FEMALE 


\section{LITTLE NATURE LIBRARY}

\section{BUTTERFLIES WORTH KNOWING}

By CLARENCE M.' WEED, D. Sc.

\section{AUTHOR OF}

Seeing Nature First, Nature Biographies, Ten New England Blossoms, The Flower Beautiful, etc.

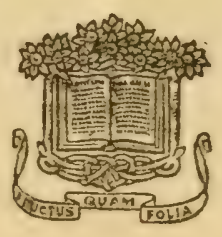

Illustrated by Forty-eight Plates Thirty-two in Color

PUBLISHED BY
DOUBLEDAY, PAGE \& COMPANY
FOR

NELSON DOUBLEDAY, INC. 1923 
Copyright, 1917, by Dodbleday, Page \& Compant

\author{
All rights reserved, including that of \\ translation into foreign languages, \\ including the Scandinavian
}




\section{PREFACE}

IN THIs little book an attempt has been made to discuss the more abundant and widely distributed butterflies of eastern North America from the point of view of their life histories and their relations to their surroundings. In so doing I have of course availed myself of the written records of a host of students of butterflies, without whose labors no such volume would be possible. Among these two names stand out preëminent-William H. Edwards and Samuel H. Scudder. Each was the author of a sumptuous work on American butterflies to which all later students must refer, both for information and for inspiration. Many others, however, have made notable contributions to our literature of these ethereal creatures. Every seeker after a knowledge of butterflies will soon find himself indebted to the writings of such investigators as the Comstocks, Denton, Dickerson, Dyar, Fernald, Fiske, Fletcher, French, Hancock, Holland, Howard, Longstaff, Newcomb, Riley, Skinner, Wright, and many others. I am glad to express my obligations to all of these for the assistance their records have given in the preparation of this book.

While a vast amount of knowledge of butterflies has already been discovered there is still more to be learned concerning them, and throughout these pages I have attempted to indicate the more important opportunities awaiting investigation. The day of the field naturalist has 
come again and the butterflies are well worthy of careful observations by many interested students.

The illustrations in the book require a word of credit. The eleven color plates of adult butterflies with wings spread have been made direct from a set of the remarkable transfers which Mr. Sherman F. Denton has been preparing for the last quarter-century, this particular set having been prepared especially for this book. Transfers of this sort were used as insets in Mr. Denton's work on the "Moths and Butterflies of the United States," published in a limited edition by J. B. Millet Company, Boston. The other plates not reproduced from photographs are from drawings by Miss Mary E. Walker or Mr. W. I. Beecroft. In case the photographs are not of my own taking, credit is given beneath each. Two of my photographs have already appeared in "Seeing Nature First" and are here used by permission of its publishers, J. B. Lippincott Company.

State Normal School, 


\section{CONTENTS}

PAgtace

List of Colored Illustrations . . . . . xi

List of Other Illustrations . . . . . . xiii

\section{PART I}

\section{INTRODUCTION}

Butterfly Transformations . . . . . 5

Butterflies and Moths . . . . . . . . 13

The Scents of Butterflies . . • • • . . 15

Butterfly Migrations . . • • . • . . 16

Hibernation or Winter Lethargy . . . . . 17

Aestivation or Summer Lethargy . • . . . 21

Feigning Death in Butterflies . . . . . 22

Coloration of Butterflies $\quad$. . . . . . 24

Selective Color Sense in Butterflies • . 32

Warning Coloration and Mimicry • • . 33

Heliotropism in Butterflies . . . . . . 35

Parasitic Enemies of Butterflies a . . . 40

Rearing Butterflies from Caterpillars . . . 43

Photographing Butterfles - . . . . . 47

Butterfly Collections . . • • • . . 49 


\section{PART II}

The True Butterfles-Superfamuly Papilionoidea

Parnassians (Parnassiinae)

Swallowtails (Papilionidae) .

Black Swallowtail; Giant Swallowtail; Blue Swallowtail; Green-clouded Swallowtail; Tiger Swallowtail; Palamedes Swallowtail; Short-tailed Papilio; Zebra Swallowtail; Synopsis of the Swallowtails Whites, Orange-tips, and Yellows (Pieridae).

The Tribe of the Whites: White or Imported CabbageButterfly; Gray-veined White; Checkered White; Great Southern White; Synopsis of the Whites.

The Tribe of the Orange-tips: Falcate Orangetip; Olympian Orange-tip; Synopsis of the Orangetips .

The Tribe of the Yellows: Brimstone or Cloudless Sulphur; Dog's-head; Clouded.Sulphur; Orange Sulphur; Pink-edged Sulphur; Black-bordered Yellow; Little Sulphur; Dainty Sulphur; Synopsis of the Yellows.

Nrmphs (Nymphalidae)

The Tribe of the Fritillaries: Gulf Fritillary; Variegated Fritillary; Diana Fritillary; Regal Fritillary; Great Spangled Fritillary; Silver-spot Fritillary; Mountain Silver-spot; White Mountain Fritillary; Meadow Fritillary; Silver-bordered Fritillary; Synopsis of the Fritillaries

The Tribe of the Crescent-spots: Baltimore 
Checker-spot; Harris's Checker-spot; Silver Crescent; Pearl Crescent; Synopsis of the Crescentspots

The Tribe of the Angle-wings: Violet-tip; Hopmerchant or Comma; Gray Comma; Green Comma; Red Admiral or Nettle Butterfly; Painted Beauty; Painted Lady or Cosmopolite; Mourningcloak; American tortoise-shell; White J Butterfly or Compton Tortoise; Buckeye; Synopsis of the Angle-wings (I. Polygonias-II. Vanessids) . .

The Tribe of the Sovereigns: Viceroy; Banded Purple; Red-spotted Purple; Vicereine; Synopsis of the Sovereigns .

The Tribe of the Emperors: Goatweed Emperor; Gray Emperor; Tawny Emperor; Synopsis of the Emperors . . . . . . . . . . . 207

Meadow-Browns or Satrrs (Agapetidae) . . . 214

Common Wood Nymph or Grayling; Southern Wood Nymph; Pearly Eye; Eyed Brown; White Mountain Butterfly; Arctic Satyr; Little Wood Satyr; Other Meadow-browns; Synopsis of Meadow-browns

Heliconians (Heliconidae) Zebra Butterfly

Milkweed Butterflies (Lymnadidae) . . . . 232 Monarch; Queen

SNout Butterfles or LoNG-BEAKs (Libytheidae) .

236 Snout Butterfly

Metal-Marks (Riodinidae) 239 Small Metal-mark; Large Metal-mark 
Gossamer-wings (Lycaenidae)

The Tribe of the Hairstreaks: Great Purple Hairstreak; Gray Hairstreak; Banded Hairstreak; Striped Hairstreak; Acadian Hairstreak; Olive Hairstreak; Synopsis of the Hairstreaks . . . 242

The Tribe of the Coppers: Wanderer; American Copper; Synopsis of the Coppers . . . . . 252

The Tribe of the Blues: Spring Azure; Scudder's Blue; Tailed Blue; Silvery Blue: Synopsis of the Blues

\section{PART III}

The Shipper Butterflies-Superfamily Hesperioidea . . . . . . . . . . . 266

Giant Skrppers (Megathymidae) . . . . . . 267 Yucca-borer Skipper

Common Skippens (Hesperiidae) . . . . . .
The Tribe of the Larger Skippers: Silver-spotted Skipper; Long-tailed Skipper; Juvenal's Duskywing; Sleepy Dusky-wing; Persius's Dusky-wing; Sooty Wing

The Tribe of the Smaller Skippers: Tawny-edged Skipper; Roadside Skipper; Least Skipper 278 


\section{LIST OF COLORED ILLUSTRATIONS}

PAGE

Viceroy Butterfies Visiting Strawberries (On Cover) The Regai Fritillary . . . . . . Frontispiece The Carelina locust • . . . . . . 33

The Black Swallowtall . . . . . . 48

'The Cynthia Moth . . . . . . . . 49

Gtant Swallowtatls . . . . • . • . 64

The Blue Swallowtait . . . . . . . . 65

Two of the Swallowtalls: Palamedes and

Gtant • • . . • • • . • . 66

The Green-clouded Swallowtail . . . . 67

Caterpillars of the Green-clouded SwalLOWTAIL • . . . • . • . • . 80

The Tiger Swallowtall . . . . . . . . . 96

Imported Cabbage Butterfly . . . . . 97

Clouded Sulphur Butterfly . . . . . 112

The $\mathbb{Z}$ ebra Swallowtall: Summer Form . . 112-113

The Zebra Swallowtail Visiting Papaw

BLossoms . . . . . . . . . . 112-113

Some of the Tribe of Yellows . . . . 113

Silver-spot Fritillary and Gulf Fritilitary 128

Gulf Fritillary, Silver-bordered Fritil-

Lary, and Baltimore Checker-spot • • . 129

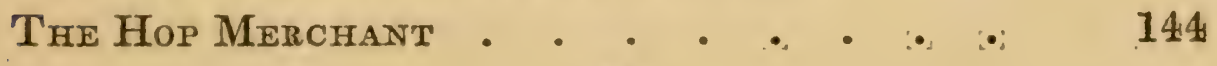




\section{xii LIST OF COLORED ILLUSTRATIONS}

PACE

Three Angle-wings (American Tortoiseshell, Red Admiral, Violet-tip): Upper SURfACE . . . . . . . . . . . 160-161

Three Angle-wings (American Tortoiseshell, Red Admiral, Violet-tip): Lower Surface . . . . . . . . . . 160-161 The Palnted Beauty . . . . . . . . 161

Three More Angle-wings: Buckeye, Painted Beauty, Cosmopolite • . • . . . . 176 The Mourning-Cloak . . . . . . . 177 Some Common Skippers . . . . . . . 192 The Stages of the Viceroy . . . . . . . 193 Banded Purple, Red-spotted Purple, and Blue-eyed Grayling . . . . . . . 208 Three Emperor Butterflies . . . . . 209 The Zebra Butterfly . . . . . . . 224 Monarch Butterfly, Crysalis and Cater-....... PILLAR . . . . . . . . . . . 241 Spring Azure, Falcate Orange-tip, Bronze Copper, and Great Purple Hair-streak - 256 Silver-Spotted SkIPper . . . . . . . . 273 


\section{LIST OF OTHER PLATES}

Swallowtail Butterfly Just out of Chrysalis

Tiger Swallowtail; Hammock Caterpillar .

Butterfly Feigning Death; Butterfly in Hibernating Position . . . . . . . .

Monarch Butterfly: Change from CaterPillar to Chrysalis . . . . . . . . 32-33

Monarch Butterfly: Change from Chrysalis to Adult . . . . . . . . . . . 32-33

Migration of Monarch Butterflies . . . 48-49

The Improved Open Vivarium . . . . . 48-49

Black Stallowtail Visiting Thistle . . . 64-65

Imported Cabbage Butterfly, Magnified . 64-65

Imported Cabbage Butterfly; Blue-eyed Grayling . . . . . . . . . . . 81

Four-footed Butterfles: Viceroy and MoURNING-CLOAK . . . . . . . . . 145

Monarch Butterfly Resting; Flashlight

Photograph of Monarchs in Mrgration . . 160

Photographs of a Pet Monarch Butterfly . 225

The Snout Butterfly; the Giant Swallowtail 240

Stages of the Gray Hair-Streak . . . . . 257

The Silver-Spotted Skipper . . . . . . 272 

BUTTERFLIES WORTH KNOWING 



\section{BUTTERFLIES}

\section{PART I}

\section{INTRODUCTION}

In popular esteem the butterflies among the insects are what the birds are among the higher animals - the most attractive and beautiful members of the great group to which they belong. They are primarily day fliers and are remarkable for the delicacy and beauty of their membranous wings, covered with myriads of tiny scales that overlap one another like the shingles on a house and show an infinite variety of hue through the coloring of the scales and their arrangement upon the translucent membrane running between the wing veins. It is this characteristic structure of the wings that gives to the great order of butterflies and moths its name Lepidoptera, meaning scalewinged.

In the general structure of the body, the butterflies resemble other insects. There are three chief divisions: head, thorax, and abdomen. The head bears the principal sense organs; the thorax, the organs of locomotion; and the abdomen, the organs of reproduction.

By examining a butterfly's head through a lens it is easy to see the principal appendages which it bears. Projecting forward from the middle of the top is a pair of long feelers or antennae. Each of these consists of short joints which 
in general may be divided into three groups: first, a few large joints at the base connecting the feeler with the head; second, many rather small joints which make up the principal length; third, several larger joints which make up the outer part or "club" of the antennæ. In the case of the Skippers, there are in addition a number of small joints coming to a sharp point at the end of the club. Just below the insertion of the antennae on each side of the head

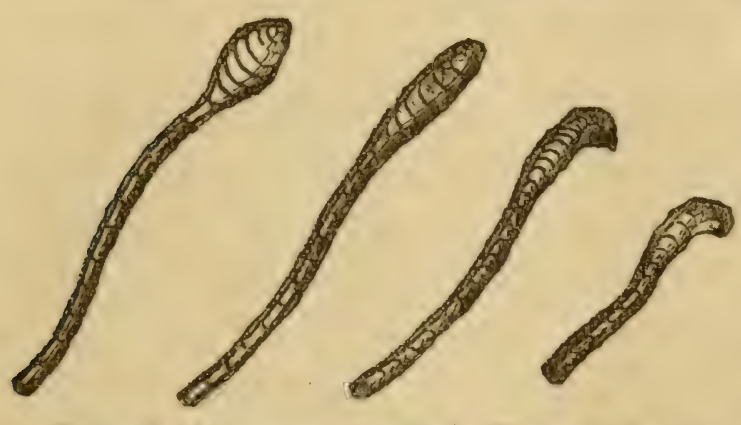

Butterfly Antennae, magnified. (From Holland) are the large compound eyes, which are almost hemispherical. With a powerful glass, one can see the honeycomb-like facets, of which there are thousands, making up each eye. Just below the eyes there are two hairy projections, called the palpi, between which is the coiled tongue or sucking tube. (See plate, page 64-65.)

Anatomically the thorax is divided into three partsthe prothorax, the mesathorax, and the metathorax; but the lines of division between these parts are not easily seen without denuding the skin of its hairy covering. The prothorax bears the first pair of legs. The mesathorax bears the front pair of wings and the second pair of legs. The metathorax bears the hind pair of wings and the third pair of legs. In many butterflies, the first pair of legs are so reduced in size that they are not used in walling.

The abdomen is composed of eight or nine distinct rings or segments, most of which have two spiracles or breathing pores, one on each side. It also bears upon the end of the 
body the ovipositor of the female or the clasping organs of the male.

\section{Butterfly Transformations}

The butterflies furnish the best known examples of insect transformations. The change from the egg to the caterpillar or larva, from the caterpillar to the pupa or chrysalis, and from the chrysalis to the butterfly or imago is doubtless the most generally known fact concerning the life histories of insects. It is a typical example of what are called complete transformations as distinguished from the manner of growth of grasshoppers, crickets, and many other insects in which the young that hatches from the egg bears a general resemblance to the adult and in which there is no quiet chrysalis stage

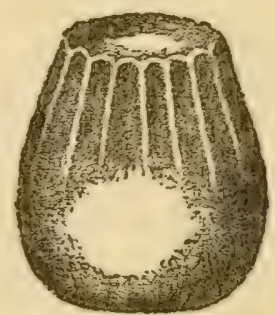

Egg of Baltimore Butterfly, much magnified. (From Holland) when the little creature is unable to eat or to move about.

\section{The Growth of the Caterpillars}

Caterpillars are like snakes in at least one respect: in order to provide for their increase in size they shed their skins. When a caterpillar hatches from the egg it is a tiny creature with a soft skin over most of its body but with rather a firm covering for its head. While we might fancy that there could be a considerable increase in size provided for by the stretching of the soft skin it is easy to see that the hard covering of the head will not admit of this. So the story of the growth of a caterpillar may be told in this way: 
A butterfly lays an egg upon a leaf. Some days later the egg hatches into a larva, which is the technical name for the second stage of an insect's life. In the case of the butterfly we call this larva a caterpillar. The little caterpillar is likely to take its first meal by eating the empty egg shell. This is a curious habit, and a really satisfactory explanation of it seems not to have been made. Its next meal is likely to be taken from the green tissues of the leaf, commonly the green outer surface only being eaten at this time. The future meals are also taken from the leaf, more and more being eaten as the larva gets older.

After a few days of this feeding upon the leaf tissues the little caterpillar becomes so crowded within the skin with which it was born that it is necessary to have a larger one. So a new skin begins to form beneath the first one. Consequently the latter splits open in a straight line part way down the middle of the back just behind the head. Then the new head covering is withdrawn from the old one and the caterpillar wriggles its way out of the split skin and finds itself clothed in a new one. At first all of the tissues of the new skin are soft and pliable and they easily take on a larger size as the body of the caterpillar expands. A little later these tissues become hardened and no further expansion is possible.

This process of skin-shedding is called moulting. The cast skin is often called the exuviae. The period of the caterpillar's life between the hatching from the egg and this moult is often called a stage or instar-that is, the caterpillar up to the time of this moult is living in the first caterpillar stage or instar.

During the actual moulting the caterpillar is quite 


\section{INTRODUCTION}

active in freeing itself from the exuviae. But as soon as it is free it is likely to rest quietly for some hours while the tissues of the new skin are hardening. Then it begins feeding upon the leaf again and continues taking its meals at more or less regular intervals for several days. By that time it will again have reached its limit of growth within this second skin and the process of moulting must be repeated. It takes place in the same way as before and the caterpillar enters upon the third instar of its larval life.

This process of feeding and moulting is continued for several weeks, the number of moults being usually four. During the later stages the increase in size is more marked each time the skin is shed, until the caterpillar finally reaches its full growth as a larva and is ready for the wonderful change to the quiet chrysalis in which all its caterpillar organs are to be transformed into the very different organs of the butterfly.

In the case of butterfly larvae one of the most interesting features of the growth of the caterpillar is that of the remarkable changes in colors and patterns of marking which the caterpillar undergoes. One who had not followed these changes would often be at a loss to recognize caterpillars of slightly differing sizes as belonging to the same species. These changes commonly show a remarkable adaptation to the conditions of life, and generally tend to the concealment of the caterpillar upon its food plant. The stages of growth of the green-clouded swallowtail caterpillar are illustrated on plate opposite page 80 .

Before each moult the caterpillar is likely to spin a silken web upon the leaf surface. It then entangles its claws in the web to hold itself in place while the skin is cast. (See plate, page 1\%.) 


\section{The Change to the Chrysalis}

(See plate, pages 32-33.)

A week or ten days after the last moult of its caterpillar growth the larva commonly becomes full fed and ready to change to the chrysalis state. The details of the way in which this is accomplished vary greatly with different butterflies, as will be noted in the stories of many species later in this book. In general, however, the caterpillar provides a web of silk which it spins against some surface where the chrysalis will be secure and in this web it en-
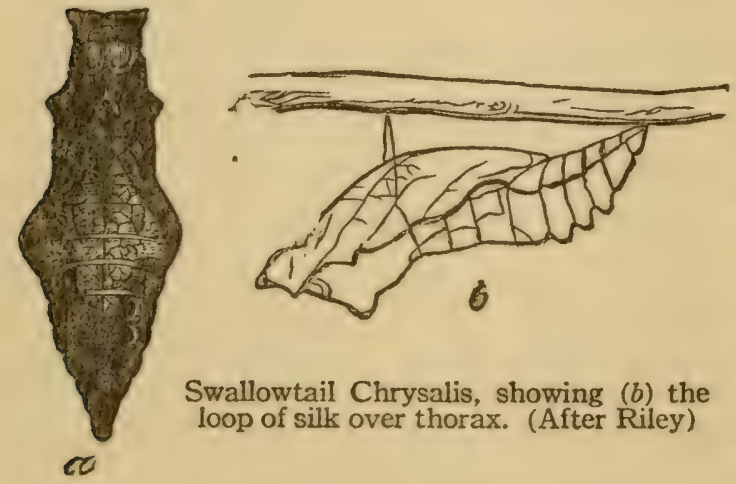

Swallowtail Chrysalis, showing (b) the loop of silk over thorax. (After Riley)

tangles its hind legs. Sometimes there is the additional protection of a loop of silk over the front end of the body. After the legs have become entangled the caterpillar hangs downward until the skin splits open along the median line of the back and gradually shrinks upward until it is almost free, showing as it comes off a curious creature which has some of the characteristic features of a chrysalis. It is seldom at this stage of the same shape as the chrysalis. When the caterpillar's skin is nearly off this chrysalis-like object usually wriggles its body quickly in a manner to entangle a curious set of hooks attached to the upper end in the web of silken thread. This hook-like projection is called the cremaster, and it serves a very important purpose in holding the chrysalis in position. 
As soon as the cremaster is entangled in the web the cast skin usually falls off and for a very short period the creature hanging seems to be neither caterpillar nor chrysalis. It is in fact in a transition stage between the two, and it very soon shortens up and takes on the definite form of the chrysalis, the outer tissues hardening into the characteristic chrysalis skin.

From the fact that this chrysalis skin shows many of the characteristic features of the future butterfly it is evident that the change from the caterpillar to the butterfly really began during the life of the larva. The nature of the process by which this change takes place has long been a puzzle to scientists. For the making of a butterfly is one of the most wonderful phenomena in the outer world, and it has challenged the attention of many acute observers. Some two centuries ago the great Dutch naturalist, Swammerdam, studied very carefully the development of many insects, especially the butterfly. He found that if he placed in boiling water a caterpillar that was ready to pupate or become a chrysalis, the outer skin could easily be removed, revealing beneath the immature butterfly with well-developed legs and antennae. From these observations he was led to believe that the process of growth was simply a process of unfolding; that is, as Professor Packard has expressed it, "That the form of the larva, pupa, and imago preëxisted in the egg and even in the ovary; and that the insects in these stages were distinct animals, contained one inside the other, like a nest of boxes or a series of envelopes one within the other." This was called the incasement theory and it was held to be correct by naturalists for nearly a century. It was discredited, however, about a hundred years ago, but not until another fifty 
years had passed was it definitely replaced by another and much more convincing theory propounded by Weismann. According to Weismann's theory, which is now wellestablished, the process of development internally is a much more continuous one than the external changes would indicate. So far as the latter are concerned we simply say that a caterpillar changes to a chrysalis and a chrysalis to a butterfly, the transition in each case requiring but a very short time. Internally, however, it has been going on almost continuously from the early life of the caterpillar. The various organs of the butterfly arise from certain germinal disks or "imaginal" buds, the word "imaginal" in this case being an adjective form of imago, so that the imaginal buds are really simply buds for the starting of growth of the various organs of the imago or adult. As the caterpillars approach the chrysalis period these imaginal buds rapidly develop into the various organs of the butterfly. This process is helped along by the breaking down of many of the tissues of the larva, this broken-down tissue being then utilized for the production of the new organs. About the time the chrysalis is formed this breaking-down process becomes very general, so that the newly formed chrysalis seems largely a mass of creamy material which is soon used to build up the various parts of the butterfly through the growth of the imaginal buds.

\section{The Change to the Butterfly}

(See plate, pages 32-33.)

There is probably no phenomenon in the world of living creatures which has attracted more attention than the change of the chrysalis into the butterfly. It is not strange that this is so. We see upon a tree or shrub or wall 
an inert, apparently lifeless object, having no definite form with which we can compare it with other things, having neither eyes nor ears nor wings nor legs-an object apparently of as little interest as a lifeless piece of rock. A few minutes later we behold it again and note with astonishment that this apparently inanimate being has been suddenly transformed into the most ethereal of the creatures of earth, with an exquisite beauty that cannot fail to attract admiration, with wings of most delicate structure for flying through the air, with eyes of a thousand facets, with organs of smell that baftle the ingenuity of man to explain, with vibrant antennae, and a slender tongue adapted to feeding upon the nectar of flowers-the most ambrosial of natural food. So it is not strange that this emergence of a butterfly has long been the theme both of poets and theologians and that it attracts the admiring attention of childhood, youth, and age.

Fortunately, this change from chrysalis to butterfly may readily be observed by any one who will take a little trouble to rear the caterpillars or to watch chrysalids found outdoors. The precise method of eclosion, as we call this new kind of "hatching," varies somewhat with different species but in general the process is similar in all.

Those chrysalids which have a light colored outer skin are especially desirable if we would watch this process. One can see through the semi-transparent membrane the developing butterfly within, until finally, just before it is ready to break out, the markings of the wings and body show distinctly. If at this time the chrysalis is placed in the sunshine it is likely to come out at once, so that you can observe it readily. It usually breaks apart over the head. 
and the newly released legs quickly grasp hold of the empty skin as well as of the support to which it is attached. It then hangs downward with a very large abdomen and with the wings more or less crumpled up, but decidedly larger than when they were confined within the chrysalis. The wings, however, soon begin to lengthen as they are stretched out, probably through the filling of the space by the body juices. Commonly, the hind pair of wings become full size before the front ones. In a short time the wings attain their full size, the abdomen becomes smaller, through the discharge of a liquid called meconium, and the butterfly is likely to walk a few steps to a better position where it will rest quietly for an hour or two while body and wing tissues harden. After this it is likely to fly away to lead the free life of a butterfly. (See plate, page 16.)

These changes from larva to chrysalis and from chrysalis to adult in the case of the Monarch Butterfly are illustrated on the plates opposite pages 32-33. A little study of these photographs from life will help greaily to an understanding of the process.

Some very interesting observations have been made by Mr.J. Alston Moffat upon the method of the expansion of the wings. In summarizing his investigations he writes:

"When a wing is fully expanded, and for an hour or two after, the membranes can be easily separated. Entrance for a pin-point between them is to be found at the base of the wing where the subcostal and median nervures come close together. The membranes are united at the costal and inner edges, which have to be cut to get them apart; but they are free at the outer angle. At that time the nervures are in two parts, half in one membrane and half 
in the other, and spen in the centre. The fluid which has been stored up in the pupa enters the winglet at the opening referred to, expanding the membranes as it passes along between them, and the nervures at the same time, and when it has extended to every portion of the wing, then it is fully expanded. The expanding fluid is of a gummy consistency, and as it dries, cements the membranes together, also the edges of the half-nervures, and produces the hollow tubes with which we are so familiar."

\section{BUtTerfles AND Moths}

The butterflies and moths both belong to the great order of scale-winged insects - the Lepidoptera. They are distinguished, however, by certain general characteristics, which hold true for the most part in both groups. The butterflies fly by day; the moths fly by night. All of the higher butterflies go into the chrysalis state without making a silken cocoon, while most of the higher moths make such a cocoon. The bodies of the butterflies are usually slender, while those of the larger moths are stout. The antennae of the butterflies are generally slender and commonly en-

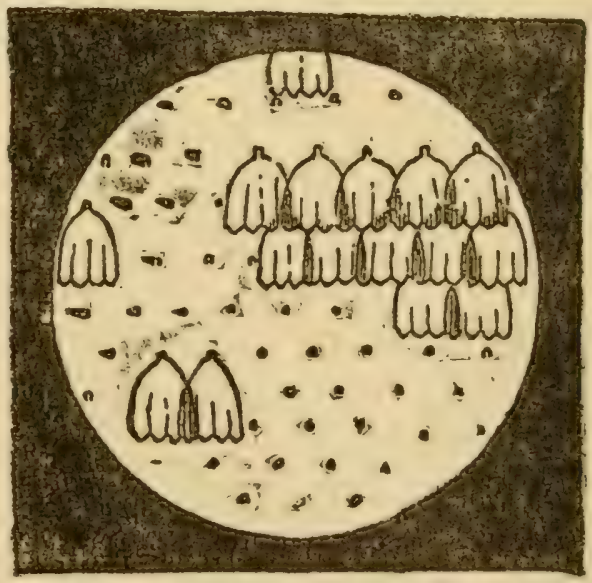

Butterfly wing scales, magnified. (From Holland)

larged at the tip into a miniature club. The antennae of the larger moths are commonly feathery or are long and slender, tapering gradually toward the tip. 
The characteristic features that distinguish a moth from a butterfly are well illustrated in the plate opposite page 49, which shows one of the largest and most beautiful moths in the world. It is the Cynthia moth. As may be seen, the newly emerged moth is resting upon the silken cocoon in which it spent its period as a pupa or chrysalis. This cocoon was attached by the caterpillar to the twig from which it hangs at the time it spun the cocoon. The feathered antennae, the hairy legs, the thick thorax, and large abdomen - all show very clearly in this side view of the moth. As will be seen, the wings are large and very suggestive of those of a butterfly and have the characteristic eye-spots toward the tip and the crescent marks in the middle, which are so often found on the wings of the larger moths.

Some of these large moths on cloudy days occasionally fly during daylight and, by the uninitiated, they are often mistaken for large butterflies. One who will notice their structure, however, will readily see the characteristic featu of the moth.

In the caterpillar stage, there are no hard and fast differences between the larvae of butterflies and those of the higher moths. In each case, the insect consists of a wormlike body, having a small head provided with biting jaws and simple eyes or ocelli. Back of the head are the three rings of the thorax, each of which bears a pair of jointed legs. Back of these three rings there are a considerable number of other body rings making up the abdomen, on the middle of which there are commonly four or five pairs of fleshy prolegs, not jointed but furnished at the tip with fine claws. At the hind end of the body there is another pair of prolegs similar in structure. 


\section{The Scents of Butterflies}

Many students of American butterflies have occasionally mentioned the fact that certain species seem to give off a distinct scent which has frequently been spoken of as a pleasing fragrance, suggesting sandalwood or some other aromatic odor. The general subject as exemplified by butterflies of other lands has been studied for many years by Fritz Müller; and certain English entomologists have paid considerable attention to it. A translation of the Muiller publications and an excellent summary of our present knowledge of the subject is published in Dr. Longstaff's book on butterfly hunting.

The odors given off by butterflies are divided into two principal kinds, namely: first, those which are repulsive to the senses of man, and evidently for the purpose of protecting the butterflies from birds and other vertebrate enemies - these are found in both sexes; second, those which are evidently for the purpose of sexual attraction and confined to the male butterflies-these scents are usually attractive to the senses of man.

The aromatic scents of the second group are generally produced by means of certain scales or hairs of many curious forms, which are scattered over the surface of the wings or are placed within certain

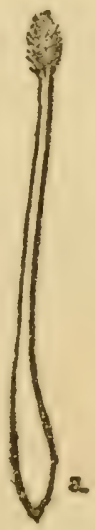

Androconia from wings of male butterflies special pockets, generally near the borders of the wings. These scales or hairs are called androconia. Some of them much magnified are represented in the picture above. 
Our knowledge of the scents given off by American butterflies is very fragmentary, and it is highly desirable that many more observations should be made upon the subject. If collectors generally would make careful notes, both in the field and upon the freshly killed butterflies at home, we ought soon to be able greatly to extend our knowledge. By holding the butterfly with a pair of forceps, one can often determine whether the fragrance is emitted. It is often helpful also to brush the hairs or tufts where the androconia are attached, using a small, dry camel's hair brush for the purpose.

\section{Butterfly Migrations}

Migration seems to be a general instinct in the animas world, developed when a species becomes enormously abundant. At such times this instinct apparently overcomes all others and the creatures move on regardless of obstacles and conditions that may mean certain death to the vast majority. Such migrations among mammals have often been recorded, one of the most notable examples being that of the little lemmings which migrate at periodical intervals in a way which has often been described. Among the insects such migrations have been frequently noticed, and the phenomenon has apparently been observed oftener among the butterflies than in any other group. Entomological literature during the last hundred years contains a great many records of enormous flights of butterflies over long distances, extending even from Africa into Europe or from one part of America to another far remote. As such migration is likely to happen whenever a species becomes extremely abundant it prob- 


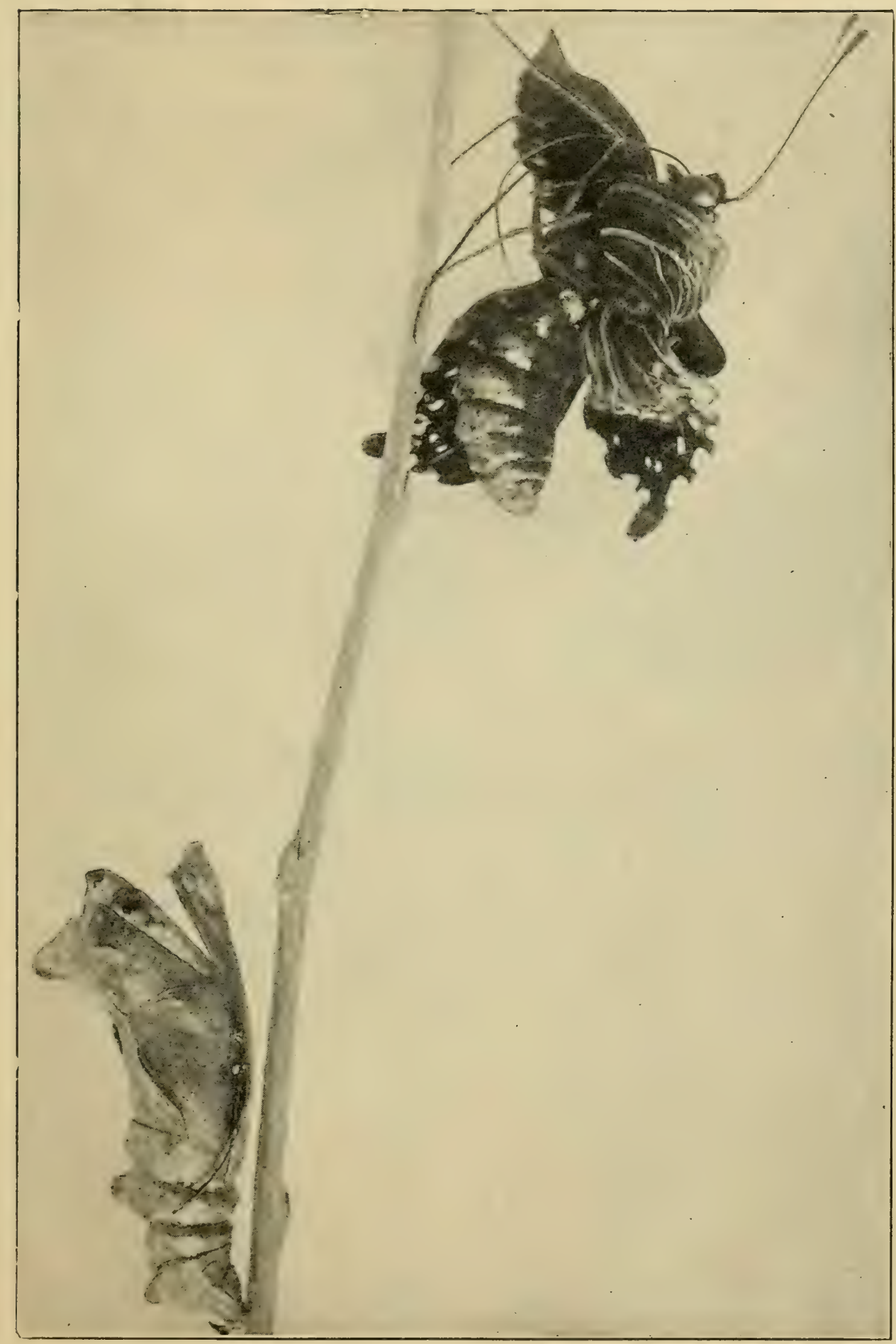

Photographed from life by $A$. H. Verrill See page 12 SWALLOWTAIL BUTTERFLY JUST OUT OF ITS CIIRYSALIS. TIIE CHIRYALIS SKIN BELOW 


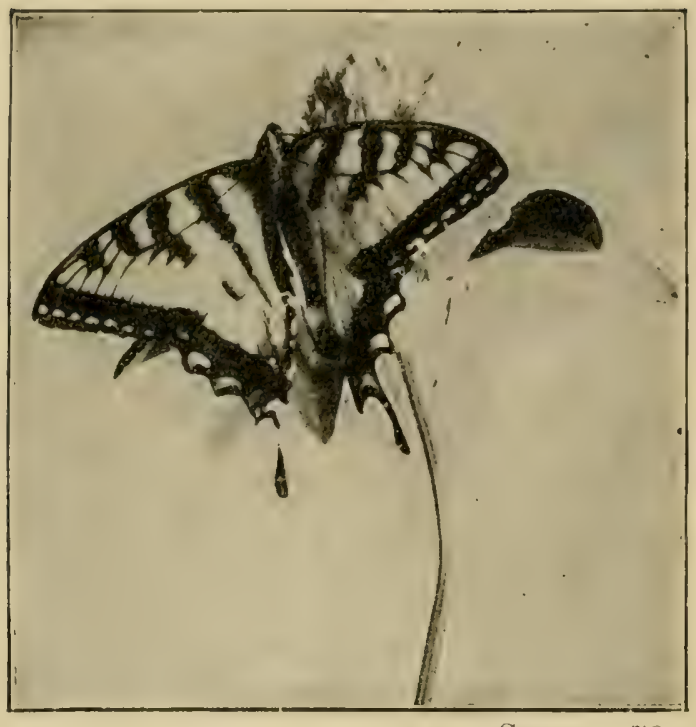

See page \%?

TIGER SWALLOWTAIL

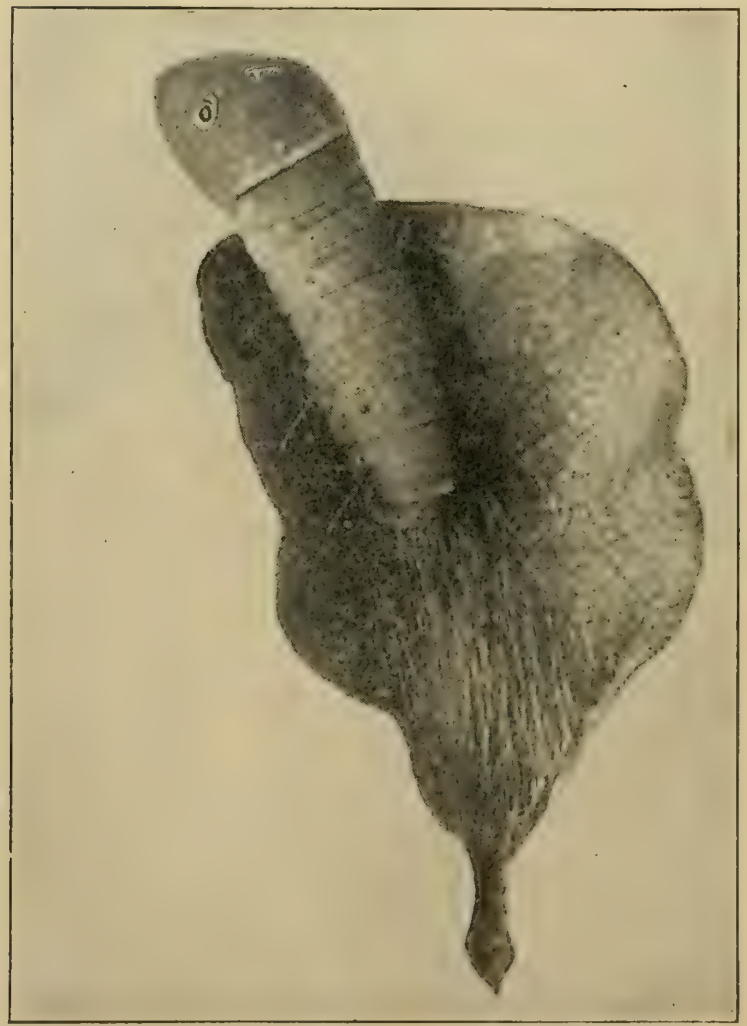

Photographed from life

See page 7

THE HAMMOCK CATERPILLIR ON ITS HAMMOCK 
ably is Nature's way of providing for an extended food supply for the succeeding generations. That it results in the death of the great majority of the migrants is cloubtless true, but it must lead to vast experiments in extending the geographic area inhabited by these species. Numerous examples of such migrating swarms will be found in the pages of this little book. (See plates, pages 17, 48-49, 160.)

The migrations thus considered are only exceptional occurrences. There is, however, a regularly recurring annual migration on the part of some butterflies which is also a phenomenon of extraordinary interest. The most notable example is that of the Monarch which apparently follows the birds southward every autumn and comes northward again in spring. There is much evidence to indicate that in some slight degree other butterflies have a similar habit, although the present observations are inadequate to determine to what extent this habit has become fixed in most of these species.

\section{Hibernation or Winter Lethargy}

The ways in which butterflies spend the winter are always of peculiar interest to the naturalist. Here are creatures with four distinct stages of existence, each of which has the possibility of carrying the species through the season of cold. It is necessary to learn for each insect which stage has been chosen for the purpose, and if possible to find the reasons for the choice.

As a rule the related members of a group are likely to hibernate in a similar stage. Thus most of the Swallowtails pass the winter as chrysalids while practically all the Angle-wings pass the winter as adults. This rule, how- 
ever, has many exceptions, for one will often find closely re?ated species which differ in the stage of hibernation.

As one would expect, the conditions of hibernation vary greatly with the latitude. In the severe climate of the far north the conditions are likely to be more uniform than in the South where the milder climate permits greater variation to the insect. In some cases where a butterfly hibernates in only one stage in Canada it may pass the winter in two or more stages in Alabama or Florida.

In many other orders of insects the egg is a favorite stage for hibernation. Even in the closely related moths it is often chosen by many species, but comparatively few butterflies pass the winter in the egg stage. The little Bronze Copper may serve as one example of this limited group.

The conditions as to hibernation by the larvae of butterflies are very different from those of the egg. It has been estimated that probably half of all our species pass the winter in some stage of caterpillar growth. This varies all the way from the newly hatched caterpillar which hibernates without tasting food to the fully grown caterpillar which hibernates full fed and changes to a chrysalis in spring without eating anything at that time. A large proportion, however, feed both in fall and spring, going through the winter when approximately half grown.

The Graylings and the Fritillaries are typical examples of butterflies which hibernate as newly hatched larvae. The eggs are laid in autumn upon or near the food plants and the caterpillars gnaw their way out of the shells and seek seclusion at once, finding such shelter as they may in the materials on the soil surface. In spring they begin to feed as soon as the weather permits and complete their growth from then on. 
The half-grown caterpillars may hibernate either as free creatures under boards, stones, or in the turfy grass, or they may be protected by special shelters which they have provided for themselves in their earlier life. In the case of the latter each may have a shelter of its own or there may lbe a common shelter for a colony of caterpillars. Among the examples of those hibernating in miscellaneous situations without special protection the caterpillars of the Tawny Emperor, the Gray Emperor, the Pearl Crescent, and some of the Graylings are examples. Among those which hibernate in individual shelters the Sovereigns, among which our common Viceroy is most familiar, are good examples. Among those which hibernate in a tent woven by the whole colony for the whole colony the Baltimore or Phaeton butterfly is perhaps the best example.

The caterpillars that hibernate when full grown may be grouped in a way somewhat similar to those which are half grown. Many species simply find such shelter as they may at or near the soil surface. The Clouded Sulphur is a good example of these. Others pass the winter in individual shelters made from a leaf or blade. Several of the larger Skippers are good examples of this condition. So far as I know none of our species pass the winter in colonial shelters when full grown.

It would be natural to suppose that the great majority of butterflies would be likely to hibernate in the chrysalis state. Here is a quiet stage in which the insect is unable to move about or to take any food, in which it seems entirely dormant and as a rule is fairly well hidden from the view of enemies. We find, however, that only a rather small proportion of our butterflies has chosen this stage 


\section{BUTTERFLIES}

for survival through the winter. The most conspicuous examples are the Swallowtails, nearly all of which hibernate in the chrysalis stage. Other examples are the various Whites, the Orange-tips, and isolated species like the Wanderer, and the Spring Azure and the American Copper. Practically all the butterflies that pass the winter as chrysalids have a silken loop running around nex. the middle of the body which helps to hold them securely through the long winter months. Apparently none of those chrysalids which hang straight downward are able to survive the winter.

An adult butterfly seems a fragile creature to endure the long cold months of arctic regions. Yet many of our most beautiful species habitually hibernate as adults, finding shelter in such situations as hollow trees, the crevices in rocks, the openings beneath loose bark or even the outer bark on the under side of a large branch. It is significant that most of the adult-wintering Angle-wings are northern rather than southern species, some of them being found in arctic regions practically around the world. One of the few southern forms that hibernates as an adult is the Goatweed Emperor.

These examples are all cases of true hibernation in a lethargic condition. There are certain butterlies, however, which pass the winter as adults that remain active during this period. Obviously this is impossible in latitudes where the winter is severe, and it involves migration to a warmer climate. The one notable illustration of this is the Monarch butterfly which apparently flies southward to the Gulf states at least and there remains until spring, when individuals come north again. The southward migration may be begun in Canada when the butterflies 
gather together in enormous flocks that remind one of the gathering of the clans with the migrating birds. This is one of the least understood of insect activities but it has been observed so often and over so long a period of years that there seems to be no questioning the general habit.

Like everything else in relation to living things there are numerous variations in the prevailing modes of hibernation. In the case of many species one can find combinations of two or more stages in which the winter is passed. Probably if we could observe with sufficient care we might be able to ind somewhere examples of almost any conceivable double combination-as egg with larva or chrysalis or adult - the insect hibernating in two of these stages. Many cxamples are known in which both chrysalis and adult of the same species pass the winter and also of those in which young and well-grown larvae pass the winter. As one would expect, the conditions as to such combinations are likely to be more variable in southern than in northern regions.

Notwithstanding ail the attention which has been paid to butterfiy life-histories there is still some uncertainty in regard to the hibernation of many of our species. One of the most interesting series of observations which a young naturalist could undertake would be to learn positively how each species of butterfly in his locality passes the winter.

\section{Aestivation or Summer Lethargy}

In some species of butterflies there is a special adaptation to passing through the hottest part of the summer season. in a state of lethargy which is suggestive of the torpor of 
the hibernating period. This phase of butterfly existence has not been extensively studied and there are indications that it exists more generally than has been commonly supposed. It has been noticed even in northern New England that some of the Angle-wings seek shelter and become lethargic during August. Apparently this is an adaptation to single broodedness, helping to carry the species through the year without the exhaustion incident to the continued activity of the butterfly.

In more southern regions, especially in the hot, dry climates where vegetation withers in midsummer, it is well known that some caterpillars become lethargic, remaining inactive until the fall rains start vegetation into growth. The Orange-sulphur butterfly is a good example of this.

This summer lethargy offers excellent opportunity for careful study. Any observer who finds a butterfly hidden away in summer under boards, the bark of a tree, or in a stone pile should look carefully to see what species it is and how the butterfly behaves. Such observations should be sent to the entomological journals in order that our knowledge of the subject may be increased.

\section{Feigning Death}

The fact has long been noticed that various butterflies have the habit at times of feigning death and dropping to the grcund where they may lie motionless for a considerable period. This habit is most easily observed in some of the Ancle-wings, especially those which hibernate as adults. Those species have the under surfaces of their wings colored in various bark-picturing patterns and ap- 
parently live through the winter to some extent, resting beneath the bark of large branches or upon the trunks of trees. Many of them also secrete themselves in hollow trees or beneath loose bark or in board piles or stone walls. It is probable, however, that during the long ages when these insects were adapting themselves to their life conditions, before man interfered with the natural order and furnished various more or less artificial places for hibernation, these butterflies rested more generally upon the under side of branches than they do now.

Even in warm weather when one of these butterflies is suddenly disturbed it is likely to fold its legs upon its body and drop to the ground, allowing itself to be handled without showing any signs of life. This habit is doubtless of value, especially during hibernation or possibly during the summer lethargy or aestivation, the latter a habit which may be more general among these butterflies than is now supposed. As the insect lies motionless upon the ground it is very likely to blend so thoroughly with its surroundings that it becomes concealed, and any bird which had startled it from the branch above would have difficulty in finding it.

Some very interesting observations have been made upon the death-feigning instincts of various other insects, especially the beetles. But no one so far as I know has yet made an extended study of the subject in relation to our American butterflies. It is an excellent field for investigation and offers unusual opportunities for photographic records. One of the pictures opposite page 32 shows a photograph which I took of a Mourning Cloak as it was thus playing 'possum. This species exhibits the instinct to a marked degree. 


\section{Coloration}

The caterpillars of butterflies and moths form a large part of the food of insect-eating birds. These caterpillars are especially adapted for such a purpose and in the economy of nature they play a very important part in keeping alive the feathered tribes. During the long ages through which both birds and insects have been developing side by side, there have been many remarkable inter-relations established which tend on the one hand to prevent the birds from exterminating the insects and on the other to prevent the insects from causing the birds to starve. The most important of these, so far as the caterpillars are concerned, are the various devices by which these insects protect themselves from attack, by hiding away where birds are not likely to find them, by clothing their bodies with spiny hairs, by other methods of rendering themselves distasteful, or by various phases of concealing coloration. On the whole, the examples of the latter are not so numerous or so easily found in the case of the larvae of butterflies as in those of moths.

Perhaps the basal principle of concealing coloration is the law of counter-shading, first partially announced by Prof. E. B. Poulton, and later much more elaborately worked out by Mr. Abbott H. Thayer, and discussed at length by Mr. Gerald H. Thayer in his remarkable volume, "Concealing Coloration in the Animal Kingdom." The law of counter-shading is tersely stated in these words: "Animals are painted by nature darkest on those parts which tend to be most lighted by the sky's light and vice versa." As this law works out on most animals that live 
on or near the ground, the upper part of the body exposed to the direct light from above is dark; and the under part, shut off from the upper light and receiving only the small reflection from below, is enough lighter to make the appearance of the creature in its natural environment of a uniform tone from back to breast.

Nearly all caterpillars illustrate this law of countershading. If they are in the habit of feeding or resting with their feet downward the back will be darker and the under side lighter, but if they are in the habit of feeding or resting in the opposite position these color tones will be reversed. One can find examples of such conditions almost any summer's day by a little searching of trees or shrubs.

This law of counter-shading, however, is really only the basis for the coloration of caterpillars or other animals. It tends, chiefly, to make the creature appear as a flat plane when seen from the side, and may be said in a way to prepare the canvas upon which Nature paints her more distinctive pictures. A great many examples of color markings that tend to conceal the caterpillar amid its natural surroundings may be found by any one who will study the subject and it offers one of the most interesting fields for investigation. The chapter on caterpillars in the abovementioned book by Mr. Thayer should serve as a starting point for any one taking up the subject.

Butterflies differ from caterpillars and from most other animals in the fact that their coloring is chiefly shown upon the flat surfaces of the wings. Consequently, there is less opportunity for the various phases of counter-shading which is so commonly shown in the larger caterpillars. The bodies of nearly all butterflies do exhibit this phenom- 
enon, but these bodies are relatively so small that countershading plays but a little part in the general display.

Upon the outstretched membranes of the butterflies' wings Nature through the long ages of development has painted a great variety of pictures. Those which tend to protect the insect by concealment amid its surroundings are most commonly spread on the under surface of the wings. Especially is this true in the case of those species which pass the winter as adults or which have the habit of resting upon the bark of trees, the sides of rocks, or the surface of the ground. We here find some of the most interesting examples of obliterative coloring that occur in nature. Some butterflies have taken on the look of tree bark, others the sombre appearance of weathered rocks, while still others are painted with the images of flowerets and their stems.

\section{Dazzling and Eclipsing Colors}

Many of the butterflies, especially the Angle-wings, which are marked on the under surface in various protective colors, are admirable examples of that phase of animal coloring which is spoken of as dazzling coloration. This is apparently one of the most important protective devices to be found in Nature and the validity of it is now generally conceded by naturalists. One phase of it, which may be called eclipsing coloration, seems to have been first definitely formulated by the late Lord Walsingham, a famous English entomologist who enunciated it in an address as president of the Entomological Society of London. The most significant paragraphs in that address were these:

"My attention was lately drawn to a passage in Herbert Spencer's 'Essay on the Morals of Trade.' He writes: 
'As when tasting different foods or wines the palate is disabled by something strongly flavored from appreciating the more delicate flavor of another thing afterward taken, so with the other organs of sense a temporary disability follows an excessive stimulation. This holds not only with the eyes in judging of colors, but also with the fingers in judging of texture.'

"Here, I think, we have an explanation of the principle on which protection is undoubtedly afforded to certain insects by the possession of bright coloring on such parts of their wings or bodies as can be instantly covered and concealed at will. It is an undoubted fact, and one which must have been observed by nearly all collectors of insects abroad, and perhaps also in our own country, that it is more easy to fcilow with the eye the rapid movements of a more conspicuous insect soberly and uniformly colored than those of an insect capable of changing in an instant the appearance it presents. The eye, having once fixed itself upon an object of a certain form and color, conveys to the mind a corresponding impression, and, if that impression is suddenly found to be unreliable, the instruction which the mind conveys to the eye becomes also unreliable, and the rapidity with which the impression and consequent instruction can be changed cannot always compete successfully with the rapid transformation effected by the insect in its effort to escape."

Lord Walsingham then goes on to suggest that this intermittent play of bright colors probably has as confusing effect upon birds and other predaceous vertebrates as upon man; and that on this hypothesis such colors can be accounted for more satisfactorily than upon any other yet suggested. Since then the significance of this theory has 
been repeatedly pointed out by Professor Poulton, Mr. Abbott $\mathrm{H}$. Thayer, and various other authorities upon animal coloring. The terms dazzling and eclipsing have been applied to the phenomenon.

Shortly after Lord Walsingham propounded this theory I called attention* to its fitness in explaining some of the most interesting color phases shown by American insects, notably the moths and locusts which have brilliantly colored under wings and protectively colored upper wings.

The animals of the north show numberless color phases of interest. One of the most curious of these is exhibited by several families of insects in which the outer wings are protectively colored in dull hues and the under wings brightly colored. For example, there are many species of moths belonging to the genus Catocala found throughout the United States. These are insects of good size, the larger ones measuring three inches in expanse of wings, and the majority of them being at least two thirds that size. Most of them live during the day on the bark of trees, with their front wings folded together over the back. The colors and markings of these wings, as well as of the rest of the exposed portions of the body, are such as to assimilate closely with the bark of the tree upon which the insect rests. In such a situation it requires a sharp eye to detect the presence of the moth, which, unless disturbed, flies only at night, remaining all day exposed to the attacks of many enemies. Probably the most important of these are the birds, especially species like the woodpeckers, which are constantly exploring all portions of the trunks of trees.

*Popular Science Monthly, 1898, "A Game of Hide and Seek." Reprinted in the Insect World, 1899. 
The chief beauty of these Catocalas, as they are seen spread out in the museum cabinet, lies in the fact that the hind wings, which, when the moth is at rest in life, are concealed by the front ones, are brightly colored in contrasting hues of black, red, and white in various brilliant combinations. These colors, in connection with the soft and blended tones of the front wings, make a very handsome insect.

It is easy to see that when one of these Underwing Moths is driven to flight by a woodpecker or other barksearching bird it would show during its rapid, irregular flight the bright colors of the under wings which would be instantly hidden upon alighting and the very different coloring of the upper wings blending with the bark would be substituted. Consequently, the bird would be very likely to be baffled in its pursuit.

\section{Coloration of Locusts}

On the rocky hills and sandy plains of New England there are several species of grasshoppers or locusis that also illustrate these principles. If you walk along a strip of sandy land in summer, you start to flight certain locusts which soon alight, and when searched for will be found closely to assimilate in color the sand upon which they resi. On a neighboring granite-ribbed hill you will find few if any of this species of locust, but instead there occur two or three quite different species, which when at rest closely resemble the lichen-covered rocks. This resemblance is very striking, and is found in all stages of the insect's existence. If now you go to a lowland meadow, still another color phase will be found to prevail-the green grass is swarming with the so-called "long-horned" grass- 
hoppers, which are green throughout with linear bodies, and long, slender legs and antennae.

Each of these three groups of insects is adapted to its particular habitat. All are constantly persecuted by birds, and have been so persecuted for unnumbered ages in the past. In every generation the individuals have varied, some toward closer resemblance to environment, others in an opposite direction. The more conspicuous insects have been constantly taken, and the least conspicuous as constantly left to reproduce. Were the three groups to change places to-day, the green grasshoppers from the meadows going to sandy surfaces, the sandcolored locusts going to rocky hills, and the "mossbacks" from the hills to the lowland meadows, each would become conspicuous, and the birds would have such a feast as is seldom spread before them.

The species living on sand and rocks are often "flushed" by birds. Those which flew but a few feet would be likely to be captured by the pursuing bird; those which flew farther would stand a better chance of escaping. Similarly, those which flew slowly and in a straight line would be more likely to be caught than those which flew rapidly and took a zigzag course. As a consequence of the selection thus brought about through the elimination of those which flew slowly along the straight and narrow way that led to death, you will find that most locusts living in exposed situations when startled fly some distance in a rapid, zigzag manner.

But still another element of safety has been introduced by some species of these locusts through the adoption of the color tactics of the Catocala moths. The under wings of the common Carolina locust - the species most aburd- 
ant along the highway - are black, bordered with yellowish white. The base of the hind wings of a related species living on the Western plains is bluish, while in the large coral-winged locust of the Eastern states the hind wings are red, bordered with black. In nearly all of the species of these locusts frequenting open localities where they are liable to disturbance by birds or other animals, the hind wings exhibit contrasting colors in flight. Most of them also fly in a zigzag line, and alight in a most erratic manner. Many times I have had difficulty in determining the exact landfall of one of these peculiar creatures, and I believe Lord Walsingham's suggestion is well exemplified in them. (See page 33.)

The most famous example of a combination of this dazzling coloring of the upper wing surface with a definite protective coloring of the under wing surface is the Kallima butterfly which is illustrated in almost every book dealing with animal coloration. The under wing surface bears a striking resemblance to a leaf and the hind wings project to form a tail which looks like the petiole of the leaf, and there is also a mark running across the wings which mimics the midrib. When the butterfly is flying the brilliant colors of the upper surface are visible, but when it alights these are instantly replaced by the sombre tone of the under surface, so that apparently the insect completely disappears and in its place there is only a leaf attached to a branch in a most natural position. In Dr. Longstaff's book there is an illustration of another tropical butterfly, Eronia cleodora, which resembles on its under surface a yellow disease-stricken leaf but on its upper surface gives a brilliant combination of black and white. This insect alights upon the leaves which it resembles 
and is a striking example of both dazzling and mimicking coloration.

Many of our own butterflies, notably the Angle-wings, are excellent examples of a similar combination. In flight they reveal conspicuous colors which are instantly hidden upon alighting and then one only sees the bark-like or dead leaf-like under surface as may be seen in the plate opposite pages 160-161. The iridescence upon the upper wing surface of many butterflies, whose under wing surface is colored in concealing tones, is doubtless also of great use to the insect in a similar way. There is a splendid opportunity here for some observer to study this phase of butterfly activity and to get photographs of the insects amid their natural surroundings.

In their book upon "Concealing Coloration" the Messrs. Thayer have called attention to many interesting phases of dazzling coloration. They show that bright marks like the eye-spots or ocelli, which form so prominent a feature on the wing surfaces of many butterflies, really helped to conceal the insect amid its natural surroundings, by drawing the eye away from the outlines of wings and body so that the latter tend to disappear. Their discussion of this subject opens up another vast field for outdoor observations of absorbing interest, in which there is great need for many active workers.

\section{Selective Color Sense}

One who collects the Underwing moths soon discovers that the light colored species which resemble the bark of birch trees are likely to be found upon the trunks of those trees, and that the dark colored kinds wbich resemble the 


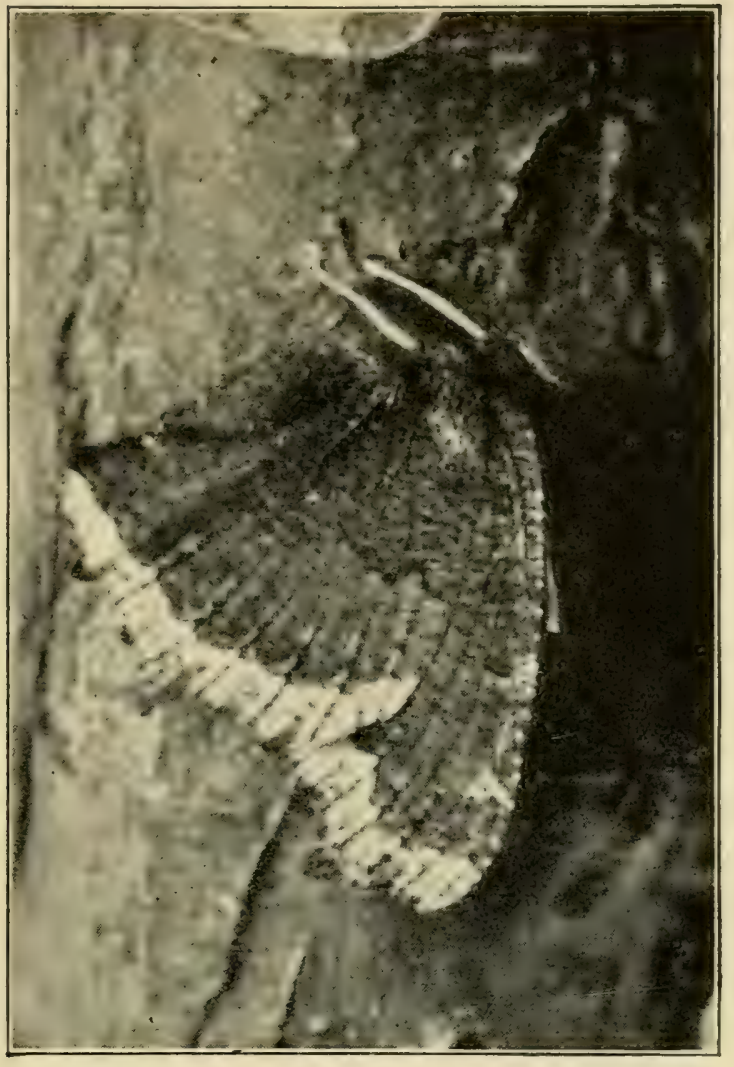

Sec page 23

BUTTERFL FEIGNING DEATH, HANGING TO BARK BY ONE FOOT

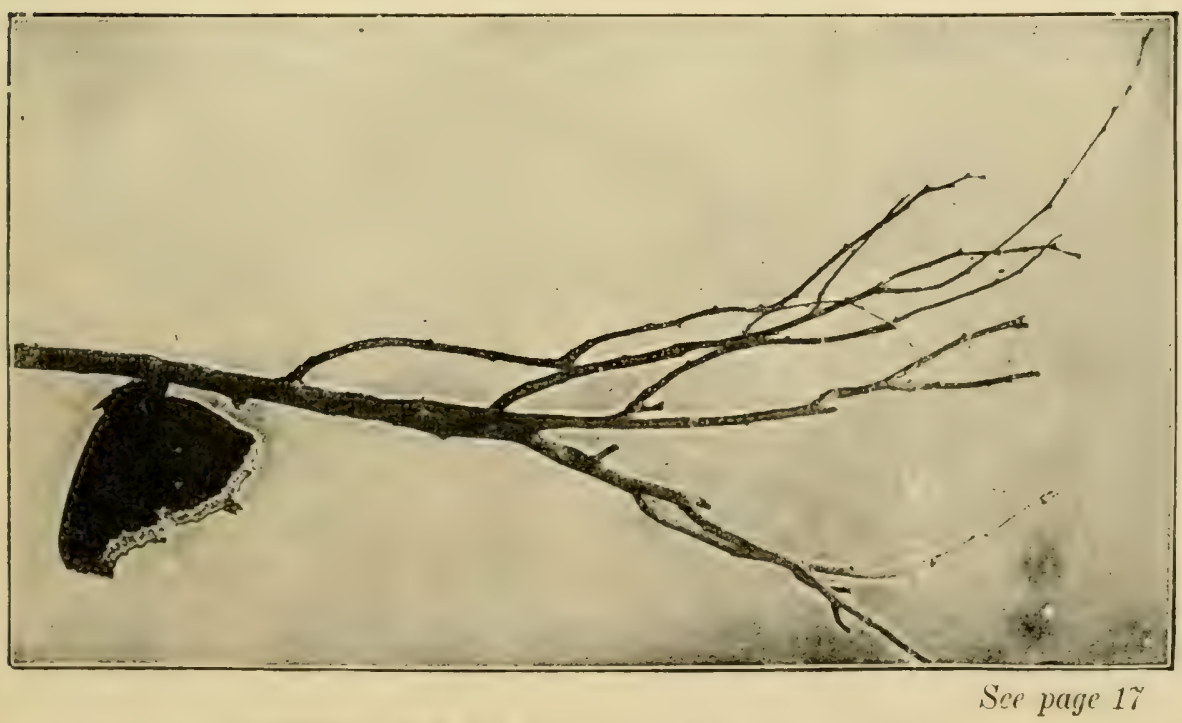

BUTTERELY IN HIBERNATING POSITION 


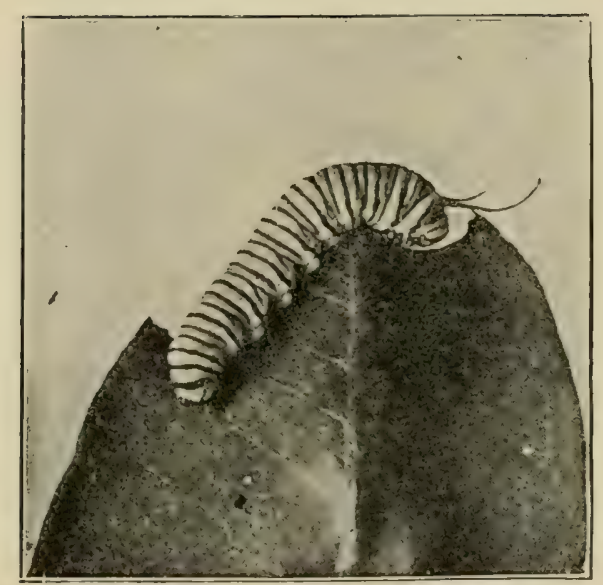

Caterpillar feeding upon leaf of milkweed

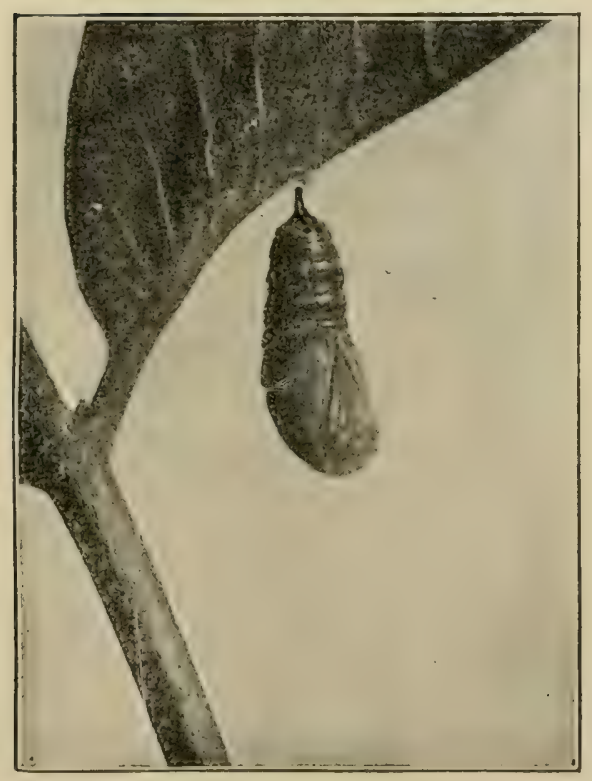

The transition stage

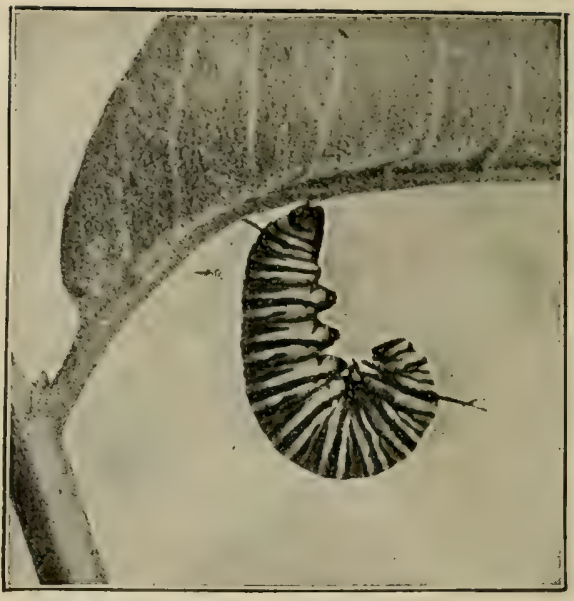

Caterpillar hung up for the change to the chrysalis

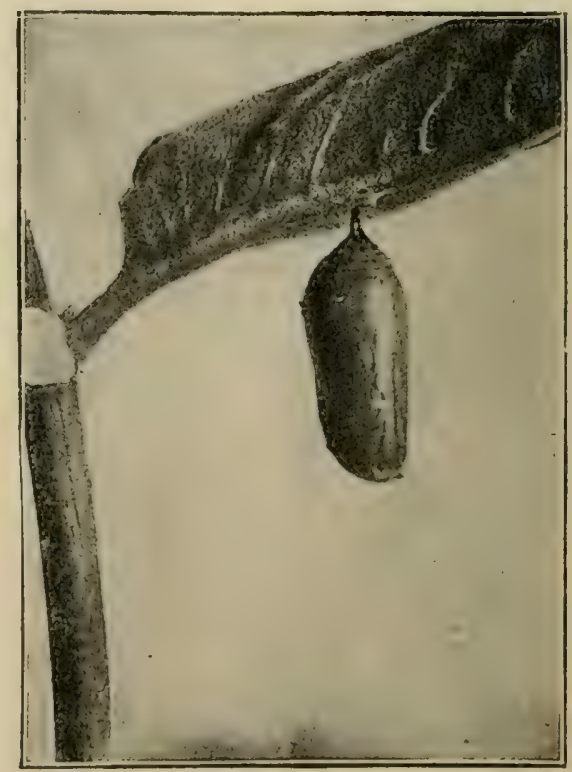

The Chrysalis

THE MONARCH BUTTERFLY: CHANGE FROM CATERPILLAR TO CHRYsalis. Photographs from life. (See pages 8-10, 233) 


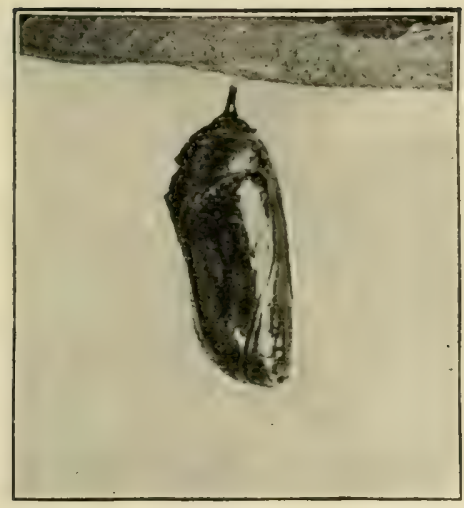

Chrysalis showing butterfly ready to emerge

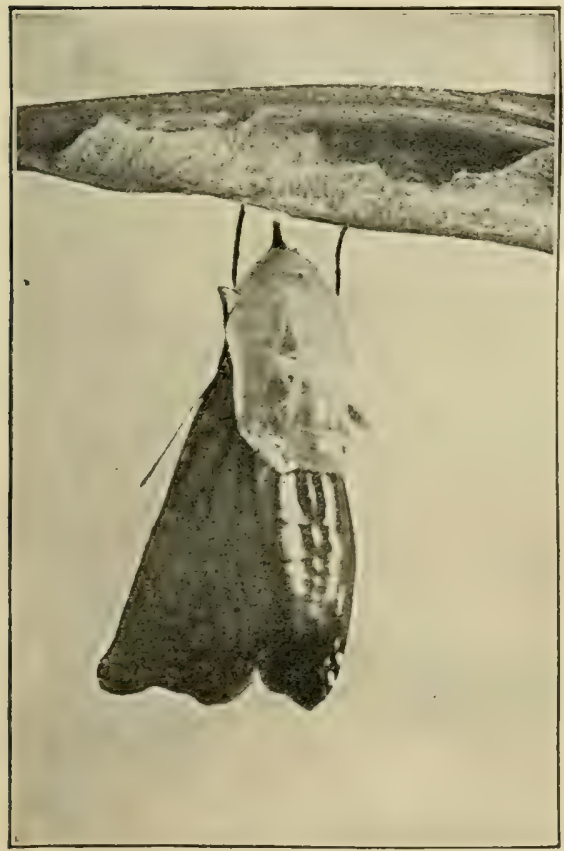

Butterfly just out of chrysalis

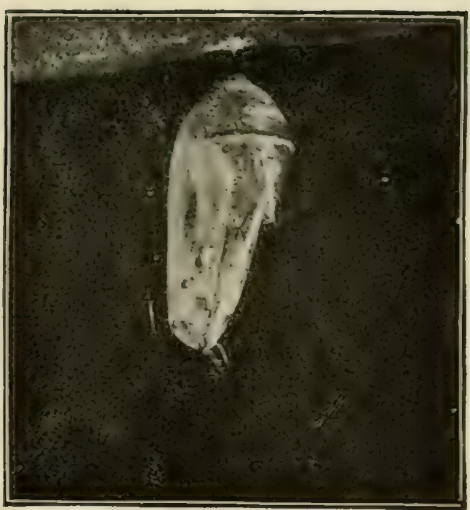

The empty chrysalis

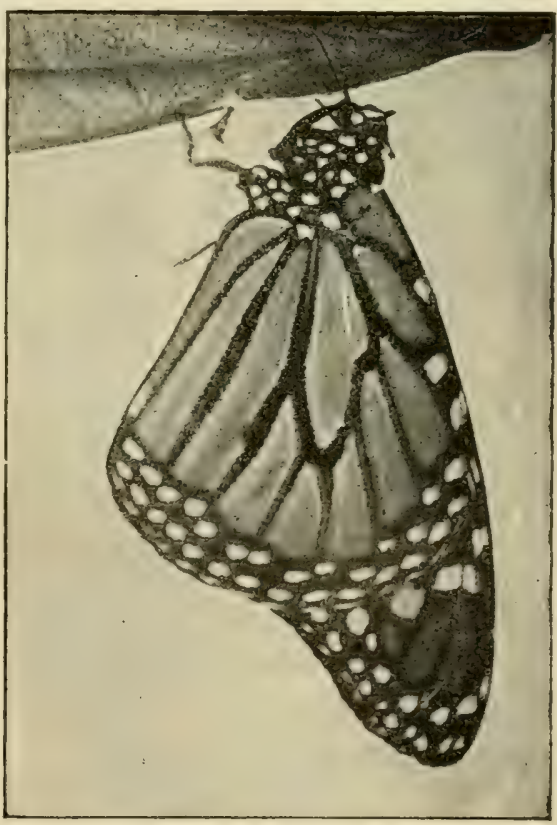

Side view a little later

THE MONARCH BUTTERFLY: THE CHANGE FROM CHRYSALIS TO ADULT. Photographs from life (Sce pages 10-13, 235) 


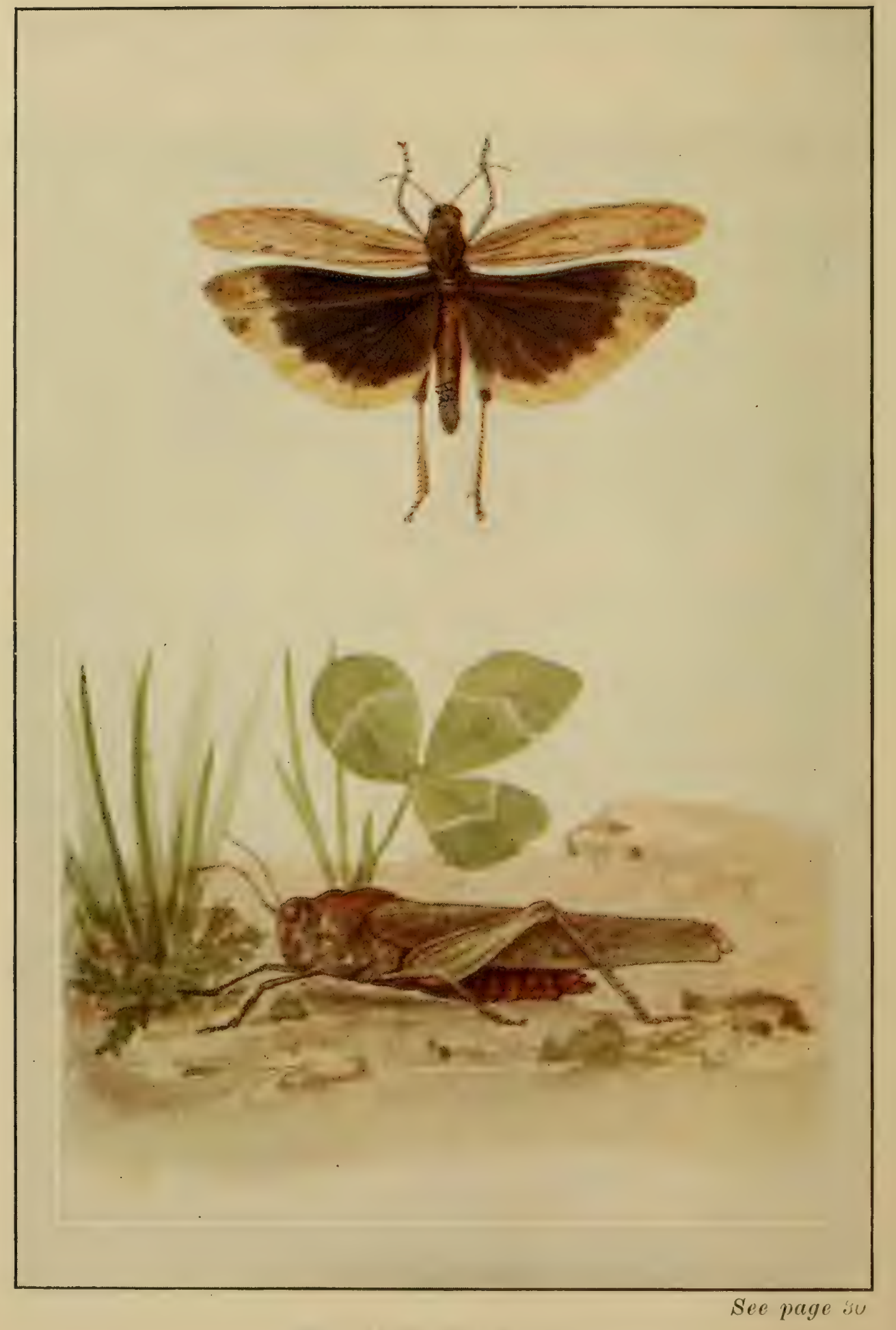

'IHE CAROLINA LOCUST

Above, with wings expanded as in flight 
bark of maple trees are likely to be found upon the trunks of these. Obviously, were this not true the protective coloring would avail but little and it is evident that these moths are able to select a background which is of advantage in helping to conceal them.

There is much evidence to show that in a similar way the butterflies are able by means of a well-developed color sense to select the places where they alight. One of the most notable examples is that of a South American species, Peridromia feronia. This is a silvery gray butterfly which alights head downward upon the bark of certain palm trees that have silvery gray stems and remains there with its wings fully expanded so that it utilizes the background in much the same way that the Underwing moths do. "When disturbed they will return to the same tree again and again."

One who will observe the habits of our Angle-wings and other butterflies which have obliterative coloring of the under wing surface can easily learn that these insects select rather carefully the places where they alight. It will be found that as a rule each species utilizes a background that blends with its own coloring. It is probable that this habit is much more common in other groups of butterflies than has been realized. Much evidence of this sort has been collected regarding the butterflies of Europe and other countries, as well as near our own borders in America.

\section{Warning Coloration and Mimicry}

The colors of a great many animals, including a considerable percentage of American butterflies and their larvae, have been commonly explained by the theory of 
warning colors. According to this theory animals which were for any reason not edible by birds and mammals have developed various striking combinations of color such as black and yellow, red and black, or black and white, in order to advertise to their foes their inedible qualities. This theory has been very generally accepted by naturalists and will be found expounded at length in many books published during the last quarter century.

The whole subject of the validity of warning coloration has recently been brought up for reconsideration by the illuminating investigations of Mr. Abbott $\mathrm{H}$. Thayer and discussed at length in the book upon "Concealing Coloration" already mentioned. In an appendix to this book dated 1908 Mr. Thayer states that he no longer holds the belief that "there must somewhere be warning colors." He has convincingly shown that a large proportion of the animals which were supposed to be examples of this theory are really illustrations of concealing coloration. But there yet remain various facts which have been conclusively proven that apparently require the theory of warning colors to explain them. Here is another field in which there is a real need for much careful investigation under conditions that are rigidly scientific.

Along with the theory of warning coloration the theory of mimicry has been propounded. According to this if a butterfly in a given region shows warning coloration, having developed such coloration because it is distasteful to birds and mammals, it may be mimicked by another butterfly in the same region belonging to another group, the latter butterfly being edible, but benefiting by its resemblance to the distasteful species, because birds of mammals mistake it for the latter and do not attempt to 
catch it. The most notable example of such mimicry in North America is that of the Monarch butterfly, which is supposed to be the distasteful species, and the Viceroy butterfly, which is supposed to mimic it. Several other instances of mimicry are found among our own butterflies, while in South America, Africa, and Asia there are numberless examples.

\section{HeLtotropisM}

It has long been known that the green surfaces of plants respond to the stimulus of the sun's rays in a most remarkable manner. This response has commonly been called heliotropism and it has been carefully studied by botanists all over the habitable world. More recently, the fact has been observed that many animals respond in certain definite ways to the stimulus of direct sunshine and the same term has been applied in this case. Very little attention has been given to the subject of heliotropism until within a few recent years. But the observations which have been made by Parker, Longstaff, Dixey, and others open up a most interesting field for further observation. An admirable summary of our present knowledge of the subject has been published by Dr. Longstaff in his book "Butterfly Hunting in Many Lands."

One of the earliest observations upon this subject was that published in my book "Nature Biographies" which appeared in June, 1901, concerning the habit in the Mourning Cloak: "On a spring-like day early in November (the Sth) I came across one of these butterflies basking in the sunshine upon the ties of a railway track. It rested with its wings wide open. On being disturbed, it would fly a short 
distance and then alight, and $I$ was interested to notice that after alighting it would always turn about until the hind end of its body pointed in the direction of the sun, so that the sun's rays struck its wings and body nearly at right angles. I repeatedly observed this habit of getting into the position in which the most benefit from the sunshine was received, and it is of interest as showing the extreme delicacy of perception toward the warmth of sunshine which these creatures possess."

A little later, some very elaborate observations were made upon this habit of the Mourning Cloak by Prof. G. H. Parker of Harvard University. Professor Parker noticed that during the warm spells in winter the butterflies came out of their hiding places and after alighting, always placed themselves with their heads away from the direction of the sun and their bodies lying nearly at right angles to the sun's rays. By experiment, he found that they adjusted themselves to this position as soon as they were fully exposed to direct sunshine, even if at the time of alighting they were in a shadow. He found that this movement was a reflex action through the eyes, for when the eyes were blinded no such adjustment took place. He called it negative heliotropism.

Dr. Longstaff uses the term orientation for this adjustment of the butterfly to the sun's rays and he finds it is a very general habit, especially with the Angle-wings, for the butterfly thus to orient itself after alighting, in such a way that the hind end of the body points toward the sun. This occurs not only with those species which keep their wings spread open when they alight but also with those in which the wings are closed together and held in a vertical position on alighting. 
Various explanations of this phenomenon have been offered but apparently none of them are yet generally accepted. Were the habit confined to butterflies like the Mourning Cloak, it would seem easy to prove that a main advantage was found in the benefit derived from the heat rays of the sun. Were it confined to those species which always fold their wings on alighting, it would seem easy to believe that it was a device for reducing the shadow cast by the insect to its lowest terms. It has also been suggested that the habit is for the purpose of revealing to the fullest extent the markings of the butterfly. Evidently there is here an ample field for further investigation before definite conclusions are reached.

\section{List and Shadow Observations}

Another field for most interesting studies upon the habits of living butterflies has been opened up by the very interesting discussion of list and shadow in Colonel G. B. Longstaff's fascinating book, "Butterfly Hunting in Many Lands." He there summarizes his numerous observations upon butterflies in various localities which he has seen to lean over at a decided angle when they alight. He defines "List" as "an attitude resulting from the rotation of the insect about its longitudinal axis, as heliotropism results from a rotation about an imaginary vertical axis at right angles to this." The name is adapted from the sailors' term applied to a vessel leaning to one side or another in a storm.

Apparently this interesting habit was first called to the attention of European entomologists by an observation of 
Colonel C. T. Bingham made in 1878 , but not published until long afterward. The observation was this:

"The Melanitis was there among dead leaves, its wings folded and looking for all the world a dead, dry leaf itself. With regard to Melanitis, I have not seen it recorded anywhere that the species of this genus when disturbed fly a little way, drop suddenly into the undergrowth with closed wings, and invariably lie a little askew and slanting, which still more increases their likeness to a dead leaf casually fallen to the ground."

Long before this was printed, however, a similar habit had been observed by Scudder in the case of our White Mountain butterfly (Oenis semidea). But this species is so exceptional in its habitat that the habit seems to have been considered a special adaptation to the wind-swept mountain top. The possibility of its being at all general among the butterflies in lowlands seems to have been overlooked.

The observations recorded by Longstaff relate chiefly to various members of the Satyrid group. For example, a common Grayling, Satyrus semele, was watched many times as it settled on the ground. As a rule three motions are gone through in regular sequence: the wings are brought together over the back; the forewings are drawn between the hind wings; the whole is thrown over to right or left to the extent of thirty, forty, or even fifty degrees.

This habit, of course, is of advantage to the insect. It seems possible that the advantage might be explained in either of two ways: first, the leaning over on the ground among grasses and fallen leaves might help to render the disguising coloration of the insect more effective, the large ocelli serving to draw the eye away from the outline 
of body and wing; second, the listing of the butterfly toward the sun tends to reduce the shadow and to hide it beneath the wings. There is no doubt that when a Grayling butterfly lights upon the ground in strong sunshine the shadow it casts is more conspicuous than the insect itself and the hiding of this might be of distinct advantage in helping it to escape observation. It is significant that in England the butterflies observed appear to lean over more frequently in sunshine than in shade. An observation of Mr. E. G. Waddilove, reported by Colonel Longstaff, is insteresting in this connection:

"A Grayling settled on a patch of bare black peat earth, shut up its wings vertically, and crawled at once some two yards to the edge of the patch to where some fir-needles, a cone or two, and a few brittle twigs were lying, and then becoming stationary threw itself over at an angle of some forty-five degrees square to the sun. It thus became quite indistinguishable from its surroundings."

Apparently, some of the Angle-wings may have the same habit, for in Barrett's "Lepidoptera of the British Islands," there is a note in regard to Grapta C-album to the effect that it is fond of sunning itself in roads, on warm walls, or on the ground upon dead leaves in sheltered valleys. "Here, if the sun becomes overclouded, it will sometimes close its wings and almost lie down, in such a manner that to distinguish its brown and green marbled under side from the dead leaves is almost impossible."

Here is a most fascinating opportunity for American observers to determine definitely the facts in regard to our numerous species of butterflies that may show this habit. An observer with a reflex type of camera might easily be able to get pictures that would be of great value in helping 
to determine the principal facts in regard to the subject. Our common Graylings and numerous species of Anglewings are so abundant and easily observed that they offer splenaid opportunities to any one who will undertake a serious study of the subject.

\section{Parasitic Enemies}

All three of the earlier stages of butterflies-egg, larva, and chrysalis - are subject to attack by various parasitic insects which develop at the expense of the host. Such parasites are probably the most important check upon the increase of butterflies, and along with birds, mammals, and bacterial diseases, they help to keep up that balance of nature which in the long run maintains a surprising uniformity in the numbers of each kind of butterfly.

For the most part these insect parasites are small fourwinged flies, although many of them are two-winged flies. In either case the life stages show a series of changes much like those of the butterflies themselves. Each parasite exists first as an egg, second as a larva, third as a pupa, and fourth as an adult fly. The larval stage, however, is simply that of a footless grub which lives within the body of its victim absorbing its life blood and gradually killing it.

The parasites of butterfly eggs are legion. They are tiny flies whose life-story in briefest summary is this: The butterfly lays an egg. The parasite fly finds this egg soon after it is laid, and pierces the shell with her tiny, sharply pointed ovipositor and deposits inside of the shell her own microscopic egg. This egg within the egg soon hatches into a curious little larva that develops at the expense of the contents of the butterfly egg shell, and soon absorbs 


\section{INTRODUCTION}

the whole of them. The parasite larva now changes to a pupa which a little later changes again to an adult fly like the one that laid the parasite egg in the beginning. Of course the butterfiy egg never hatches into a caterpillar.

One of the most interesting questions in regard to these egg parasites is this: How does the tiny parasitic fly find the newly laid egg? One would think that the proverbial search for a needle in a haymow would be an easy task compared with that of a fly about as large as the head of a pin finding a butterfly egg of similar size upon some part of one of the millions of leaves upon the trees and shrubs in field and forest. Yet the search is successful, as every one who has tried to get caterpillars from eggs found out of doors will testify. On a later page in this book, in connection with the story of the life of the Mourning Cloak butterfly, I have recorded some observations upon the little parasite which seemed to have been riding around upon the body of the butterfly waiting for her to lay her eggs.

For one parasite upon the eggs of butterflies, there probably are dozens that attack the caterpillars. A large proportion of the butterfly larvae brought in from outdoors, especially those which are half-grown or more, will yield not butterflies but parasites. This is the experience of practically every one who attempts to rear these insects, and it emphasizes the value of the advice that in order to get fine specimens, it is desirable to rear them from eggs laid by butterflies beneath netting or in cages.

The life-histories of the parasites that attack caterpillars vary greatly. The simplest are those of the large Ichneumon flies: The mother fly lays an egg beneath the skin of the caterpillar. The egg hatches into a larva that absorbs the fatty parts of the body of the caterpillar, 
gradually growing larger and larger until at last it reaches a length of possibly an inch. By this time it is likely to have absorbed so large a part of the inside of the caterpillar that the latter dies. The parasite larva now changes to a pupa, either inside or outside the skin of the caterpillar, and a little later changes again to an adult Ichneumon fly.

In the case just given, one egg only was deposited within the skin of the caterpillar. In many others, however, a large number of eggs may be so deposited by a single fly. A special group of Ichneumon flies, called the Microgast-

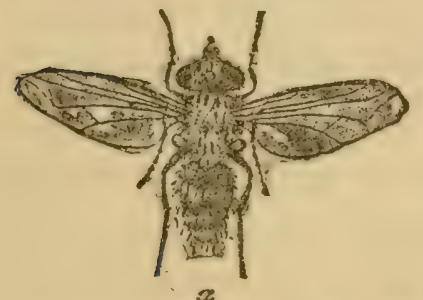

Tachinid Parasite; a, fly: a puparium. ers, contains many parasites that have this peculiarity. The Microgaster larvae on coming forth from the caterpillar have the habit of spinning tiny cocoons within which they change to pupae. By collecting some cabbage worms which are nearly full grown, and keeping them in a glass jar one can generally get a considerable number of these Microgaster cocoons and rear the flies from them.

Another group of caterpillar parasites is still more minute. They are called the Chalcid flies. Their life-histories are full of interest, and might easily furnish opportunity for a long lifetime of study and experiment. One is likely to get hundreds of these Chalcid flies from a single caterpillar.

Another interesting group of parasites is that of the two-winged Tachina flies (see cut on this page). The lifestory of some of these is comparatively simple: a buzzing 
fly, looking much like a large housefly, lays a small whitish egg upon the skin of a caterpillar. This egg is glued tightly and is large enough to be readily seen by the unaided eye. It hatches into a tiny larva that eats its way through the part of the shell glued to the caterpillar's skin, and through the latter at the same time. So the newly hatched Tachina larva finds itself in the body of its caterpillar host. It lives there, absorbing the fatty juices around it until at last it either kills or stupefies its unfortunate victim. It has then become full grown as a larva, and its last larval skin hardens into a brown pupacase within which the little creature changes into a pupa. It may or may not have burrowed through the skin of the caterpillar before this happened. A little later the pupa changes to a Tachina fly which breaks apart the pupa case and flies out into the world.

It has lately been found, however, that many Tachinids have much more complicated life-histories than this. I have already discussed some of the more important of these in my book entitled, "Seeing Nature First" (pages 150-158).

One can frequently rear parasites from the chrysalids of butterflies, but in many cases it is probable that these began their parasitic development in the caterpillars, which were able to change to chrysalids before being killed. In some cases, however, the chrysalids seem to be attacked, especially by certain Ichneumon flies.

\section{Rearing Butterflies Fron Caterpillars}

There are few things in the world more interesting to watch than the wonderful changes which a moth or butter- 
fly goes through in the course of its life. You find on a tree or shrub a wormlike caterpillar. You take it in charge, placing it in a box or jar where you can provide leaves for its food and soon it either spins around itself a silken shroud, thus hiding from your sight, or else it simply seems to change to a lifeless object without eyes or wings or legs, unable to move about and motionless, save for a slight wriggle when you touch it. Yet if you keep the shroud or the mummy-like object for two or three weeks you are likely to see a beautiful moth come from the shroud or a glorious butterfly break out of the mummy case. (See plate, page 49.) So you can get the realest kind of moving pictures by simply bringing in the caterpillars that are easily found in garden, field, and wood.

To collect these caterpillars it is only necessary to be provided with a pair of sharp eyes and an empty coffee can or some other form of tin box. Go out into the garden or along the borders of the woods. Look carefully. If you see places where leaves have been eaten, search the leaves near by and you are likely to find one or more of the caterpillars that caused the injury. Transfer them to the box and take them home with a few leaves of the food plant. There place them in some form of vivarium, which simply means a box or cage in which you can keep living creatures. The most satisfactory cages for rearing caterpillars are those which are open above so that there is not even a glass plate between the observer and the insect. This kind of vivarium is easily made by using a band of some sticky substance like the tree tanglefoot with which trees are commonly banded, or a strip of sticky fly paper. Any wide shallow box may be used by simply placing an inchwide band of the sticky material around the vertical sides 
near the top. The caterpillars will be free to move all over the open box but they cannot cross the band to escape. Fresh leaves are easily placed in the open box and the withered ones removed.

The same plan may be adopted with wide glass jars, like the ordinary battery jar. Choose a rather large one and smear the inner side near the top with a band of sticky material. The caterpillars are thus prevented from crawling out, but they are open to observation at all times. (See plate, pages 48-49.)

In the case of the caterpillars that change to butterflies no soil need be placed in the bottom of the jar as these will attach their chrysalids to the sides or to a stick or board which may easily be put in. In the case of many caterpillars that change to moths, however, it is desirable to place about two inches of soil in the bottom of the jar. Then if the caterpillars are not cocoon spinners they can burrow into the soil when they are ready to change to pupae.

Instead of applying the sticky material directly to the glass a strip of sticky fly paper may be glued to it.

As a rule the butterfly caterpillar easiest to find lives upon cabbages. Go into the garden and you are likely to see a dozen green caterpillars upon as many cabbage plants. Bring in several of the larger ones and place them in a vivarium with some fresh cabbage leaves. In a few days some of them will be likely to fasten themselves to the vertical sides of the vivarium and shed the caterpillar skin. Each thus becomes a chrysalis. About ten days later this chrysalis skin will break open and a white Cabbage butterfly will come out.

So your caterpillar goes through the four different 
stages of insect life. It was first an egg laid upon the leaf by a butterfly; the egg hatched into the caterpillar or larva; the larva changed to the chrysalis; the chrysalis changed to the butterfy or adult insect.

One of the most satisfactory ways to rear the caterpillars of butterflies is to get the females to lay their eggs upon the food plant. In the case of many species this is not diff. cult. The simplest way is to enclose the mother butterfly in a small gauze bag tied over the branch of the food plant. If she has eggs ready to deposit she is very likely to lay them under these conditions. After they are laid the mother butterfly may be allowed to escape, but it is well to replace the gauze protection as a safeguard against many sorts of enemies which may destroy the eggs or the young caterpillars that hatch from them. Another way is to enclose the butterflies with a twig of the food plant in a glass jar, sealing it tight to prevent the leaves from wilting. The butterfly is likely after she has quieted down to lay her eggs upon the leaves. According to William G. Wright, who speaks from his long experience with the butterflies of the West Coast, these genera will lay their eggs on anything: Parnassius, Argynnis, Euptoieta, Neonympha, and all members of the family Satyridae. In these cases one can get the eggs by simply enclosing the butterflies in glass jars or gauze nets without even the leaves of the food plant. William H. Edwards found in his long experience that one can get the eggs of practically all butterflies in confinement, provided only the insects are sufficiently mature so that the eggs are ready to be laid. He found that the cause of failure to get eggs from many of the Fritillaries early in the season was that the eggs were not mature and that from the same kinds of butterflies with 
which he failed early in the summer he got plenty of eggs in September.

There is here a rich field for observation and experiment for every naturalist who wishes to take up the study of butterflies. He can be sure of the parentage of the caterpillars and can trace them from the very moment of egglaying through all their wonderful changes until they become butterflies again.

\section{Photographing Butterflies}

There is a famous old saying that to make hare stew it is first necessary to catch your hare. So if one wishes to make perfect pictures of butterflies it is first necessary to get the caterpillars. For though caterpillars are not butterflies they are butterflies in the making and they will show you most interesting stages in nature's manufacture of these dainty and exquisite creatures. This is not, however, the chief reason why the photographer should get them. He will wish to make perfect pictures and in order to do this he must have not only perfect specimens but living butterflies which are willing to look pleasant while he makes comparatively long exposures under conditions of light that he can control. If you catch a butterfy outdoors and bring it in you will be likely to ind that it is by no means a docile subject. The sunlight shining through the nearest window will be a call which you cannot counteract and your butterfly will constantly respond to it in a most vexing manner. So you must catch the butterfly young and take advantage of a brief but docile period in their lives when they are willing to pose before your camera in quite a remarkable manner. This is the period just 
after the butterfly emerges from the chrysalis when its wings are fully developed but before the tissues have hardened and the muscles in the thorax are strong enough for flight. At this time the butterfly is perfect, every scale is in its place and every spot of color is at its best, and it will rest quietly upon a flower, leaf, or twig while you adjust the camera and expose the plate. From one such specimen one can get many pictures upon different flowers and with different angles of view. (See plates, pages 160, 225.)

In order to make admirable photographs of living butterflies it is by no means necessary to have a regular photographic studio. If one has a room lighted from the north or east one can arrange for exposure near the window, using cardboard reflectors to make the light more even from both sides. In such a situation one soon learns the exposure periods required and can easily get many beautiful photographs.

A collection of prints of the butterflies of one's locality iwould be one of the most interesting photographic exhibits that an amateur could select. It is comparatively easy to get rather full sets showing the life-histories of several of our larger species and such sets are of course of especial interest. In the case of those caterpillars which make nests upon the food plant, like the Painted Beauty larva which remains for weeks feeding upon the leaves of the 'common wild everlasting, the taking of the pictures of the different stages is comparatively easy. One can keep the plant with the stem in water, and get the caterpillar to change to the chrysalis, and emerge as the butterfly, in the nest made from the flower heads and the upper leaves. 


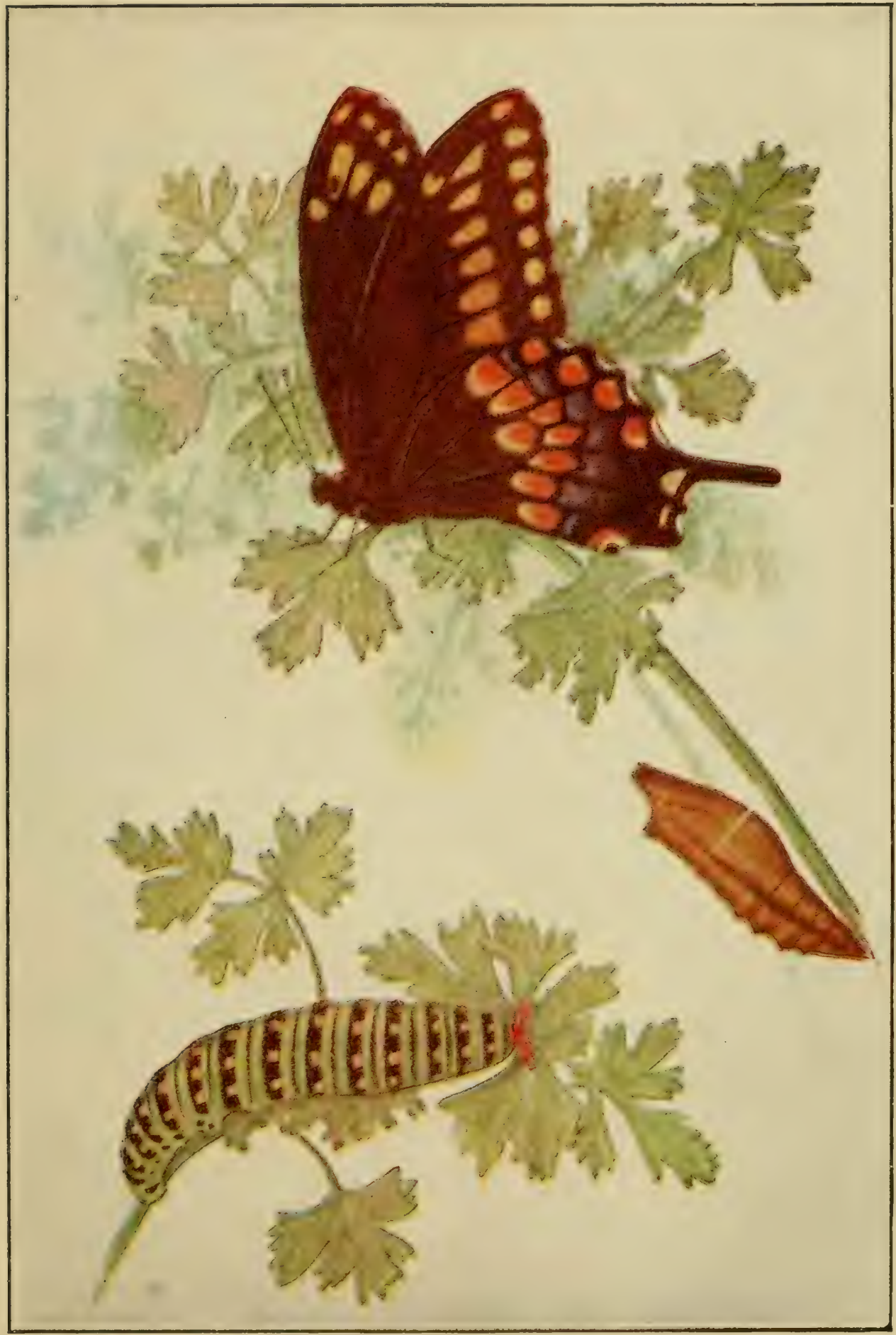

From a drawing by W. I. Beecroft

See page 59

THE BLACK SWALLOWTAIL

Caterpillar, chrysalis and butterfly 


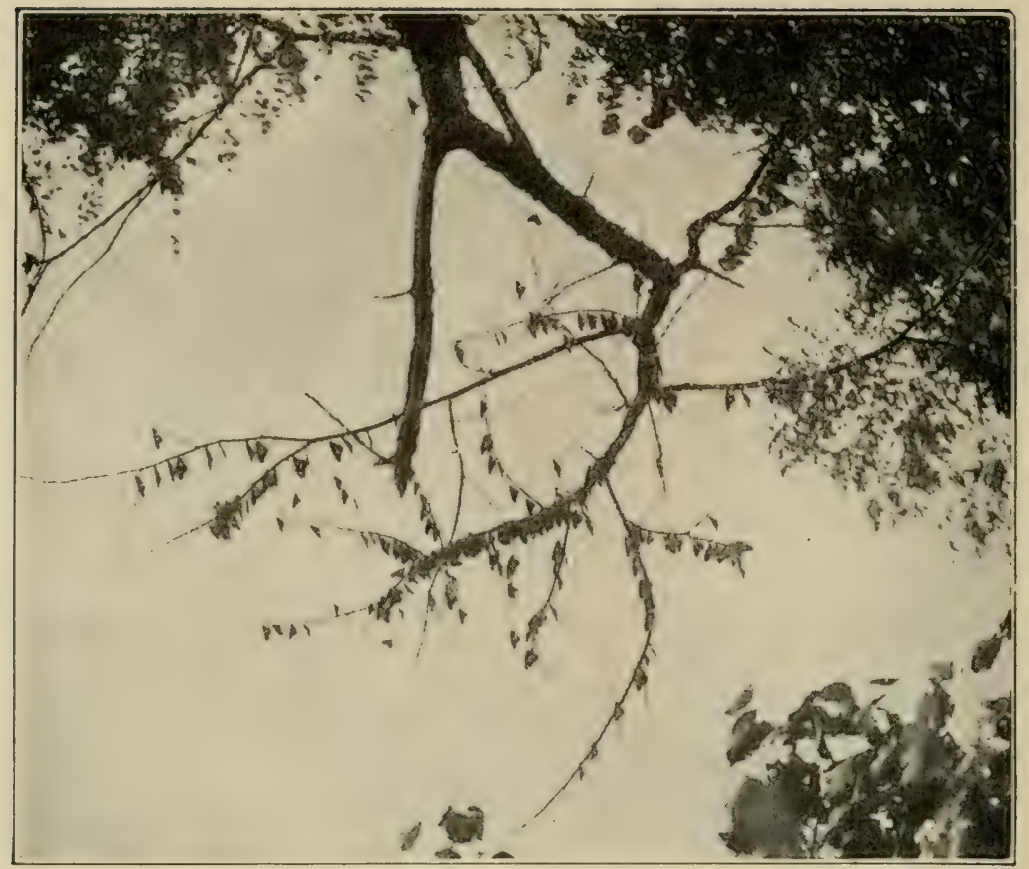

Two hundred Monarchs resting on one dead limb

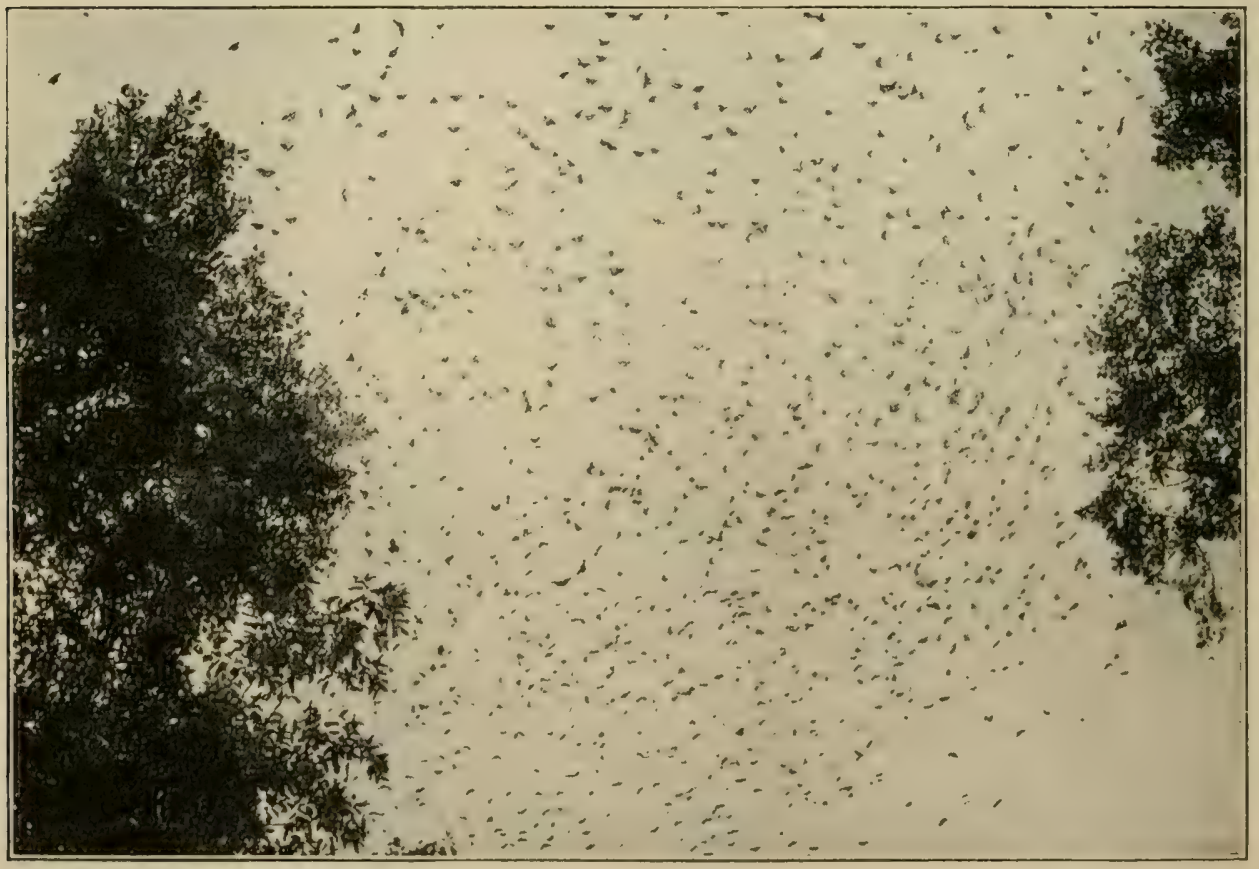

Photographed by Craig S. T'iomas

See pp. 16, 235

"When a stick was thrown into the tree the air was full of Monarchs" 


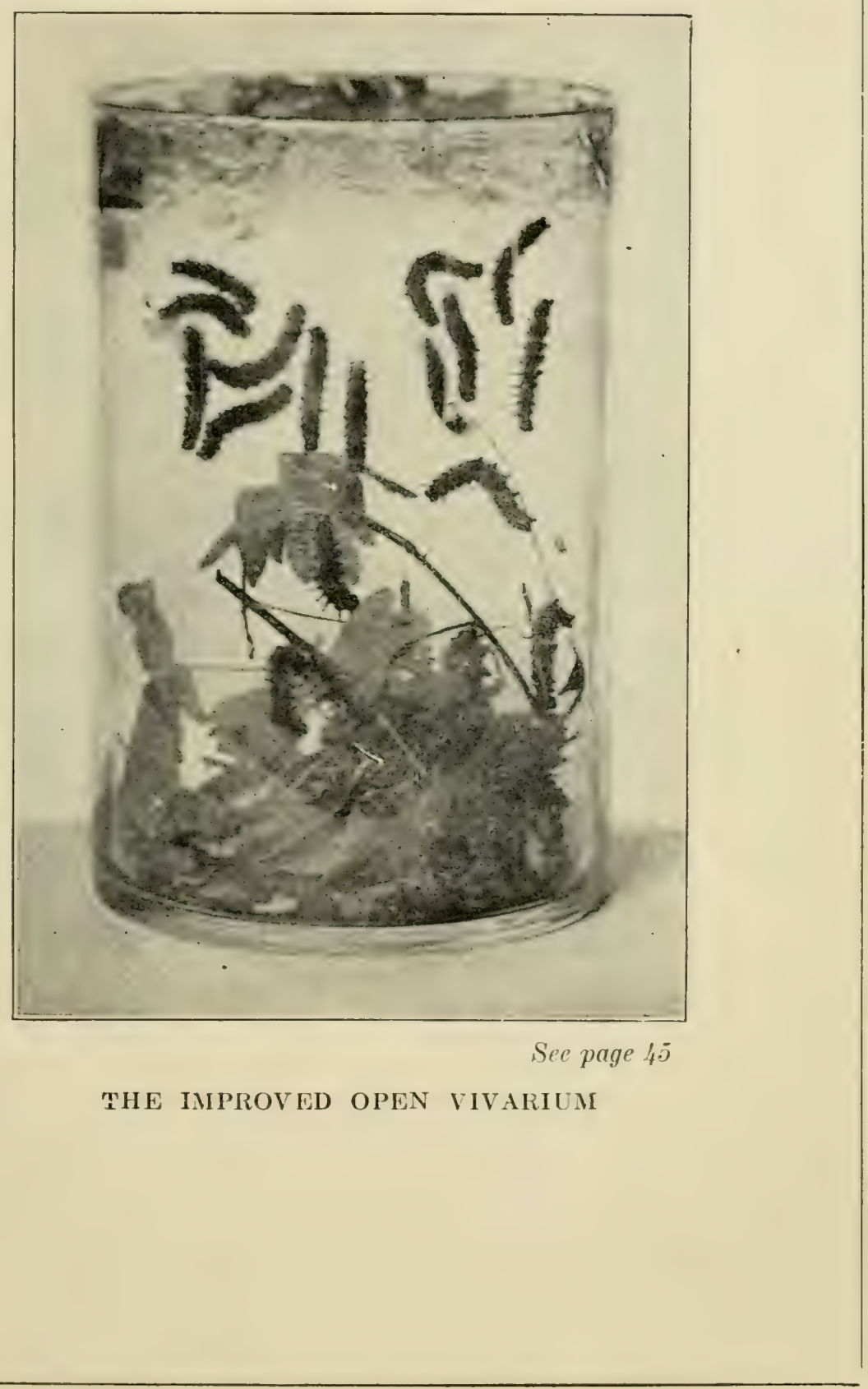




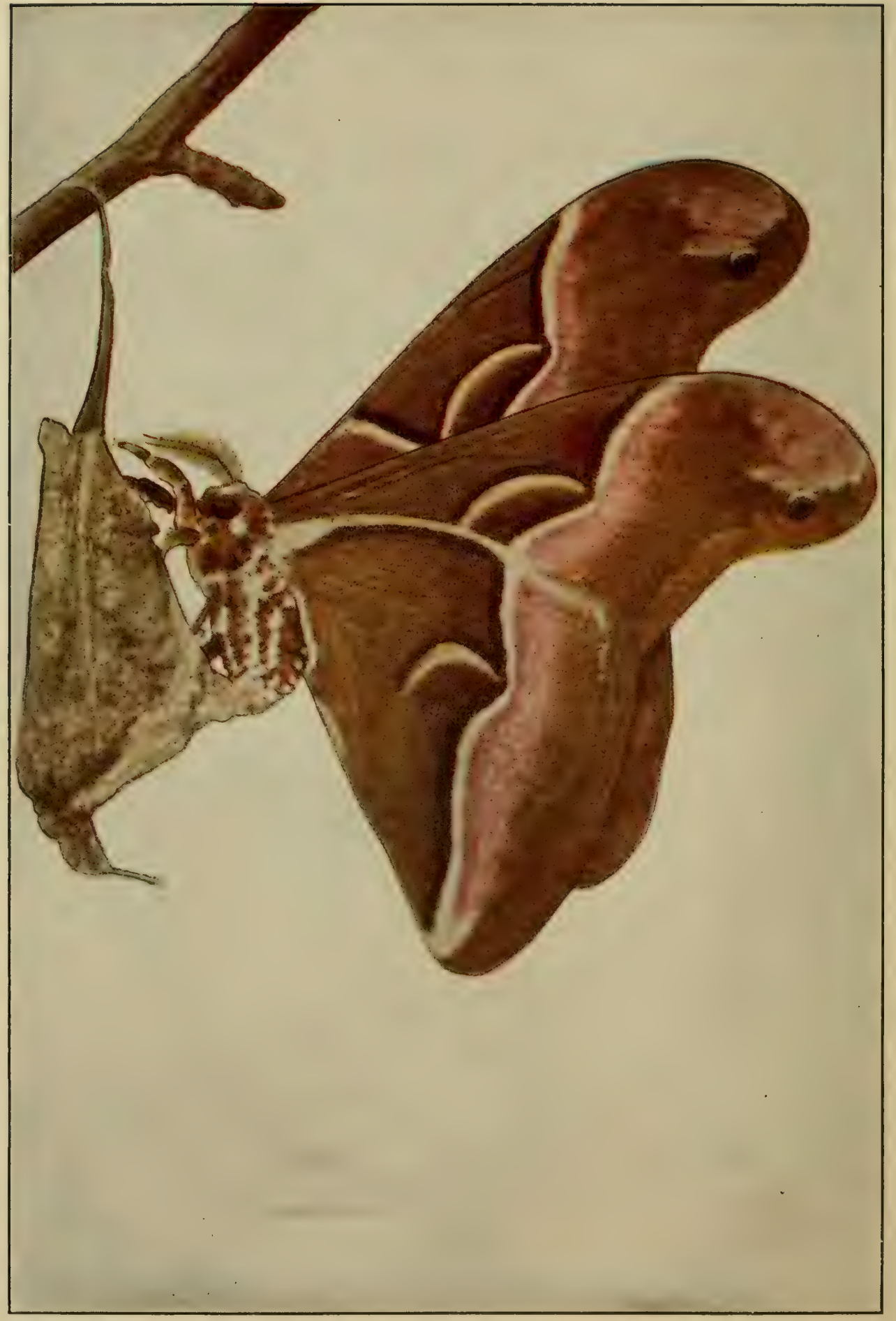

From a photograph from !ne by $A$. H. Verrill.

See page 14 TIIE CYNTIIIA MOTII AND TIE COCOON FROM WIIICII IT CAME 


\section{Butterfly Collections}

There are few groups in Nature which offer such advantages to the collector as that of the butterflies. They are easily obtained, easily preserved, and retain their beauty for a long period even under exposure to strong light. They offer opportunities for serious study in which one cannot only review the facts which others have already discovered, but also hope to contribute something of value to the sum of human knowledge.

The mistake most commonly made by beginners with butterflies, as with other collections, is to undertake too much. Instead of starting on the hopeless task of making a collection of the butterflies of the world, it is much better to start with the intention of making a collection of those of one's own town. In the latter case one can hope soon to attain the desired end and then, if one wishes, it is a simple matter to reach out and make a collection of the butterflies of the state or even of the particular region in which the state is located. The natural limitations for a collection in New England is to make a collection of New England butterflies. There is a splendid example of such a collection on exhibition in the museum of the Boston Society of Natural History. This contains representatives of practically every kind that has been collected in New England, and yet there are less than a hundred species in all. So it is apparent that a local collection should be attainable by any enthusiastic student and the very fact that the number of species is limited adds interest and satisfaction to the pursuit.

The main value of any collection of objects lies in the 
point of view of the collector. The most natural point of view for a beginner is that of the local fauna, as indicated in the previous paragraph. Such a collection best serves as a basis for a study of the subject but it may well lead to a broader field through some special phase of scientific interest. Thus while it would be hopeless for most persons to attempt a collection of the butterflies of the world it would be entirely reasonable for one to start a collection of all the species in the world of any given genus or tribe, and such a set of specimens would soon come to possess decided scientific value. Or, instead of the point of view of generic or family relationship, one could take the point of view of special geographical distribution. Thus a collection of all the butterflies found within a certain number of degrees of the North Pole showing the circumpolar butterfly fauna would have great scientific interest.

There are also various other points of view which could be followed in making a collection. There are already in many of the museums of the world collections of butterflies which illustrate the various phases of true mimicrythe resemblance of one species to another in the same region. This is a field in which one could spend a lifetime of endeavor, and secure results of great value to the world of science. An easier problem for most collectors in the United States would be a collection made from the point of view of resemblance to environment, including such examples as the Angle-wings that show a bark-like set of marks on the under surface. Yet another point of view would be that of hibernation, the making of a collection of all butterflies that hibernate as adults.

These are only a few suggestions. There are many 
other phases of butterfly life which could be utilized as the basis for interesting collections. The important thing is to have a definite object in view and to make the collection a basis for a real study of the subject, so that the collector will not only be growing intellectually but will also be making a real contribution to our scientific knowledge.

\section{Collecting Apparatus}

To collect and preserve butterfies in proper condition for study, certain apparatus is necessary. Perhaps the first essential is the collecting net for catching butterflies in the field. The simplest way to obtain this is to buy it of the dealers in entomological supplies. Nets in considerable variety and at various prices are offered in the catalogues of these firms. One can make, however, a net at home with little difficulty. One need only obtain an iron wire about one fifth of an inch in diameter and bend it into a circular ring a foot or fifteen inches wide, leaving the ends projecting at right angles to the circle and hav ing a blacksmith weld them together so as to form a spur about four inches long. Now thrust this spur into some convenient handle, such as a broomstick, and sew over the wire circle a bag of mosquito netting, Swiss muslin, or some similar fabric. It is better that this material be green or black rather than white.

After the butterflies are caught, they must be killed, so some form of killing bottle is necessary. Most collectors use a cyanide bottle, in which the fumes of cyanide of potassium kill the insects. One of the best ways to make this is to place in a wide-mouthed bottle two or three lumps of cyanide of potassium, approximately an inch across. Over this place some fine sawdust and on top of 
the sawdust, pour liquid plaster of paris carefully so that it will harden into a layer about half an inch thick. Allow the plaster to become thoroughly dry, then insert the stopper into the bottle and it will be ready for use. It is better to use a ground glass st.opper so that the bot-
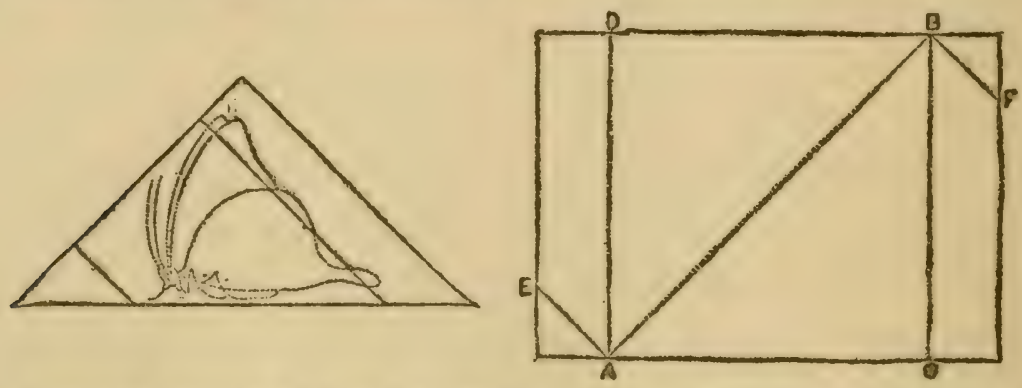

Butterfly Envelopes. Fold first on line $A B$; then on $A D$ and $C B$; then on $B F$ and $E A$. (From Holland)

tle will always be air tight. The sawdust is often omitted, the plaster of paris being poured directly over the cyanide. The special advantage of the sawdust is that it tends to absorb the cyanide in case it liquefies, as it often does in damp weather. As this cyanide is a deadly poison, it

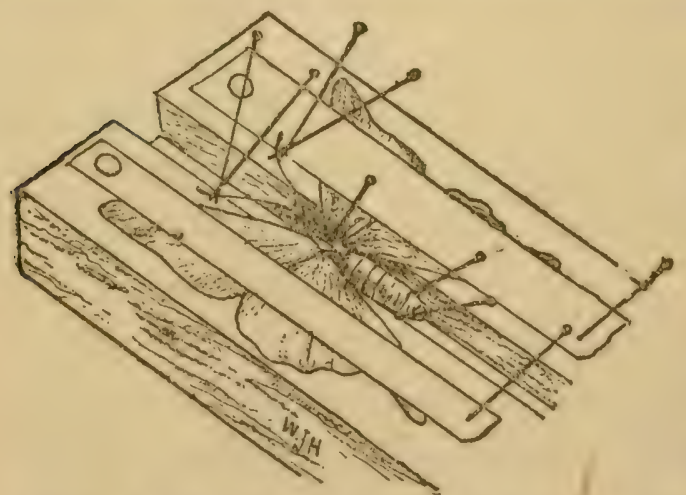

Setting Board with Butterfly in place. (From Holland) is better to let a druggist prepare the bottle or else to buy it already prepared of the dealers in such supplies.

After the specimens have been killed in the cyanide bottle, some method of keeping them is necessary. The simplest way is to preserve them with their wings closed together in pieces of paper folded over into triangles as indicated on the 
accompanying diagrams. Such specimens may be kept for an indefinite time and if one wishes to mount them later, it is only necessary to place them for a few hours in a relaxing jar, which is simply a closed vessel with enough water in the bottom to saturate the air with moisture. A great advantage of keeping the specimens in these paper covers is that they require so little room and are easily stored away in tin cans or boxes where they are safe from dust and destroying enemies.

Those butterflies which are to be preserved in the ordinary way, in drawers or cabinets, must be spread out and held in position while the body is drying so that the wings will remain expanded. For this purpose, some form of a setting board is necessary. These may be bought of dealers or made at home. One of the simplest kinds consists of two thin strips of pine board, a foot or more long, nailed to end pieces with a space between the two boards wide enough to accommodate the bodies of the butterflies. Beneath this open space, a piece of thin cork is tacked. The pin on which the butterfly is fastened is pushed through the cork until the wings of the insect are level with the boards. The wings are then brought forward with a needle point until they are in the desired position and they are then held in place by pieces of glass or by bits of cardboard fastened down by pins. The butterflies must be left in this position until thoroughly dry.

Special insect pins should be used for butterflies. These are longer than common pins and have rounded heads. They are offered for sale by entomological dealers. Instead of pinning the insects and preserving them 
in cabinets, one may keep them in the Riker mounts, which have the advantage of being sealed so that there is no chance for dust or museum pests to reach the specimens. If one wishes to collect extensively, one will need

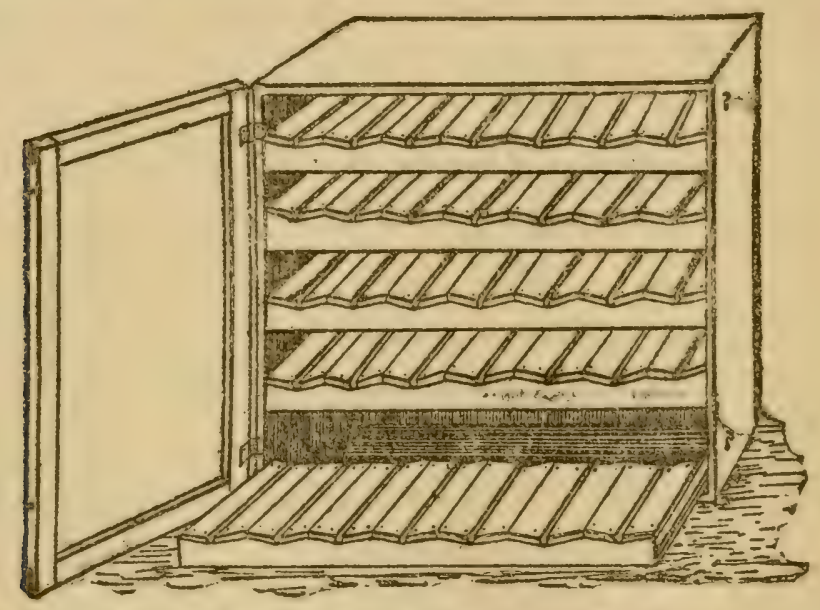

Drying Box for Setting Boards. (After Riley)

a considerable number of setting boards and it will be worth while to prepare for them a special drying box like that shown in the picture above. 


\section{PART II}

\section{THE TRUE BUTTERFLIES}

\section{Superfamily Papilionoidea}

The great suborder of butterflies is commonly separated into two principal groups called superfamilies. One of these includes all of the higher butterflies and is named Papilionoidea. The other includes the lower Skipper butterflies and is named the Hesperioidea. The former are characterized by small bodies and relatively large wings, straight clubbed antennae, and the fact that the caterpillars do not make cocoons when preparing for the chrysalis state.

The most authoritative classifications of butterfly families are based upon the peculiarities of wing venation and are admirably discussed in such books as Holland's "Butterfly Book" and Comstock's "How to Know the Butterflies." Without attempting to go into the technical details of structure it will sufice here to give the list of families which compose the superfamily Papilionoidea:

The Parnassians. Parnassiidae.

The Swallowtails. Papitionidae.

The Whites, Orange-tips, and Yellows. Pieridae.

The Nymphs. Nymphalidae.

The Satyrs or Meadow-browns. Agapetidae.

The Heliconians. Heliconiäce.

The Milkweed Butterflies. Iynadidae. 
The Long-beaks. Libytheidae.

The Metal-marks. Riodinidae.

The Gossamer-wings. Lycaenidae.

It must not be thought that such a list necessarily indicates the degrees of development of the respective families, for this is not true. It is simply a linear arrangement adopted for convenience by leading authorities, notably Dr. Harrison G. Dyar in his standard "Catalog of American Lepidoptera."

\section{THE PARNASSIAN BUTTERFLIES}

\section{Family Parnassiidae}

It is perhaps a bit unfortunate that the group of butterflies, which is commonly chosen to head the list of families, is one that is rarely seen by most collectors. The Parnassians are butterflies of the far north or of high elevations in the mountains. The four species credited to North America have been collected in Alaska and the higher elevations of the Rocky Mountains, so there is very little probability of any of them being found in the Eastern states.

While, structurally, these butterflies have a close affinity with the Swallowtails, one would never suspect it from their general appearance. Their bodies are large and all of the wings well rounded, so that there is more of the suggestion of a large moth than of the Swallowtail. The coloring is also more moth-like than with most butterflies, the wings being very light colored and nearly transparent, with markings of gray and brown, arranged in dots and splashes. 
All our species belong to the genus Parnassius. The caterpillars show their affinity with those of the Swallowtails by having the curious scent organs or osmateria just back of the head. They feed upon such alpine plants as stonecrop and saxifrage and are well adapted by their structure and habits to the bleak surroundings of the mountain tops.

As a typical example of the environment in which these butterflies live, we may take the alpine valleys of such mountain regions as Pike's Peak. Prof. M. J. Elrod has described a visit where, at an altitude of 11,500 feet in the month of August, Parnassius smintheus was flying by thousands, and the earlier stages were so abundant that a water ditch had the surface covered as far as one could see with the dead or dying caterpillars. In such situations, where ice forms at night, and snow frequently falls by day, these butterflies develop apparently in greater numbers than almost any of our other species are known to do in warmer regions.

\section{THE SWALLOWTAIIS}

\section{Family Papilionidae}

This is probably the most distinctive family of all our familiar butterflies. Its members are characterized by being on the whole the largest butterflies in our region and by having the hind wings prolonged into curious tail-like projections, suggestive of those of a swallow. In general, the basal color of the wings is blackish though this is commonly marked in various striking ways with yellow, green, or blue, while the margins of the wings are commonly 
adorned with red or orange spots. These butterflies are also characterized by certain peculiarities in the branching of the wing veins which will be found pictured in more technical works.

The caterpillars of these butterflies have the characteristic form pictured on the plate of the Swallowtails opposite page 80 . When full grown they are large, fairly smooth-bodied worms, showing at most on the surface sparse fine hairs or fleshy threadlike projections. Their most characteristic feature is found in the scent organs called osmateria situated in the back just behind the head. These are thrust out, generally, when the caterpillar is disturbed and appear as orange $\mathrm{Y}$ - or V-shaped organs from which an offensive odor is commonly given off. They are supposed to serve the purpose of preventing injury by enemies, possibly birds, monkeys, and other vertebrates. Structurally, they are like long tubular pockets that can be turned inside out. When the pocket is in place it is getting a pocketful of odors. When it is inverted it lets these odors free. On this account Professor Comstock has aptly called these caterpillars "the polecats of the insect world."

When ready to pupate, these Papilio caterpillars spin a web of silk upon some more or less flattened surface and a loop of silk near by. They entangle their hind legs in the former and keep their heads through the latter so the loop supports the body a little behind the head. Then they change to chrysalids which are held in place by these sets of silken threads.

The chrysalids are rather large and angular and generally take on colors approximating their surroundings. They vary so much in different species that one familiar 
with them can recognize the chrysalis and know the kind of butterfly it will produce.

\section{The Black Swallowtail}

\section{Papilio polyxenes}

While the Black Swallowtail is not so large as some other members of the group, it is probably the best known to most people. It is found throughout many months of the year in practically all parts of North America south of Canada, and has the habit of flying freely about fields and gardens in search of flowers from which to suck its nectar food, and of plants on which to deposit its eggs. The female butterflies have a remarkable ability in selecting only members of the great family Umbelliferae for this purpose. In consequence the caterpillars are generally to be found feeding upon carrots, parsnips, parsley, and various wild species belonging to this order. (See plates, pages 48 and 64-65.)

The eggs of the Black Swallowtail are laid one in a place upon the leaves of the food plant. Each egg is a small, yellowish, smooth, and ovoid object. It may often be found by watching the butterflies as they fly low in search of umbelliferous plants, and seeing one stop for a minute or so while she lays the egg.

About ten days after the egg is laid it hatches into a small black caterpillar marked in a characteristic fashion with a blotch of white in the middle of the body which is suggestive of a saddle. The caterpillar immediately begins to feed upon the green substance of the leaf, continuing thus about a week before the first moult. At this time it does not change much in appearance, still being a 
spiny creature blackish in color and marked by the curious white saddle. A little later it moults again, retaining its original coloring. At each moult, of course, it gets larger and feeds moie freely upon the celery or other plant on which it may happen to be.

When the caterpillar becomes about half grown it takes on a very different appearance from that of its early life. The skin is smooth rather than spiny, and the general colors are green, black, and yellow. The ground color of the skin is green, which is marked with black crossbands along the middle of each body ring. On these bands there are many large dots of orange yellow, the whole coloring giving the insect a very striking appearance, especially when it is placed by itself against a plain background. When they finally become full grown in this larva state, these caterpillars are almost two inches long.

The larvae of the Black Swallowtail have certain characteristics in which they differ from many other caterpillars. After each moult they do not devour their cast skins, which happens in the case of many of their relatives. When feeding, as well as when resting, they remain exposed upon the leaf and seem never to attempt to conceal themselves, as is the habit with a large proportion of caterpillars. It is probable that this instinct for remaining exposed to view bears some relation to the curious means of protection possessed by this as well as other Swallowtail caterpillars. When disturbed one of these larvae will push out from just back of the head the strange-looking, orangeyellow $Y$-shaped organ which gives off a very disagreeable odor. These osmateria organs are generally believed to be defensive against the attack of birds and various other 
enemies, although they seem not to be effective against insect parasites.

The full-grown caterpillars are likely to leave their food plants when ready to change to the chrysalis state. They wander in various directions until suitable shelter is found. A piece of board, a fence post, or possibly the bark of a tree will answer for this purpose. Here the caterpillar spins a mat of silk in which to entangle its hind legs and a short distance away near the front end of the body it spins a loop of silk attaching the ends to the support. These serve to hold the chrysalis in place during this helpless period. After the loop is made the caterpillar keeps its head through it so that the loop holds the insect in position a short distance back of the head. It is now ready to moult its last caterpillar skin and become a chrysalis.

One who has watched hundreds of these caterpillars go through this change, Miss Mary C. Dickerson, describes the process in these words: "In this final moult the chrysalis has to work very hard. The bulk of the body is again slipped forward in the loosened caterpillar skin, so that this becomes tensely stretched over the anterior end, and very much wrinkled at the posterior end. The skin splits back of the head and is forced back by its own taut condition and by the efforts of the chrysalis, until only the extreme posterior end of the chrysalis is within it. Then the chrysalis withdraws this posterior end with its many very tiny hooks, from the skin on the dorsal side, and, reaching around, securely fastens the hooks into the button of silk. Then the old skin is removed both from its fastening to the chrysalis and from its attachment in the button of silk."

A short time after the caterpillar's skin has thus been 
cast off the chrysalis takes on a brownish color which as is so often the case is likely to vary somewhat according to the tint of the surrounding surfaces. This is doubtless a protective device and helps the insect to escape attack by birds during the long period of exposure. For this butterfly passes through the winter only in the chrysalis condition, and the larva which went into the chrysalis in September does not come out as a butterfly until the following May or June. There are, however, two broods of the butterflies in the North and at least three in the South. As the adults live for about two months and there is considerable variation in the periods of their development it happens that one can find these Black Swallowtail butterflies upon the wing almost any time in warm weather, either North or South.

\section{The Giant Swallowtail Papitio thoas}

The largest of our North American butterflies is a magnificent insect with a wing expanse of some four inches and with a rich coloring of black and yellow more or less suffused with greenish or bluish iridescence that gives it a striking beauty as it flies leisurely about from flower to flower or stops to lay an egg upon some bush or tree. The tails are long and expanded toward the tip, their prevailing color being black with a broad splash of yellow near the end. In a general way we may say that the upper wing surface is black marked with two bands of orange-yellow, while the under surface is yellow marked with two bands of black. (See plate, page 64.) 


\section{THE SWALLOWTAILS}

The Giant Swallowtail is a tropical species which is abundant throughout the Southern states and during recent years seems to have been gradually extending its northern range. It is now commonly found as far north as forty-two degrees latitude, from Nebraska eastward. In New England it is occasionally taken in Connecticut, Massachusetts, and even in Maine, but its appearance in this region is exceptional.

In the orange-growing regions of the Southern states the caterpillars of this butterfly feed freely upon the leaves of citrus fruits and they are often called "orange puppies" or "orange dogs." Probably their curious appearance and their habit of resting for long periods upon leaf or twig gave rise to this name. In the region indicated the lifehistory of the insect may be summarized thus:

The mother butterfly deposits the eggs singly upon the young growth of orange or other citrus fruit trees, generally near the tips of leaves or branches. About a week later each egg hatches into a caterpillar that feeds upon the young leaves, resting upon the lower surface when not eating. After a few days of this feeding the caterpillar becomes too large for the skin with which it was born and it moults, coming forth with a new skin which soon hardens so that it can begin feeding again. A week or so later it moults for the second time, and continues these processes of feeding and moulting until full grown, which is perhaps a month from the time of hatching from the egg. At first the caterpillars eat only the succulent young leaves and branches, but as they grow larger they feed more freely upon the older foliage. They are very voracious and when abundant may often do much damage especially to young trees. When ready to change to the chrysalis each cater- 
pillar attaches itself by silken threads to the bark of the trunk or branch of the tree. Here it changes to a chrysalis which takes on a color so similar to that of the bark that the insect is surprisingly difficult to discover. A fortnight or so later it changes again into a fully developed butterfly that sallies forth in search of the nectar of flowers. (See plate, page 240.)

These "orange dogs," like the caterpillars of other Swallowtail butterflies, have curious yellow scent organs which, when the caterpillar is disturbed, protrude from the upper surface just behind the head. These give forth a very disagreeable odor which is believed to serve the purpose of repelling birds and possibly other enemies. It has been noticed that these caterpillars are not molested by birds although they are attacked by various insect enemies. Each mother butterfly is known to be able to deposit four or five hundred eggs and it has been suggested that the injuries of the caterpillars may be checked by shooting the butterfly upon the wing with cartridges loaded with small bird shot. In the South there are several broods in a season.

The life-history of this species in more northern regions differs in the choice of the food plant and the number of broods. It feeds upon various members of the rue family, including common rue and prickly ash, as well as upon certain poplars and probably other trees. It is two brooded and apparently winters as a chrysalis. The butterflies of the first brood come from the chrysalis about the last of May and are found on the wing during June. Those of the second brood come from the chrysalis about the last of July and are found on the wing during August and September. The length of time required from the laying of the egg to the emergence of the butterfly varies greatly with 


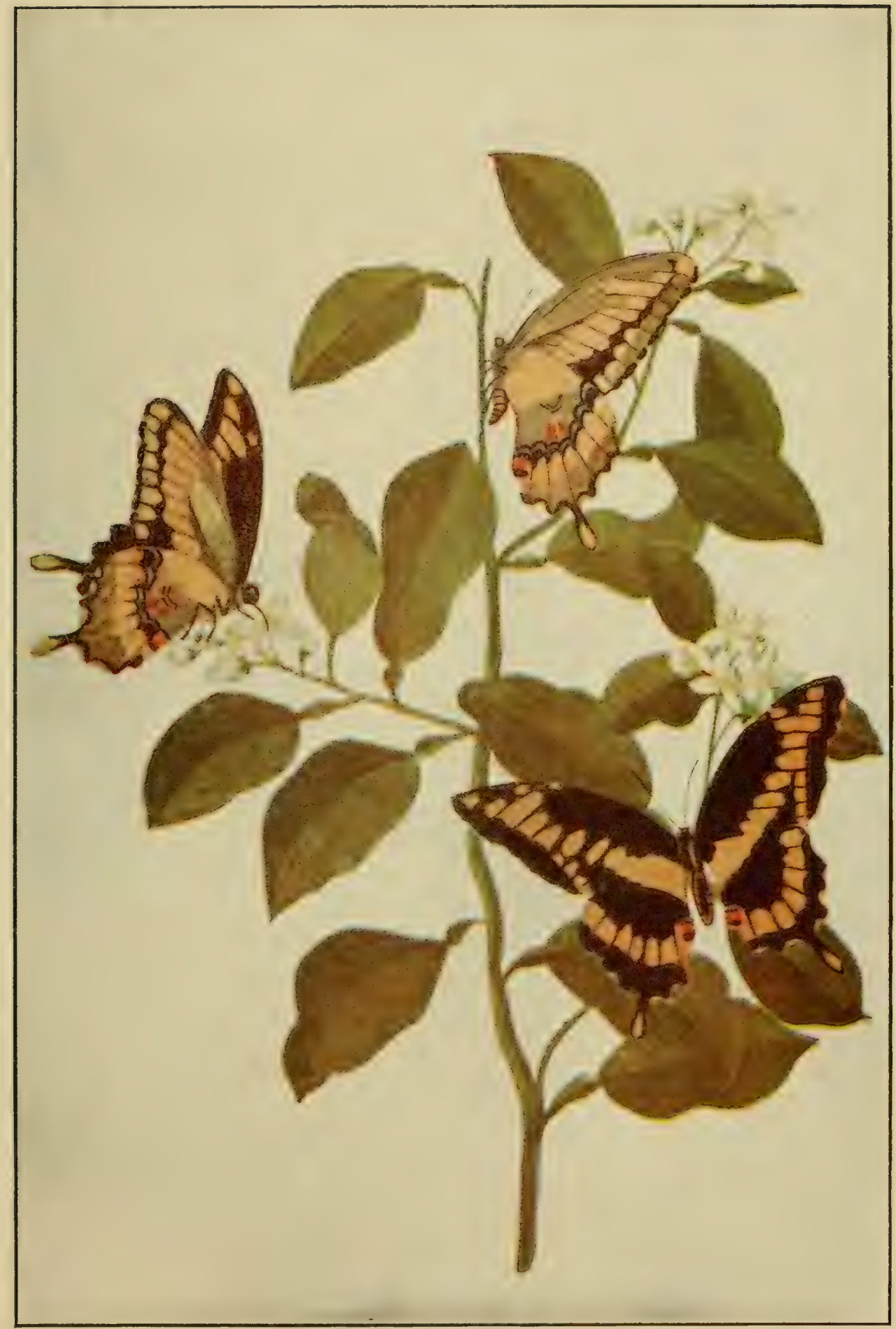

From a drazoing by Mary E. Walker

See page 62

GIANT SWALLOWTAILS

Visiting blossoming branches of the orange tree. (Reduced) 


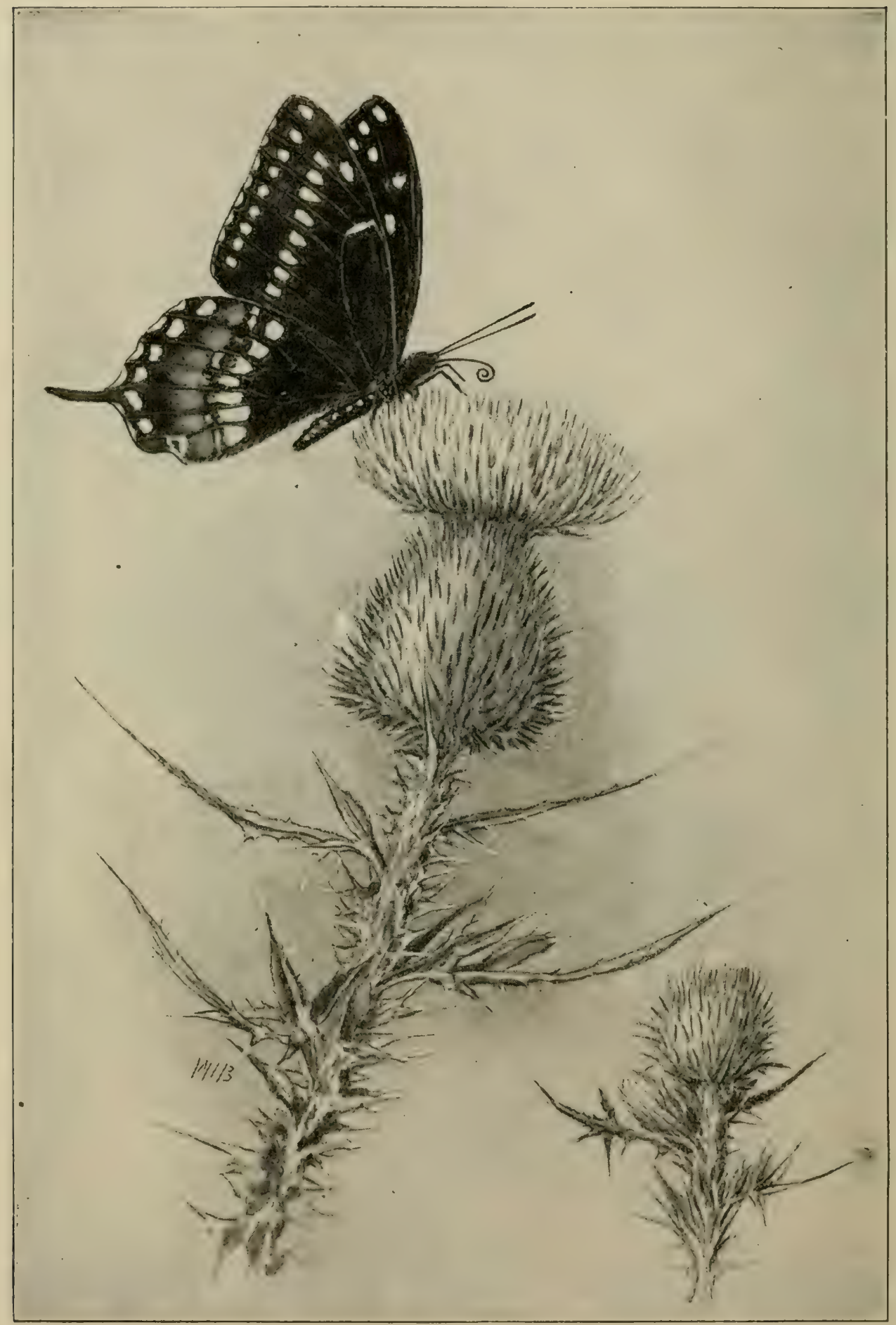

See page 5y

BLACK SWALLOWTAIL VISITING THISTLE, SHOWING THE TONGUE PARTIALLY UNCOILED 

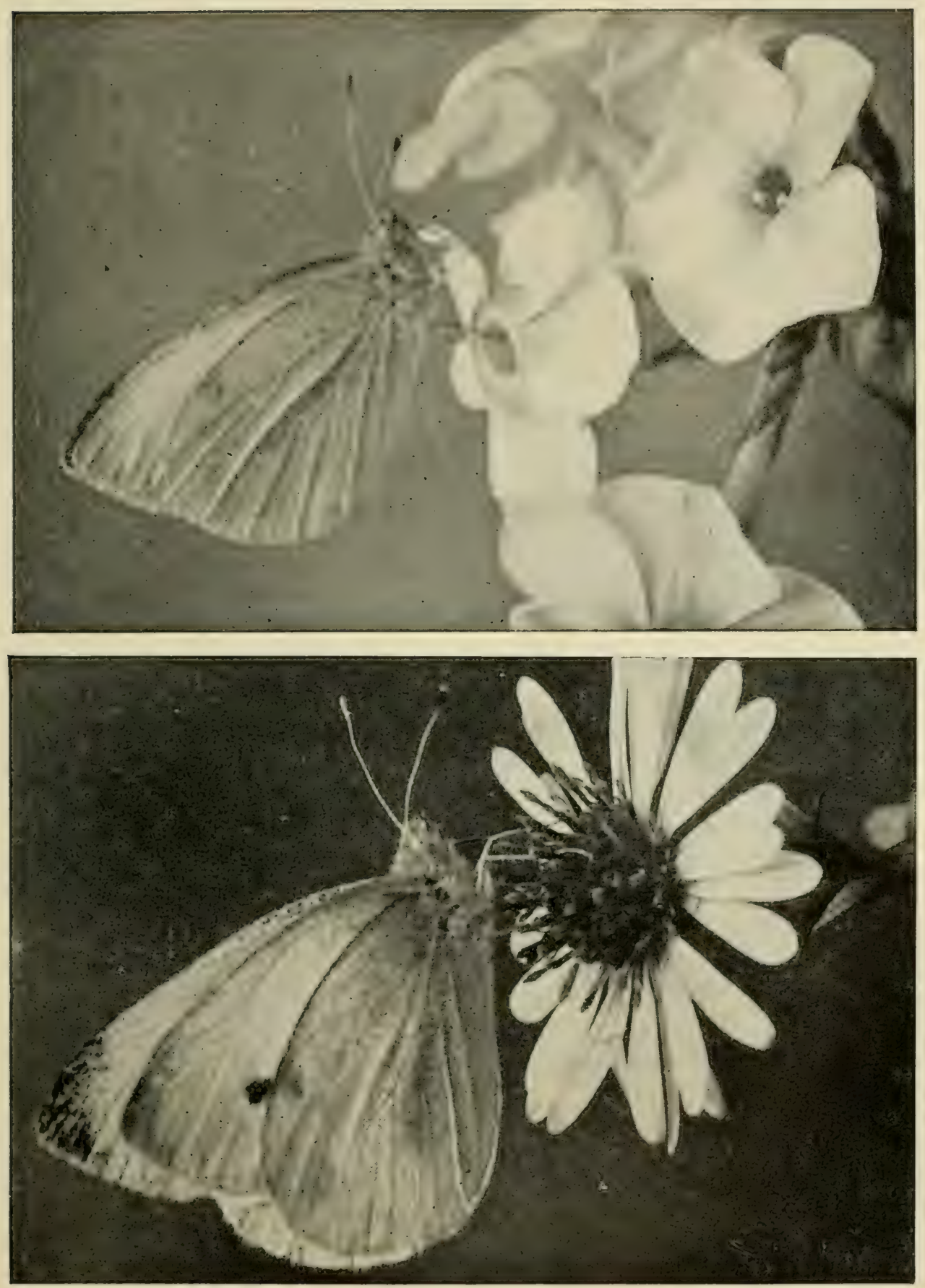

Photographed from life

See page 83

IMPORTED CABBAGE BUTTERFLY

(A good deal magnified) 


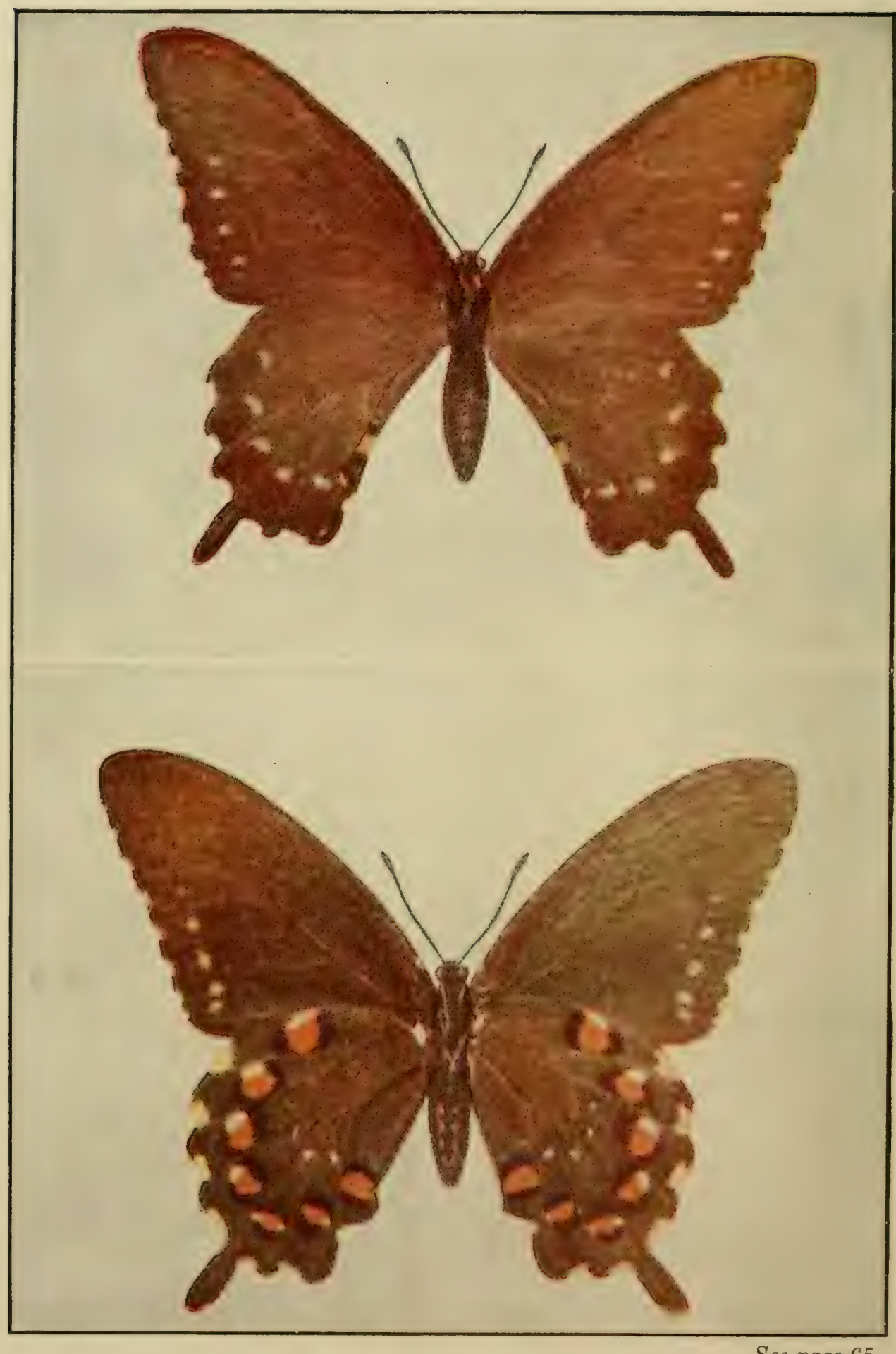

See page 65

THE BLUE SWALLOWTAIL

Upper surface above; lower surface below 
the locality and the temperature. It commonly extends over a period of four or five weeks.

\section{The Blue Swallowtail}

\section{Laertias philenor}

The Blue Swallowtail is said to have closer affinity with the splendid butterflies of the tropics than most of our other Papilios. The sheen of metallic color upon its wings is certainly suggestive of the broad expanse of similar colorings in the gorgeous butterflies from South America. This species is easily recognized by the general blackness of the front wings and the basal parts of the hind ones as seen from above, about two thirds of the area of the latter being overlaid with blue-green scales that give the metallic lustre characteristic of the species. Near the outer border of the basal half of the front wings there is a row of about five rather indistinct whitish spots, this row being continued more distinctly on the hind wings. On the under surface the white spots of the front wings are more pronounced than on the upper, while each hind wing is brilliantly marked with about seven large orange spots, part of them fringed on one or both sides with a distinct margin of white. The extreme side borders of all four wings are distinctly marked with white crescents and the fringes on the tails as well as more or less of the darker fringes of the hind wings are of a beautiful purple color. In the males each hind wing has along the inner border a slender, pocketlike depression which is said to be the seat of the scent organs. (See plate, page 65.)

This splendid butterfly is a southern species. It is 
found from the Carolinas to California, being at times extremely abundant in certain localities over this great region. It seldom occurs as far north as New England and in a general way east of the Rocky Mountains its northern limit approximates that of forty-three degrees of latitude. It varies considerably in size and differs greatly in abundance in different localities and different seasons.

Probably the commonest food plant of the caterpillars is the Dutchman's Pipe or Aristolochia, which is fre-

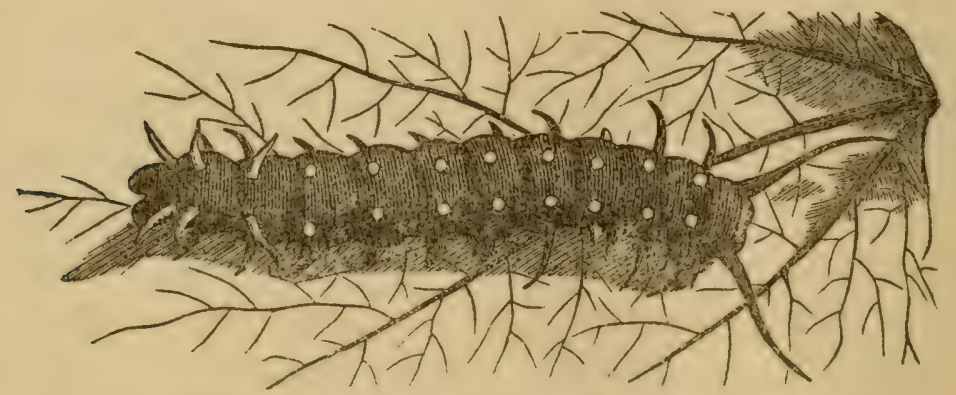

Caterpillar of the Blue Swallowtail. (After Riley)

quently planted as an ornamental vine for porch aaornment. It also feeds upon wild ginger or Asarum and probably upon other plants. A dozen or more eggs are laid upon a leaf by the mother butterfly, usually in a cluster or grouped near together. They hatch a week or so later into small brownish caterpillars which remain together for awhile in little groups that feed side by side upon the leaf, beginning at the margin and working toward the centre. As they become larger they feed more freely and gradually disperse so that each forages for himself. As they approach maturity their appetites become voracious and their presence is often shown by the defoliated condition of the branches. They have back of the head the osmateria or scent organs which are commonly found 


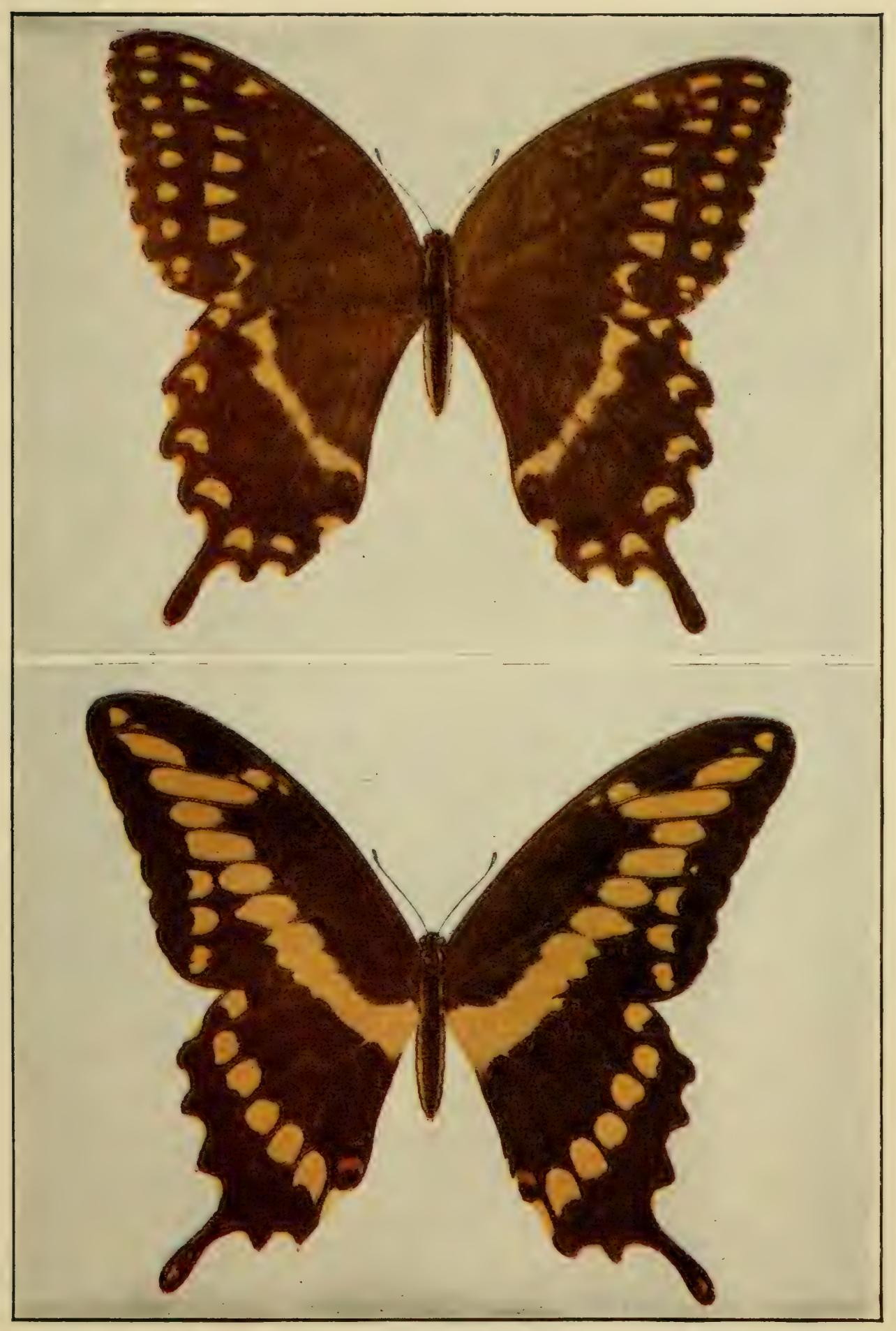

TWO OF THE SIVALLOWTAILS

(Three fourths natural size)

The Palamedes (see page 76)

The Giant (see page 62) 


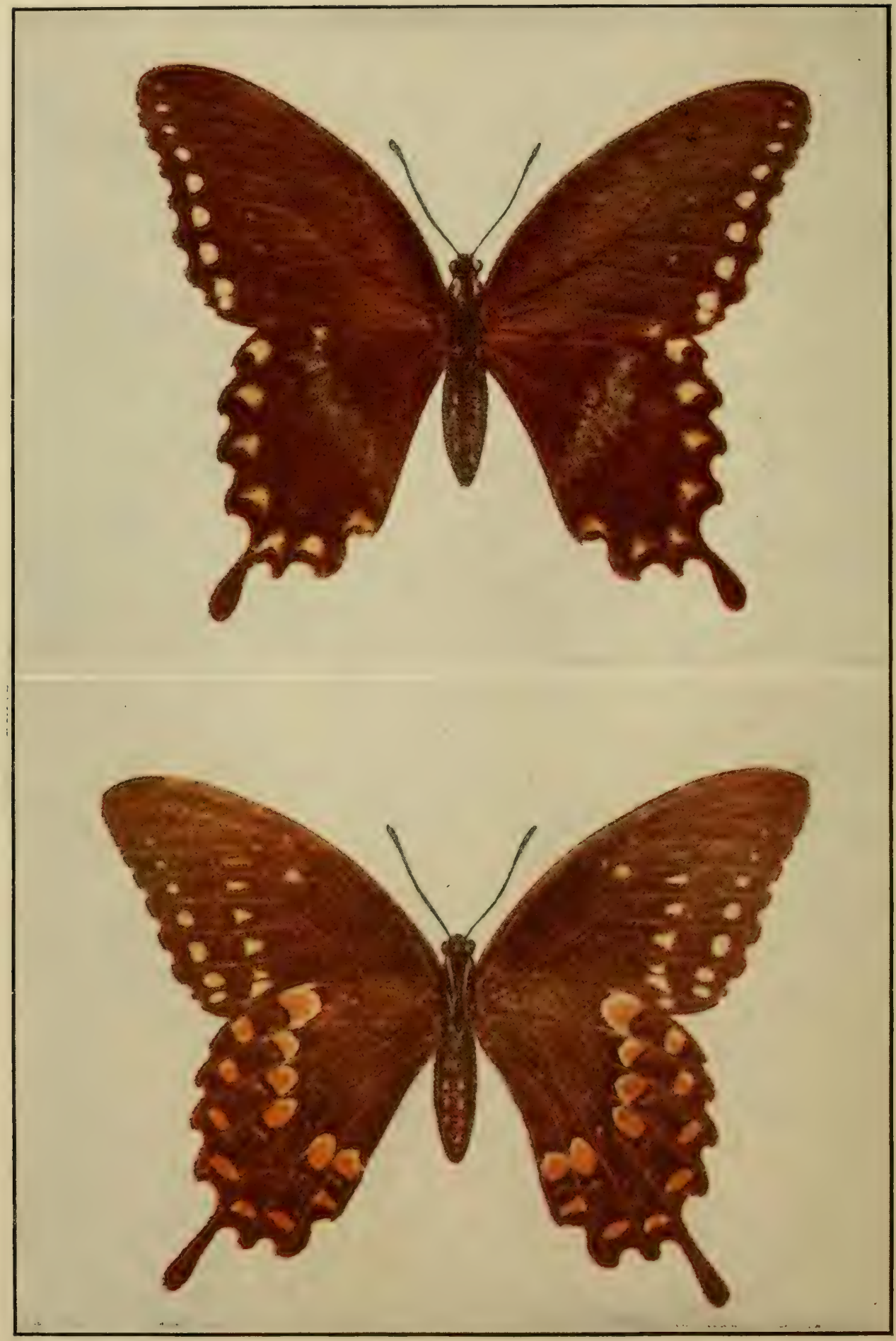

See page 67

THE GREEN-CLOUDED SWALIOWTAII

ITper surface above: lower surface below 


\section{THE SWALLOWTAILS}

in the other caterpillars of this genus, but the odor emitted by them is likely to be less pronounced than usual.

When full grown the caterpillars find such shelter as they may and each spins a bit of silken web and a silken loop which hold it while it changes to the chrysalis. This chrysalis is very likely to take on the colors of the immediate surroundings and thus be rather difficult to see. If the egg was laid by one of the spring or early summer butterflies, the chrysalis will soon change to a butterfly which will appear toward midsummer and which may lay eggs for another brood of caterpillars. These caterpillars mature to chrysalids the same season and some of them are believed to change into butterflies in autumn, these butterflies hibernating through the winter; while others are believed to remain unchanged through the winter and disclose the butterfly the following spring. This is an exceptional condition for the Swallowtails and it is worth while to make careful observations along its northern limits to learn more definitely the facts as to the winter condition.

\section{The Green-clouded Swallowtail}

\section{Papilio troilus}

This beautiful butterfly is essentially a southern species and is found over a wide range of territory from the Mississippi River to the Atlantic Ocean. It occurs as far north as New Hampshire and Vermont and has even been reported from Alberta, Canada. It is easily recognized by the blue-green clouding of the upper surface of the wings, the general color being velvety black with distinctive 
rows of yellow spots along the margins of the front wing. These spots are present also on the hind wing where they are almost changed to blue because overlaid with a general cloudiness of this color. On the under surface of the hind wings there are two rows of orange-brown spots, the inner row being nearly crescent-shaped and the outer row oblong. In the living insect the tail projections on the hind wings are usually twisted into a vertical plane at right angles to the plane of the wings.

The caterpillars of this species feed upon the leaves of sassafras and spice bush. The distribution of the butterfly appears to be closely related to the distribution of these plants.

As is the case with so many of our Swallowtail butterflies, the Green-clouded Swallowtail passes through the winter in the chrysalis stage. Late in spring the butterflies emerge and soon afterward lay their eggs singly upon the leaves of sassafras or spice bush. The eggs soon hatch into lead-colored caterpillars, largely covered with spiny warts. Each caterpillar cleverly makes a protecting nest by eating out a narrow strip in the leaf which frees a flap along the margin that is turned back upon the leaf, making a case in which the larva lives. It spins a silken carpet on one side of the case and rests upon this carpet when at home. During its feeding periods it goes outsicle and eats the tissues of the other parts of the same leaf. It continues to occupy this first nest for a week or more by which time the rest of the leaf is likely to be pretty well consumed.

Having passed the first moult and thus become larger and having practically eaten itself out of its first house and home the caterpillar now crawls to a larger leaf where 


\section{THE SWALLOWTAILS}

it proceeds to make a more enduring structure. In this case it does not need to bite a channel along one side of the midrib as it did before, but instead it begins to spin silken threads transversely across the upper surface in such a way as to fold over the border of the leaf and make a tubular chamber in which it has plenty of room to move about. It uses this as its home for some time thereafter, wandering out at evening to feed upon neighboring leaves as its hunger necessitates. In this way it continues to feed and grow for a week or two. Then it finds it necessary to construct still another home, which it does by bringing together the opposite sides of a leaf, taking care to have a door-like opening at the base of the blade next the leaf stalk. This third home serves it to the end of its larval existence. It goes in and out as necessary, remaining concealed when it casts its skin and until the body tissues harden afterward. Apparently it devours the cast skin and thrusts the hard covering of the head out of the nest. Consequently these little homes are clean and sanitary and serve admirably their protecting purpose.

The full-grown caterpillars have the curious appearance of those of the other Swallowtails. The third ring behind the head is greatly swollen, making, with the rings directly in front of it, a characteristic picture suggesting a grotesque face with large eye-like spots at the top. The general color is green, darker above than below, and there are six rows of blue dots along the body. (See plate, page 80.)

When ready to change to the chrysalis, the caterpillars desert their leafy homes and on a twig or board or stone each spins a bit of silken webbing and a silken loop. They now change to chrysalids which are likely to resemble the color of the background and which are somewhat smoother 
than many of the Swallowtail chrysalids. About two weeks later the butterflies emerge.

\section{The Eclosion of the Butterfly}

The transformation of a chrysalis into a butterfly is always one of extraordinary interest. Comparatively few definite descriptions of this process have been given by careful observers. One of the best of these is that written by Mr. Scudder in connection with the emergence of this butterfly, and it is so accurate and complete that it seems worth while to quote it at length:

"The butterfly generally emerges from the chrysalis early in the day," writes Mr. Scudder, "and the first signs of the immediate change are strong forward and backward movements of the chrysalis at intervals of a few seconds; perhaps the third or fourth attempt will be successful, when a click may be heard at the distance of several feet; but all the subsequent movements are absolutely noiseless, though rapid; at intervals of three or four seconds, spasmodic movements similar to the first carry on the process; first the split continues along the thorax; then it runs down either side between the legs and wings, ultimately to the tips of the antennae. As this progresses, the actions become more strenuous and more frequently repeated; with eager efforts the butterfly pushes forward its half-detached head; now an antenna springs from its case, at once assuming its natural attitude; the other soon follows, and then the wings are partially drawn from their sheaths, and while in this position seem to be used as levers or arms to aid in withdrawing the rest of the body; next the legs appear, seize the upper part of the chrysalis skin, and speedily withdraw the whole body. It is now a 


\section{THE SWALLOWTAIIS}

curious-looking object, the wings wrinkled and bloated, and, although the whole process of escape lasts little more than half a minute, already twice the size of the sheaths they lately occupied. The insect crawls upward until it finds a secure resting place, and there remains until ready for flight; each half of the tongue, drawn independently from its receptacle, is rolled in a separate spiral, and now while the wings are gradually expanding the insect applies all its energies to uniting their two parts, incessantly rolls and unrolls them, and beginning simultaneously at the base, gradually fits them together by their interlocking joints; in about fifteen minutes all but the tips are perfectly united; these require nearly fifteen minutes more, and are not fairly interlocked until the wings are fully expanded, nearly a full half hour after the escape from the chrysalis; the wings, however, are still tender, and generally require two hours to stiffen. When at last the insect ventures upon flight, it is not with an uncertain flutter, but boldly and steadily, as if long accustomed to the action."

The butterflies of this second brood of the season are likely to begin to appear early in August, continuing to become more abundant throughout that month. These lay eggs upon the same food plant and the caterpillars grow to maturity in the same way as those of the first brood. They become full grown during September or October, and then change to chrysalids which remain dormant until the following spring. The species thus has two broods each year and passes the winter only in the chrysalis state.

These beautiful butterflies are likely to be found in the sort of situations where the food plants of the larvae are 
growing. Open groves, the borders of woods, and the margins of streams or marshes are the places where one is most likely to find spice bush and sassafras. These are the places to look for these butterflies which one may often see in graceful flight near the ground, pausing now and then to seek a sassafras leaf or to sip the nectar from a flower.

\section{The Tiger Swallowtail}

\section{Papilio glaucus}

One of the many things that make a study of the lifehistories of butterflies of great interest is the variations in the development of many of the species. One who follows the simplest life-story of a butterfiy and sees the egg change to larva and the larva change in size and form and color with each successive moult and then change again into the seemingly inert chrysalis, from which there finally comes the winged butterfly-unlike the egg, unlike the larva, unlike the chrysalis - a creature of perfect beauty, wonderfully adapted to living freely in the air and sipping ambrosial nectar from the flowers-one who follows these changes with awakened vision can scarcely fail to have a sense of wonder as to the laws that govern such intricate phenomena. But the marvel is still more pronounced in the case of those butterflies which have two or more forms arising from the same lot of eggs in a way which science has as yet not adequately explained.

The splendid Tiger Swallowtail is an example of this dimorphism which is of especial interest because of the fact that the extra form is confined to one sex and to only a part of the geographical area over which the butterfly is 


\section{THE SWALLOWTAILS}

found. The species occurs over a very large part of the North American continent, being found from ocean to ocean and from Canada to Florida. In the region north of approximately the fortieth degree of latitude there is but one form of the insect-the familiar yellow-and-black striped butterfly which every one has seen visiting the lilac blossoms in May or June. South of this, however, part of the females take on an entirely different appearance, being almost wholly black with the hind wings touched with lines of blue and bordered with crescents of yellow and orange. The curious thing about it is that a certain mother butterfly may lay a dozen eggs part of which will develop into the usual yellow form and the rest into the black form, both lots being of the same sex. This black form is so entirely distinct in appearance that the two were originally described as separate species, and they were long considered such, until breeding experiments determined the precise condition. (See plate, page 1\%.)

This species is of interest also for another reason. The caterpillars during their later life are remarkable examples of that curious resemblance to the head of a serpent which is thought to have a real protective value in frightening away attacking birds and possibly other enemies. The rings of the body just back of the head are much swollen and on the top of the swollen part there are two large circular marks which bear a striking resemblance to eyes. When the insect is at rest it withdraws its head and holds up the front of the body in such a way as certainly to suggest at the first glance that one is looking at the head of a small snake, an impression which is likely to be enhanced when the caterpillar pushes out the curious yellow scent organs from the ring near the top of the head, these 
organs taking on the forked appearance of a snake's tongue.

Obviously it is exceedingly difficult to get definite observations under natural conditions to determine whether these seeming resemblances are really of value to the caterpillar in frightening away birds or other enemies. About the only direct evidence which $I$ have come across upon this point is found in this paragraph by Dr.J.L. Hancock:

"When I recall the first sight of this larva, the impression gained of it was a most curious one. The forward mask-like face was remarkably startling. This mask, bearing eye-like spots and the light transverse ridge, gave it an aspect which might easily be mistaken for real eyes and a mouth. This contrivance is only a false face in no way connected with the real eyes and mouth. One might imagine the shock that a bird, or other predaceous enemy, would experience when looking upon this grinning mask. This is in reality the effect produced, for $I$ have seen small birds so alarmed that they lost their appetite and curiosity for these larvae after a brief glance at them. It is certain that these singular markings have the effect of terrifying their bird enemies."*

The yearly cycle of the Tiger Swallowtail is much like that of the related species. It passes the winter as a chrysalis, the butterflies coming forth just about the time that the lilacs bloom. They remain upon the wing for a few weeks and deposit their eggs upon a great variety of trees and shrubs, for the food plants of the larvae are unusually varied and include tulip trees, birches, wild cherries, apples, poplars, ash, and several other common trees or

*“Nature Sketches in Temperate America," p. 146. 
shrubs. These eggs soon hatch into caterpillars that feed upon the leaves and make for themselves resting places by spinning a web of silk transversely across the surface of the leaf. They remain upon these silken webs when not feeding and in later life are likely to cause the leaf on which the web is made to curl into a partial tube. When fully developed they change to chrysalids which give forth the summer brood of butterflies in July and August. These in turn lay eggs for the caterpillars which change to chrysalids in autumn and remain in that condition until the following spring.

\section{The Short-tailed Papilio}

\section{Papilio brevicauda}

Were one enough of a magician to make one butterfly over into another it would be comparatively easy to take a Black Swallowtail and transform it into this species. One would only need to trim off the long tails so that they project very slightly from the angles of the hind wings and to change the yellow spots to orange. He would thus accomplish what Nature through the long ages seems to have accomplished in a limited northern area in Newfoundland and around the Gulf of St. Lawrence, for the Short-tailed Papilio is confined chiefly to this region, where it lives a life very similar to that of the Black Swallowtail. The caterpillar feeds upon the leaves of various members of the parsley family and is said to have learned to warm itself during the middle of the day by resting upon stones and gravel which have absorbed the sun's heat rays. Presumably there is but one brood a year and the insect hibernates as a chrysalis. 


\section{BUTTERFLIES}

\section{The Palamedes Swallowtail}

\section{Papilio palamedes}

If the magician who had succeeded in converting a Black Swallowtail into the Short-tailed Papilio wished to try his hand on making a Palamedes Swallowtail he could not do better than to use again the same black butterfly. He would only need to make it about one half larger, retaining practically all its color markings and the outline of its wings and tail. For this species bears a remarkable resemblance to the Black Swallowtail, seeming to be a giant variety induced by the warmth of the southern climate where it lives, and possibly by the more generous supply of the magnolia and sassafras leaves upon which the caterpillars feed.

This species is distinctly a southern form occurring as far west as the Mississippi River throughout the more Southern states. As one would expect in the long seasons and warm climate of this region there are several broods each year and the caterpillars often hibernate as well as the chrysalids. The adult butterflies are lovers of the sun and are said to roost at night upon the tops of live oak and palmetto trees.

\section{The Zebra Swallowtail}

\section{Iphiclides ajax}

Most of our Swallowtail butterflies are so distinctive in form and colors that they are easily distinguished from one another, but the Zebra species is so different from all the 
rest that when it is once seen it is likely always to be remembered. The striking combination of green and black stripes with very long tails, set off by beautiful crescents of blue and of red, at once distinguishes this fine butterfiy in any of its varying forms.

Three distinct forms of this species occur, namely:

Marcellus, the early spring form, small in size with short tails, that show white only on the tips;

Telamonides, the late spring form, somewhat larger, with tails a little longer and showing more white on the outer half;

Ajax, the summer form, decidedly larger with tails very long.

It would be a comparatively simple matter to understand these forms if they were simply seasonal variations, with three broods, each form succeeding the other as the season advances. But this is far from being the case. We have instead the most complicated and confusing series of conditions imaginable-conditions for which no one has yet given satisfactory explanations.

To make a fairly clear statement of what happens, suppose we assume that we start with twenty over-wintering chrysalids. In April ten of these disclose their butterilies which are Marcellus, the early spring form. In May the other ten disclose their butterflies which are Telamonides, the late spring form. We thus have these two forms appearing successively in spring from the same set of overwintering chrysalids.

After flying about for a short time the Marcellus or early spring Swallowtails lay eggs upon the leaves of papaw trees or bushes. These eggs soon hatch into caterpillars that feed upon the leaves and grow rather rapidly. 
A little more than a month later they mature into butterflies which are Ajax, the summer form.

In a similar way the Telamonides or late spring butterflies lay eggs soon after they appear, also upon papaw leaves, and these eggs in about a month mature into Ajax, the summer form.

So we have Ajax, the summer form, developing directly from both the early spring or Marcellus and the late spring or Telamonides butterflies.

These Ajax butterflies in their turn lay eggs for caterpillar young. These soon mature into a brood of butterflies which are of this same Ajax form. There may be successive broods through the summer, practically all of them being this same Ajax summer form.

The last brood of caterpillars, however, change to chrysalids which do not disclose the butterflies until the following spring. And then the first that come out are the Marcellus form and the last the Telamonides form. So we may have these two forms maturing from the same brood of autumn caterpillars.

This seems a sufficiently complicated life-history to suit the most persistent solver of puzzle problems, but there is an additional factor which adds much to the possible confusion of the broods. In each brood of caterpillars from the earliest to the latest there are a certain number of chrysalids which remain dormant through the remainder of the scason and the following winter, maturing into butterflies the next spring. Consequently at the end of every winter there are a miscellaneous lot of chrysalids which represent every brood of caterpillars that lived the previous season, and all of these develop into either Marcellus or Telamonides butterflies. 
Such a condition of affairs certainly represents what an old New Englander would be likely to call a "mixed-up mess," and it is difficult for science to find rhyme or reason to explain it. It speaks eloquently for the perseverance of W. H. Edwards that he was able with infinite patience through years of study and experiment to untangle this intricate web of butterfly existence.

While the preferred food plant of this species is papaw, the caterpillars are also known to feed upon the spice bush and upland huckleberry. When full grown these caterpillars are about two inches long and of a general pea-green color, banded transversely with yellow and black, and having an especially conspicuous band of this sort on the third ring behind the head. The scent organs are protruded when the larva is disturbed and emit an offensive odor. The chrysalids are green or brown according to the surroundings.

The Zebra Swallowtail is a southern butterfly found as far west as Texas and the Rocky Mountains and having its northern limits in a zone ranging approximately from Massachusetts to Nebraska. It is especially abundant in the Southern states east of the Mississippi River.

Mr. S. F. Denton found this species abundant in southern Ohio where the females laid their eggs upon the small papaw bushes. They selected the leaves of these bushes for sleeping quarters, "clinging to the under side of the leaves where early in the morning they might be taken with the fingers."

\section{Other Swallowtails}

Several other Swallowtail butterflies are found within the limits of the United States, especially in the Far West 
and along the southern boundaries. Some of these occasionally migrate east or north so that they are collected in the Central states. Thus Papilio daunus, $P$. oregonia, and $P$. zolicoan are all found in the "List of Nebraska Butterflies," published by Mr. H. G. Barber, and the same species have been taken in other states in or near the Mississippi Valley. These and various others are described and pictured in Dr. Holland's excellent "Butterfly Book."

Synopsis of the Swallowtails

Tiger Swallowtail: Yellow form (Papilio glaucus turnus). Expanse $3 \frac{1}{2}$ to 5 inches. Upper surface of wings bright yellow with each black margin marked with a row of yellow spots. Both sexes throughout its range. Black form (Papilio glaucus glaucus). Black all over with blue markings on outer half of hind wings and row of straw-yellow crescents on borders of same. Females only, and only south of about latitude 40 degrees.

Giant Swallowtail (Papilio thoas or Papilio cresphontes). Expanse 4 to $5 \frac{1}{2}$ inches. Upper surface black with two bands of yellow starting at the inner margin of the hind wings and coming together as a row of yellow spots at the outer angles of each front wing. A yellow spot on each black tail. Under surface yellow.

Zebra Swallowtail. Expanse 3 to $3 \frac{1}{2}$ inches. Easily known by the stripes of green upon black and the long, slender tails. The different forms vary in size and in the length of the tails. Scientific names are: Early Spring Form, Iphiclides ajax marcellus; Late Spring Form, I. ajax telamonides; Summer Form, I. ajax ajax.

Green-clouded Swallowtail (Papilio troilus). Expanse $3 \frac{1}{2}$ to 4 inches. Black with about seven yellowish spots 


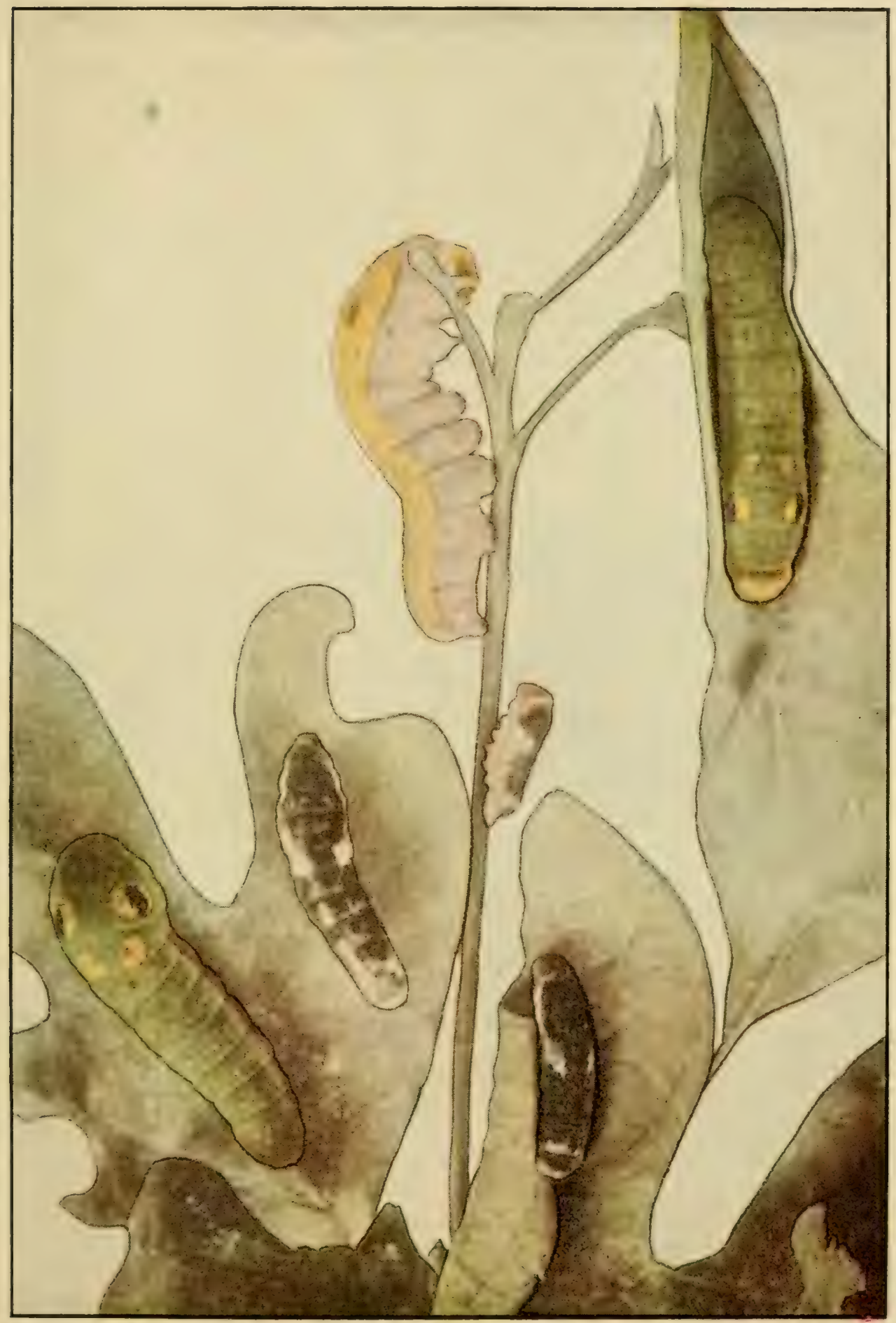

From a photograph from life by $A . H$. Verrill

See pages 7,67

CATERPILLARS OF THE GREEN-CLOUDED SWALLOWTAII.

In various stages of growth 


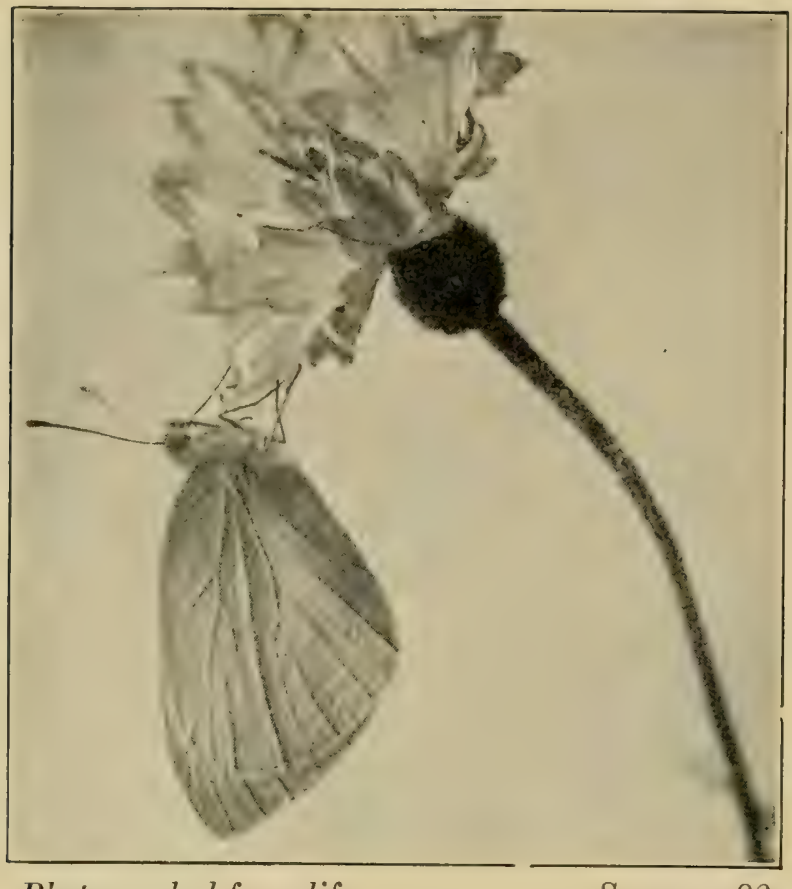

Photographed from life

See page 83

IMPORTED CABBAGE BUTTERFLY

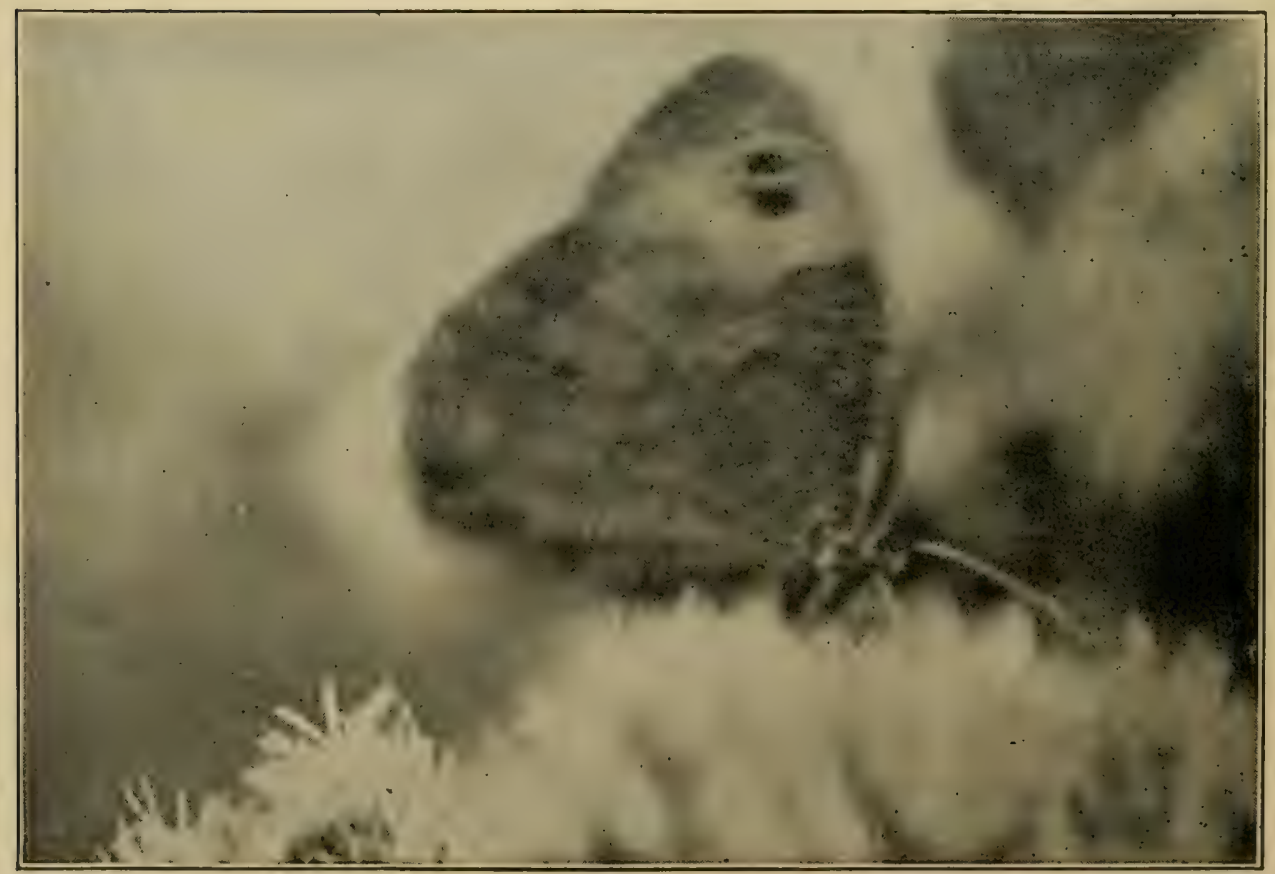

Photographed from life

See page 215

BLUE-EYED GRAYLING VISITING JOE PYE WEED

(Magnified) 
on outer margin of each front wing and eight marginal spots on each hind wing, those at the ends of row orange, the rest yellowish or bluish. Outer half of hind wings clouded with greenish blue. Under surface black with two distinct rows of yellowish spots on front wings and two rows of orange spots on hind wings.

Blue Swallowtail (Laertias philenor, often called Papitio philenor). Expanse about 4 inches. Black or brownish black with most of hind wings showing a bluish green iridescence. A row of marginal spots on each hind wing, more or less distinct on the front wings. Outer fringe with broad white markings interrupted by black ones. Under surface of each hind wing with seven large orange spots, some with partial borders of white.

Black Swallowtail (Papilio polyxenes or Papitio asterias). Expanse about 3 inches. Black with two conspicuous rows of yellow spots on outer half of wings, more distinct in males. On hind wings rows of blue spots or splashes between the yellow ones. Orange-red circle with black centre at inner angle of each hind wing. Under surface with markings more distinct and more orange yellow.

Short-tailed Swallowtail (Papilio brevicauda). Much like the Black Swallowtail but generally smaller, with very short tails, and with the yellow markings more or less changed to orange. Confined to the limited region of Newfoundland and the lands bordering the Gulf of the St. Lawrence.

Palamedes Swallowtail (Papilio palamedes). Expanse 4 to $4 \frac{1}{2}$ inches. Much like the Black Swallowtail but considerably larger. A curved yellow line on the head back of each eye. Found only in the South. 


\section{THE WHITES, ORANGE-TIPS, AND YELLOWS}

\section{Family Pieridae}

The most familiar and abundant American butterflies are classified together under the family name Pieridae, or the Pierids. Three groups or tribes of them are popularly known as the Whites, the Orange-tips, and the Yellows. Our two commonest butterflies, the White or Imported Cabbage Butterfly and the Sulphur Yellow Eutterfly, are typical representatives of this family. Most of the rest, like these, are of moderate size with rounded wings which are more or less marked with black. There are six well-developed legs and the caterpillars of practically all the species are cylindrical greenish worms which under a lens are seen to be covered with short hairs. When the caterpillars are ready to change to chrysalids they spin a web of silk upon the supporting surface and just back of it, a loop of silk that serves to hold the chrysalis in place and keep it from swaying back and forth. The chrysalids are characterized by having a pointed projection on the front of the head, the rest of the body being more or less angular.

Notwithstanding their close general resemblance to their food plants, the caterpillars of this family suffer from attack by various enemies. Birds find many of them, not only eating them themselves but also using them freely for feeding the nestlings. Parasitic insects also take a heavy toll from these caterpillars. This attack of enemies is doubtless a chief reason why many of the common species are not much more destructive. 


\section{THE TRIBE OF THE WHITES}

Three white butterflies of approximately the same size are found widely distributed over the United States. The most abundant species is the White or Imported Cabbage butterfly. The next in abundance is probably the Checkered White, and the rarest in most localities is the Gray-veined White which is a northern form.

\section{The Whire or Imported Cabbage Butterfy}

\section{Pieris rapae}

There is probably no butterfly which one can generally find so easily in its early stages as the White or Imported Cabbage butterfly which is found practically wherever cabbages are grown and is generally so abundant that caterpillars and chrysalids are readily discovered. In the Northern states the insect passes through the winter within the chrysalis, coming forth rather early in spring as the familiar white butterfly with black dots upon the wings and blackish front angles of the fore wings. (See plates, pages $64-65$ and 81 .)

The butterflies that thus appear in spring fit freely about over fields, meadows, and gardens, sipping the nectar of various early flowers through their long, coiled tongues and stopping occasionally to alight upon the leaf of a cabbage or other plant of the mustard family to deposit the small, pale yellow eggs which remain attached by a sort of glue. The adult butterfies continue their 
leisurely life for a fortnight or more, thus extending the laying of the eggs over a considerable period.

About a week after being deposited the egg hatches into a tiny green caterpillar that begins feeding upon the tender surface of the cabbage leaf. It is commonly called the cabbage worm and it is doubtless the most generally destructive insect affecting this crop. It continues to feed for several days before the first moult, after which it becomes decidedly larger and begins to eat again more voraciously than before. It undergoes several successive moults during the next two or three weeks before it becomes full grown as a caterpillar. Unlike most butterfly larvae it has changed very little in its general appearance during its growth. It is always of a pale green color, strikingly like the glaucous green of the cabbage leaf, a fact which doubtless helps to conceal it from the eager eyes of birds and other animals.

When the caterpillar is thus full fed it is likely to leave its food plint and find shelter elsewhere. Sometimes it will stop on the lower surface of the outer leaves, but more commonly it will find a piece of board, an overhanging stone, a fence-post, or the side of a building, where it will prepare for the change to the chrysalis. It will do this by spinning a silken thread upon the surface in which to entangle its hind legs and a loop of silk near by with which to hold its body. When these preparations are completed the insect will cast its last caterpillar skin, emerging as a grayish or brownish chrysalis, the color usually varying with the color of the surrounding surface.

A week or more later the chrysalis skin bursts open and 
the white butterfly emerges to expand and dry its wings before it flies away for its leisurely life. There are two or more broods each season, the number varying with the latitude. There is a decided variation in the length of time required for the completion of the cycle from egg to butterfly. In hot weather the insect may mature in about three weeks while in cooler weather it may require as much as five weeks.

\section{Its Introduction and Dispersal}

While it is well known that a large proportion of our most destructive insects have been imported from Europe, it is only in comparatively few cases that man has been able to make careful records of the times and places where the insects were introduced and to follow the spread of the pest from these original centres. The Imported Cabbage butterfly is one of the few species of which this is true. This insect has been known for centuries in Europe, where it feeds freely upon the leaves of cabbages and turnips. So far as known it was first introduced into North America about 1860, when it appeared in Quebec. Eight years later it was again introduced into the region of New York City. From these iwo points the insect spread gradually in various directions until in 1871 it covered the whole of New England and various parts of New York and New Jersey. From then on it spread even more rapidly and was evidently accidentally introduced into various parts of the country which became new centres of distribution. Of course it would be very easy for this to happen through the shipment of cabbages from one part of the country to another. Within thirty years of the time of its first in- 
troduction it had become a serious pest over practically all the United States and Canada.

The introduction and spread of such a pest is of interest in itself, but in this case there is to be noted the additional fact that the presence of this foreigner has practically led to the extinction of two native species of butterflies, both closely related to each other and to the invader and both feeding upon the same plants. An almost pure white butterfly-the Gray-veined White-was formerly exceedingly abundant in many of the Northern states, while farther south there was another species, the Checkered White, which was also abundant. Both of these have now so completely disappeared that in some localities they are almost never seen, while their imported relative has become perhaps the most abundant of all American butterflies.

\section{The Gray-veined White}

\section{Pieris napi}

One would naturally suppose that when a butterfly was reduced to the greatest possible simplicity in its coloring there would be little chance for the development of geographical or seasonal varieties. But he would only have to study a large collection of specimens of this species, taken at different seasons and in different regions, to find his supposition at fault. Here is a butterfly which is essentially a slender black-bodied creature with four white wings scarcely touched with color, and yet we are told that there are eleven varieties in the United States so distinct that they have received scientific names, not to 
mention various others which have been found in Europe. This is indeed a remarkable showing and it is a striking illustration of the infinite variations which Nature can produce with the most limited materials.

To me the seasonal variations of a butterfly are always of greater interest than those which are geographical. We know that in the case of a great many animals, from insects to mammals, the different conditions of climate and physical environment found in different regions produce variations of many sorts. So it does not seem especially strange that in Alaska there should be a different form of a certain butterfly than is found in Virginia. But that in the same locality there should be two or more forms of a butterfly existing under identical conditions as to climate and environment is not so easily explained. In the case of the Gray-veined White we collect in early spring in New England, or other Northern states, a lot of chrysalids. We keep them until the butterflies come forth and we find even here two distinct forms, one smaller and more delicate than the other, with both surfaces of the wings pure white: scientists call this form, virginiensis; the other larger with the under surface of the wings slightly tinted with yellow: scientists call this form oleracea. The first named has but one brood a year while the second lays eggs which develop into caterpillars that produce butterflies of still a third form, in which the upper surface of the wings is pure white with a slightly greater expanse: scientists call this form cruciferarum. These three varieties occur in Eastern regions and may be found in the same localities, and differ considerably from various geographical varieties found in the Far West. 
The caterpillar of the Gray-veined White is a bit smaller than those of the nearly related forms, and in color is green with no distinct longitudinal markings, but with many fine dots of black over the surface. The cylindrical body is covered with a fine down. When feeding upon cabbage it is more likely to attack the outer than the inner leaves, and so even when abundant it is less troublesome to gardeners than the imported species. It is now, however, so rare that it seems to feed chiefly upon wild cruciferous plants and is more likely to be found along the borders of open woods than in gardens and fields. The winter is passed in the chrysalis state.

\section{The Checkered White}

\section{Pontia protodice}

Some years ago the Checkered White was commonly called the Southern Cabbage Butterfly but the general distribution of the imported species has had the same effect upon its abundance in the South that it has had upon the Gray-veined White in the North. Consequently, it is now much less abundant than formerly, even in the Southern states where it is most at home. There are two fairly distinct forms: the spring form and the summer form. The latter is practically of the same size as the Imported Cabbage Butterfly: the males have the hind wings nearly white above and the fore wings with a few black dots or spots upon their outer halves. The females are much more definitely marked, having the upper surface of both pairs of wings marked in black or brownish black in such a way as to enclose a large number of white diamonds. The 


\section{THE TRIBE OF THE WHITES}

spring form is decidedly smaller and the markings are much less distince than in the summer form.

The seasonal history of this species is comparatively simple. In winter the chrysalids are found. From these chrysalids in early spring the small butterfies of the spring form come forth. These lay eggs upon various cruciferous plants which hatch into greenish caterpillars that eat the leaves and soon mature so far as their caterpillar stage is concerned. They are then about an inch long, with downy cylindric bodies more or less marked with rather pale yellow stripes, touched here and there with purplish green or dotted slightly with fine black dots. These caterpillars now attach themselves by means of a button of silk and a silken loop to some support like a piece of board, the side of a stone, or almost any available shelter. Each casts its larval skin and appears as a grayish chrysalis from which probably a fortnight later the summer form of the butterly emerges. There are commonly two broods of this summer form, making three sets of butterflies for the entire season. The caterpillars of the second summer brood of butterflies go into the chrysalis stage in autumn to remain throughout the winter.

Some very interesting observations upon the sleeping habits of this butterfly have been made in St. Louis by Mr. and Mrs. Phil Rau. The insects were found abundantly resting upon the seed heads of white snakeroot. Early in October, when a warm south wind was blowing, the great majority of the butterfies slept horizontally with their heads toward the wind. At other seasons and in other places, many of them were found in a vertical position but practically all had their bodies toward the wind prevailing at the time. The observers were unable 
to ascertain definitely whether the insects thus oriented themselves at the time of alighting, so that their wings presented the least resistance to the force of the wind, or whether this was a mechanical result of the breezes.

\section{The Great Southern White}

\section{Pontia monuste}

There used to be in the Northern states before the advent of the Imported Cabbage butterfly a familiar white butterfly which then laid its eggs upon cabbages in much the same way that the imported pest now does. One who has seen this northern Gray-veined White and then sees the Great Southern White will be likely to think of the latter as a larger edition of the former, for in the males of the southern species the wings are practically white save for a narrow dusky border at the outer angle of the front pair, although in the female this dusky margin is wider and the hind wings show a series of dusky triangles near the margin. There is also a curious black marking suggestive of a crescent on each front wing near the middle of the front border, which helps to make the appearance of this butterfly very distinct from that of any other.

Although this species is at times so abundant that it swarms in great flocks and although it has been known for many years, its life-history seems not to have been carefully worked out since it was first described by Abbott more than a century ago. The caterpillars feed upon cruciferous plants and when full grown are about an inch and a half long, of a general yellow color, more or less 
striped with purpe lines. The species is distinctly tropical extending northward into our Southern states.

Dr. G. B. Longstaff reports this species as abundant in Jamaica where he found that the clubs of the antennae of the living insects showed a beautiful turquoise blue color, although another observer described them as bright green with a tinge of blue. This is an interesting color variation for a member of this group. In the tropics also there are two forms, one belonging to the dry season and one to the wet season.

\section{Synopsis of the Whites}

Imported Cabbage Butterfy (Pieris rapae). Expanse 2 inches. Upper surface white with a black marginal dash on the front outer angle of the front wing. One round black spot on each of the four wings in the male. Two round spots on each of the front wings in the female and one round spot on each of the hind wings. Under surface of hind wings yellowish white; spots on front wings in same position as on upper surface. A spring form (immaculata) is smaller and the black spots are almost obsolete.

Gray-veined White (Pieris napi). Expanse 2 inches. Upper surface white with only a darker marginal splash next the body. Under surface white with gray veins.

Checkered White (Pontia protodice or Pieris protodice). Expanse 2 inches. Upper surface white, strongly marked especially in the female with dark grayish brown on both pairs of wings. Along the outer margins these marks are so arranged as to enclose white diamond spots. Male with front wings only lightly marked and hind wings scarcely marked at all. Under surface much like upper, with a slight yellowish tinge in female. 
Great Southern White (Pontia monuste or Pieris phileta.) Expanse $2 \frac{1}{2}$ inches. General color white with a narrow black margin around apical angle of front wings. These margins are wider in the female, in which sex there is a series of marginal spots on the hind wings. Easily known by its large size.

\section{THE TRIBE OF THE ORANGE-TIPS}

When one sees a gossamer-winged butterfly flitting from flower to flower on a bright June day it seems one of the most ethereal of earth's visions. One could readily fancy that the whole sight-flowers, butterilies, and all-might easily vanish into thin air. So it is something of a shock to hear scientists talk about fossil butterflies and to realize that these fragile creatures have been living generation after generation for untold millions of years. A realization of this fact, however, helps us to understand the many wonderful ways in which butterflies in all stages of their existence have become adapted to the conditions of their lives.

There is perhaps no group of butterflies whose beauty seems more fragile than that of the Orange-iips. These are delicate creatures, with slender bodies and almost gauzy wings, of a size somewhat smaller than our common white and yellow butterflies. Perhaps the most remarkable feature is the marking of the wings, the upper sides of the front pair having an orange patch near the apex and the under sides having a background of delicate whitish or yellowish green, lined and spotted with darker coloring in a very characteristic way. This peculiar marking is so 


\section{THE TRIBE OF THE ORANGE-TIPS}

significant that it has been called "flower picturing." To understand the reason for its existence one has only to watch the butterflies in their native haunts. He will find them flitting from blossom to blossom among the plants of the mustard family-the Cruciferae. This is one of the most characteristic families in the plant world: the foliage for the most part is small and delicate and the flowers have a characteristic four-petaled structure, being practically always of small size and generally toned in whites or yellows. When an Orange-tip is at rest upon these blossoms it merges so completely into the background that it disappears from view. Should a bird chase one of these insects through the air it would see chiefly the orange tips which are so marked upon the upper side of the wing, and when the butterlly closed its wings and lighted among the flowers the orange color would instantly disappear and there would be only an almost invisible surface against the background of flower and leaf.

The adaptations of these Orange-tips to the conditions of their lives are by no means confined to this remarkable resemblance to the flowery background. In the case of some species the whole yearly cycle has been adapted to correspond to the yearly history of the cruciferous food plant. As is well known many species of the mustard family spring up early in the season, put forth their blossoms which quickly develop into fruits and then die down, the species being carried through until the next year by the dormant seeds. In a similar way the Orange-tips feed as caterpillars upon the host plant through the spring, completing their growth before the plant dies and then changing to chrysalids which remain dormant through summer, 
fall, and winter and come forth as butterflies early the following spring. The insect has thus adapted itself in a most remarkable manner to the yearly history of its plant host.

\section{The Falcate Orange-tip}

Synchloe genutia

The Falcate Orange-tip is about the only member of this tribe generally distributed east of the Rocky Mountains. This is a beautiful insect which is sparingly found even as far north as New England. It is more abundant throughout the Southern states, occurring south at least as far as Texas. It appears to be a good illustration of the adaptation of its development to that of its food plants. The eggs are laid upon leaves or stems of such springflowering Cruciferas as rock cress (Arabis), and hedge mustard (Sisymbrium). On hatching the caterpillars feed upon stems, leaves, flowers, and even seed pods of these

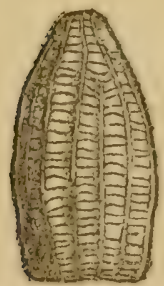

Egg of Synchiloe genutia, magnified 20 diameters.
(From Holland) plants, becoming mature in a few weeks and changing to chrysalids under the protection of such shelter as they can find. In the Northern states these chrysalids remain unchanged until the following spring when the butterflies emerge and are found upon the wing for a few weeks in May and early June. In some southern regions at least the species is evidently double-brooded, as Dr. Holland reports that he has talsen the butterflies in late autumn in the western portion of North Carolina.

This Falcate Orange-tip is one of the daintiest and most exquisite of northern butterflies. It is a prize which any 


\section{THE TRIBE OF THE ORANGE-TIPS}

collector will find joy in possessing. It is easily recognized by its general white color, which in the female is relieved only by a distinct black mark on the upper suriace of the front wings and a row of marginal markings upen all the wings. The male is slightly smaller and is at once known by the orange blotch on the outer angle of the upper surface of the front wing. This outer angle projects into a distinct point which gives the species its name Falcate. (See plate, page 256.)

Dr. J. L. Hancock has described in a most interesting manner the way in which this Orange-tip loses itself among the flowers of rock cress. In northern Indiana he found this butterfly abundant in April at the time of the blossoming of Arabis lyrata. The butterflies would be flying about, easily seen in the air. Then they would suddenly disappear and could be found only after the most careful search. They had simply lit upon the flower heads, when the flower picturing of the under surface of the wings blended perfectly with the appearance of the clustered flower.

"The green markings of the under side of the wing," writes Dr. Hancock, "are so arranged as to divide the ground color into patches of white, which blend with or simulate perfectly the petals of the clustered flowers. The eyes of the butterfly are delicate pale green and the antennae are whitish, all of which adds to the effectiveness of the blend. The flowers of Arabis have white petals with the centre yellowish green, as is also the calyx. There is a shade of pink outside the base of the petals. All in all, the adaptation of insect to flower here displayed is one of rare exquisiteness."

*“Nature Sketches in Temperate America", p. 83. 
Di. Hancock found that the butterflics were able to cling on the flowers during strong winds very persistently, so that even when a storm blew across the sand dunes they were likely to remain in position. They also have the instinct to rest very quietly after they have lit upon the clustered flower heads.

\section{The Olympian Orange-tip}

Synchloe olympia

In various parts of the Southern states there is at least one other Orange-tip butterfly which is found occasionally in connection with the Falcate Orange-tip. It was named Olympia many years ago by William $\mathrm{H}$. Edwards. It is a delicate white species marked with black and yellow very lightly both above and below, the yellow showing only on the under side of the hind wings and that part of the front wing which is exposed when the insect is at rest. Strictly speaking, this is not an Orange-tip because the orange color is lacking in both sexes.

This is rather a rare species which occurs occasionally from the Atlantic states to the Great Plains south of a line drawn from northern Maryland to northern Missouri. Like its allies the larvae feed upon various cruciferous plants, the hedge mustard being one of these and the adults visit the flowers of the same family. They doubtless have habits similar to those of the Falcate Orange-tip, and the extreme delicacy of color must render them practically invisible when resting upon the small white flowers of most crucifers.

Most of the Orange-tip butterflies are found on the 


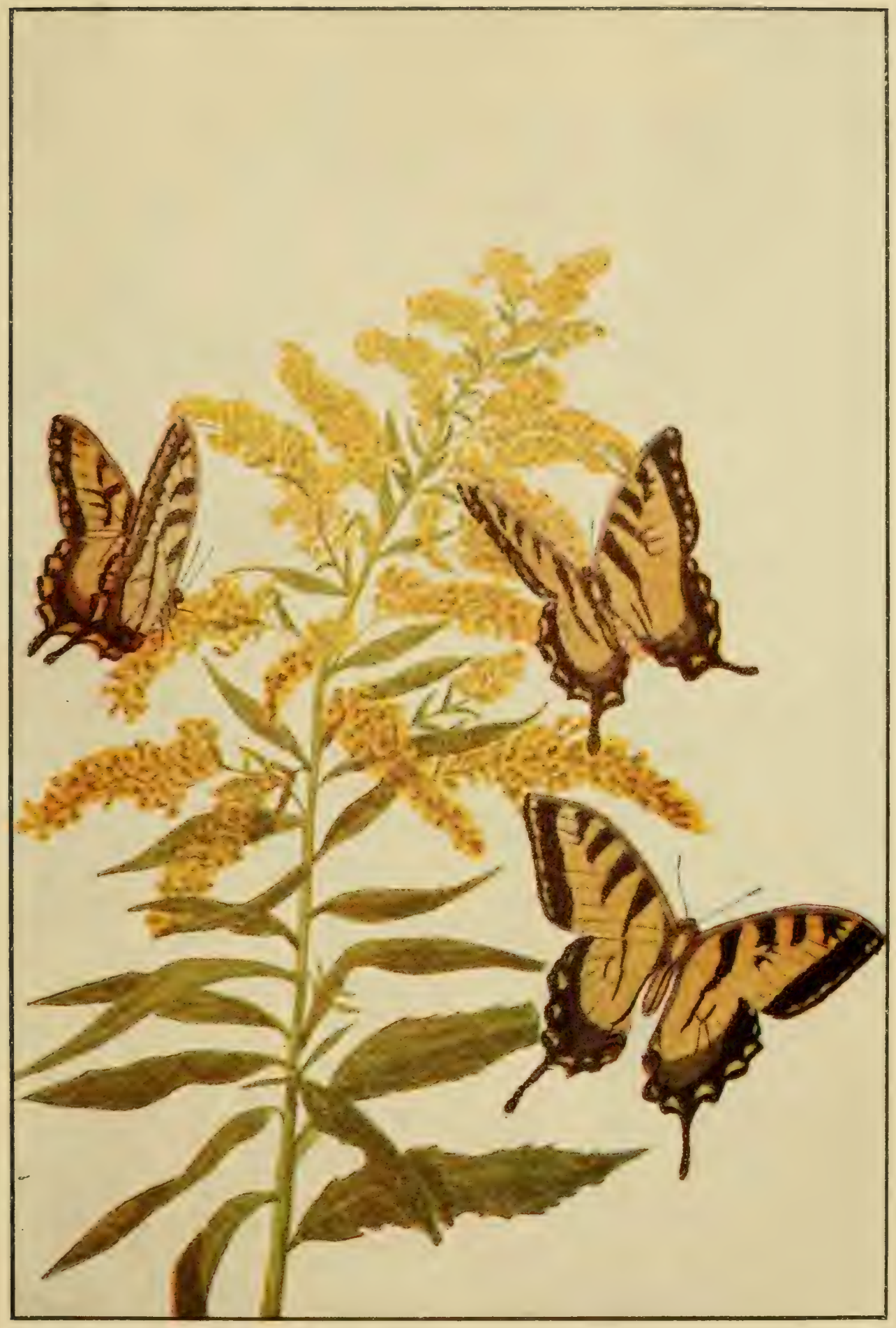

From a drawing by Mary E. Walker

See page 79

THE TIGER SWALLOW'TAIL

(Reduced) 


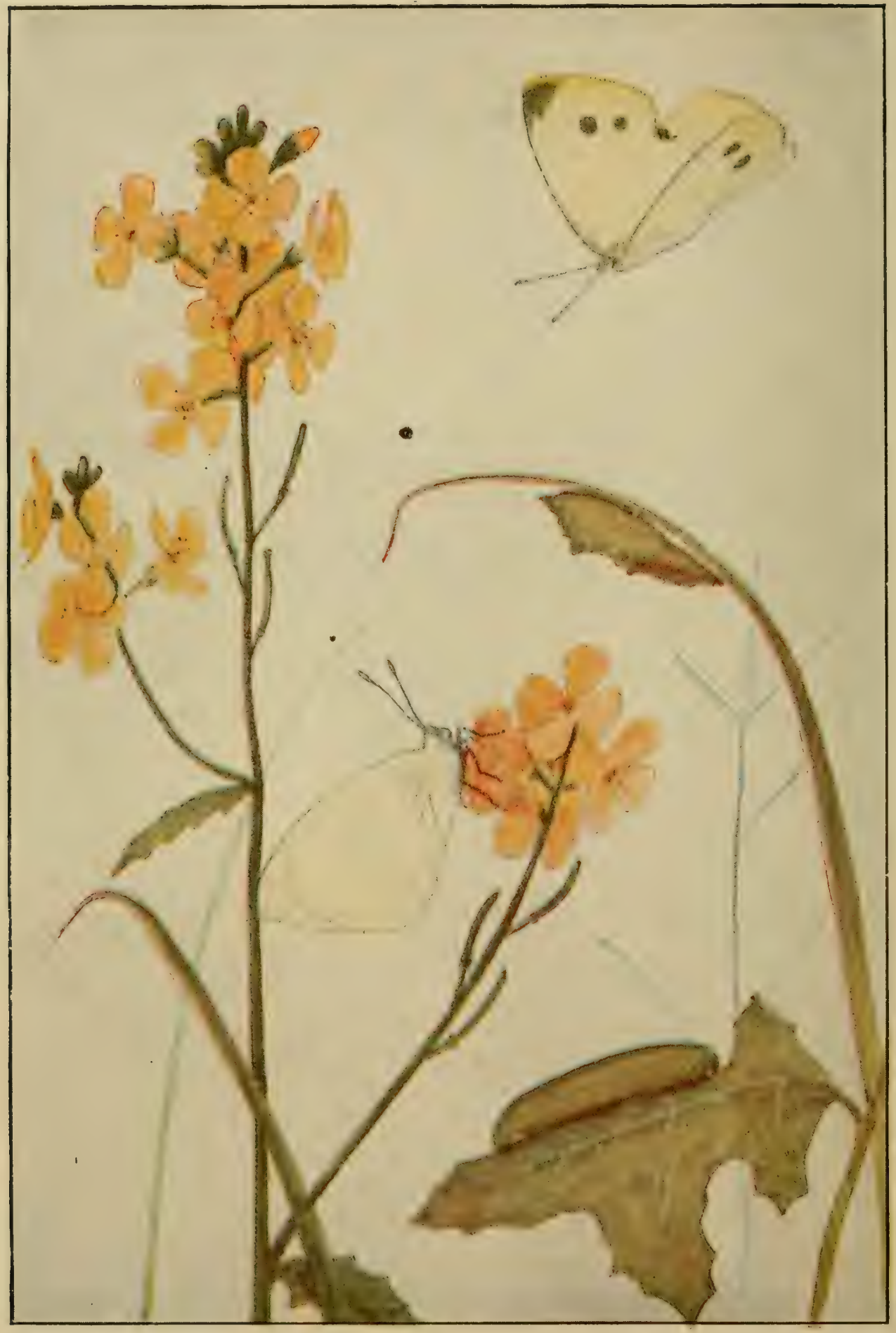

From a drawing by W. I. Beecroft

See page 83

THE IMPORTED CABBAGE BUTTERFLY

Caterpillar, chrysalis, and butterflies 


\section{THE TRIBE OF THE YELLOWS}

Pacific Slope, ranging from Alaska southward, several of them being especially abundant in the western mountain regions. About eight species are recognized as belonging to our fauna, some of which have several well-marked varieties.

\section{Synopsis of the Orange-tips}

Falcate Orange-tip (Synchloe genutia, Anthocaris genutia or Euchloe genutia). Expanse $1 \frac{2}{5}$ inches. Tips of front wings projecting in a hooked angle. Orange blotch on upper surface near tip in male, absent in female.

Olympian Orange-tip (Synchloe olympia, Euchloe olympia or Anthocaris olympia). Expanse $1 \frac{1}{2}$ inches. Wings white above in both sexes with greenish black markings at base of all wings and along front margin of front wings, especially at apex. No orange patch.

\section{THE TRIBE OF THE YELLOWS}

A large proportion of our most abundant and conspicuous butterflies belong to the Tribe of the Yellows. Sometimes it is called the Tribe of the Red-horns because the antennae of the living insects are so often red. These insects vary in size from the large Brimstones or Cloudless Sulphurs, expanding three inches, to the delicate little Dainty Sulphur, expanding scarcely an inch. The distinctive characteristics of the tribe are found in the very gradual enlargement of the joints of the antennae that form the club, and the stout palpi, the last joints of each of the latter being short. 


\section{The Brimstone or Cloudless Sulphur}

\section{Callidrayas eubule}

Practically all northern butterflies are variously marked in different colors, while the butterflies of tropical regions are commonly tinted in monotone, though often showing a splendid iridescence. One with very little experience can tell the look of a tropical butterfly and would be likely to say at once that the Cloudless Sulphur is one of these. The upper surface of the wings of the male is a clear plain sulphur with merely the narrowest possible fringe of brown around the margin made only by the colored marginal scales. The under surface is lighter and sparsely dotted in brown. In the females the marginal brown takes on the shape of a series of small crescents and there is a single round brown eye-spot just in front of the middle of each front wing.

While the Cloudless Sulphur is without doubt essentially a tropical species it has an extraordinary geographical range. It is extremely abundant in Mexico, Cuba, and the tropical zone in South America. It extends south even to northern Patagonia and north to New England, Wisconsin, and Nebraska.

Presumably in the tropics this species breeds continuously, one generation following another in regular succession unless interrupted by drought or other natural phenomena. In our Southern states there is more or less interruption by the winter season, so that it is commonly considered to have only two broods, the butterflies hibernating. Farther north there is probably only one brood in summer, and perhaps not even that in the extreme limit 


\section{THE TRIBE OF THE YELLOWS}

of its range. For there is pretty good evidence that the specimens seen in the Northern states are migrants from the south, coming singly or in scattered flocks in early summer, and if they lay eggs the butterflies of the new generation return south in autumn. But the precise conditions are not well known and need careful observations in various localities.

The life-story of a generation of these butterflies is much like that of the other Yellows. The eggs are laid, one in a place, on the leaflets of various species of wild senna (Cassia) and soon hatch into cylindrical caterpillars that devour the tender leaflets. In a few weeks the caterpillars mature and change to curious and characteristic chrysalids. The head projects in the shape of a cone and the back is so concave as to give the side view of the chrysalis a very striking appearance.

Like so many of the Yellows this butterfy is sun-loving and social in its habits. Great numbers flock together, their large size and bright coloring rendering them very conspicuous. They often alight on the ground to sip moisture when they have been likened to beds of yellow crocuses. They also fly long distances in flocks that attract much attention. It is likely that the northward distribution takes place in summer through such migrating hosts.

\section{Other Sulphur Butterflies}

The Large Orange Sulphur is a closely related butterfly of about the same size, in which the coloring is uniformly orange-yellow instead of lemon-yellow. It also belongs to the tropics, occurring in our extreme Southern states and ranging occasionally as far north as Nebraska. 
The Red-barred Sulphur is another splendid butterfly, somewhat larger than the Brimstone, which is easily distinguished by the broad reddish bar across the upper surface of the front wings. It is tropical but migrates rarely even as far north as Indiana, Mllinois, and Wisconsin.

\section{The Dog's-head Bucterfly}

\section{Meganostoma caesonia}

The Dog's-head butterfly furnishcs one of the most remarkable examples of accidental resemblance in wing markings that can be found in the whole order of scalewinged insects. It is comparable with the skull and crossbones on the back of the death's-head moth. In the butterfy the middle of the front wings has a broad band of yellow against a black margin on each side and the yellow outlines make an excellent silhouette of the profile of a poodle with a large black eye-spot in exactly the proper place. The females are less brightly colored than the males but they still show the dog's-head silhouette.

'This is a southern species, which occasionally strays as far north as New York City, New Hampshire, Wisconsin, and Iowa. The larvae feed on species of Amorpha and are believed to be three-brooded in southern regions where the butterfly occurs.

The California Dog's-head is eren more beautiful than the southern species. It is remarkable for its pink and purple iridescence - a characteristic which is not common in the butterflies of the Yellow and the White Tribes. The silhouette of the Dog's head is less perfect than in the more eastern species, and the yellow color tones are 


\section{THE TRIBE OF THE YELLOWS}

more tinged with orange. The female is strikingly different, the wings being plain pale yellowish buff marked only with a round blackish eye-spot near the middle of each front wing and the barest suggestion of a dark line around the extreme margin.

\section{The Clouded Sulphur}

\section{Eurymus philodice}

It is an interesting fact that the butterfly which one is most likely to find in fields and along roadsides during practically all the weeks of summer has seldom if ever been noted as a destructive insect. The Clouded Sulphur is probably the commonest species in its group. There may be times when the White Cabbage butterfly or other forms are more abundant, but the Clouded Sulphur retains its place season after season, with comparatively little noticeable variation in its numbers. This is doubtless an illustration of an insect which has established such relations with its food plants and its various insect and other enemies that it remains in a fairly stable equilibrium-an example of what is often called the balance of nature.

The Clouded Sulphur is about the only mediumsized yellow butterfly generally found in the Northeastern states. The adults may be seen from spring until autumn. They lay eggs upon clover and other plants. These eggs hatch into small green caterpillars that feed upon the leaves and are protectively colored so they are comparatively seldom seen. When the food plant is disturbed they drop to the ground, 
crawling up again upon stems and leaves when the disturbance is over.

These caterpillars moult several times during their growth. When full grown they find such shelter as they are able and each spins a silken web over part of the surface. It then fastens its hind legs into this web and later spins a loop near the front end of the body. It pushes itself beneath this loop and waits for several hours before the skin breaks open along the back and is gradually shuffied off revealing the chrysalis in position. A week or two later the fully deviloped butterfly emerges from the chrysalis.

These yellow butterflies lend a distinctive charm to our summer landscapes. They are constantly to be seen fluttering from place to place, lightly visiting flowers of many kinds from which they suck the nectar, and gathering in great colonies by roadside pools where they seem to sip the moisture. There are many references to this insect in the writings of New England authors. It evidently was an especial favorite of James Russell Lowell who has often referred to it in passages like this:

"Those old days when the balancing of a yellow butterfly over a thistle bloom was spiritual food and lodging for a whole forenoon."

\section{The Orange Sulphur}

Eurymus eurytheme

Were one able to take a Clouded Sulphur butterfly and change the yellow to a deep orange color he could easily make a specimen that would pass for the present 


\section{THE TRIBE OF THE YELLOWS}

species. The resemblance is very remarkable and shows the close affinity between these two beautiful insects.

Like so many others of this group the Orange Sulphur is essentially a tropical species. In the eastern United States it is rarely found north of latitude forty degrees, but south of that it becomes increasingly abundant as one approaches the tropics. It occurs from the Carolinas to Texas, and over the great range in which it lives it takes on many different forms and habits. It is one of the most remarkable examples of variation in coloring exhibited by any of the butterflies. Nearly a dozen species names have been given to its various disguises, all of which are now recognized as synonyms. In the more northern regions where it is found, only one of these forms usually occurs, but in other places bright yellow and pale white varieties are found.

The life-history of this butterfly along latitude forty degrees is very similar to that of the Clouded Sulphur. There seem to be usually two broods and the caterpillars live upon leguminous plants, especially alfalfa, buffalo clovers, wild senna, and other species of Trifolium and Cassia. Apparently also it hibernates in both the caterpillar and the butterfly stages.

In the extreme Southwest-as on the plains of Texasthe vegetation dries up completely in summer so that there is no succulent leafage for the caterpillars to live upon. In such cases the insect must aestivate rather than hibernate. This species apparently succeeds in doing this by having the caterpillars go into a more or less lethargic condition in which they pass the summer. The adult butterflies utterly disappear in June and are not seen again until early in autumn when the autumn rains have 
started the growth of vegetation anew. The insects then make up for lost time and produce several broods in rapid succession.

In the Imperial Valley of California this butterfly is a serious pest to alfalfa growers. It continues to reproduce throughout a very long season, one brood following another from March until December, and in mild winters there seems sometimes to be practically no cessation of its activities. Mr. V. L. Wildermuth found that the development of a generation in breeding cages in this valley varied from twenty-two to forty-four days, the latter in cool, the former in hot weather. The stages in the first and the third broods in spring varied thus: Egg, first six days, third four days; larva, first thirty days, third twelve days; chrysalis, first eight days, third five days. In this case the first generation extended from March 15 to April 30 and the third from May 28 to June 20. After the fourth brood of butterflies there was such an overlapping of the various stages that it was impossible to distinguish the broods.

\section{The Pink-edged Sulphur}

\section{Eurymus interior}

This beautiful butterfly was first made known to the world of science by Louis Agassiz, the great naturalist who did so much to arouse a scientific interest among Americans. He found it on a famous expedition to the northern shores of Lake Superior, which not only served to bring to light many interesting phases of geological history but also laid the foundation for the copper mining 


\section{THE TRIBE OF THE YELLOWS}

industry which has since become so important in that region. The butterfy thus brought to light has been found to be a characteristic northern species, occupying a rather narrow belt nearly along the fiftieth degree of latitude and extending west almost to the Pacific Coast. The species is occasionally taken as far south as the White Mountains and there are indications that in this region there are two broods a year. The male butterflies are known at once by a beautiful pink edge on all the margins; they bear otherwise a close resemblance to our common Sulphur Yellow. The females are much lighter in color, often having no black markings on the upper surface of the hind wings.

\section{The Black-bordered Yellow}

\section{Eurema nicippe}

This is essentially a tropical butterfly which has spread out over most of our Southern states where it is abundant and widely distributed. It adds a distinct touch of color and life to many landscapes when the butterflies swarm by thousands upon clover blossoms and other low vegetation. The eggs are laid upon the leaves of clover and more especially upon some common species of Cassia, such as wild senna. Each egg soon hatches into a small greenish cylindrical worm, colored and striped in such a way that as it rests upon the leaf it is easily overlooked. This larva develops rapidly and soon becomes about an inch and a quarter long, being rather slender and fairly smooth. It now spins a bit of silk upon a twig or some similar support and also the frailest sort of a sillen loop 
to pass around its back. It now entangles its hind feet in the bit of silk and soon casts off its last caterpillar skin, emerging as a curious looking chrysalis about three quarters of an inch long with a remarkable pointed projection on the front of the head. When seen through a hand lens this pointed projection and the well-developed characteristic wing sheaths give the chrysalis a remarkable resemblance to some of the twig hoppers or Membracids. The colors vary considerably with the surroundings but are commonly toned in various shades of green and yellow brown.

A little later each chrysalis breaks open to disclose one of the beautiful butterflies.

The conditions under which this butterfly lives at the limit of its northern range are not well determined. It is probable that many of those seen here have flown from considerably farther south, and that these migrants lay eggs from which a brood of butterflies develops, these native born appearing late in summer. Presumably the latter hibernate, but whether they can do this successfully under the rigorous conditions of our northern winters has never been determined. In fact, Scudder wrote some years ago that no caterpillars had ever been found in New England. Here is an interesting opportunity for some young observer to make a real contribution to science.

\section{The Little Sulphur}

\section{Eurema lisa}

Were one to imagine a Clouded Sulphur butterfly reduced to half its usual size and built with a corresponding 


\section{THE TRIBE OF THE YELLOWS}

delicacy of structure, one would have a pretty good idea of the beautiful little creature called by the above name. I well remember in my college days taking what was probably the first of these butterflies ever collected in the region of our Michigan college. It was a prize that very likely had wandered north from Indiana but which served to add much glory to the little collection in which I took such pride, for this is essentially a southern species In many regions of the South it is so abundant that it can be taken by any one. It ranges from coast to coast and extends south into the tropics. In the eastern region it is found from southern Wisconsin to southern New England, occurring sparingly and locally in various places along the line thus indicated.

The food plant of the species is chiefly wild senna or other kinds of Cassia. The mother butterfies deposit the eggs singly on leaves or stems, generally on the small leaflets of the compound leaf. Less than a week later each egg hatches into a cylindrical greenish caterpillar that feeds upon the leaflets in a characteristic fashion. Instead of devouring the blade from the margin inward it gnaws narrow strips between the smaller veins. When not feeding, the caterpillars protect themselves from observation by birds or other enemies by resting motionless along the stem of the leaflet or else along the midrib on the under side. As is well known the leaflets of Cassia, like other leguminous plants, close at night. It is probably on this account that these caterpillars feed chiefly by day. The general green color of the skin and the straight stripe along the side help to make this caterpillar very inconspicuous when it is at rest.

When full grown the caterpillar reaches a length of three 
quarters of an inch. It now finds some bit of shelter on which it spins a bit of flat web and a silken loop to hold it in place as it becomes a chrysalis. It then changes and remains quiescent for ten days or more when it emerges as the dainty butterfly.

Notwithstanding its abundance and its successive broods its life-history is none too completely worked out. There is still opportunity for careful observations upon the way in which it passes the winter in various parts of its range. While in the South it apparently hibernates as an adult, this fact is not certain in the more northern localities.

Notwithstanding its diminutive size this butterfly has been known to swarm in such enormous numbers as to seem a veritable cloud. The most notable record of this has been quoted by Scudder in connection with a swarm that invaded the Bermuda Islands, in 1874, on the first day of October. It was described in these words:

"Early in the morning several persons living' on the north side of the main island perceived, as they thought, a cloud coming over from the northwest, which drew nearer and nearer to the shore, on reaching which it divided into two parts, one of which went eastward and the other westward, gradually falling upon the land. They were not long in ascertaining that what they had taken for a cloud was an immense concourse of small yellow butterflies, which flitted about all the open grassy patches in a lazy manner, as if fatigued after their long voyage over the deep. Fishermen out near the reefs, some few miles to the north of the islands very early that morning, stated that numbers of these insects fell upon their boats, literally covering them。" 


\section{THE TRIBE OF THE YELLOWS}

As is the case with so many of the related yellow butterflies there is an albino variety of this species. It has been given the variety name aloc although it is really a pale yellow rather than a true albino form.

\section{The Dainty Sulphur}

Nathalis iole

While the Little Sulphur butterfly seems about as delicate a creature as one could ask to see, it loses that distinction when it is compared with the still smaller Dainty Sulphur. The latter expands scarcely an inch when its wings are stretched apart, and its slender body and antennae help to give the suggestion of extreme delicacy. There is more marking of black upon the sulphur-yellow wings than is the case with the larger form, the upper portion of the front wings showing only a broad yellow band upon a background of darker color. The under wings are nearly all yellow.

\section{Synopsis of the Yellows}

Brimstone or Cloudless Sulphur (Callidryas eubule or Catopsitic eubule). Expanse $2 \frac{1}{2}$ inches. Upper surface of male clear, light, sulphur yellow. Female with a brown spot in front of middle of each front wing and a narrow brown margin on all the wings. Under surface deeper yellow with sparsely scattered brownish dots.

Red-barred Sulphur (Callidryas philea or Catopsilia philea). Expanse 3 inches. Easily known by the reddish orange bars on the sulphur-yellow wings.

Large Orange Sulphur (Callidryas agarithe or Catopsilia 
agarithe). Expanse 2 $\frac{1}{2}$ inches. Distinguished at once by its uniform orange-yellow color.

Dog's-head Buiterfly (Zerene caesonia, Colias caesonia or

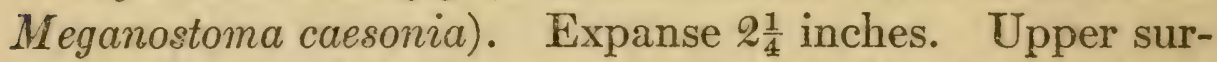
face yellow with black inner and outer borders on front wings and black outer border on hind wings. The black and yellow of each front wing so combined as to make a distinct dog's head with black eye.

Clouded Sulphur (Eurymus philodice or Colias philodice). Expanse 2 inches. Upper surface sulphur yellow with blackish borders, the yellow brighter in the male than in the female. Male with line between yellow and black distinct, a black spot just in front of the middle of each front wing and an orange spot near the middle of each hind wing. Under surface of male deeper yellow, with spots as on the upper surface but without black margin, and with a row of sub-marginal brownish dots on each wing. Female with upper surface more generally suffused beiween marginal mark and the yellow part with more or less duskiness both above and below. Spots on each wing much as in male. In the white form of the female (pallidice) the yellow is replaced by white.

Pink-edged Sulphur (Eurymus interior). At once distinguishable from philodice by the narrow pink edge of all the wings, showing both from above and from below, slightly smaller as a rule.

Orange Sulphur (Eurymus eurytheme or Colics eurytheme). Expanse $2 \frac{1}{4}$ inches. Much like Clouded Sulphur in markings except that prevailing color-tone is orange yellow.

Black-bordered Sulphur (Eurema nicippe, Xanthidia nicippe or Terias nicippe). Expanse 2 inches. Upper 


\section{THE TRIBE OF THE YELLOWS}

surface of wings bright orange with a small black dash in front of the middle of each front wing and a broad black border on all the wings. In the females the borders are interrupted at the rear. Under surface slightly brownish yellow, minutely striated and clouded when exposed when the butterfly alights.

Little Sulphur (Eurema euterpe, Eurema lisa, Xanthidia lisa or Terias lisa). Expanse 1 inch. Easily known by its small size and delicate structure. Upper surface of wings yellow with distinct black borders. Under surface yellow with indistinct spots.

Dainty Sulphur (Nathalis iole). Expanse 1 inch. Easily known by its small size and narrow yellow wings with black bars across the outer angles and black bands across the back border of the front wings and the tront border of the hind wings.

\section{The Nymphs}

\section{FAMILY Nymphalidae}

A large proportion of our most familiar butterflies belongs to this family. The Fritillaries, the Angle-wings, the Sovereigns, and the Emperors are tribes in which practically all the species are of medium or large size. The Crescent-spots include a few which are rather small.

The combinations of characters by which the $\mathrm{Nymph}$ family is distinguished are these: Front legs dwarfed into lappets; scaly antennae; veins of fore wings not swollen at base; wings of normal shape, not much longer than wide. Larvae cylindrical, but varying greatly in form, 
color, and skin coverings. Chrysalids angular in most species, in others rounded.

The stories of the lives of the many members of this family vary considerably, as one would expect from their variety and numbers. We may take, however, the life of the familiar Antiopa or Mourning Cloak as typical of the group. Briefly summarized, its story may thus be told:

During sunny days in spring one may often see a beautiful purple-back butterfly, having a cream-colored border along the outer margin of its wings, flying leisurely about, in the vicinity of woods and in the open fields. This insect is called the Antiopa or Mourning Cloak; it is represented natural size in plate opposite page 145. It has passed the winter in this adult condition, having found shelter in some retreat where it is not directly exposed to the storm and stress of the weather.

When the leaves of the elm, willow, and poplar trees are nearly expanded, these butterflies deposit their eggs upon the twigs. These eggs are laid in clusters encircling the twigs, there being twenty or more in each cluster. In the act of oviposition, the butterfly keeps her wings spread out, moving the body and abdomen about as the placing of the eggs necessitates.

About two weeks after the clusters of eggs are thus laid upon the twigs of the food plant, they hatch into small blackish caterpillars, each emerging from the egg shell through a small hole that it eats out of the upper surface. They thus enter upon the second stage in their life-history - the larva or caterpillar stage. As soon as hatched, they crawl to the nearest leaf upon which they range themselves side by side, with their heads toward the margin of the leaf. They feed in this position, nibbling at the green 


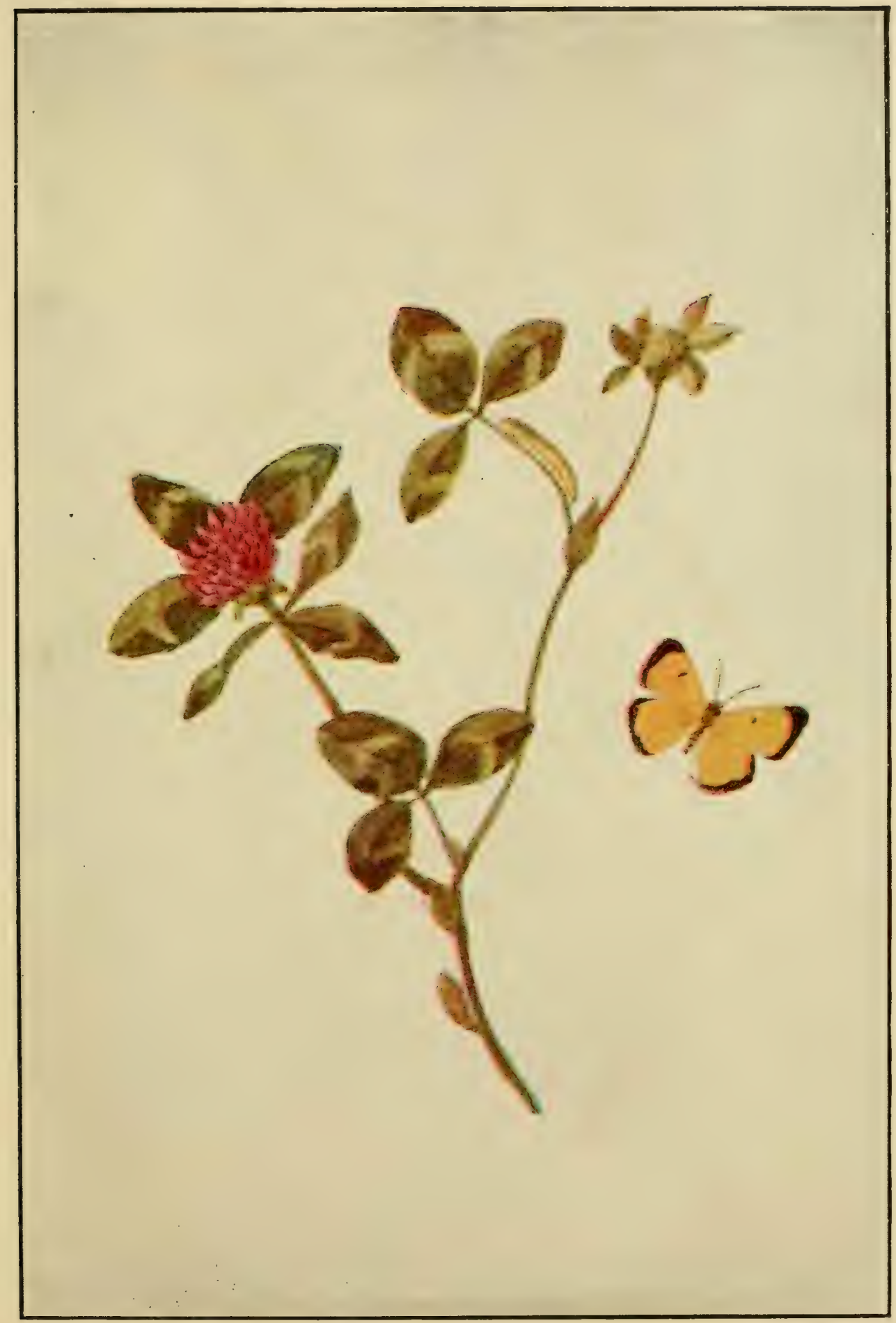

From a drawing by Mary E. Walker

See page 101

THE CLOUDED SULPHUR BUTTERFLY

Caterpillar and butterfly on red clover plant. (Reduced) 


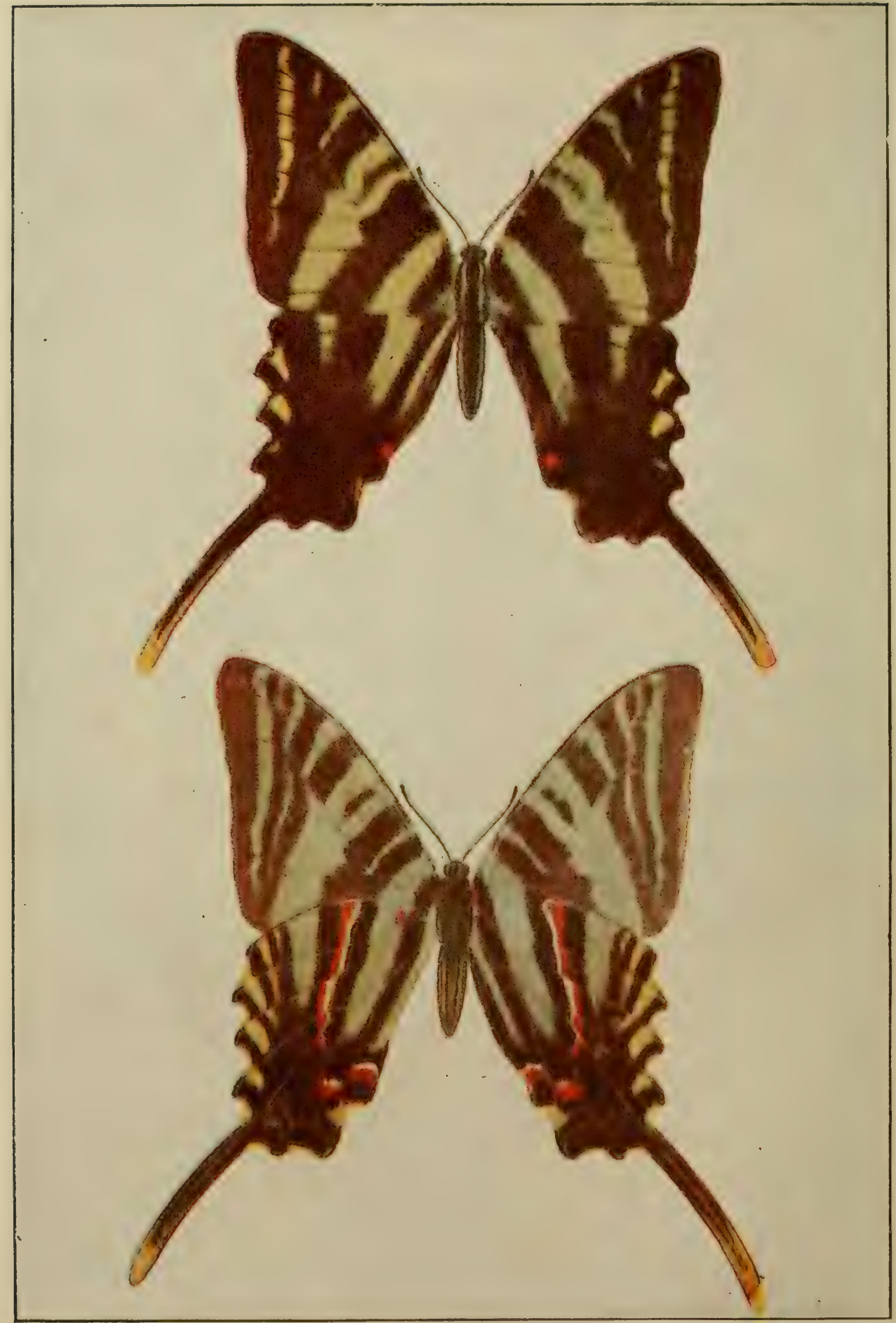

See page 76

THE ZEBRA SWAILOWTAIL

Summer form: upper surface, above; under surface, below 


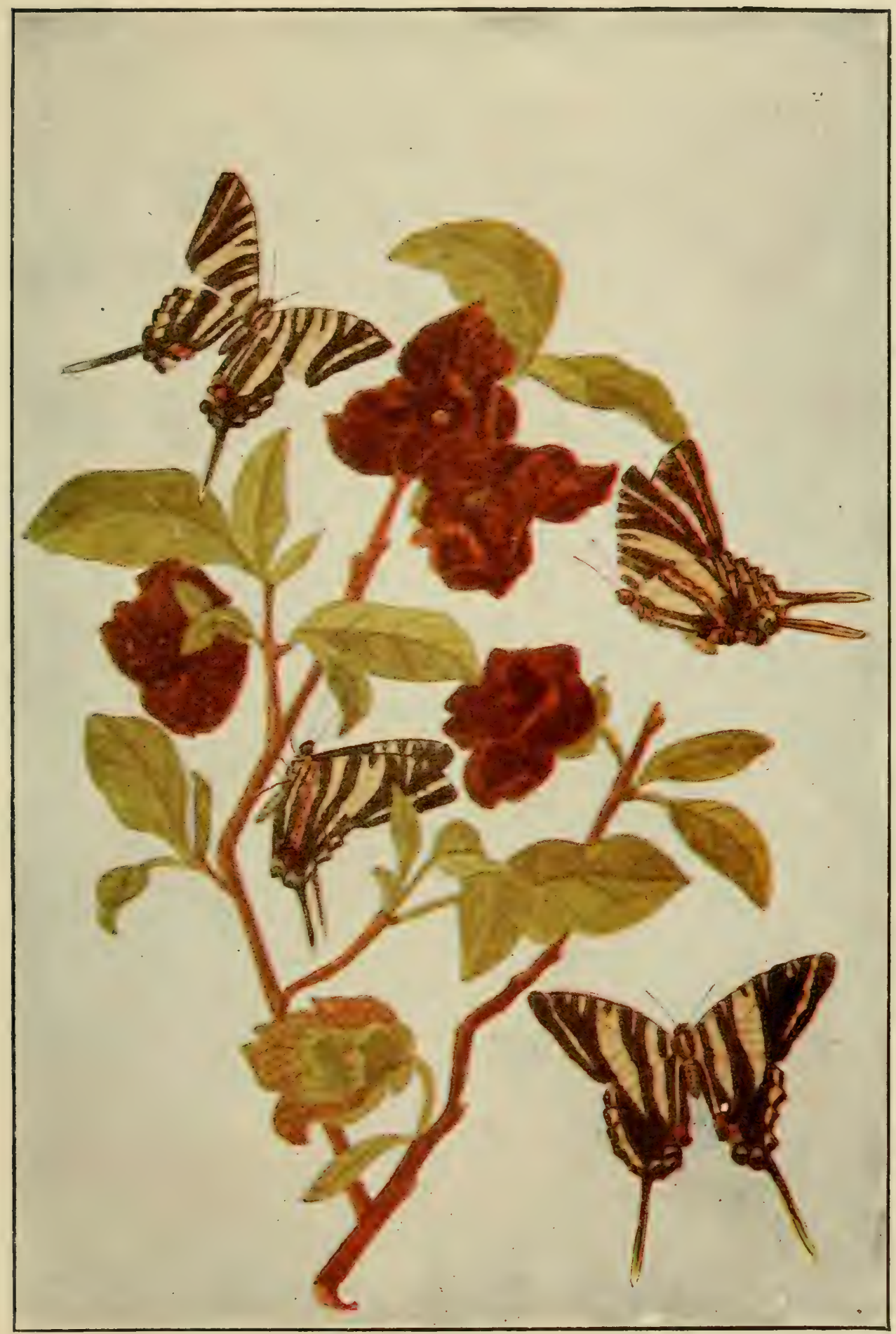

From a drawing by Ifary E. Walleer

See page 76

\section{ZEBRA SWALLOWTAILS}

Visiting blossoming branches of the pawpaw tree. (Reduced) 

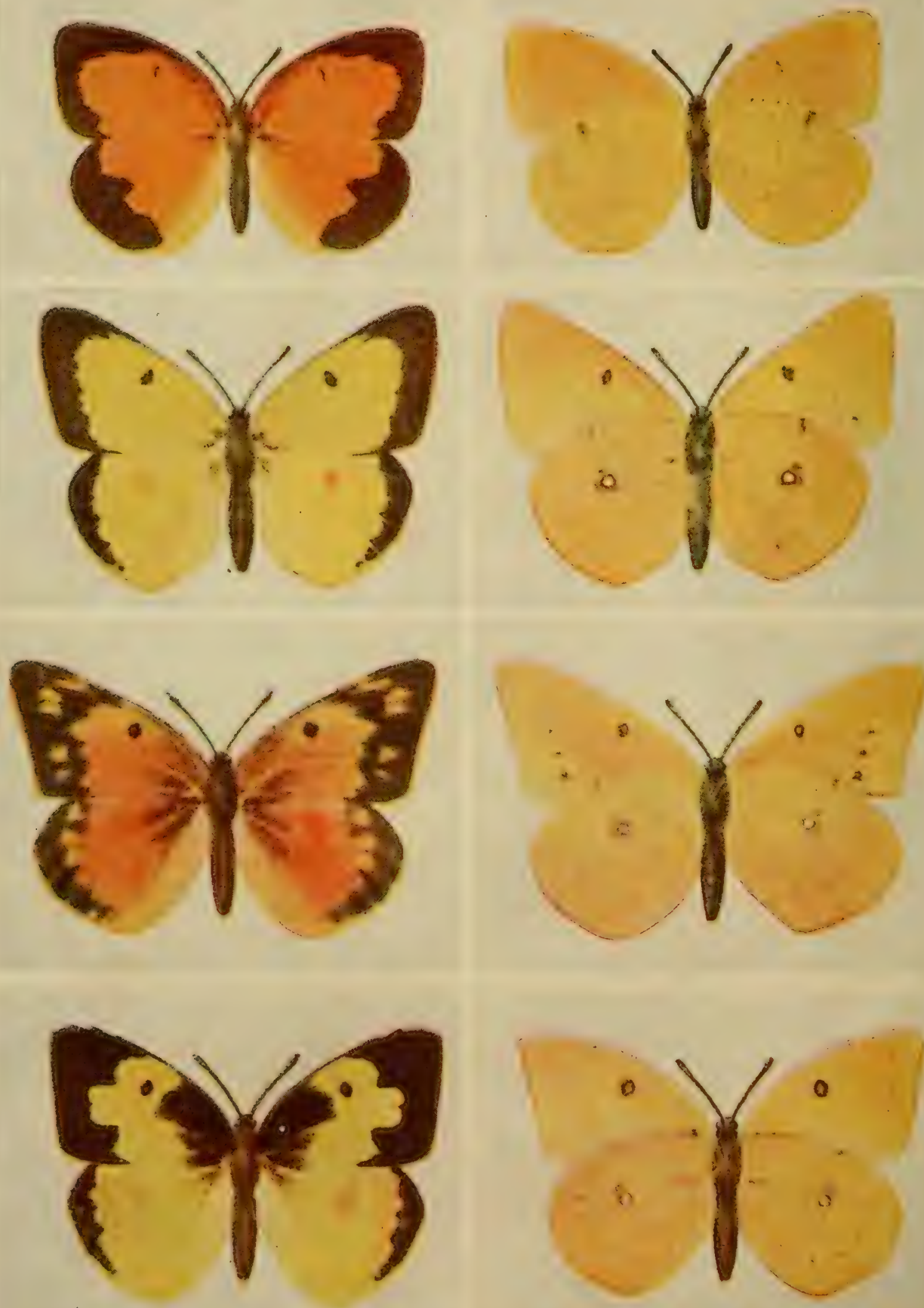

See pages 9'-11:

SOME OF THE TRIBE OF YELLOWS

upper surfaces at left; under surfaces at right

(1) The Black-bordered Yellow-male; (2) the Clouded Sulphur-male;

(3) the Orange Sulphur-female; (4) the Dog's-head-male 
surface of the leaf-blade and leaving the network of veins untouched.

These caterpillars continue to feed in this manner for about a week, remaining side by side when feeding, and marching in processions from one leaf to another as the food supply is exhausted. Wherever they go, each spins a silken thread on the surface traversed, so that the combination of all the threads makes a sort of carpet that serves as a foothold for the caterpillars. At the end of the week they moult or cast their skins, a process in which the skin of each larva splits open along the back, and the larva crawls out covered with a new skin that had been formed beneath the old one. This new skin stretches somewhat after the caterpillar emerges, so

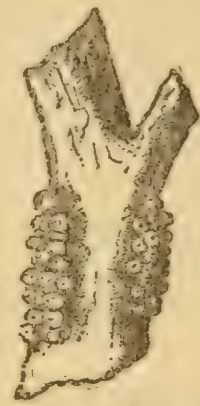

Egrs of Mourning-Cloak, laid in a cluster on a twig. (From Holland). that the insect is able to increase considerably in size. At the period of moulting, the caterpillars remain quiet for a short time, but they soon become active again and begin feeding with increased voracity.

During the next three weeks, this moulting process is repeated three times, the caterpillars becoming larger each time, and leaving their cast skins upon the denuded iwigs. They soon scatter more or less over neighboring leaves, but remain in closely associated colonies. As they increase in size, they eat more and more of the leaf substance; when half grown, they devour all but the mid-rib and the side veins; but when they get larger, only the midribs are left.

The carpet web that they form becomes more conspicuous as the caterpillars become full grown. They then leave the tree or shrub on which they have been feeding, and scatter about, seeking some sheltered situation. Hav* 
ing found this-perhaps beneath a stump or along the under side of a fence-each caterpillar spins a web of silk along the surface. It then entangles the hooked claws of its hind legs in the silken web, and lets its body hang vertically with the head end curved upward. It remains in this position some hours before the skin along the back just behind the head splits apart and is gradually wriggled upward, until finally it is all removed and there hangs in place of the caterpillar a peculiar object having no definite form. But it rapidly assumes a definite form - that of the chrysalis-which is grayish brown, different specimens varying somewhat in shade.

In this quiet chrysalis, the insect is apparently almost as inert as a mummy. If you touch it it will wriggle a little, but otherwise it hangs there mute and helpless. On the inside, however, the tissues are being made over in such a wonderful way that, in about two weeks, from the mummy case into which the caterpillar entered there comes a beautiful butterfly.

When this butterfly first breaks through the mummy shell, its wings are very small, although its body, antennae, and legs are well developed. By means of the latter, it clings to the empty chrysalis, while its wings expand. At first these wings are short, but as soon as the insect takes a position in which the wings hang downward, they begin to expand, and soon reach full length, but are more or less crumpled longitudinally, and the front wings are not so wide as the hind ones, hanging limply inside the latter.

After the butterfly has thus reached its full form and size, it crawls from the chrysalis to some neighboring support, where it rests quietly for half an hour or more. During the latter part of this time it exercises its un- 
used muscles by slowly opening and closing its wings, until it finally flies away.

\section{THE TRIBE OF THE FRITILLARIES}

This is one of the most distinctive tribes of the family of Nymphs. The clubs of the antennae are about twice as long as broad and curiously spoon-shaped. The palpi are large and bushy, with the last joint very short. Most of the species are rather large and practically all are beautifully mottled in various tones of brown, red, black, and silvery gray. A large proportion of our midsummer butterflies are members of this tribe.

\section{The Gulf Fritillary}

\section{Agraulis vanillae}

In tropical America there is a genus of butterflies called Agraulis. These are fairly large insects, approximating the size of the Viceroy, which show most beautiful colors in the tropical sunshine. One member of this genus has come north to our Southern states, and is occasionally found as far up as Virginia and southern Illinois, extending below this from ocean to ocean. It reveals on its upper surface the most exquisite tints of iridescent purples and browns, suggesting by its form and color as thus seen a tropical species. The lower wing surface, when the wings are closed in their natural position, shows only a spangled effect of silver-white and brown, which is very suggestive of the under surface of our northern Spangled Fritillaries. So this beautiful species may fittingly be called the Gulf 
Fritillary, carrying over from the north some of its peculiar beauty and connecting with the equally distinctive beauty of the tropical south.

Like so many other southern butterflies the eggs of this species are laid upon the leaves of passion vines. The caterpillars develop very rapidly and when matured are yellowish or brownish yellow, striped with darker lines along the back and sides. There are black branching spines, arranged in rows beginning on the head and running backward on the body. The whole cycle of life from egg to butterfiy may take place within the short period of a month and one brood succeeds another in so irregular and rapid a fashion that it is difficult to determine definitely the number of broods in a season.

\section{The Variegated Fritillary}

Euptoieta claudia

There is something in the appearance of the upper surface of this butterify that suggests the other Fritillaries on the one hand and the Emperors on the other. The coloring and marking is a bit like the former and the shape of the wings like the latter. The general color is a golden brown with darker markings arranged in bands and eye-spots in a rather complicated pattern. The under surface, so far as it is exposed when the butterfly is at rest, is a beautiful marbled combination of gray and brown which is probably distinctly obliterative in the haunts of these insects. The front wings have the outer margin concave in the middle, giving a special prominence to the shape of each front outer angle. 


\section{THE TRIBE OF THE FRITILLARIES}

This butterfy is a southern rather than a northern species, but it is found occasionally from Montana to Massachusetts and southward to Arizona, Mexico, and Florida. Even in northern Indiana it is very seldom found and is considered rare in the southern part of that state. Around Buffalo, New York, it is also rare and is not common in the vicinity of New York City. In the more Southern states, however, it is abundant and extends well through the continent of South America.

There is considerable evidence to indicate that this butterfly hibernates as an adult. In the more southern regions it probably also hibernates in other stages, especially the chrysalis and the larva. In regions where it is domble-brooded, as it appears to be in the latitude of New York City, the seasonal history seems to run something like this: the partly grown caterpillars which have passed the winter in shelter at the suriace of the soil feed upon the leaves of violets and certain other plants. They change to chrysalids, probably in May, and emerge as butterflies in June. These butterflies lay eggs for a summer brood of caterpillars which may feed upon the leaves of vioiets, May apples, portulaca, and stonecrop. They grow into cylindrical worms of a general reddish yellow color, marked by longitudinal stripes of brown upon the sides and a row of whitish dots upon the back. They become matured in time to disclose the butterflies of the second brood in August and September. Presumably these butterflies lay eggs that develop into caterpillars which hibernate when partially grown.

Farther south there are probably three broods a year and hibernation may take place in various stages. There is good opportunity for careful work in determining the 
life-history of the species in different latitudes. The butterfly is found in much the same situations as the other Fritillaries, flying over meadows and along the borders of woods.

\section{The Diana Fritillary}

\section{Argynnis diana}

This magnificent butterfly differs from the other Fritillaries in the fact that the females are so unlike the males that only a skilled naturalist would even guess that they are related. Both sexes are rather rare and are found only in a comparatively narrow range extending from West Virginia to Missouri, northward to Ohio and Indiana, and southward to Georgia and Arkansas.

This species was first described by Cramer a long time ago from specimens of the male sex. It was later described by Say and other writers all of whom saw only the males. The other sex was first recognized by William H. Edwards, whose account of its discovery as given in his splendid work on the Butterflies of North America is worth quoting:

"No mention is made of the female by any author," wrote Mr. Edwards, "and it seems to have been unknown till its discovery by me in $\mathbf{1 8 6 4}$ in Kanawha County, West Virginia. On the 20th August, I saw, for the first time, a male hovering about the flowers of the iron-weed (Vernonia fasciculata), and succeeded in taking it. Two days afterwards, in same vicinity, while breaking my way through a dense thicket of the same weed, hoping to find another Diana, I came suddenly upon a large black 
and blue butterfly feeding so quietly as to allow me to stand near it some seconds and watch its motions. It seemed to be a new species of Limenitis, allied to Ursula, which it resembled in color. But on taking it, I saw it was a female Argynnis, and the general pattern of the under wing left little doubt of its affinity to the Diana, male, despite its total difference in color and of upper surface. Subsequent captures confirmed this conjecture, and out of the large number that have since bcen taken the males have been of the known type and the females black, with no tendency in either to vary in the direction of the other.

"When my attention was called to the species I found it not very uncommon, always upon or near the iron-weed, which is very abundant and grows in rank luxuriance upon the rich bottom lands of the Kanawha River, frequently reaching a height from eight to ten feet and in August covered by heads of purple flowers that possess a remarkable attraction for most butterflies. Both sexes. are conspicuous, the males from the strong contrast of color and the females from their great size and the habit of alighting on the topmost flower and resting with wings: erect and motionless. It is an exceedingly alert and wary species, differing in this from our other Argynnids. At the slightest alarm it will fly high into the woods near which, upon the narrow bottoms or river slopes, it is invariably found. It is a true southern species, sensitive to cold, not to be looked for in the cooler part of the morning but flying down from the forest when the sun is well up. From eleven to three o'clock is its feeding time."

The life-history of this fine butterfly is similar to that of 
the lesser Fritillaries. The butterflies appear from midsummer onward, the males preceding the females, and the eggs are laid on or near violets in August or September. The larvae hibernate and mature early the following summer. As they approach the chrysalis stage they are rather large velvety black caterpillars with brown heads and rows of fleshy barbed spines that show an orange tint at their bases. There is thus but one generation each year.

\section{The Regal Fritillary}

\section{Argynnis idalia}

The Regal Fritillary, fresh from the chrysalis, still showing the marvelous sheen of its iridescence, furnishes one of the most beautiful exhibitions of color in the world of nature. Over the whole wing surface there are tiny scales that reflect the sunlight in an almost dazzling manner, giving a distinct purplish tone especially to the hind wings.

The Regal Fritillary is one of the largest butterflies of the distinctive group to which it belongs. The wings expand some three inches and the rather thick body is more than an inch long. The general ground color of the wings is brown, with distinct markings of blackish which in the hind wings almost obscure the brown. On each of the latter as seen from above there is a distinct row of cream-colored spots across the middle, duplicated by a similar row of brown spots near the margin. The under surface of both pairs of wings is much lighter and thickly mottled all over with light cream-colored spots of a large size and more or less triangular shape. (See frontispiece.) 
Like the other Argynnids, the Regal Fritillary is singlebrooded during the year and it has a rather remarkable longevity in each stage of its life. The newly hatched caterpillars go into hibernation and live through the winter without feeding, finding shelter at the surface of the ground, especially beneath the leaves of violets which form their chosen food plants. When the snow has disappeared and the warmth of the spring sun brings them out of their winter lethargy these tiny caterpillars feed upon the violet leaves and grow slowly for several weeks. They then change to chrysalids, the time for doing this virying considerably with the individual and doubtless with the warmth of the situation in which each is living. The length of time spent in the chrysalis varies also, but in general it seems to be less for those which develop into male butterflies than for the females. It is a curious fact that the former may be found for nearly two weeks before any of the latter appear.

The first butterflies of this species are usually disclosed from the chrysalis late in June or early in July. They continue to come forth for several weeks, apparently until nearly the middle of August. They lead a leisurely life, visiting freely the flowers of goldenrod, iron-weed, boneset, Joe Pye weed, and especially swamp milkweed. They are most likely to be found in lowlands and along the borders of swamps where these favorite flowers are growing. It evidently requires some time for the eggs to develop within the ovaries, for the butterfly cannot begin laying these until the latter part of August. They apparently are normally deposited on the under side of violet leaves, although so far as I know no butterfly has been seen thus laying her eggs. It would be an interest- 
ing point for some young observer to determine. Even the eggs take a long time to develop, not hatching for three or four weeks after they are laid. When they do hatch the tiny caterpillars seem not to eat at all but to go directly into hibernation.

These butterflies are to be found in their preferred habitats almost any time during July, August, and September. Apparently many of them live as adults for nearly three months so that whether we consider the egg, the larva, the chrysalis, or the adult we have in this species an unusual duration of life. This is doubtless an adaptation to the fact that the species must get through the year with only one brood.

This unity of habit with no such variations as occur in many butterflies with a wider range north and south is apparently correlated with the distribution of this butterfly. It is found in a belt of territory running from New England and the Atlantic states westward at least to Nebraska along a line which approximates the annual isotherm of fifty degrees Fahrenheit.

\section{The Great Spangled Fritillary}

\section{Argynnis cybele}

To one who wanders much in the woods and open fields there are few summer scenes more characteristic of the season than that of a group of milkweeds in full flower, surrounded by a host of brown butterflies busily sucking the nectar from the curious pink blossoms. There are likely to be several species of these winged creatures, but in many regions of America the largest and most conspicu- 
ous will generally be the Great Spangled Fritillary. This butterfly is easily recognized by its large size and its combination of two colors of brown, with whitish or silverish spots scattered over the lower surface of the wings.

The life-history of this insect is of peculiar interest on account of the way in which it passes the winter. The mother butterfly remains upon the wing through many weeks in summer, so that toward the end of August or early September a large proportion of the specimens have a decidedly frayed appearance. They are patiently waiting for the season of the year when they can deposit their eggs, apparently knowing by instinct that this must not be done until early autumn. When the proper season arrives they lay their eggs upon the leaves or stems of wild violets, apparently without much reference to the particular species. Sometimes they have been reported simply to drop the eggs loosely upon the violet plant with no attempt to fasten them in place. Having thus deposited the eggs the mother butterflies soon die.

It would not seem strange if these eggs remained unhatched until the following spring, but the iact is that the eggs hatch very soon into small caterpillars that eat off part of the shells in order to escape and sometimes eat also part of the shell remaining after they have emerged. Various good observers have apparently established the fact that these tiny caterpillars eat nothing else before winter sets in. It seems curious indeed that they should not nibble at the leaves or stems of the violet plants in order to be slightly prepared for the long fast that awaits them before they will find food upon the young buds the following spring. The case is somewhat similar to that of 
the common tent caterpillar which becomes a fully formed caterpillar within the egg shell before the end of autumn, but remains unhatched until the following spring. In the present case the caterpillar hibernates outside of the egg shell rather than within it.

When at last the warm sunshine of spring starts the violets into new growth the tiny caterpillars begin feeding upon the succulent tissues. They nibble away day after day for a week or more before they become so large that they have to cast their skin for the first time. They then feed again and continue this process of feeding and moulting until early in summer. They are likely to hide themselves during daylight and have the reputation of being difficult to rear under artificial conditions.

The ftll-grown caterpillar wanders along the surface of the ground in search of suitable shelter for the chrysalis period. When it comes to a large stone with sides projecting more or less horizontally or a log lying upon the ground or even a large piece of loose bark it is likely to stop and change to the pupa or chrysalis. In this condition it is dark brown in color and well covered with thickened tubercles, especially along the back of the abdomen.

About a fortnight later the chrysalis breaks open and the fully developed butterfly comes forth. It rests quietly for a time while its wings expand and the tissues harden and then sallies forth for its long period of flight; for this insect is single-brooded in the Northern states at least and the butterflies that thus mature late in June or early in July are likely to remain alive until early in September. So they have a comparatively long life for a butterfly that does not hibernate as an adult. 


\section{The Silver-spot Fritillary}

\section{Argynnis aphrodite}

Our brown Fritillaries are seldom found without several species mingling together. This is not strange, for they have similar habits throughout their entire lives. So when you see a bevy of butterflies collected around the midsummer blossoms of the milkweed, you are pretty sure to find that the Great Spangled Fritillary is associated with the Silver-spot and probably one or two other related forms. The Silver-spot is generally decidedly smaller than the one first named and the surest way to be certain of it is to look on the under side of the hind wing and see whether there is a broad band of buff between the two outer rows of silver spots. If this band has disappeared or is nearly all taken up by the brown ground-color of the wing, you may be pretty sure we have the Silver-spot Fritillary.

When one has firmly fixed in mind the life cycle of one of these butterflies, one has a model after which to fashion the rest, for our several species are remarkably alike in this respect.

The Silver-spots are on the wing for several weeks in summer. During the latter part of this time the females lay eggs upon violet leaves. These eggs shortly hatch into caterpillars that go directly into hibernation, taking no food before winter sets in. The following spring they feed upon violet leaves and mature in time to change to chrysaiids and emerge as butterflies in early summer. There is but one brood a year and the species is widely distributed over southern Canada and the Northern states. It extends 
south to Virginia and Pennsylvania and west to Nebraska, Montana, and Washington.

\section{The Mountain Silver-spot}

\section{Argynnis atlantis}

If one were able to take a Silver-spot Fritillary and reduce its size about one third he would have a wonderfully good imitation of the present species. Except for the size, about the only difference in the markings is found in the blackish border along the margins of the Mountain Silverspot which is not present in the other species. The buff sub-marginal border line on the under surface of the wings between the rows of silver spots is also wider in the mountain species.

The distribution of this butterfly justifies its name. It is preëminently a northern species, being especially abundant in the White Mountains of New Hampshire and ranging northward far into Canada and west through British America as far as the Mackenzie River. A pair of these butterfiies were captured by Merritt Carey on July 16 , 1903, on the summit of Mount Tha-on-tha, in the Nahanni Mountains, at an altitude of 2,500 feet. The southern limit of its distribution approximates the isotherm of forty-five degrees. It extends southward in mountainous regions through New York and Pennsylvania and is found in Michigan, Illinois, and Iowa. It also occurs in the Rocky Mountain region of Colorado.

The various species of Argynnis show a remarkable uniformity in their life-history. Like the others, this butterfly is single-brooded, laying the eggs on or near violets late in 


\section{THE TRIBE OF THE FRITILLARIES}

summer, the eggs hatching into larvae that take no food until the following spring. They then feed upon the violet leaves, become mature, and change to chrysalids in time for the butterflies to emerge in June in New Hampshire. These butterflies remain upon the wing for several weeks. They usually appear a week or two earlier than Aphrodite or Cybele in regions where all three species are found. It is worth while for the collector to take a hint from this fact and do his Silver-spot collecting early. For after the other species appear it is not so easy to tell which is Atlantis when the butterflies are on the wing. It is most likely to be found in open places in the woods, apparently preferring such situations to the broad expanse of fields and meadows.

\section{The White Mountain Fritillary}

\section{Argynnis montinus}

This is distinctly a mountain butterfly, known to be found only near the top of Mount Washington and other neighboring parts of the White Mountains. It generally occurs between the altitudes of four thousand and fiftyfive hundred feet. It is doubtless closely related to a somewhat similar form found farther north and west, but its isolation from them is complete. Apparently it is single-brooded and very little is known of the early stages. The butterflies visit the flowers of goldenrod and those of the alpine sand-wort which are abundant in the sub-alpine home of this species.

This variety is interesting as a living souvenir of the day when New England was buried beneath the ice-sheet. 


\section{The Meadow Fritillary}

\section{Brenthis bellona}

The fact of variation is one of the most universal things in nature. No two animals are exactly alike and every plant differs from every other plant. That this is true of the structure of living things is easily observed but it is not so well known, because not so easily observed, that most species of animals differ also in the precise phases of their growth. We know that the variation in form and color has brought about the remarkable adaptations to surroundings which we call mimicry and protective coloration. A little consideration will make it evident that the variation of different individuals in periods of growth must have led also to the adaptation of the life stages to the conditions of the changing seasons. This is particularly true in the great majority of insects which show remarkable adaptations in their various broods to the seasonal conditions of the localities where they live.

From this point of view the attractive little Meadow Fritillary is of especial interest. We are indebted to the studies of S. H. Scudder for our knowledge of the remarkable variations in its growth. These are so complicated that in order to make plain the varying conditions it seems necessary to separate the broods in a somewhat hypothetical manner.

We will begin with what we shall call Group A: The butterlies are on the wing in May and early June. They have just come from the chrysalis and continue living for three or four weeks before they deposit eggs, this time being required in order that the eggs may develop in the 


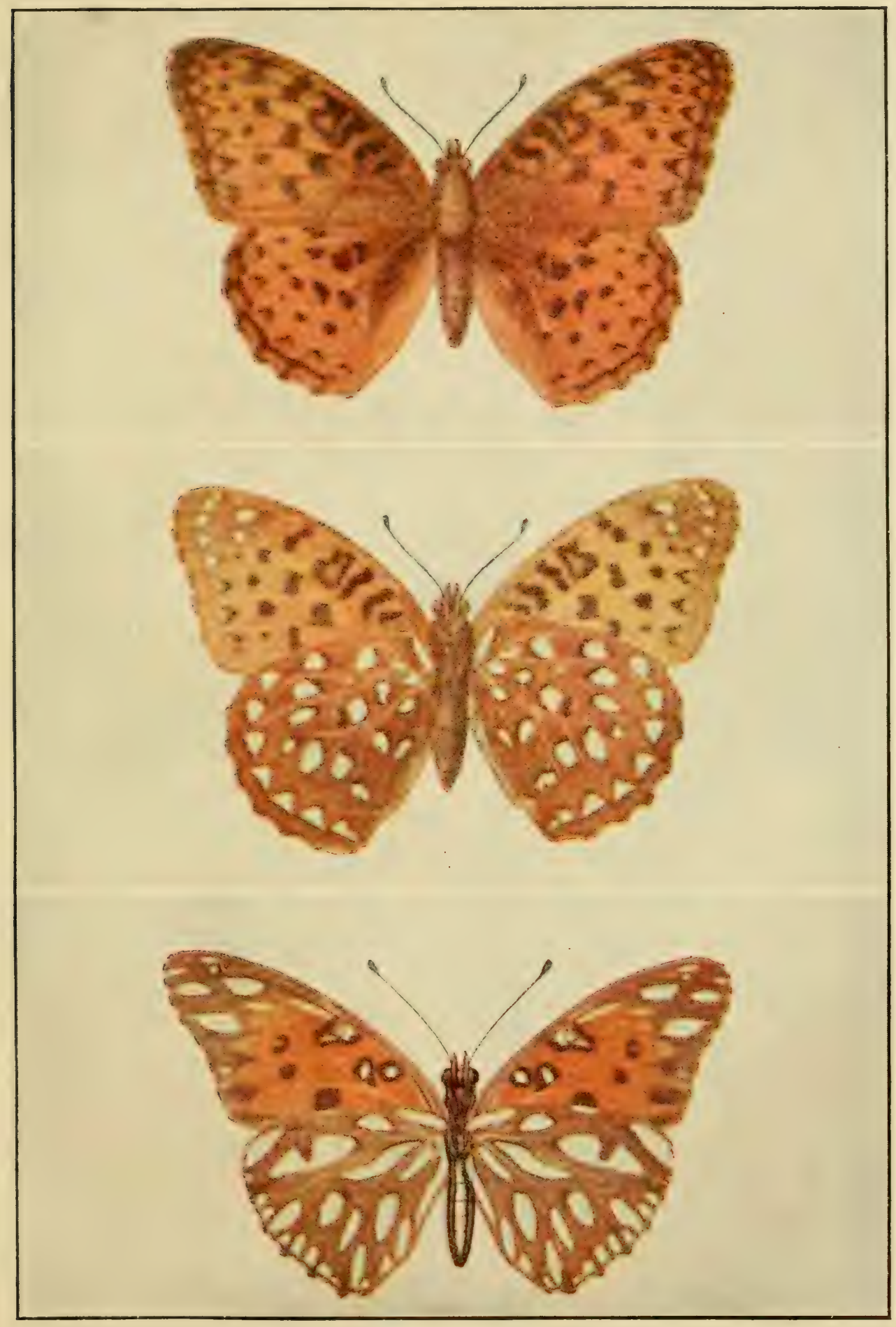

THE SIIVER-SPOT FRITILLARI

Upper and lower surfaces (see page 125)

'I'HE GULF FRIT'ILLARY

Lower Surface (see page 115) 


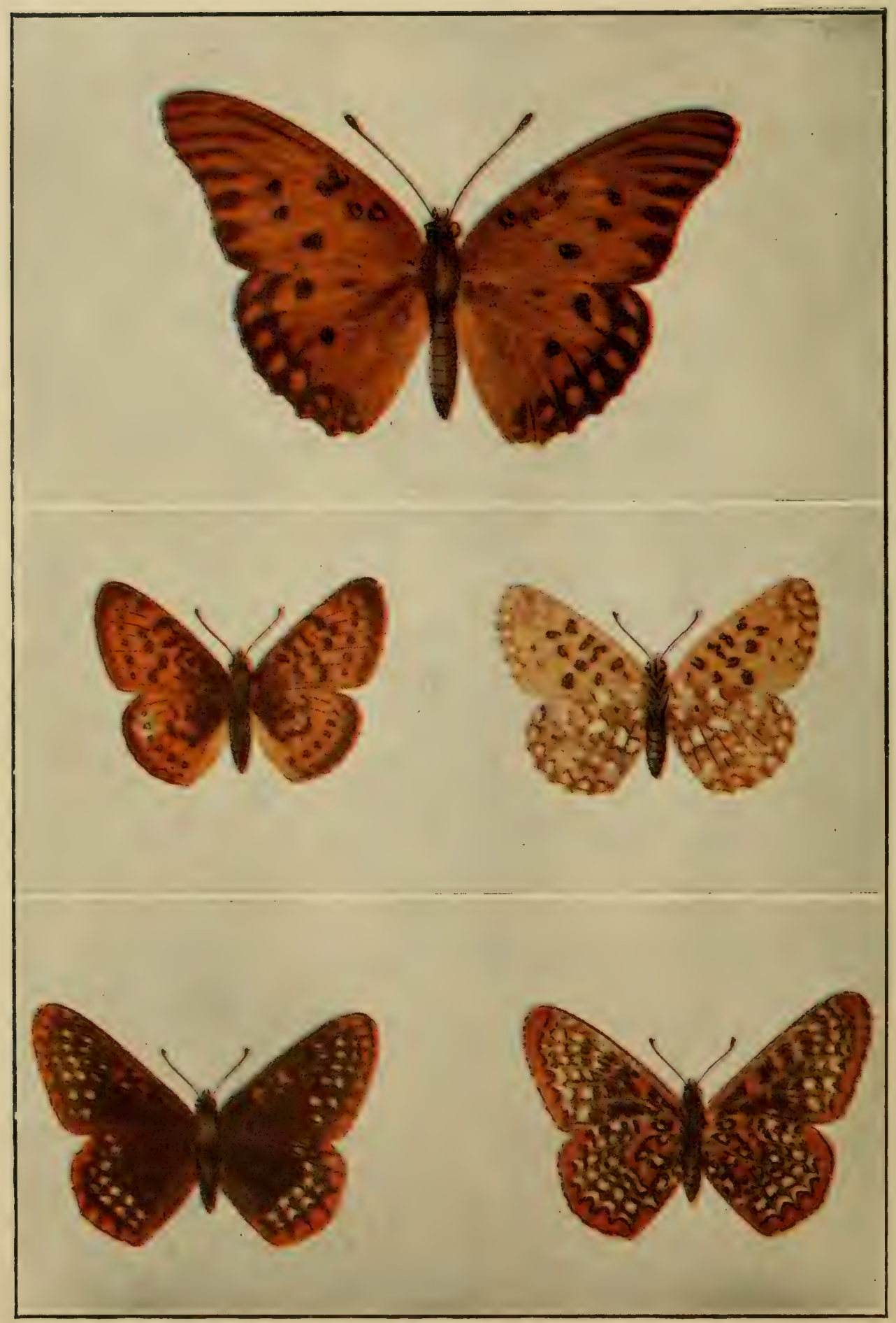

THE GULF FRITILLARY (see page 115)

THE SILVFR-BORDFRED FRITILLARY

Upper and under surfaces (see page 131)

THE BALTIMORE CHFCKFR-SPOT

Upper and under surfaces (see page 135) 
ovaries of the butterflies. These eggs hatch in about a week and the caterpillars become full grown a month later. They then change to chrysalids in which condition they remain another week, thus requiring five or six weeks for the newly laid egg's to mature into butterflies. Supposing the eggs were laid the first week in June, the butterflies of this second brood would appear about the middle of July. The eggs in the ovaries of some of these butterflies also require several weeks before they are ready to be laid, so that it may be about the tenth of August when this happens. These hatch and mature to chrysalids during the next six weeks, the butterflies of this brood emerging about the middle of September. These in turn lay eggs at once apparently, no extended period being required for their development before they are laid. The eggs hatch during the latter part of September and the young caterpillars feed upon the violet leaves for two or three weeks, moulting perhaps twice and becoming approximately half grown. They now stop feeding and go into a lethargic condition in which they hibernate. Then in spring they awaken and feed again upon the violet leaves for a short time, becoming mature and changing to chrysalids sufficiently early to emerge as butterflies late in May.

In this hypothetical group we have a fairly normal condition of a three-brooded butterfly hibernating in the stage of the half-grown larva and requiring some weeks for the development of the eggs in the ovaries of the butterflies in the case of the first two broods but not of the third.

In another group, which we may designate as B, the conditions may be similer acept that the butterflies lay their eggs very soon after coming from the chrysalis in the case of all three broods. Obviously there would be a tendency 
here for hastening the earliness of the broods so that the hibernating caterpillars might either become larger or might go into the hibernating condition earlier than those of Group A.

In Group $\mathrm{C}$, the variation takes place in the larvae rather than in the butterflies. These may go on in the normal way up to the time the caterpillars of the summer brood become half grown. Then they become lethargic, ceasing to feed and to all appearances going into hibernation. They remain in this condition until the following spring when they come forth from their winter's sleep and feed upon the violets in precisely the same way as the caterpillars of the third brood of Groups A and B.

In Group $\mathrm{D}$ we have another interesting variation of the larvae. These are the same as $\mathrm{C}$ up to the time of becoming lethargic, that is, the larvae of the summer or second brood become lethargic at the same time as those of Group $\mathrm{C}$ but instead of continuing in this condition until the following spring they remain in lethargy only three or four weeks, then they wake up (having apparently then changed their caterpillar minds) and begin to feed, soon maturing and changing to chrysalids from which butterflies emerge late in September or early in October. The result is that these butterflies lay eggs so late that the cold nights come on apace and the little caterpillars apparently take no food at all but go into hibernation immediately. In consequence these must eat for a longer period the following spring, so that the butterflies into which they mature will be likely not to appear until well along in June.

It is probable that even this rather elaborate statement does not do justice to all the variations in the development 
of this little butterfly. But perhaps enough has been said to help us to understand something of the way in which such insects are able to adapt their life habits to the conditions of their environment. It is easy to see that if conditions should so change as to give any one of these groups a decided advantage over the others, the tendency would be for the other groups to disappear and for the group of favored habits to survive.

The Meadow Fritillary is common in Canada and the Northern states east of the Rocky Mountains. It is found especially in lowland meadows and along the borders of swamps, the very situations chosen by the food plants of the larva, the blue and the white violets. The butterflies may be often seen sipping nectar from the various species of mint and related plants found in such situations. It is commonly associated with the Silverbordered Fritillary, from which it is easily distinguished because it has no silver spots upon its wings.

\section{The Silver-bordered Fritillary}

\section{Brenthis myrina}

This attractive little butterfly bears a close general resemblance to the Meadow Fritillary, from which it differs chiefly by the continuous row of silver spots along the border of the under side of both pairs of wings. It is found in the same localities as the other and its life-history is very similar.

The present species is widely distributed in North America, being found as far west as the upper Mississippi Valley and the Rocky Mountains, and southward as far as 
the Carolinas. In New England and the Atlantic states it is one of the commonest of the smaller butterflies.

Beginning with the butterflies which are seen in the fields and meadows in September, the yearly cycle of this insect may be summarized in this way: the eggs laid in September hatch in a few days into tiny caterpillars, some of which become lethargic at once, while others begin feeding upon the violet leaves and continue thus to feed until they are about half grown. These then also become lethargic and find shelter just above the soil surface where they remain until the following spring. They then begin to feed again upon the violet leaves and at about the same time the other caterpillars which became dormant as soon as hatched, also waken and feed upon these leaves. Naturally those which were half grown at the beginning of spring are likely to mature and change to chrysalids two or three weeks earlier than those which were so small at the beginning of the season. Consequently the fresh butterflies will be found from late in May to the latter part of June. Presumably those which first appeared have developed from the larger caterpillars and the later ones from the smaller caterpillars.

The butterflies of this first brood of the season lay their eggs upon the violet leaves, generally upon the upper surface of the blade, but occasionally upon the stems or upon near-by grasses. These eggs hatch in about a week into caterpillars that mature during the next three or four weeks, coming forth as a second brood of butterflies late in July or early in August. These in like manner lay their eggs and develop into a third brood which matures as butterflies in September. These lay eggs that hatch into the caterpillars which live through the winter. There 
are thus three broods of butterflies during the year and it is probable that there is the same remarkable variation in the habits of the different broods that have been found in the case of the Meadow Fritillary.

\section{Synopsis of the Fritillaries}

Gulf Fritillary (Agraulis vanillae). Expanse $2 \frac{3}{4}$ inches. Apex of each front wing produced into a distinct angle. Upper surface of all wings reddish brown, marked with black spots and an interrupted black border, the border on the hind wings enclosing round red-brown spots. Under surface, so far as it shows when insect is at rest, nearly covered with large silver-white spots. Found only in the more Southern states.

Variegated Fritillary (Euptoieta claudia). Expanse 2 $\frac{1}{2}$ inches. Apex of each front wing produced into a distinct angle. Upper surface of all wings fulvous brown, thickly marked with buff and brownish black. A sub-margina! row of black dots on each of the wings, outside of which is a row of buff crescents on the blackish border. Under surface, as it shows when the butterfly is at rest, beautifully marbled in creamy browns and deeper browns. No distinct silver spots in either surface.

Diana Fritillary (Argynnis diana). Male. Expanse $3 \frac{1}{2}$ inches. Apex of fore wings rounded. Upper surface of all wings, with a little more than basal half, solid brownish black and the rest of the surface orange-brown, marked with darker brown round spots and vein lines. Under surface light buff, marked with black, with silver crescents and spots on hind wings. Female. Expanse 4 inches. Upper surface of all wings blackish with bluish or greenish iridescence, and marginal third marked with 
blue spots and stripes. These are more prominent on the hind wings. Under surface slaty brown with prominent silver crescents on the hind wings.

Idalia or Regal Fritillary (Argynnis idalia). Male. Expanse 3 inches. Front wings fulvous brown with black spots and markings. Hind wings black except at base with a row of fulvous brown sub-marginal spots and an inner row of whitish or bluish white spots. Female. Expanse $3 \frac{1}{2}$ inches. Similar to male except for larger size and the fact that the two rows of spots on the hind wings are yellowish brown.

Great Spangled Fritillary (Argynnis cybele). Expanse $3 \frac{1}{4}$ inches. Greneral color of wings fulvous brown with black markings on upper surface and black and silver markings on under surface. The yellow band between the rows of silver spots on hind wings is broad. There is a distinct narrow fulvous stripe on the upper side of the hind wing just inside the outer margin, and a similar stripe along the margin of the front wing, more or less interrupted by the veins.

Silver-spot Fritillary (Argynnis aphrodite). Expanse 3 inches. Similar to the Great Spangled but a little smaller, and with the buff yellow band between the rows of silver spots on the lower surface much narrower and al. most disappearing at the rear.

Mountain Silver-spot (Argynnis atlantis). Expanse $2 \frac{1}{4}$ inches. Known by its smaller size and the black marginal border stripe on all the wings, with no brown line dividing this stripe.

Silver-bordered Fritillary (Brenthis myrina). Expanse $\mathbf{1} \frac{3}{4}$ inches. Known by its small size and a marginal row of silver spots on the under side of each of the wings, and 


\section{THE TRIBE OF THE CRESCENT-SPOTS 135}

with many other silver spots scattered over the under surface of the hind wings.

Meadow Fritillary (Brenthis bellona). Expanse 2 inches. Easily known by the absence of silver spots on all the wings. The wings are long in proportion to their width.

\section{THE TRIBE OF THE CRESCENT-SPOTS}

The members of this tribe have the following combinations of characters: scaly antennae, with a short stout club some three times as long as broad, and a pair of slender palpi in which the terminal joint is only about half as long as the middle one. There may or may not be a slight ridge running lengthwise of the naked part of the antennal club.

Although more than fifty distinct species belonging to this tribe have been found in North America, very few of these are distributed through the eastern part. Only four are so abundant and widely distributed that they need be treated of here.

\section{Baltimore Checker-spot}

\section{Euphydryas phaeton}

To the naturalist those islands in the seas which are remote from the mainland have long been of especial interest. The life upon them is likely to show the results of many generations of living under unique conditions. The plants and animals are generally distinctive, many of the species having characteristics which differentiate them markedly from those upon the mainland. They show in a thousand ways the effect of isolation and so are 
of especial value when one attempts to determine the results of unusual conditions upon living things.

In a somewhat similar way the peat bogs or sphagnum swamps which occur here and there over a large part of North America are of especial interest, because in a way they are biological islands in which the conditions of a long past age are preserved until the present. These nearly always occur in a little valley surrounded on all sides by hills. Here the water has collected originally into a pond or lake, which has been gradually filling up through the growth of peat mosses and a special set of other plants that develop in such situations. One can still find many stages in the process. In some bogs the surface will be practically covered, although the water beneath may still be so abundant that the matted moss quakes as one walks over it. Sometimes such bogs are really dangerous because the walker may drop through to the water beneath. In most of the bogs, however, the little lake is nearly filled but shows the surface over a small area.

The conditions in these peat bogs have changed little since civilization began. They are relics of an earlier era which have come down to us as types of conditions that once existed very generally. The plant life is unique and consists almost entirely of forms which are found practically nowhere else. There are comparatively few animals living in these peat bogs and all of these are likely to be of especial interest. Among the insects none is more remarkable than the Baltimore Checker-spot butterfly which has several peculiarities that differentiate it from the other members of the group. It seems to have come down to us unchanged from a far remote past and to be living its tranquil life to-day in precisely the same 


\section{THE TRIBE OF THE CRESCENT-SPOTS 137}

manner as during the time when the mammoth and the mastodon were likely to invade its haunts.

The Baltimore is probably the most local in its distribution of any of the butterflies found throughout Canada and the Northern states. It is to be looked for only in peat bogs and swamps, and it has a remarkable unity in its life-history whether it be found in northern Canada or as far south as West Virginia. The butterfly itself is rather large, measuring a little more than two inches across its expanded wings and being colored with an unusual combination of fulvous and yellow upon a black background. It is present as a rule only from about the first of June to the middle of July. The eggs, in bunches of from one hundred to four hundred, are laid upon the leaves of the plant commonly called snake-head or turtlehead (Chelone glabra). They do not hatch for nearly three weeks; then the little caterpillars emerge together and usually each eats a little of the empty egg shell. They are then likely to form a thin web over the under surface of the leaf beneath which they remain as a small company feeding upon the succulent green tissue. A little later they are likely to begin the construction of a miniature nest by spinning a silken web over the young leaves at the top of the plant. From this time on this silken nest serves as their home, and they utilize it almost as effectively as do our familiar American tent caterpillars the nest which they make in the forks of the wild cherry tree. The Baltimore caterpillars often wander more or less from their tent-like home but they generally come back to feed as well as to moult. If the nest is injured by wind or rain, all the caterpillars turn out to repair it and as the need for new food supplies arises they also unite to enlarge the 
tent. This habit of working together for the common good is very suggestive of the similar habits of the American tent caterpillars. Doors for going in and out are left in the tent during its construction.

The tent thus made is likely to be deserted after the first moult and a new and larger one constructed on another part of the plant. Two or perhaps three such nests may be made from the time the caterpillar hatches until after the second moult. The last nest made is very likely to be upon some neighboring bushy plant or at least to include some branches of such a plant if the bulk of the nest is made upon snake-head. For after the third moult the caterpillars stop feeding and become more or less quiet, thus beginning a nine months' fast, during which they are simply to wait until the return of spring. This fast may be begun any time from the middle of August until early in September, and even when brought indoors the caterpillars cannot be induced to eat. It is evidently the way in which the species has bridged over the winter during the thousands of generations of its existence, and the instinct is so firmly fixed that it cannot be changed. Even in West Virginia, where the caterpillars would have plenty of time during the summer to mature as butterflies that would bring forth another generation of caterpillars that might pass the winter, the condition is the same as in the far northern regions.

So within the shelter of the silken nest these Baltimore caterpillars remain from the middle of August until May. Then when the spring sunshine has sufficiently warmed their cool retreats they come forth and feed greedily upon the young leaves. They now soon make up for lost time and complete their growth as caterpillars very 


\section{THE TRIBE OF THE CRESCENT-SPOTS 139}

quickly. When full fed they wander about in all directions, each hunting its own shelter before becoming a chrysalis. Having found a twig or branch that suits their purpose each hangs downward and changes to a brownish yellow chrysalis, more or less marked with black. It remains in this condition for about a fortnight, when it comes forth as the Baltimore butterfly which thus appears again about the first of June.

These butterflies seem to have some of the character. istics of their unique surroundings. There are very few flowers in the peat bogs and it is significant that the butterflies instead of flitting from flower to flower, as do most of our familiar species, fly rather in a slow and lazy fashion from leaf to leaf, lighting upon the foliage or frequently upon the surface of the moss or ground. They seem lethargic and have little of the animation which we usually associate with the name butterfly.

In my mind the Baltimore is associated with the White Mountain butterfly as a survivor of a former geologic period. The latter was developed under colder conditions and now survives only on a few isolated mountain peaks; but the former has survived wherever the peat bog has held its sway during the long ages that the surrounding landscape has been taking on its present-day condition. Many things in the life of the Baltimore point to its primitive condition: the laying of the eggs in loose clusters, the long lethargy of the caterpillars, the limited flight of the butterflies-all indicate a creature with habits firmly fixed by long ages of development in a definite environment.

No collector should feel sure that the Baltimore is not to be one of his trophies until he has visited in June every peat bog or sphagnum swamp in his locality. One may 
search years without finding it, and then come across a dozen in a single day. I well remember the interest with which I first found this species on the margin of a great swamp in Michigan when I was eager for every new butterfly to add to my collection. I had never seen it alive before and the thrill with which the first specimen was captured can be realized only by those remembering similar experiences.

\section{Harris's Checker-spot}

\section{Cinclidia harrisii}

This little butterfly so closely resembles the Pearl Crescent and the Silver Crescent that on the wing it is easily mistaken for them. It really looks more like them than it does the Baltimore Checker-spot, which is considerably larger and darker colored than the present species. This is essentially a northern form occurring only in a narrow strip of country east of Minnesota and Wisconsin, running on the north through southern Canada and on the south through Michigan, New York, and Massachusetts.

This insect is one of the best-known botanists among all the butterflies. In the very difficult group of asters which has caused endless confusion to human botanists these insects seem always able to select the one species-Aster umbellatus. It has been repeatedly found that the caterpillars would starve rather than eat the leaves of other kinds of asters, and so far as known they have never been found feeding outdoors upon any other.

These butterflies appear along roadsides and in open 


\section{THE TRIBE OF THE CRESCENT-SPOTS 141}

fields about the middle of June. They are often very abundant and are much more generally distributed than the Baltimore Checker-spot. A few weeks later the females lay their eggs upon the aster leaves, the eggs being deposited in clusters of twenty or more on the under side of the leaf. Early in July the little caterpillars come forth and remain together in colonies as they feed upon the green tissues of the leaves. Each is able to spin a silken thread so that wherever they go they weave a web and they soon protect themselves with a slight silken shelter, which is suggestive of the nests made by the Baltimore caterpillar. They continue to live in this manner for several weeks in July and August, growing rather gradually and becoming approximately half grown before the frosts of autumn. Unlike the Baltimore caterpillars they now desert their nests and find shelter at or near the surface of the ground. Here they hibernate, to come forth the following spring and feed again upon the new growth of the aster plants, often doing considerable damage by denuding the young shoots of their leaves. They become full grown in time to change to chrysalids so that the butterflies may emerge in June.

\section{The Silver Crescent}

\section{Charidryas nycteis}

While this species has not the broad distribution for which the Pearl Crescent is notable it occurs over a large part of the United States. Its distribution is bounded broadly by a line running from southern Canada north of Maine to a point in southern Canada north of Montana, whence it 


\section{BUTTERFLIES}

runs south through Wyoming and Utah to the corner of Arizona, and thence east through New Mexico and Texas to Ohio and West Virginia, extending south near the coast to North Carolina. It thus includes a broad belt of territory occupying fully one half of the area of the United States.

Throughout this vast area the Silver Crescent is often a purely local species, occurring abundantly during its brief season in some favorable locality but seldom being seen in other places near by. In the north it is single-brooded, the butterflies appearing on the wing during June and commonly disappearing early in July. Late in June the females lay their eggs in clusters of a hundred or less on the under surface of the leaves of various composite plants, notably sunflowers, asters, and a common species of Actinomeris. A week or more later these hatch into little caterpillars that feed together in colonies upon the green tissues of the leaf, taking only the succulent parenchyma and leaving the network of veins. As one leaf is thus denuded they migrate to another, in this way passing from leaf to leaf for several weeks in summer. They continue to feed until about half grown when they desert the food plant and find shelter at the soil surface. Here they become lethargic and hibernate until the following spring. They then arouse again and feed upon the tender leaves of the new growth, continuing to eat and grow for a few weeks before they become mature as caterpillars and change to chrysalids. A little later the chrysalids disclose the butterflies which as already indicated appear in June.

In more southern regions the life-story of the species is not so simple. There is at least a partial second brood and 


\section{THE TRIBE OF THE CRESCENT-SPOTS 143}

it is probable that in many localities the species is both single-brooded and double-brooded. In such a case some of the caterpillars go into hibernation probably about midsummer, remaining quiescent through the later weeks of summer and all the weeks of fall and winter, while others would mature to chrysalids and butterflies in summer, and the butterflies would lay eggs for a second brood of larvae which would hibernate when partially grown. There are opportunities for careful observers to do good work upon the life-history of this species in many parts of its range.

\section{The Pearl Crescent}

\section{Phyciodes tharos}

Some years ago Mr. Samuel H. Scudder, the most notable student of New England butterflies, wrote a delightful essay with the title "Butterflies as Botanists." From his long experience in rearing the eggs of these insects he concluded that the egg-laying females know in a most remarkable way the precise kinds of leaves upon which to oviposit. He educed many illustrations in proof of the fact and quoted a remark of Asa Gray, the most eminent of American botanists, that is worth repeating. At that time Scudder had reason to believe that the Pearl Crescent laid its eggs exclusively upon the New England aster. Now the asters as a group have been a source of much trouble to the botanists who have attempted to classify them as to species and variety. The various forms are so similar to one another that different authorities have not agreed as to the limitations of the species. So when Gray was told that this little butterfly was able always to distinguish 
and select for her egg-laying a single species of this vexing tribe he replied: "If your butterfly selects only that, it is a better botanist than most of us."

While later observers have found that this beautiful little insect is not so exclusive in its choice of a food plant as was formerly believed, it serves to illustrate the fact that a large proportion of the caterpillars of this group have a very narrow range of food plants. In nearly every case where the food is thus restricted the insect feeds only upon species which are closely related to one another, generally falling within a single genus according to the classification of the botanists.

There has been much discussion in regard to the way in which the mother butterfly knows the particular species which she chooses for oviposition. Experiments apparently have shown that she is not dependent upon the sense of sight but rather upon the sense of smell, which as is well known is much more highly developed in insects than in the higher animals. I suppose it is not very strange that a creature which has fed from infancy upon leaves with a certain taste and odor should in its later life respond only to that particular odor and should neglect all others. In a way the butterfly itself is a product of the plant and it probably is not necessary to assume that each butterfly differentiates the odors of all kinds of plants but only that she responds to the fragrance of the one with which she has been particularly associated.

This idea may suggest to various observers an interesting point of view. When you see a butterfly flying leisurely from plant to plant and alighting upon the leaves rather than the blossom, you may be pretty sure that she is bent upon egg-laying. Now watch her to see if she goes at once 


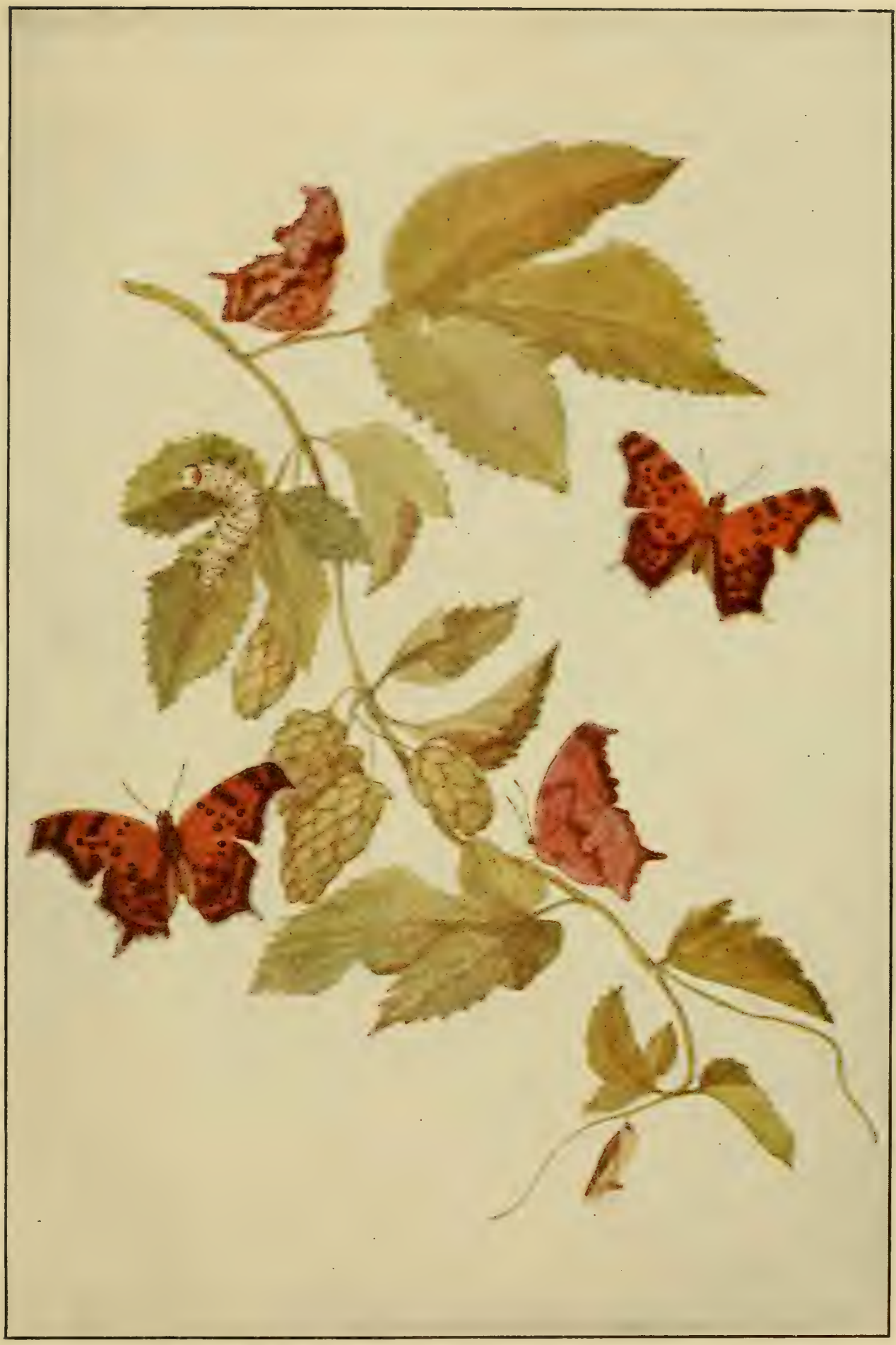

From a drawing by Mary E. Walker

See page 153 THE HOP MERCHANT

Caterpillar, chrysalis, and butterflies. (Reduced) 


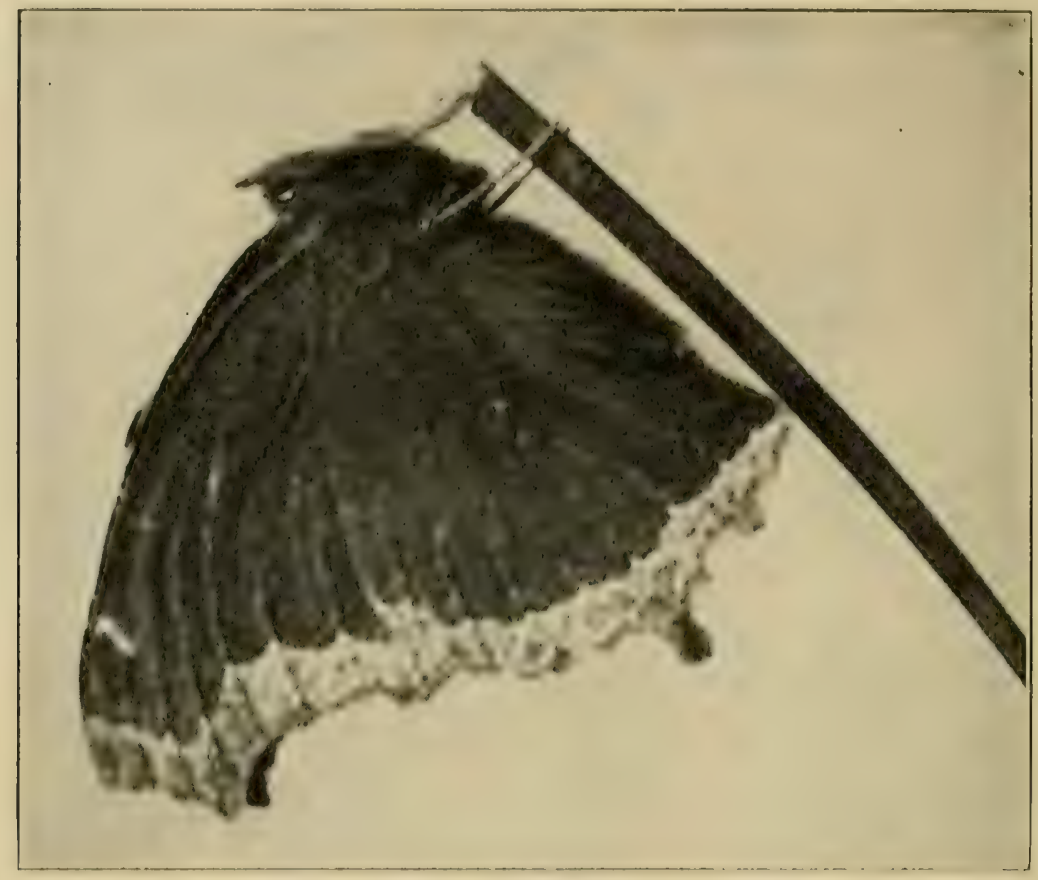

Momning-Cloak Seepages 112,171

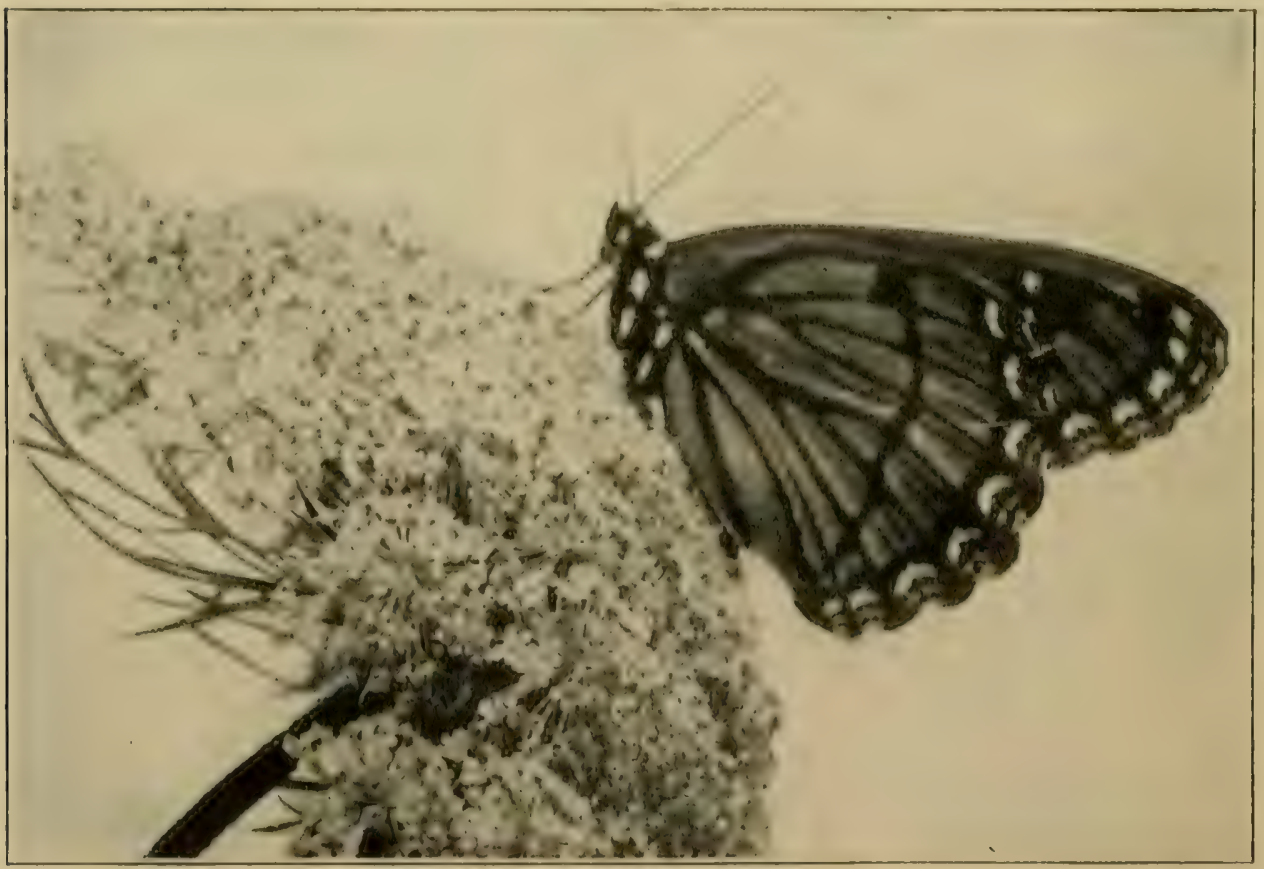

The Viceroy visiting wild carrot flowers

See page 195

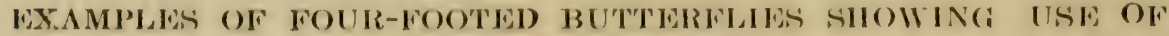
THE FOUR IUGS 


\section{THE TRIBE OF THE CRESCENT-SPOTS 14.5}

to the particular kind of leaves she finally selects or does she stop momentarily upon neighboring plants, apparently trying to find the one from which the fragrance emanates until at last she reaches it. Such observations have only rarely been recorded and if carefully made, notes being taken on the spot, they would lave decided scientific value.

\section{Abundance and Distribution}

Few butterfies are more abundant or more widely distributed throughout North America than the beautiful little Pearl Crescent. It occurs over practically the whole of the United States and Canada and is found from early in spring until late in autumn. It is a rather small species with a wing expanse of only about an inch and a quarter, the upper surface of the wings being that tone of reddish brown called fulvous, more or less marked with black wavy lines and dots. The under surface is similar in color, with a small silver crescent near the outer margin of each hind wing.

These butterflies are not very active creatures, although they are commonly found in meadows and pastures along brooks and by the borders of open woods. Instead of laying their eggs singly as do so many of the more active butterflies, they lay them in clusters, often of a hundred or more, one layer of eggs being placed above the other upon the aster leaf. In at least one case observed, the caterpillars hatch from the layer farthest away from the leal surface before those of the layer next the leaf surface emerge. This is an interesting provision, for were the latter to come out first they would be likely to disarrange the unhatched eggs. The caterpillars appear about a week 
after the eggs are laid and remain together in crowded colonies that feed upon the upper surface of the aster leaf. At first they eat only the green tissue, leaving the bare veins, although they are not careful to denude the entire surface of the leaf as so many other caterpillars do. As one leaf is exhausted they pass to another near by, continuing thus to feed in companies for a few weeks. Their general color is blackish, although the black is relieved with yellow dots along the back and a band of a similiar color on each side. Unlike the larger social caterpillars of the Mourning Cloak and other butterflies these larvae do not spin any threads as they crawl from place to place, so there is absolutely no nest made upon the aster leaf. This may possibly be correlated with the fact that these caterpillars are sluggish creatures and when disturbed drop quickly to the soil beneath.

When the caterpillars are full grown, they fall or crawl to the ground and scatter more or less in search of shelter. Each attaches itself to any protection it may have found and changes to a grayish or brownish chrysalis more or less angular. It remains in this condition for a period that varies greatly with the weather conditions, averaging about two weeks.

There are two distinct forms of these butterflies which vary so greatly that they were once considered separate species. They are now known, however, to be only seasonal variations. In New England two broods of the insect occur, one in spring, the other in summer. The spring form is called technically Phyciodes tharos tharos. In this form the under surface of the hind wings is very distinctly marked with blackish spots. The summer form is called Phyciorles tharos morpheus. It is noticeably 


\section{THE TRIBE OF THE CRESCENT-SPOTS $14 \%$}

larger than the spring form and it has very few markings on the under surface of the hind wings.

\section{The Yearly History}

As it occurs in New England the yearly history of this little butterfly runs something like this. The spring form of the adult appears in May and lays eggs upon the aster leaves. These eggs hatch into caterpillars that feed upon the aster leaves for several weeks and then change to chrysalids, remaining in the latter stage ten days or two weeks. They then come from the chrysalids in the form of the summer butterflies which begin to appear about the middle of July and continue to emerge for at least a month. These lay eggs upon the aster leaves again and the little caterpillars that hatch from them feed for a few weeks or until about the last of September. They are then only partially grown, but they make no attempt to complete their transformation at this time. Instead they drop to the ground and go into hibernation, remaining in this condition until early the following spring. They then begin feeding again and complete their development in time to emerge as the spring form of the butterfly in May.

Some very interesting experiments by William H. Edwards have shown that the smaller, darker spring form of the butterfly is due to cold. He placed upon ice chrysalids that would normally produce the summer form and found that the specimens so treated produced the spring form.

This butterfly is one of the best known examples of the variation in the yearly cycle due to differences in latitude. This is readily shown by a brief summary of its life-history, from north to south.

In the far northern climate of Labrador there is but one 
brood a year and the butterflies belong to what I have been calling the spring form. The butterflies appear on the wing in early summer, lay their eggs upon the aster leaves, and die. The eggs hatch into caterpillars that feed for several weeks, then become dormant and remain in such shelters as they can find until the following spring. They then change to chrysalids to emerge as butterflies a little later. There is thus but one brood a year and the only form of the butterfiy is the small, darker colored variety.

As far south as southern Canada there is a slight variation in this yearly cycle. The spring form of the butterflies appears in May and lays eggs. The eggs hatch into caterpillars; part of these caterpillars mature within a few weeks, change to chrysalids, and come out in July or August as the larger summer form of the butterfly, which in turn lays eggs for the caterpillars that are to winter over in a dormant condition and mature the following season. But the significant fact is that not all of the caterpillars which thus have hatched in spring go through this cycle. Part of them become dormant when partially grown and continue dormant through summer, autumn, and winter, just as they did in Labrador. Then in spring they develop into the spring form of the butterfly, along with the caterpillars that have hatched from the eggs laid in summer. There is thus what is called an overlapping of the broods.

Farther south, in southern New England, the life-history is more definitely two-brooded each year, as already described in an earlier paragraph. Still farther south, in the region of the Virginias, it is definitely three-brooded, there being at least two summer broods during the year. 


\section{THE TRIBE OF THE CRESCENT-SPOTS 149}

How is it that the instinct to become lethargic lies dormant in the summer broods of caterpillars and shows itself only in the autumn brood? Is it perhaps due to a reaction to the colder nights of the later season? If so, possibly one could get interesting light upon the subject by experimenting with placing the summer caterpillars temporarily in an ice chest.

Synopsis of the Crescent-spots

Baltimore Checker-spot (Euphydryas phaeton or Melitaea phaeton). Expanse $1 \frac{3}{4}$ inches. General color purplish black with the upper surface marked thus: a marginal row of red-brown spots between the veins; two rows of creamy yellow spots inside of the row just mentioned; two or three small red and two or three small white spots near front border of each front wing. Under surface checkered in red-brown and creamy yellow on a blackish background.

Harris's Checker-spot (Cinclidia harrisii or Melitaea harrisii). Expanse $1 \frac{3}{4}$ inches. This species bears a close general resemblance to the Silver Crescent. It may be distinguished by the fact that the middle joint of each palpus is of uniform size from end to end instead of tapering toward its outer end. The tibial joint of the first pair of legs of the male butterfly is very thick. The upper wing surface is so marked with black that the tawny red coloring shows only in the middle.

Silver Crescent (Charidryas nycteis, Melitaea nycteis or Phyciodes nycteis). Expanse $1 \frac{3}{4}$ inches. This species may be known from Harris's Checker-spot by the fact that the middle joint of each palpus tapers from the middle to the tip and that the tibia of each front leg in the male is slen- 
der rather than stout. On the lower surface of the wings there is a narrow yellowish marginal line.

Pearl Crescent (Phyciodes tharos or Melitaea tharos). Expanse $1 \frac{1}{2}$ inches. General color much lighter than either of the preceding. Terminal joint of each palpus less than a third as long as the middle joint.

\section{THE TRIBE OF THE ANGLE-WINGS}

The special characteristic that distinguishes the members of this important group from the other Nymphs is the fact that on that portion of the club of each antenna which has not hairs there are three longitudinal ridges. The tribe includes a large number of our most familiar butterflies. Nearly all of them are rather large, with bright attractive colors. They fly freely along roadsides and in orchards, fields, and meadows so they are commonly seen by every one.

\section{The Violet-tip}

\section{Polygonia interrogationis}

The Violet-tip is one of the largest of the Angle-wings, as well as one of the most beautiful of all our species. It has a wonderful violet iridescence which is especially marked on the projecting tip of the hind wing. On fresh specimens, however, it may be seen practically all over both surfaces of the wings and in bright sunlight gives them a sheen of remarkable beauty. The expanded wings measure nearly two and a half inches, the upper surface being 
marked with dark brown upon a ground of orange-brown. The under surface has a bark-like effect in brownish gray brought about by rather indefinite markings of varying tone. The most characteristic feature is a distinct silver semicolon on the middle of the under surface of each hind wing. This marking closely resembles the Greek interrogation point and so the species was given the specific name interrogationis by Fabricius early in the history of science. It has since often been called the interrogation butterfly as a translation of its Latin name, but in as much as the marking on the wings is not at all like the English interrogation point, this has led to considerable confusion and people have considered it a misnomer. It has also been called the Semicolon butterfly which is correct enough so far as this most characteristic feature is concerned; but it leads to confusion in connection with the Latin name. The recent practice seems the better, which is to call it the Violet-tip butterfly.

\section{Life-history}

The life-history of this butterfly is much like that of the related species. Briefly summarized, this is its story:

The adult butterflies, more or less worn and faded from their long hibernation, appear in fields and pastures in May. They fly for several weeks sipping nectar from many kinds of spring flowers. The females search for the leaves of the elm, hop, nettle, false nettle, and perhaps other related plants on which they deposit their ribbed eggs either singly or in small groups, it often happening that one egg will be laid directly on top of another. About a week later the eggs hatch into small spinose caterpillars which begin feeding upon the leaves near by. They con- 
tinue to feed and grow rather rapidly until they become full size. Each then fastens a bit of pink silk to the stem of the plant or some other support, in which it entangles its hind legs and hangs downward to become a chrysalis which is remarkable for its numerous protuberances and the beautiful silvery and golden spots along the middle of the back. Within these chrysalids the change from larva to butterfly takes place, usually in less than two weeks, so that this new brood of adults appears on the wing early in July. Eggs are laid by these for a second brood of caterpillars that feed upon the host plants in the same way as the others, and mature as butterflies late in August or early in September. These butterflies visit the fall flowers and suck the juices of fallen fruits, until the cold weather of autumn warns them to seek shelter for the winter. They now find crevices within the bark of trees or places in hollow logs or stone piles or other similar situations, where they close their wings together, so that only the bark-like under surface shows, and remain quiet for long periods. They hibernate in this way, coming forth again the following season to start the cycle for the new year.

In regions where hops are grown commercially the chrysalids of these butterflies are often called "hop merchants." There is a quaint fancy that the price of the crop varies with the lustre of the golden spots upon the chrysalids. When these stand out conspicuously, according to this fancy, the hops are to sell high-bringing much gold to the owners. When these are inconspicuous the hops are to sell at a low price, with a corresponding diminution in the returns. But this fancy does not apply at all to the chrysalids when they are nearly ready to dis- 
close the butterfly, for at this time they lose their metallic lustre.

\section{The Hop Merchant or Comma}

\section{Polygonia comma}

There are two species of butterflies which commonly lay their eggs upon the hop and which resemble each other so closely in their earlier stages that they are frequently confused by ordinary observers. One is the Violet-tip or Semicolon and the other is the one which has long been called the Comma. The chrysalids of both are marked in silver and gold and the variation in the golden lustre has led hop growers to deduce from them the probable price of hops. On this account the chrysalids are commonly called Hop Merchants and the name has been transferred to the butterflies themselves. (See plate, page 144.)

The Comma is easily distinguished by the conspicuous silver mark in the middle of the under side of each hind wing. This bears a striking resemblance to a comma, hence the name. The butterflies are somewhat smaller than the Violet-tips and show to a remarkable degree the angularity in the borders of the wings. The under side is cleverly marked in imitation of the bark of trees, which is doubtless of much benefit to the species in eluding observation during the long months from October until April, when the butterflies are hibernating in such concealed shelter as each happens to find. The crevices beneath loose bark, the openings in fallen logs and hollow trees, the interspaces in stone piles, as well as the interior of buildings, all serve this purpose. 
Like the other over-wintering butterflies, the specimens that come forth in spring are commonly faded and more or less frayzed from their long wait since bursting forth from the chrysalis. They may often be seen sunning themselves on bright days in April and May, resting upon stones or logs in sheltered spots with their wings fully expanded to receive the greatest benefit from the rays of sunshine.

When spring has sufficiently advanced for the leaves of the elm and the hop to be fairly well developed, the mother butterflies lay their eggs in a curious and characteristic fashion. Under a lens these eggs look like

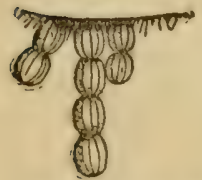

Eggs laid in string-like clusters on the un-
der side of leaf. Magn if i ed.
(From Holland) tiny barrels with vertical ribs. They are deposited in columns, the egg first extruded being attached to the leaf, generally the under surface, and those which follow are placed one upon the other sometimes to the number of six or eight, the group thus making a miniature column. Now if the egg which was first laid should hatch before the others, when the little caterpillar came out it would be very likely to cause the others to fall off and when they hatched they would find themselves in what would be to them an impenetrable forest of weeds and grasses from which there would be small chance to escape to reach the elm or hop leaves. To avoid this calamity we find an interesting adaptation. The egg at the end of the column hatches first, although it was necessarily the one laid last. The tiny caterpillar eats its way out of the shell and crawls over the other eggs to the leaf. Then the others hatch in succession.

The eggs thus deposited by the hibernating butterflies are likely to be laid late in May or even early in June. 


\section{THE TRIBE OF THE ANGLE-IVINGS 155}

They hatch into caterpillars less than a week later and these caterpillars feed for about a month, when they change to the characteristic chrysalids in which they commonly remain for a week or ten days. They then emerge as the summer brood of butterflies, most of them in New England appearing during July. These remain upon the wing for several weeks, the females laying their eggs upon the elm and hop leaves. These in turn soon hatch into caterpillars that change to chrysalids in August and emerge as butterflies late that month or during September. This autumn brood of butterflies is quite abundant for a time but soon seeks the seclusion of winter quarters to remain until the following April. There are thus two distinct broods during the year in the Northern states while as far south as West Virginia there are likely to be three broods.

These caterpillars at first simply eat small holes in the green substance of the leaf, but as they become larger each takes up its abode on the under surface of a single leaf and makes a sheltered tent in somewhat the same fashion that the Painted Lady does upon the nettle leaf. The caterpillar eats out more or less of the base of the blade on each side of the midrib, thus weakening the edges so that they can be fastened in a tent-like manner by silken threads. This serves as a resting place from which it sallies forth to feed, commonly only toward the tip of the leaf. As a result it often eats itself out of house and home and has to crawl to another leaf and construct a new shelter.

While the Comma is generally spoken of as a characteristic northern species it has a very wide range, being found from New England to Texas and from the Northwestern states to the Carolinas. It is one of those species which 
have two distinct forms of coloring. The winter form has been given the variety name harrisi. The butterflies of this brood are decidedly lighter in color than those of the summer brood to which the variety name dryas has been given. The latter was originally described as a distinct species by W. H. Edwards.

\section{The Change to the Chrysalis}

The manner in which a larva changes to a chrysalis is second in interest only to that in which a chrysalis changes to a butterfly. There are not a great many careful descriptions by competent observers of this process in print. One of the best of these is that by W. H. Edwards in his splendid work on "The Butterflies of North Amer ica," in which he describes the transformation of the Comma caterpillar. It is as follows:

"When about to transform, the caterpillar selects a convenient place on the under side of a projecting rock, or of a fence rail, or of a weather board of the house, or the mid-rib of a hop leaf, and having spun a little button of pale red silk fixes the hooks of its hind legs therein and hangs suspended, head downward, in the shape of a fishhook and remains immovable for the space of twenty-four hours, no change being perceptible except in the color of the skin, which becomes partly transparent and loses its dark color owing to its gradual parting from the chrysalis within. Suddenly, and to a looker-on without any premonitory symptom, a rent takes place in the skin at the back of the head, just wide enough to allow the passage of the chrysalis, the head of which at once emerges. By a rapid contraction and expansion of the folds of the abdomen the larva draws the skin upward, successively discovering the 
parts of the fully formed chrysalid until at last, and in scarcely more than one minute of time, the entire skin is gathered about the hind feet. It now bends itself violently to disengage the end of the chrysalis, which is long, pointe?, and hara, furnished with several little hooks, meanwhile retaining its hold of the skin by the folds of its abdomen until after a severe effort, convulsively reaching out and feeling in all directions for the object of its search, it touches the button of silk and at once grasps it with its hooks and fixes them in it securely. Then by a twisting motion it manages to disengage the loose skin which falls to the ground and the chrysalis rests. The whole process is most interesting to witness and excites renewed wonder with every repetition at the ingenuity of the moans employed and the delicacy of the instinct displayed. How to strip off the skin and much more the legs by which the creature is suspended without losing its hold, and at the same time to securely fasten the chrysalis, is a problem that would seem impossible to solve; and yet this little insect accomplishes it unerringly when to fail would be certain destruction And not this species only, but the larvae of all butterflies which form suspended chrysalids, embracing the whole of the great family of Nymphalidae, that is, a large proportion of all the existing species of butterflies, undergo a similar transformation.

"The chrysalis is now green in color, soft and indefensible, susceptible to the slightest injury, and for a few moments the several parts of the future butterfly may be seen and readily separated; the wings folded close and enveloping the thorax, the antennae, and proboscis stretched at length along the back; but very speedily a complete 
casing is formed by the exuding from parts of the body of a viscous fluid, which binds together the tender parts and covers the whole with a coating like varnish. This soon hardens and the chrysalis is ready to take its chance against injury."

\section{The Gray Comma}

\section{Polygonia progne}

This butterfly is rather darker colored, especially on its under side, than the one last discussed. The silver marking takes on a little more definitely the form of an $\mathrm{L}$ than a comma, and the under surface of the wings is darkened by many blackish thread-like lines running across the veins. When at rest with wings closed these butterflies are very easily overlooked.

Except for a difference in the food plants of the caterpillar, the life-history of the Gray Comma is very similar to that of the other Comma. The butterfies hibernate, and in spring lay eggs singly on the leaves of currants, gooseberries, and related plants. The eggs soon hatch into caterpillars that feed upon these leaves but do not make any suggestion of a nest. They grow slowly and change into angular chrysalids which disclose the summer brood of butterflies in July. These lay eggs for another brood of caterpillars which mature into butterflies in August and September. These generally go into hibernation before the middle of October, sometimes choosing simply the under side of a branch where their dark coloring, so near like that of the bark, is likely to cause them to be overlooked by their numerous enemies. 


\section{The Green Comma}

\section{Polygonia faunus}

The Angle-wings exhibit interesting variations in the geographical distribution of the species. Some are characteristic members of the Canadian fauna, others of the Alleghanian fauna. Some of those which are characteristic of the former are scattered south well into the latter, but the Green Comma is distinctively a northern species-being found abundantly in the great regions traversed by the trappers of the Hudson Bay Company and occurring south as far as northern New England, being very rare as far south as northern Massachusetts. It is abundant on the higher slopes of the White Mountains.

As one might expect from the short seasons of the far northern regions in which this butterfly lives, there is only one brood each year. In consequence the adult butterflies live a long time. Coming from the chrysalis generally the first weeks in August, they remain upon the wing a month or more before they go into hibernation. They come from their winter quarters in May and commmnly continue alive until late in June. Thus it is eviuent that many of these butterflies must live at least ten months as adults, an extraordinary longevity for one of these frail creatures.

The caterpillars are known to feed upon the foliage of several kinds of plants. These include alder, currant, gooseberry, willow, and black birch, the last two named apparently being those most often chosen.

Mr. S. H. Scudder called attention to the fact that these butterflies are able to make a slight clicking noise as they 
start into flight. He described his experience in these words:

"Starting up a pair just at my feet on the Mt. Washington carriage road one day, I stopped abruptly to see whether they would settle again. After flying a few yards away to escape the cause of their disturbance, one turned back and dashed straight at my face, turning only when within three or four inches of my nose, and then suddenly whisked off with a distinct click as it did so, snapping its fingers, as it were, in my very face. There was no sort of doubt about this click, though if it had not been made so close at hand it would probably not have been heard. But other butterflies in the tropics have long been known to emit sounds like this, which can be heard at a considerable distance; others, including some of our own butterflies, are known to produce a rustling sound by the rubbing of one wing upon another; and movements of one sort and another have been so often observed, as of the opposite rubbing of the erect wings in most Lycaenids, and the tremulous agitation of the wings in many different sorts when excited, as to leave little doubt that sounds made by themselves and for the advantage of warning their brethren play a not unimportant part in the lives of butterflies."

\section{The Red Admiral or Nettle Butterfy}

\section{Vanessa atalanta}

Among the weedy plants which have been intimately associated with mankind ever since his slow upward progress in civilization began, the nettle has probably played almost as important a part as the thistle. While 


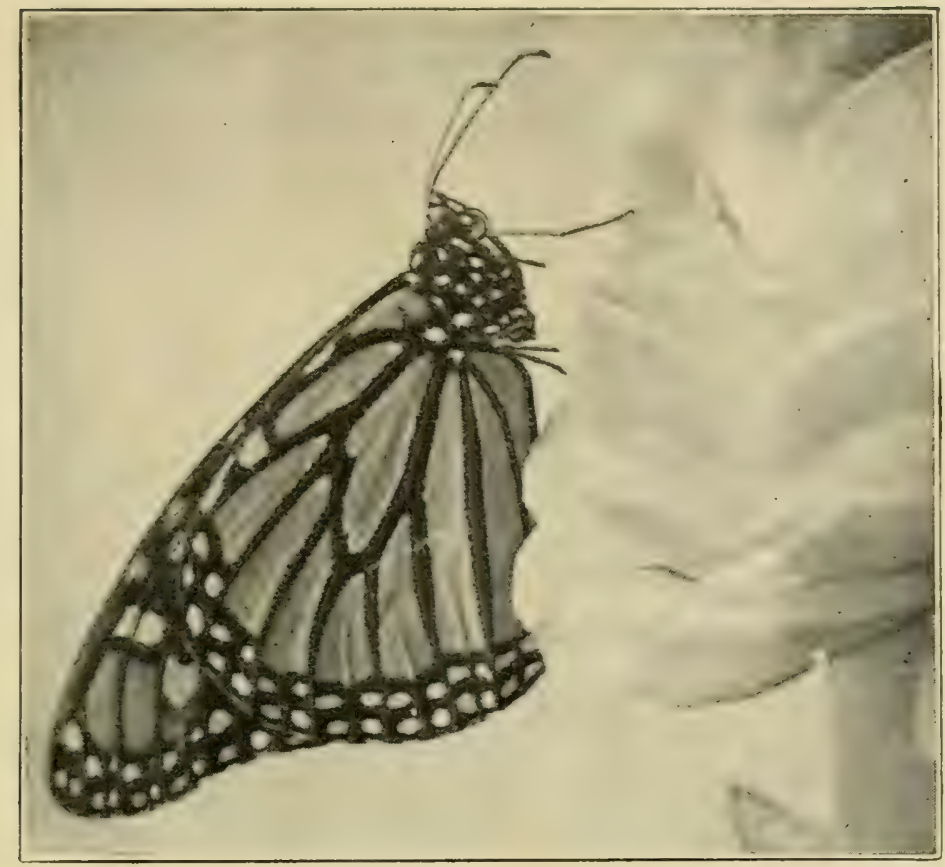

See page 233

IONARCH BUTTERFLY IN RESTING POSITION

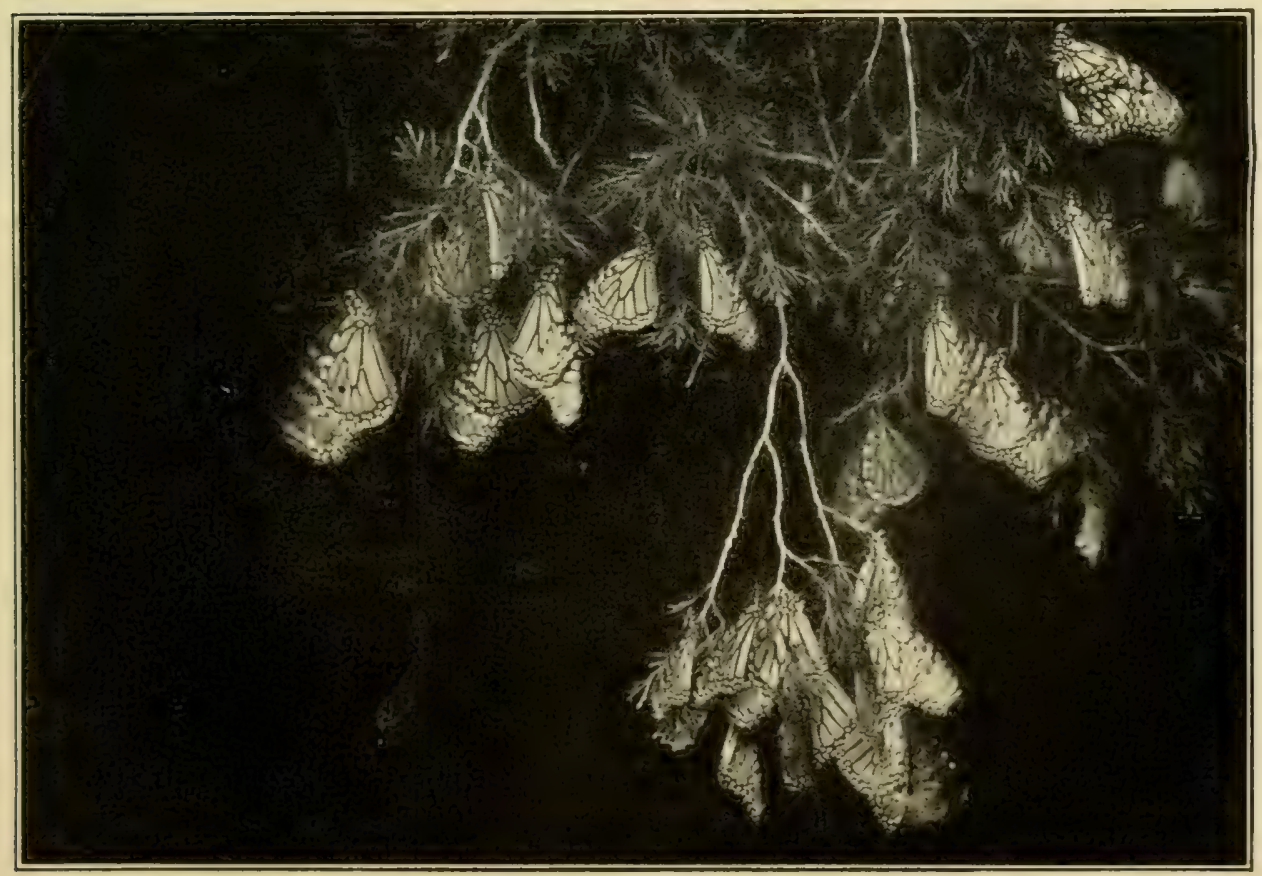

Photograph by Miss J. Brooks

See pages 17, 232

FLASHLIGHT PHOTOGRAPH OF MONARCH OR MILKWEED BUTTERFLIFS IN MIGRATION 

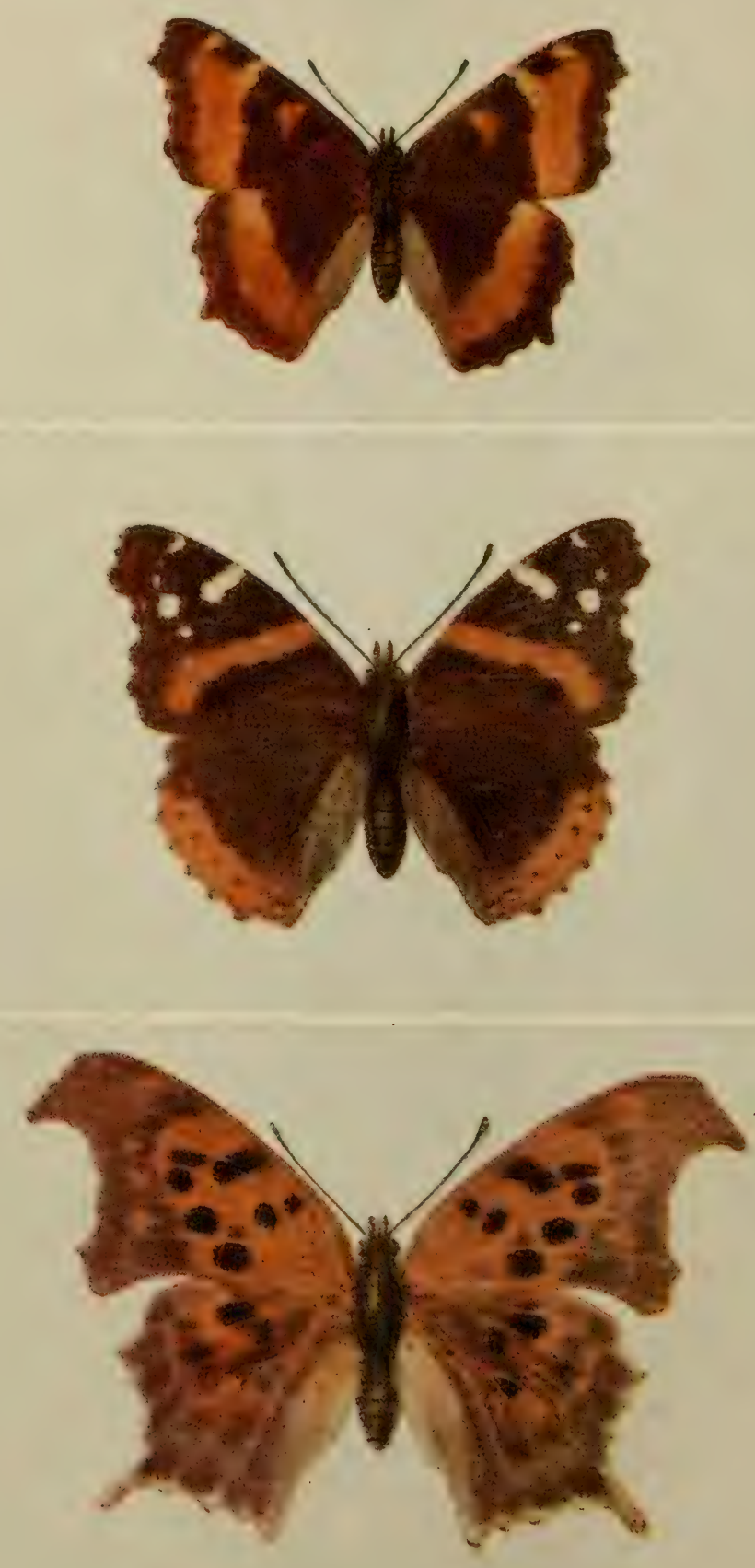

THREE ANGLE-WINGS : UPPER SURFACE

The American Tortoise-shell (see page 182)

'The Red Admiral (see page 160)

The Violet-tip (see page 150) 


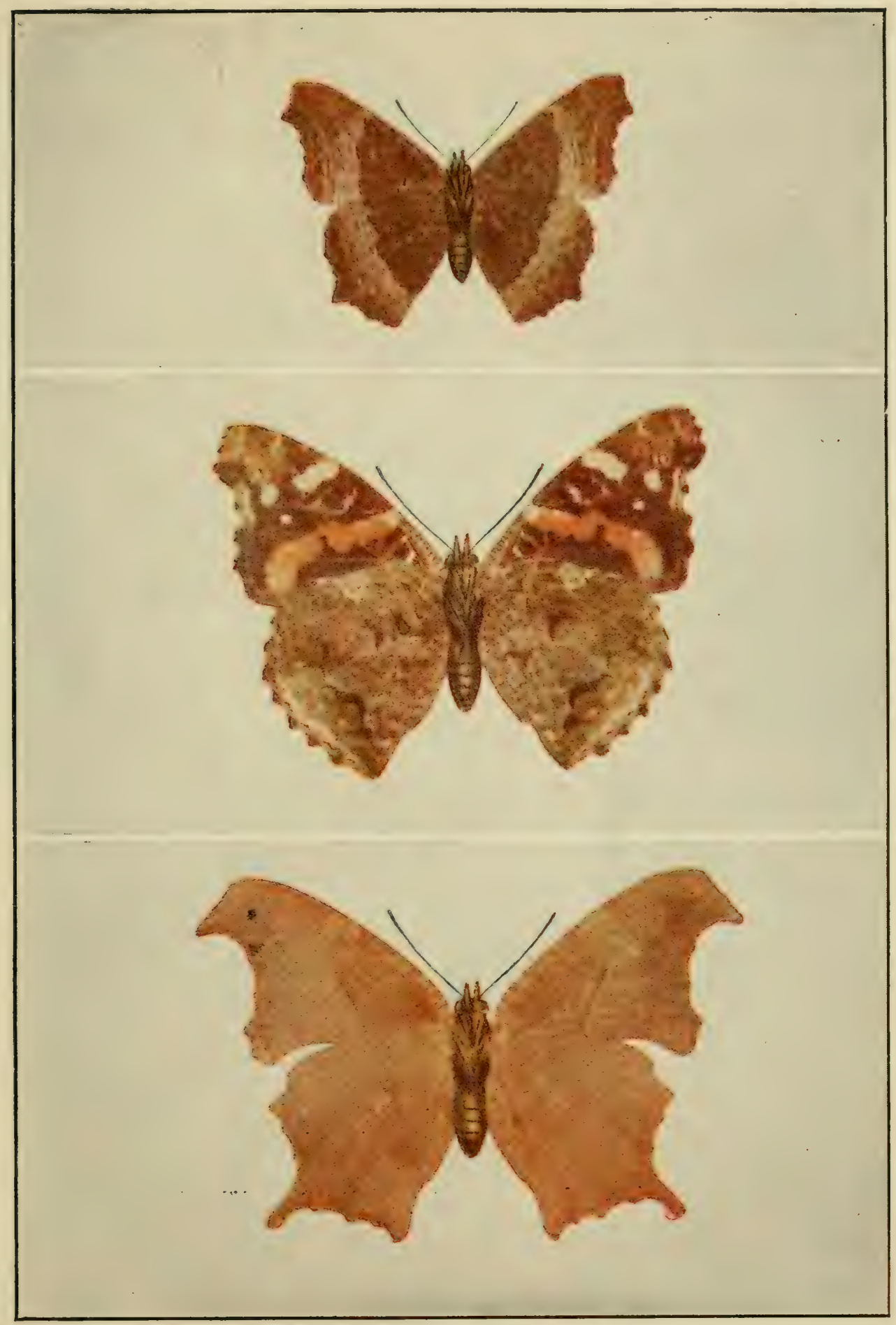

THREE-ANGLE WINGS: LOWER SURFACE

The American Tortoise-shell (see page 182)

The Red Admiral (see page 160)

The Violet-tip (see page 150) 


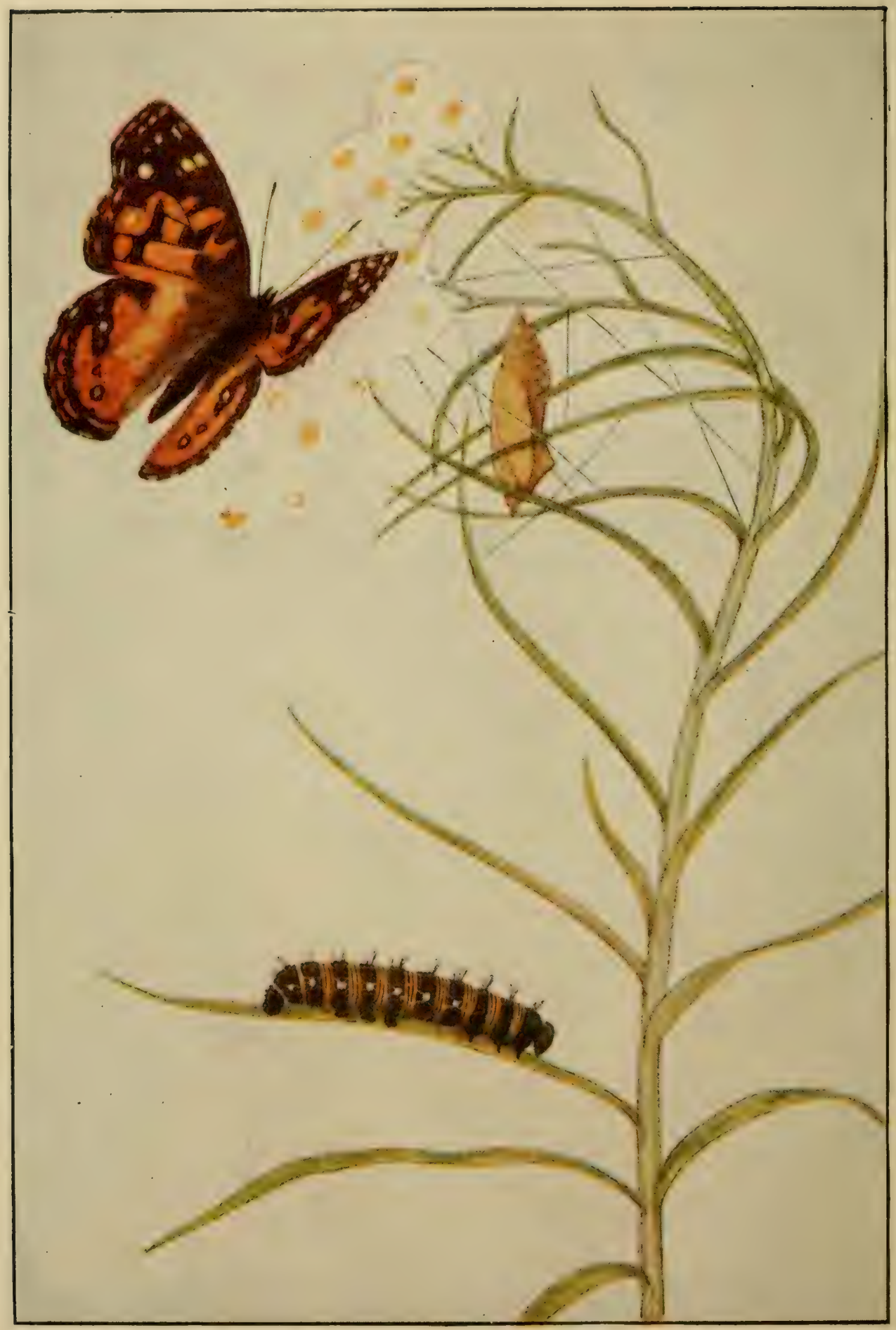

From a drarving by W. I. Beecroft

See page 163 THE PAINTED BEAU'TY

Caterpillar, chrysalis, and butterfly 


\section{THE TRIBE OF THE ANGLE-WINGS 161}

it lacks the winged seeds of the latter it is even more effectually protected from the attacks of vertebrate enemies on account of its irritating hairs. At any rate, nettles of various kind are widely distributed over the earth's surface, and consequently it is not surprising that the Nettle Butterfly or Red Admiral should be almost as cosmopolitan as the Thistle butterfly. The two species are closely related in structure and habits and the life-history of the one is very similar to that of the other.

About the middle of May one may see in open fields and along sunny highways these Red Admirals flitting from flower to flower, or stopping occasionally upon green leaves in search of opportunities to lay their eggs. Should you observe them closely you might notice that some of them seemed frayed and worn while others seemed perfectly bright and fresh.

\section{The Life-story}

Late in May and early in June these butterflies deposit their eggs upon the leaves of the nettles. As a rule only one or a few eggs are laid on a leaf, but when the butterflies are abundant many leaves upon the plant may become infested. About a week later the egg hatches into a larva, which is likely to eat more or less of the empty shell before crawling up the stem of the plant to the unfolding buds at the top. Here it makes its first nest by webbing together the still closed upper surface of a leaf not yet unfolded. It is thus able to furnish itself with protection from weather and enemies, as well as an abundant supply of succulent food. It remains in this first home about a week, then it casts its skin, still within its protection, and stays until it has recovered after the 
process. It now migrates to another larger, expanded leaf where it very cleverly proceeds to construct its second nest. In order to do this it weakens the midrib at the base of the leaf by biting nearly through it. Then it cuts a hole in the blade of the leaf at the base in such a way that the margins are made to droop, so that they can be fastened together with silk to form a little tent. We thus have a tent-like nest hanging down from the stem of the leaf on the under side of which the caterpillar will find shelter, while near at hand is the green tissue of the inner surface of the leaf waiting to be eaten. This improvised tent serves as the home during this second stage of the caterpillar. Here also the second moult commonly takes place, after which the caterpillar migrates to a new leaf and constructs its third nest. The rest of the story of the caterpillar's life consists of similar chapters. After each moult a new tent is formed and even the chrysalis is often hung within the last one.

The eggs which were laid late in May develop into butterflies during July. These in turn lay eggs for the second brood of caterpillars most of which develop into butterflies late in August or early in September, but some of which apparently remain in the chrysalis stage unchanged throughout the winter, and mature as butterflies about the middle of the following May. This is the explanation of the fact mentioned at the beginning of this discussion that one can find late in spring and early in summer some butterflies which seem worn and frayed while others seem perfectly fresh. They are all the progeny of the midsummer brood of the previous summer, but some of them have been living as full-grown butterflies through eight long months of tempestuous weather, while 


\section{THE TRIBE OF THE ANGLE-WINGS 163}

others have just been disclosed from the protecting walls of the chrysalis.

The world-wide distribution of this butterfly is shown in the statement that it occurs throughout Europe, and in North America from Newfoundland to Cuba and Guatemala. It is a safe guess that it is found in practically all localities where nettles grow.

It is not alone the association between a butterify caterpillar and its host plant which has been brought about during the long ages through which one generation has been succeeding another, but there have been also many developments of similar associations between the caterpillars and their parasitic enemies. The Red Admiral is a good example of such a development. During its long growth as a species it has been exposed to attack by vast numbers of tiny foes which live at the expense of other insects. Several of these foes have found in the bodies of the caterpillars good opportunities for growth, so that now the Red Admiral, as a species, has to reckon with many enemies among these tiny parasites. The interaction between caterpillar host and uninvited parasitic guest has much to do with the great irregularity in the numbers of the butterflies. It is simply another example of that complicated struggle for existence, by means of which nature keeps ever a fairly even balance of her myriad forces.

\section{The Painted Beauty}

Vanessa huntera

One of the most interesting phases of the study of butterflies is to learn how often they take advantage in their 
life-history of any peculiarity of the food plant which has a protective value. The Painted Beauty is an excellent illustration of this. The caterpillar feeds upon the leaves of the common Everlasting or Gnaphalium. This is an abundant and widely distributed plant, found along roadsides and in fields and pastures. It is notable for the woolly covering on stems, leaves, and flowers - this dry, hairy surface being so evident that the flowers will apparently continue in blossom when they have dried, hence its common name Everlasting or, as the French call a similar flower, Immortelle.

(Sec plate, pege 161.)

The utilization of the hairs upon the leaves is begun by the mother butterfly when she lays her egg upon the upper surface, pushing it down among the hairs so that it is almost concealed. Should you be fortunate enough to find one of these eggs you would see that it is a small, yellowish green object, looking like a tiny barrel with several vertical ribs upon its surface. A few days after the egg is laid it hatches into a minute caterpillar that begins eating off the hairs where they are attached to the leaf, in such a way that it soon has a free space beneath a bunch of these hairs which it has more or less matted together by means of silken thread. The little caterpillar has thus provided for itself a protecting nest that effectually conceals it from birds or other enemies. It now begins feeding upon the succulent surface of the rather thick leaf, where it has removed the hairs. After several days of such feeding it moults, still under the shelter of its hairy covering. This process of moulting and feeding continues for two or three weeks, the caterpillar occasionally making a new covering as needed for its food supply.

The later nests are likely to be made by folding two or 


\section{THE TRIBE OF THE ANGLE-WINGS}

three leaves together, binding them with silken thread. The caterpillar in doing this takes advantage of the fact that the terminal leaves are vertical before they have spread out, so that it is a comparatively simple matter to make a little house by binding their edges together with silken threads. The larva feeds upon the inner walls of the house it thus constructs, and as it becomes larger the buds and blossoms are also utilized for food.

When the caterpillar is full grown it thus finds itself fairly well concealed within a very substantial sort of a home. Many of them have the apparent good sense to realize that this is as safe a place as they are likely to find for shelter during the period of the chrysalis. So the caterpillar makes the nest especially secure near the centre of what might be called the ceil ng and in this web it entangles its hind legs and hangs downward, preparatory to changing to the chrysalis. A few hours later the skin splits apart and is wriggled off, leaving the chrysalis hanging in place of the caterpillar. About a fortnight later the butterfly emerges and crawls at once to the outside of the nest, where it rests quietly while its wings expand and its tissues harden. Then it flies away in search of the nectar of thistles and many other flowers which it visits freely.

This Painted Beauty is a wonderful example of harmonious coloring. The general tone of the upper surface of the wings is fulvous, with some distinct white markings on a blackish background at the outer angles of the front pair. There is also more or less blackish shading on the base and margin of all the wings with an indistinct row of about four dots, more or less run together, near the margin of the hind wing. The under surface of the wings is even 
more beautiful than the upper, and furnishes a striking example of flower-picturing. There is a little fulvous background near the middle of the front wings, but the rest of the surface is spotted and striped with blotches and circles of gray and brown in a most intricate design. On each front w ng near the outer angle are three indistinct eye-spots in a row, and on the outer half of each hind wing there are two bull's-eye circles, one smaller than the other, which form the most conspicuous feature in the marking of the insect.

When full grown the caterpillars are a little more than an inch long with a general color of velvety black, marked with fine yellow lines and more or less covered with bristly spines. There is also a distinct row of whitish spots along each side beginning a short distance back of the head.

This is a widely distributed butterfly, occurring from Canada to the Southern states and beyond. In most northern regions it seems to be two-brooded, the butterflies commonly hibernating as adults; but sometimes the winter is passed in the condition of the chrysalis. Along its southern range there are three and perhaps four broods each year.

\section{The Painted Lady or the Cosmopolite}

\section{Vanessa cardui}

Our story of this beautiful butterfly ought really to begin with that of one of the most successful plants in the world. Now a plant is successful from its own point of view when it is able to multiply abundantly in many different sorts of situations and to spread easily over a large area. The 


\section{THE TRIBE OF THE ANGLE-WINGS 167}

plant I have in mind is the thistle, which from time immemorial has been one of the commonest neighbors of man. It is found over the whole habitable globe, as well as in many parts which are scarcely habitable. It has many advantages in its struggle for life. The roots penetrate deeply into the soil; the thickened, spiny leaves are so protected by their juices and their spines that they are molested by very few enemies; the flower stalks are also clothed in a similar armature; and the great heads of flowers are surrounded with prickly involucres that generally prevent their being eaten by browsing animals or even by phytophagous insects. The brightly colored blossoms are abundantly provided with nectar and pollen, and they attract great numbers of bees, moths, and butterflies, in order to bring about cross-fertilization. But all of these advantages are of little significance so far as wide distribution is concerned, compared with the feathery seeds which are produced in such abundance and so generally scattered by the slightest breath of wind that the word thistle-down has come into general use to express a lightly moving object. These airy seeds have been riding on the wings of the wind all over the surface of the earth for untold millions of years. Doubtless during severe storms they may be carried thousands of miles, and it is easy to think that one of them might readily go half-way round the world before it found a resting place. Wherever such a seed alighted and found the condition of a moist soil and slight protection, it would be likely soon to spring into growth and to start anew the development of its ancient race.

The thistle, however, has not been entirely unmolested during its aeons of existence. There has been developing 
along with it one of the most beautiful of our butterflies which has received various scientific names and the common name of the Painted Lady, although it is also often called the Thistle Butterfly and the Cosmopolite, which latter title perhaps is to be preferred. This butterfly, however, can scarcely be considered a troublesome enemy of its host plant, for it is seldom sufficiently abundant to injure the thistle appreciably. The relation between the two is rather suggestive of that mutual toleration by which two living things develop together with advantage at least to one and without serious disadvantage to the other. The universal distribution of the food plant has led to a like distribution of the butterfly. Consequently the Thistle butterfly has long been recognized as the most cosmopolitan species of its group. (See plate, page 176.)

Aside from the wide distribution of its food plant and possibly correlated with it through the diversity of climatic conditions under which the insect has developed, this butterfly is remarkable for its powers of flight. Many instances are known where it has been taken at sea long distances from land. This is due not only to the propensity of the individual for taking aërial journeys, but also to the fact that this is one of the butterflies which has the instinct to congregate in swarms and to migrate long distances when thus congregated. In 1879 such a flock started from Africa and migrated to Europe.

One of the most remarkable things about this butterfly is our ignorance of what it does with itself in winter. American entomologists are agreed that the adult butterfly hibernates, but where it does so seems not to be known. Here is an excellent opportunity for some young naturalist to go scouting, hunting in board piles, under 
loose bark, or with a flashlight searching the interiors of hollow trees to find between November and April living specimens of this butterfly. Such a discovery would be a real service to science and should at once be made known through some scientific journal. In Europe there seems to be a belief that the insect hibernates partially at least in the condition of the chrysalis.

\section{The Life-story}

While we may not know just where the butterflies have been throughout the winter, we do know that in southern New England they begin to be seen in fields and along roadsides about the middle of May. Many of the specimens then have a ragged appearance which is a pretty good indication that they came from the chrysalis the fall before and have been lying concealed through all the weeks since. These butterflies lay their small greenish, barrelshaped eggs on the leaves of the thistle. The mother butterfly chooses the location rather carefully and deposits only one egg upon a leaf. The butterflies continue thus to visit flowers and to lay eggs until about the middle of June when apparently they perish.

About a week after the egg has thus been laid, it hatches into a small spiny caterpillar which does not take the trouble to devour its egg shell as so many other caterpillars do. Instead it crawls around to the lower side of the leaf and gnaws off enough of the silken surface of the leaf to furnish material for making a webby covering, the leaf particles being woven together by threads from the caterpillar's mouth. In this way the little creature soon provides itself with a snug enclosure which serves it as a temporary home. It remains in this home much of the 
time when not eating, going out occasionally to feed upon the green tissues of the adjacent parts of the leaf.

This first home of the young caterpillar, made as it is as a flat blanket upon a flat surface, can be used only by a very small larva. Consequently, the caterpillar soon finds these quarters too cramped and it deserts them to make a new home with larger space. This second nest is commonly made on the upper surface of a leaf, the edges of which are likely to be more or less drawn together and other supports connected from other leaves or a near-by stem. The caterpillar continues to use this nest number two as a place for remaining when not feeding and for protection during the process of moulting. But even this larger nest is likely to be given up about the time the caterpillar becomes half grown, and a third nest is begun in the upper part of the plant. This is likely to be very commodious, its walls being made of leaves or stems bound together by a silken web. Within this the caterpillar completes its growth, going out and in through one or more doors when it wishes to feed. Sometimes it even remains within this nest during the process of changing to the chrysalis, hanging downward from the upper part in much the same way that the caterpillar of the Painted Beauty butterfly does. In case it leaves the nest when fully developed it generally finds a place near by in which to pupate.

About ten days after the caterpillar has changed to a chrysalis it changes again to the adult butterfly. In southern New England these butterflies appear about the middle of July and lay eggs soon afterward, these eggs hatching into butterflies that change to chrysalids and change again to butterflies late in August or early in Sep- 


\section{THE TRIBE OF THE ANGLE-WINGS 171}

tember. This autumn brood doubtless furnishes the butterflies that will be seen upon the wing the following May, so that it is pretty certain that they must find some shelter in which to pass the intervening months.

The full-grown caterpillar of the Thistle butterfly is about one and a quarter inches long and of a general yellowish color, more or less marked with blackish as well as with paler lines of color. There are many transverse rows of spines along the segments, each yellowish spine having a circle of smaller ones at the top.

Notwithstanding its fondness for thistles, these caterpillars occasionally feed upon various other plants. One might readily expect them to be able to live upon other composites upon which they are found, but it seems a bit strange that they should be recorded as being "especially fond of mallows."

\section{The Mourning-cloak}

\section{Vanessa antiopa}

One of the most scholarly students of American insects has happily called the butterflies "the frail children of the air." It seems a fitting term for creatures so ethereal that they are readily wafted on the wings of the slightest breeze and so delicate in structure that they are likely to be sadly mutilated by the lightest touch of human hand. Such creatures one would say belong to regions of perpetual summer and have no place in the blizzard-swept winters of our Northern states.

Yet if one goes into the snow-clad woods during one of the midwinter thaws one is likely to see in every open glade several dark-colored butterflies flitting from tree to tree, or 
resting with expanded wings in the sunniest spots. These butterflies obviously have endured the coldest weather and if they are to survive until another season must continue to endure still more. This species is commonly called the Mourning-cloak butterfly-not a particularly happy name for so seautiful an insect. In England it has the more suggestive title of Camberwell Beauty, and country boys are said to call it the Yellow Edge butterfly. Its general life-story has already been told on pages 112-115.

The caterpillars of the Mourning-cloak butterflies are restricted to comparatively few food plants. In regions where they are not especially abundant, they are likely to be found upon willow, poplar, or elm. In general, as many observations indicate, they are as likely to be found upon any one of these food plants as upon either of the other two; but in certain localities where they become especially abundant it seems that they are more likely to occur upon the elm. On this account they have been called the Spiny Elm caterpillars. There is considerable evidence to show that they prefer the American elm to other species of the genus, although in the case of willow and poplar there seems to be little if any preference as to the species.

Miss Caroline G. Soule has seen the butterflies depositing their eggs upon the white and canoe birch, and it has been recorded as feeding in Labrador and Europe upon a species of birch. There is one record of the caterpiliars having been found feeding upon the hackberry, and also of their having fed greedily upon the leaves of rose bushes, and still another of their having almost defoliated a pear tree. Linden and nettle are also included in the European lists of the food plants of this species. (See plates, pages 14.5, 176.)

It is evident, however, that all of these, except the three 
first named-willow, poplar, and elm-are to be regarded as exceptional cases, and that the normal food of the species is the foliage of a plant belonging to one of these three genera.

It has generally been supposed that this species is double-brooded in central and southern New England, the butterflies of the first brood appearing early in July. These are said to deposit eggs which hatch into caterpillars that mature into butterflies early in September. These butterflies live through the winter, laying eggs the following spring.

It is very probable that as far north as southern New Hampshire the species is commonly single-brooded. During one season when the caterpillars were unusually abundant, a very careful watch was kept for the second brood in New Hampshire and Vermont by several competent observers. Only one colony of caterpillars was found and this was at Durham in the southern part of New Hampshire near the seacoast. Consequently, it seems safe to conclude that in northern and central New England, at least, a single brood is the rule rather than the exception. This involves the conclusion that the butterflies seen upon the wing early in autumn are the same ones that developed in July, and that these same butterflies remain alive through the winter and until, in the following May, they lay their eggs. Thus there is a period of ten months of existence in the butterfly state, an extraordinary length of time for a butterfly to live.

To a large extent the butterflies disappear in August, and the question arises as to what becomes of them. Our observations lead to the conclusion that they go into summer quarters similar to those which they seek out for 
winter shelter. Apparently they fly about for a few days after coming from the chrysalis and then retire to cool woods, where under the side of a log or beneath the loose bark of a dead tree they settle down and to all appearances go to sleep. The instinct to remain quiet is very strong in these butterflies. In taking the accompanying photographs, I found that even shortly after coming from the chrysalis the butterflies when disturbed would fold their wings with the antennae between them, and drawing the legs against the body would lie quietly on their sides for a long time. These same butterflies would also hang downward from a limb by the hour in the hibernating position as shown in plate opposite page 32.

In the cooler weather of early autumn, the butterflies come from their retreats and fly about in the sunshine. They are especially likely to be seen along the borders of woods or in open glades. At this time they love the sunshine, and will settle in a sunny place to bask in it.

\section{Going into Winter Quarters}

When the warm days no longer tempt them abroad, the Mourning-cloaks seek shelter in many sorts of situationsunder loose bark, in hollow trees, under culverts and bridges, in woodpiles, in crevices of rocks, or alongside logs lying on the ground. In such retreats they remain until the sunshine of spring again calls them forth.

Prof. G. H. Parker's observations indicate that these butterflies are very sensitive to changes of temperature, and he has seen the interesting action of the butterflies crawling into their hiding places, finding that this takes place each day after they had been sunning themselves. Thus he writes: 


\section{THE TRIBE OF THE ANGLE-WINGS}

"These butterflies remain during cool spring nights in places similar to those in which they hibernate in winter, viz., in openings in stone walls, in old out-houses, in openings under the bark of trees, etc. They retire to these places with considerable regularity, so that in the open woods, where dozens of individuals may have been seen flitting about, all may have disappeared a quarter of an hour later. I have watched their retreat with some care. On a clear afternoon in early April I took my stand in a woodland where many Mourning-cloak butterflies were on the wing. They continued actively flying about till approximately four o'clock, when I began to notice a diminution in their numbers. By a quarter past four not a butterfly was to be seen. During the fifteen minutes from four o'clock on I followed two to their hiding places. One alighted on the front of a fallen tree and without expanding its wings crept immediately into a large crack in the bark. The second settled on a stone fence and crept into a hole between some loose stones. The period during which this occurred was marked not so much by a diminution of light as by a rapid fall of temperature."

That the habit of lethargy in cold and of resting upon the bark of trees is practically universal with this species is shown by a statement quoted by H. G. Adams in his book, "Beautiful Butterflies," published in England in 1871. The writer quoted says: "In a wood on the summit of the Drachenfels, when the wind was rather keen, I found numbers resting on the backs of fallen trees in a state of stupor. They made no attempts to escape and when thrown into the air their wings barely opened or flapping feebly eased their fall or enabled them to seek repose on the stem of a rotten trunk." 


\section{Its Rarity in England}

In many books this species is spoken of by its English name Camberwell Beauty. It is so called because it was first observed in the neighborhood of Camberwell in the county of Surrey, England. It seems that in that country it is a very rare species. This is a bit curious considering the fact that in America it is so extremely abundant. In his attractive little book quoted above, $\mathbf{M r}$. Adams begins the discussion of this species with this statement: "This is the crowning glory of the British butterfly collector's cabinet, and a happy man is he who gets a perfect specimen of an insect which is at once so rare and so beautiful." And later in the same discussion is this further statement concerning the scarcity of the species: "In neither the larva nor the pupa state has the insect been found, we believe, in this country where its appearance occurs, except just here and there a single specimen or two, at long and uncertain intervals. About eighty years ago it was seen in many parts of the kingdom and again in 1819 , but not since then although almost every year one or more specimens are taken or seen."

A curious fact in regard to the Mourning-cloak, as found in England, is that the border around the wings seems to be much more generally white than it is with us. J. O. Westwood in his book on British butterflies describes the margin as of a white or whitish color and other writers speak of the same fact. Kirby in his "Butterflies and Moths" makes this comparative statement: "The border is whitest in British specimens, and perhaps yellowest in American ones." He speaks of it also as one of the rarest British species. It is sometimes called by the 


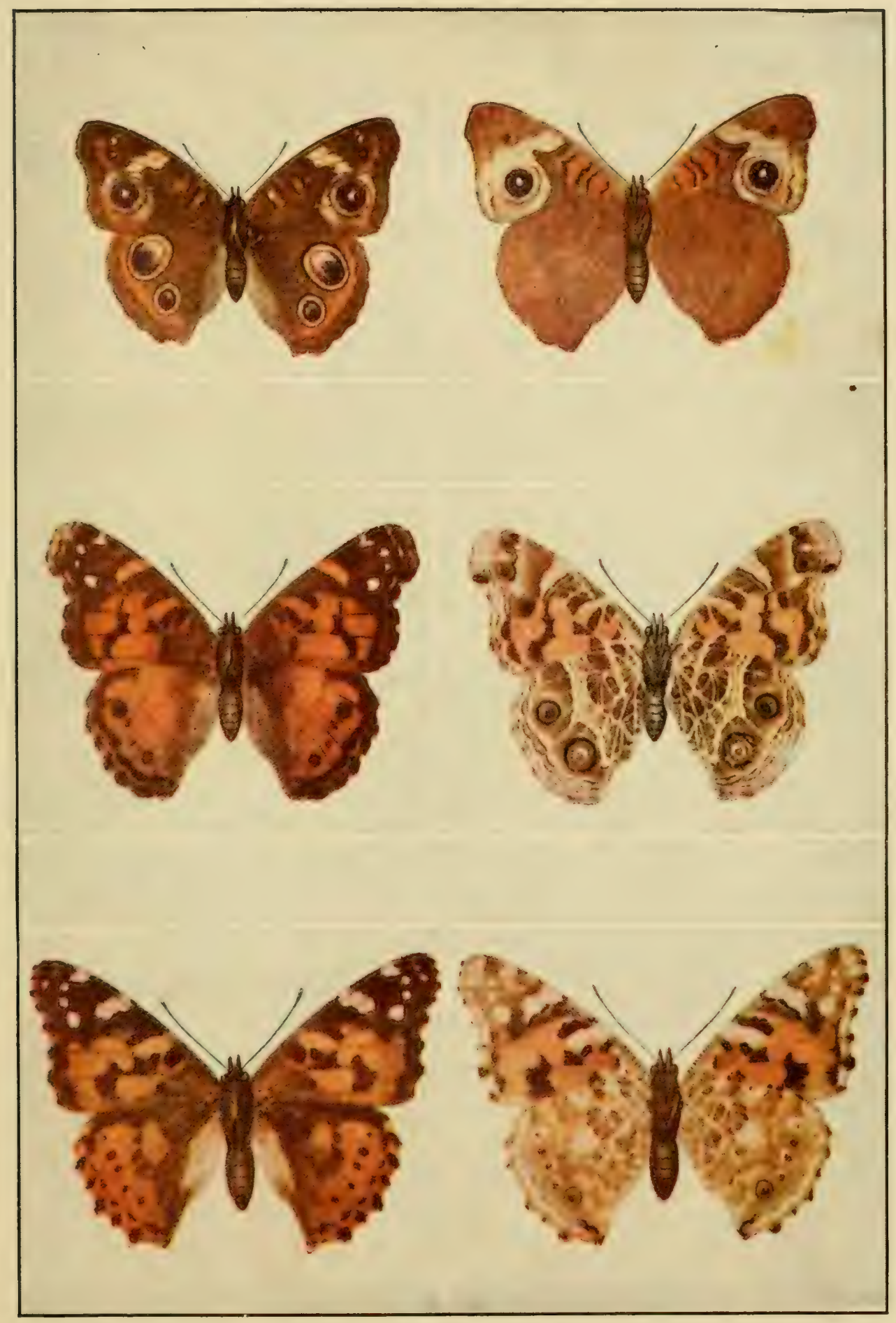

THREE MORE ANGLE-WINGS

Upper surfaces at left; under surfaces at right, slightly reduced

The Buckeye (see page 188)

The Painted Beauty (see page 163)

The Cosmopolitan (see page 166) 


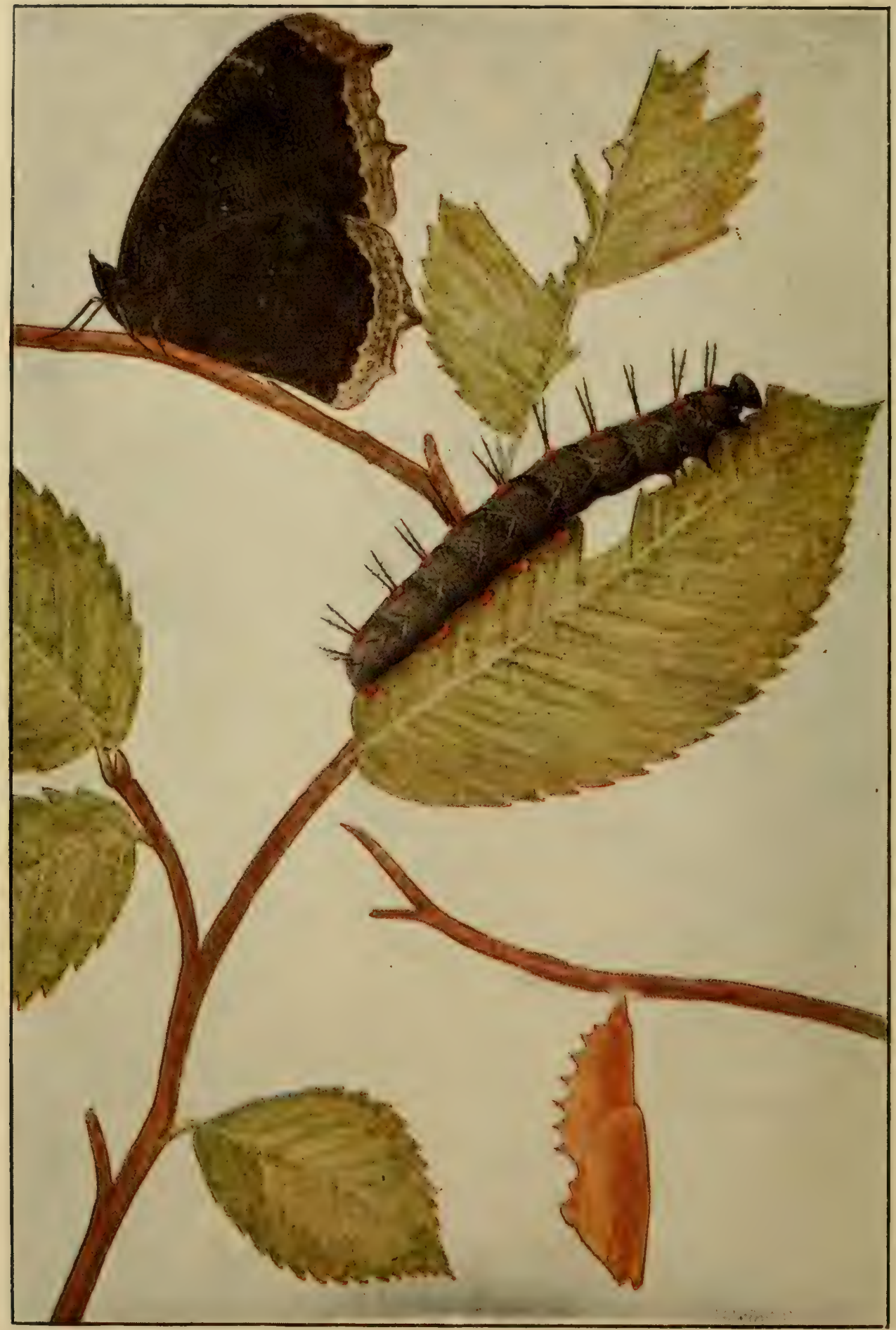

From a drawing by W. I. Beecroft

See pages 112.1\%1

THE MOURNING-CLOAK

Caterpillar, chrysalis, and butterfly 


\section{THE TRIBE OF THE ANGLE-WINGS 177}

common name the White Border and also occasionally the Grand Surprise, appellations which bear out what has been said above both in regard to the color of the border and the rarity of the insect.

The Mourning-cloaks subsist upon a considerable variety of liquid food which they suck through their long tongues. In spring, when they first come from their winter quarters, they visit the stumps of recently cut trees and suck the exuding sap, a habit which they continue whenever opportunity offers. Mr. W. F. Fiske has noticed that they commonly sip the sap of maple twigs where the squirrels have gnawed the bark. A little later they visit the willow catkins to suck the nectar secreted by these blossoms, and still later they hover about the delicate blossoms of the mayflower, or trailing arbutus, for a similar purpose. Probably many other flowers are thus rifled of their sweets, although this butterfy seems to be a less regular visitor to flowers than are many of its allies. A little later, when the aphids, or plant-lice, have become sufficiently abundant so that the so-called "honey dew" is to be found upon the infested shrubs, these MIourning-cloaks sometimes sip the liquid sweet from the surface of the leaves. In April and May they occasionally visit the flowers of moosewood, and later in the season have been observed upon the blossoms of the common milkweed. From the time the early apples ripen these butterflies may often be seen beneath the orchard trees, sipping the liquids of the fallen and decaying fruit.

\section{The Parasites of the Eggs}

One fine spring morning I came upon a Mourning-cloak depositing a cluster of eggs upon a willow twig. She was 
so busily engaged that I was able to draw near and watch the operation for some time before she flew arway. As soon as she was gone I was much interested to see a tiny parasitic fly running eagerly over the newly laid eggs, and this fly also was so busily interested in her work that I was able to cut the twig off and sit down to observe at leisure through a lens the actions of the insect. I dictated to a companion my notes of these observations and so was able to get rather a complete record of the process of oviposition.

The tiny fly would stop over one of the butterfly eggs, holding its body vertical with the hind legs far back and the other legs so straightened out as to hold the front of the body high up. Then it would insert its tiny ovipositor through the egg shell and proceed to deposit an egg of its own inside of the larger egg of the butterfly. At least it seemed a safe assumption that this was what happened although of course it was impossible to see the smaller egg at the time. While thus engaged the antennae of the tiny fly were bent directly downward to the egg beneath. In about a minute the fly withdrew its ovipositor and after running around for a few seconds again settled upon another egg and repeated the operation. Then it tried again on a third egg, after which $\mathbf{I}$ got out my watch and began timing the process. These are the results in the case of the next dozen eggs that were laid. It required:

\begin{tabular}{|c|c|c|c|c|c|c|c|c|c|c|}
\hline \multicolumn{6}{|c|}{94 sec. to lay egg No. 4.} & \multicolumn{5}{|c|}{ Then fly moved around $26 \mathrm{sec}$} \\
\hline 120 & 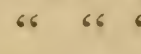 & & 66 & “ & 5. & “ & " & “ & “ & 27 “ \\
\hline 83 & “ & 66 & 66 & “ & 6. & 66 & 66 & 66 & 66 & 20 \\
\hline 92 & " & " & “ & “ & 7. & " & "6 & 66 & “ & 22 \\
\hline 7 & 6i & 6 & 66 & " & 8. & 66 & 66 & "6 & “6 & $40^{\circ 6}$ \\
\hline
\end{tabular}


$90 \mathrm{sec}$. to lay egg No. 9. Then fly moved around $42 \mathrm{sec}$.

\begin{tabular}{|c|c|c|c|c|c|c|c|c|c|}
\hline 102 & " 6 & & & “ 10. & 66 & 6" & 66 & 66 & 15 \\
\hline 120 & “ & “6 & 66 & “ 11. & "6 & “6 & 66 & 6 & 21 \\
\hline 120 & 66 & “" & s6 & " 12. & “ & 66 & "6 & ، & 18 \\
\hline 60 & "๘ & " & "s & " 13. & "6 & "6 & 66 & 66 & 25 \\
\hline 120 & "๘ & "6 & "6 & " 14 . & "s & "، & $6 s$ & "6 & 25 \\
\hline 60 & "6 & 66 & 66 & " 15. & 6 & 66 & 66 & 66 & 50 \\
\hline
\end{tabular}

It thus required an average of about two minutes per egg for the laying of these fifteen eggs. I then caught the little fly and sent her to Dr. L. O. Howard, our greatest authority on this group of insects, to learn the name of the parasite. He identified it as Telenomus graptae, a wellknown parasite of the eggs of the Mourning-cloak and related butterflies.

The most interesting thing about this observation was the fact that the little fly had apparently begun its operation before the mother butterfly had finished laying her cluster of eggs. There were thousands of willow twigs in the immediate vicinity. How did this tiny creature arrive at this particular place at the particular moment when from its own point of view it was most needed? Had it been riding around upon the body of the butterfly waiting for the time when she should lay the eggs? Or was it attracted to them from somewhere in the immediate vicinity? That this early arrival probably takes place generally is indicated by the fact that a similar observation had been made in the White Mountains by Prof. C. W. Woodworth.

The history of the egg parasite after the laying of the egg seems to be comparatively simple. It soon hatches. into a tiny larva that develops within the shell at the ex- 
pense of the contents. It finally changes to a pupa which in turn changes to the little fly that gnaws a hole through the egg shell and emerges to the outer world.

\section{The Parasites of the Caterpillars}

After hatching from the egg, the Mourning-cloak caterpillars are also subject to the attacks of various parasites. One of these is quite minute, not a great deal larger than the egg parasite. It is a tiny four-winged fly which deposits many eggs in a single caterpillar. The eggs hatch into tiny maggots that grow at the expense of the caterpillar, finally killing it and changing to four-winged flies again. As many as $\mathbf{1 4 5}$ of these parasites have been known to emerge from a single dead caterpillar. These little flies are called Chalcids by entomologists.

There is still another group of four-winged flies, some of which attack the Antiopa caterpillars. These are much larger than the Chalcid flies and are called Ichneumon flies. In the case of these, only one or two parasites develop in each caterpillar or chrysalis.

In addition to these various four-winged flies, there are certain two-winged flies, called Tachinid flies, that develop at the expense of the caterpillars. In New Hampshire, during recent years, these appear to have been the most abundant parasites of these insects. An egg is laid on the slin of the caterpillar by a two-winged Ay, similar in general appearance to the figure below. The contents of this egg shortly develop into a tiny grub that burrows through the egg shell and the skin of the catcrpillar into the inside of the body. Here it remains, absorbing the body substance of its host and gradually increasing in size. In a few weeks it becomes fully developed in this 
grub state. By this time the caterpillar has become sluggish from the effects of the parasite. If the branch upon which it feeds is disturbed, the other caterpillars are likely to crawl away, but the enfeebled victim remains in its place.

Shortly after becoming full grown, the Tachinid grub breaks through the skin of the dying caterpillar and, falling to the ground, changes to a peculiar pupa; the outer skin of the grub turns

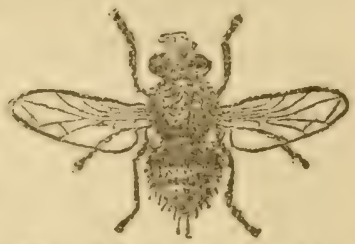

Tachinid Parasite. (Slightly magnified.)

brown and becomes hard, forming a protective covering for the body inside. A week or two later the insect undergoes another change and emerges as a two-winged Tachinid fly, like the one that laid the egg some weeks before.

\section{Other Enemies}

Besides those insects that develop on the inside of the bodies of these Antiopa caterpillars there are other insect enemies which attack them from the outside and devour them bodily. The most notable of these, perhaps, is a large beetle commonly called the Caterpillar Hunter; it is known to entomologists as Calosoma scrutator. This is a very active insect, with large strong jaws, that runs rapidly about in search of victims. In some cases it has been observed while destroying many of the Antiopa larvae.

In the Southern states a common reddish wasp-a species of Polistes - has also been observed attacking these caterpillars, and there are probably various other insects that destroy them, although definite observations showing this have not been recorded. 
The Antiopa caterpillars are such spiny creatures that comparatively few birds attack them. They are devoured, however, by the two species of cuckoos-the yellow-billed and black-billed-and it is probable that they are sometimes killed by Baltimore orioles and various other birds. They are also greedily devoured by toads, but of course they do not often come within the reach of these useful animals.

Even the adult butterflies of this species have to be on the lookout for enemies. During the long months of their life many of them probably succumb to the attacks of birds or other creatures. I have seen but one such tragedy. While riding along a country highway with a bird-loving friend one spring day we saw a male Maryland yellow-throat flit by with a Mourning-cloak in his mouth. The bird lit on a fence, from which I startled him so that he dropped the butterfly, a worn and faded, half-dead specimen. The places where the bird held the insect were indicated by missing pieces of the wings.

\section{The American Tortoise-shell}

\section{Aglais milberti}

This beautiful butterfly is one of the most distinctive of all our species. It is of moderate size, its wings rarely expanding more than two inches, and it has sufficiently irregular outlines to indicate its relationship with the Anglewings. The most striking feature of the upper surface is the broad band of orange-brown extending clear across both wings a little inside the border. The remaining surface is a darker brown marked with two orange-brown 


\section{THE TRIBE OF THE ANGLE-WINGS 183}

spots near the front margin of each front wing and having scattered iridescent scales which show plainly under a lens. The suggestion of the coloring of a tortoise-shell is easily seen in these rich brown tones. The under surface is a wonderful illustration of protective coloring. With wings closed and resting against the bark of trees or lying beneath the trees among fallen leaves, it would require a keen eye to detect the insect. (See plaies, pages 160-161.)

The American Tortoise-shell is distinctly a northern species. North of latitude forty-three degrees it seems to occur practically from ocean to ocean, extending far up to. ward the arctic region. It is commonly found in British America as far north as Fort Simpson in latitude sixty-one degrees. There are specimens in the British Museum collected by the explorer Ross in arctic America, and there are many in our own National Museum collected in the Hudson Bay region by various American explorers. In New England the species is abundant at times in New Hampshire, Vermont, and Maine. In the vicinity of New York City and Buffalo, New York, it is rather rare. And south of this latitude it is found chiefly at the higher elevations in mountainous districts. As a rule it is likely to vary in numbers from year to year, sometimes being extremely abundant while more commonly it is rather rare. These are the same sorts of fluctuations that we find in the case of the Mourning-cloak, the American tent caterpillar, and various other insects whose larvae live in colonies. The variation is probably due to the fact that when the caterpillars become unusually abundant they become correspondingly conspicuous and so provide a shining mark that is soon discovered by their insect enemies or by various fungous diseases. 


\section{The Story of Its Life}

In its manner of laying eggs this butterfly differs from most others. The great majority of our familiar species lay their eggs one in a place or possibly two or three near together. Some species deposit several in a group, while some, like the Mourning-cloak, may lay two or three dozen in a cluster. Very few, however, deposit hundreds in a bunch. Two of these are the Baltimore and this American Tortoise-shell. In the case of the latter the eggs are loosely laid, hundreds together, upon the leaves of the common stinging nettle. Probably each female can deposit six or eight hundred eggs. In less than a week the eggs hatch into minute blackish caterpillars that feed upon the tender tissues of the leaf upon which they were born and then migrate together toward the top of the plant. In their habits they are quite similar to the caterpillars of the Mourning-cloak. As each walks it spins from its mouth a silken thread and the combined effect of hundreds of these threads is to make a noticeable silken web over the leaves. The caterpillars remain in colonies, feeding together from day to day and gradually denuding the upper branches of the nettle plant, leaving an unsightly silken web as a memento of their presence. This webbing is very suggestive of the similar result left behind by a colony of Mourning-cloak caterpillars upon the twigs of elm or poplar.

When about half grown these caterpillars are likely to scatter more or less in accidental groups which may make small shelter tents from the larger leaves. In each little nest there may be four or five or more of the dark-colored caterpillars. From these shelter tents they sally forth to 


\section{THE TRIBE OF THE ANGLE-WINGS 185}

feed upon the adjacent leaves and a little later become full grown as caterpillars. Each now wanders away and finding such shelter as it is able to, spins a button of silk and becomes a chrysalis. It remains in this condition but a short time before it emerges again as the beautiful butterfly.

This species is commonly reputed to have three broods a year, hibernating both as a butterfly and as a chrysalis. It has been suggested, however, by Mr. W. F. Fiske, one of our most painstaking entomologists who has studied the butterflies of New Hampshire for many years, that it is more probably double-brooded with a period of aestivation during the later weeks of summer. This seems a very probable condition and it is to be hoped that some observer will make such a careful study of this species as to settle the point definitely.

In the case of many butterflies the distribution of the species coincides with the distribution of the food plant. This American Tortoise-shell, however, is perhaps the exception that may prove the rule, for its southward limit is far north of the southern range of the stinging nettle. Evidently, it is a species which has developed in adjustment to the cool climate of northern regions or high altitude, and it does not easily adapt itself to a warmer territory.

\section{The White-J Butterfly or Compton Tortoise}

\section{Eugonia J-album}

During bright days in March and April one is likely to find two kinds of butterflies on the wing in open glades of 
the woods. One is the familiar Mourning-cloak and the other is the Compton Tortoise-the latter generally much less abundant than the former. Both make the most of the brief periods of sunshine and quickly disappear when the sky is overcast.

The Compton Tortoise butterflies which are thus abroad in early spring have been in hibernation since October. They are helping to carry the species over from one season to another, and as the days become longer and warmer they appear on the wing more and more, seeking such liquid food as the field and forest yields during the days of early spring. The sap exuding from holes in bark made by woodpeckers, or from the tappings of the maple trees by man, the nectar of willow catkins, the moisture of roadside pools-these help to yield a precarious sustenance to these butterflies after their long winter fast. They remain upon the wing week after week, while spring slowly progresses in the northern regions they inhabit. When at last the leaves push out on their food trees-willow, birch, and elm-the females lay their eggs and then, having lived to what for a butterfly is a ripe old age, they die, after nearly ten months of adult existence.

Apparently the eggs are laid in clusters on the twigs, although this seems to be one of the many facts about butterflies awaiting observation by some careful student. The caterpillars feed together in small colonies but make no nest. They become full grown in about a month. They are then nearly two inches long with spinous, greenish bodies, striped with lighter lines. Some change to chrysalids about the middle of June and ten days later change again to butterflies, the first of which appear early in July while others continue to emerge for nearly a month. 
These butterflies may be seen rather frequently from midsummer on, visiting various flowers and sipping the juices from decaying fruits beneath the trees. At times they seem to disappear in August to reappear in October, a fact which has led some observers to suggest that there is a second brood. The caterpillars of this brood, however, have never been observed and a much more probable explanation has been made by Mr. W. F. Fiske who studied the butterflies of New Hampshire carefully for many years. He found that in the hot summer weather this butterfly goes into a seclusion similar to that of its winter rest-that is, it aestivates in summer and hibernates in winter. "The possibility that the October J-album did not represent a second brood," writes Mr. Fiske, "was rendered almost a certainty by repeated observations which failed to disclose a single specimen approximating in freshness to average August individuals, and the question of their whereabouts during the interim was unexpectedly answered one warm August day by my finding several snugly packed away under the shingles on an old roof. The theory of the aestivation of the butterflies of this group will explain a good many points hitherto obscure in the life histories of the other species."

In October these butterflies seek their winter quarters. finding them in woods and groves. Apparently they commonly rest upon the bark of the trunk as well as crawl into such crevices beneath loose bark as they can find. Here they remain through fall, winter, and spring, except when called into brief periods of activity by the unwonted warmth of the winter sunshine. Then in spring they come forth again to lay the eggs for the caterpillars of the new generation. 
The fresh butterflies are creatures of exquisitely modulated coloring. The name Compton Tortoise has reference to the rich brown tones of the upper wing surface, suggestive of those of fine tortoise-shell. In fresh specimens much of the surface, especially in the middle and along the front border, is overlaid with iridescent purple scales. Near the front outer angle of each of the four wings there is a distinct white spot, divided near the middle by a darker line of the vein running through it. The under surface is one of the best examples of mimicry of gray bark to be found in any butterfly. The tones vary considerably in different individuals, but in all the protection must be well nigh perfect when the insect is at rest with closed wings upon the bark of a tree. The striking angularity of the wing's border doubtless helps to conceal it, and the habit of dropping motionless to the ground when disturbed must also have protective value. Near the middle of each hind wing there is a small white $J$ which led to the specific name $J$-album.

This butterfly is essentially a member of the Canadian fauna. It ranges from far north in Labrador, British America, and Alaska, south as far as Pennsylvania, but toward its southern limit it occurs only on the higher elevations of mountains like the Alleghanies.

\section{The Buckeye}

\section{Junonia coenia}

Some genera of butterflies seem to belong almost exclusively to the north temperate regions, seldom occurring even in our Southern states. Others belong equally ex- 


\section{THE TRIBE OF THE ANGLE-WINGS}

clusively to tropical regions, seldom straying into the north. The Buckeye is an illustration of the latter group. The genus Junonia to which it belongs is essentially tropical, as it contains several species which are found throughout the tropics in both the Old and the New Worlds. In fact, this is apparently the only species which occurs north of the tropics. It has an extraordinary range, being found from Cuba to Massachusetts and from the Atlantic to the Pacific coasts. Toward the northern limits of its range it is very rare and one of the greatest prizes which the collector can obtain. In our Southern states it is an abundant and generally distributed butterfly and, as it hibernates as an adult and one group follows another throughout the season rather rapidly, it is likely to be taken at almost any time. (See plate, page 176.)

The mother butterflies select as food plants for the larvae various members of either the plantain or figwort families. They lay eggs, one in a place, upon the leaves of plantain, figwort, gerardia, and related plants generally near the tip of the leaves. Less than a week later these hatch into spiny caterpillars which feed upon the green substance of the leaves during the next few weeks. For the most part they eat between the veins leaving a ragged effect which may help in finding them. When full grown they change to chrysalids which hang straight downward and bear a general resemblance to those of the Thistle butterfly. Curiously enough, those chrysalids which are attacked by parasites take on a characteristic golden hue; although the normal healthy chrysalids are dark brown with a few touches of a decidedly lighter brown.

In its tropical home, where there is no winter period to interrupt its growth, this butterly doubtless continues to 
develop generation after generation without any break in the sequence. As the species goes north, however, there is necessarily such an interruption-in which case the winter seems commonly to be passed by the adult butterfly. In our Southern states there are commonly three or four broods each year, while in the northern parts of its range there is but one brood a year. In the South there is such an overlapping that all stages of the insect may be found at one time.

\section{Synopsis of the Angle-wings \\ I. The Polygonias}

The most angular of the Angle-wings are grouped in the genus Polygonia. They are characterized by having the outer margin of the front wings projecting in two places in a way to give an angular effect, and by having the hind or inner margin distinctly excised toward the outer end, so that this margin is curved rather than straight.

Violet-tip (Polygonia interrogationis or Grapta interrogationis). Expanse $2 \frac{1}{2}$ inches. Under surface of each hind wing marked by a silvery semicolon, made up of a dot and a crescent.

Hop Merchant (Polygonia comma or Grapta comma). Expanse 2 inches. A white comma with expanded tips on lower surface of each hind wing. Lower surface of all the wings mottled with brown.

Green Comma (Polygonia faunus or Graptafaumus). Expanse 2 inches. A white comma with expanded tips on lower surface of each hind wing. The lower surface of all the wings more or less mottled with green toward the margins 


\section{THE TRIBE OF THE ANGLE-WINGS}

Gray Comma (Polygonia progne or Grapta progne). Expanse 2 inches. A white comma with tips narrowed rather than expanded on lower surface of each hind wing.

\section{The Vanessids}

Our beautiful species of thegenus Vanessa may beknown by the long scales that make up the fringe on the wing margins, in alternate groups of black and white. There are also several white spots on the upper surface of the outer angle of each front wing.

Red Admiral (Vanessa atalanta, Pyrameis alalania or Cynthic atalanta). Expanse 2 inches. Upper surface of front wings blackish, marked with white spots on outer angle and a broad orange stripe across the middle.

Painted Beauty (I anessa Inuntera, Pyrameis huntera or Cynthic huntera). Expanse $2 \frac{1}{2}$ inches. Upper surface orange-brown with black, white, and blue markings. Lower surface of each hind wing with two large eye-spots, each extending across two veins.

Painted Lady or Cosmopolite (Vanessa cardui, Pyrameis cardui or Cynthia cardui). Expanse $2 \frac{1}{2}$ inches. Easily distinguished from the Painted Beauty by the four or more small eye-spots on the lower surface of each hind wing, each eye-spot being included between two veins.

\section{Other Angle-wings}

The other common Angle-wings are readily distinguished by the following characters:

Mourning-cloak (Euvanessa antiopa or Vanessa antiopa). Expanse $3 \frac{1}{2}$ inches. Easily known by the nearly black wings with creamy white borders.

American Tortoise-sheil (Aglais milberti or Vanessa 
milberti). Expanse $1 \frac{1}{2}$ inches. One of the smallest of the Angle-wings. Easily known by its small size and the broad orange band extending across the upper surface of all the wings just beyond the middle. Under surface dark mottled gray without distinct white markings.

Compton Tortoise (Eugonia j-album, Vanessa j-album or Grapta j-album). Expanse 3 inches. Best known by the straight line of the inner margin of the front wings and the white $j$ on the under side of each hind wing.

The Buckeye (Junonia coenia or Vanessa coenia). Expanse $1 \frac{3}{4}$ inches. Distinguished by the large eye-spots on the upper surface of the wings, one on each front and two on each hind wing. Eyes not hairy.

\section{THE TRIBE OF THE SOVEREIGNS}

No other small group of American butterflies has attracted so much attention as the species of the genus Basilarchia, which have been happily called the tribe of Sovereigns. These are rather large butterflies with rounded wings which are found in one species or another over practically the whole of North America. Some of them are of exceeding beauty and all of them present lifehistories of extraordinary interest. At least two of the species are the most notable examples of the mimicry of other butterflies that are shown in our fauna. They also present some extremely interesting problems for the study of natural hybrids and they illustrate in their development some of the most wonderful cases of adaptation to environment that have ever been found.

These butterflies may be considered from so many in- 


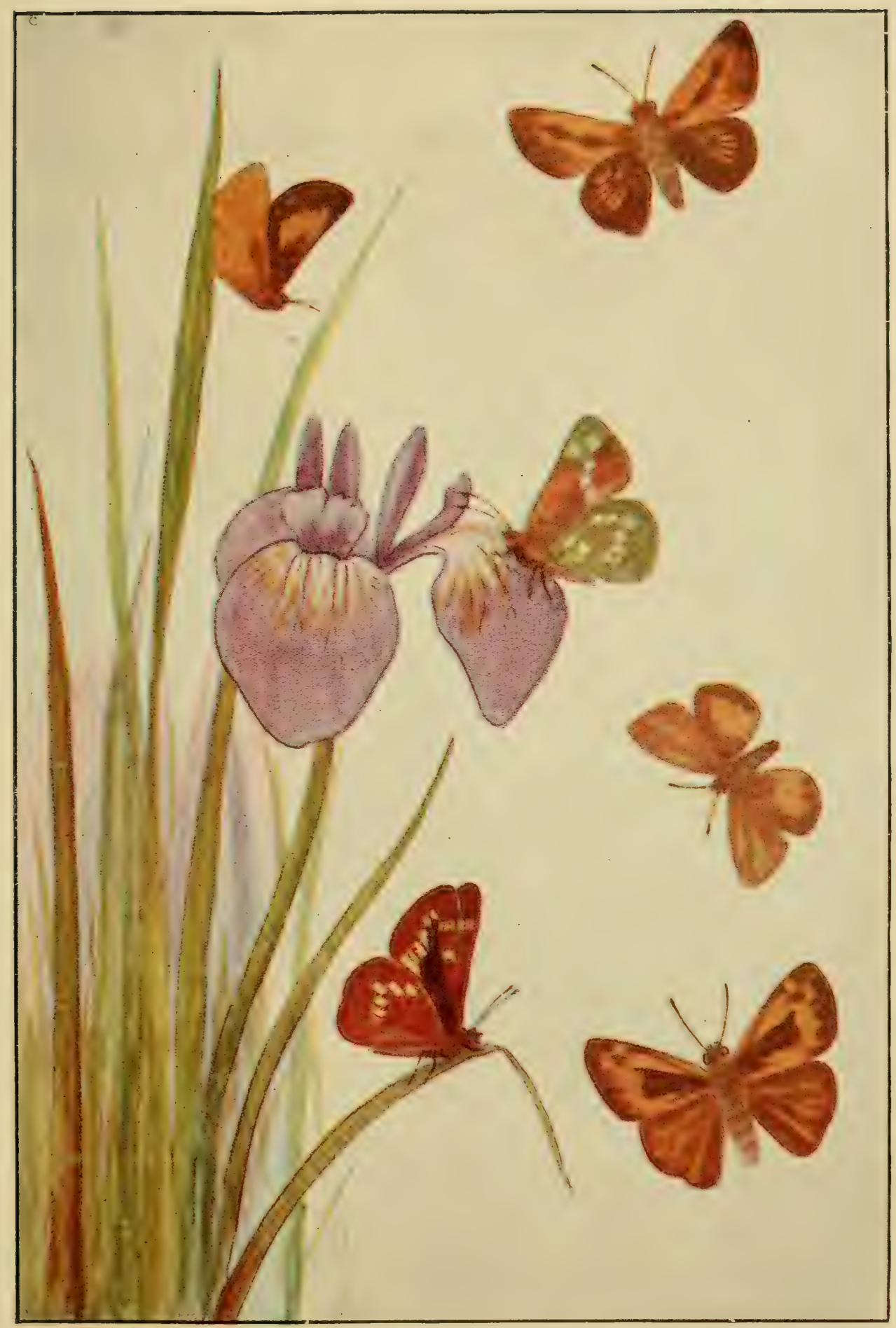

From a drawing by W. I. Beecroft

See pages 268-28\%

SOME COMMON SKIPPERS

The Long Dash, male, at top; the Vitellius Skipper, female, next below; the Canadian Slipper resting on iris flower in the middle; the Least Skipper, next below; Leonard's Skipper at rest on leaf, next; and the Sachem Skipper, male, at bottom 


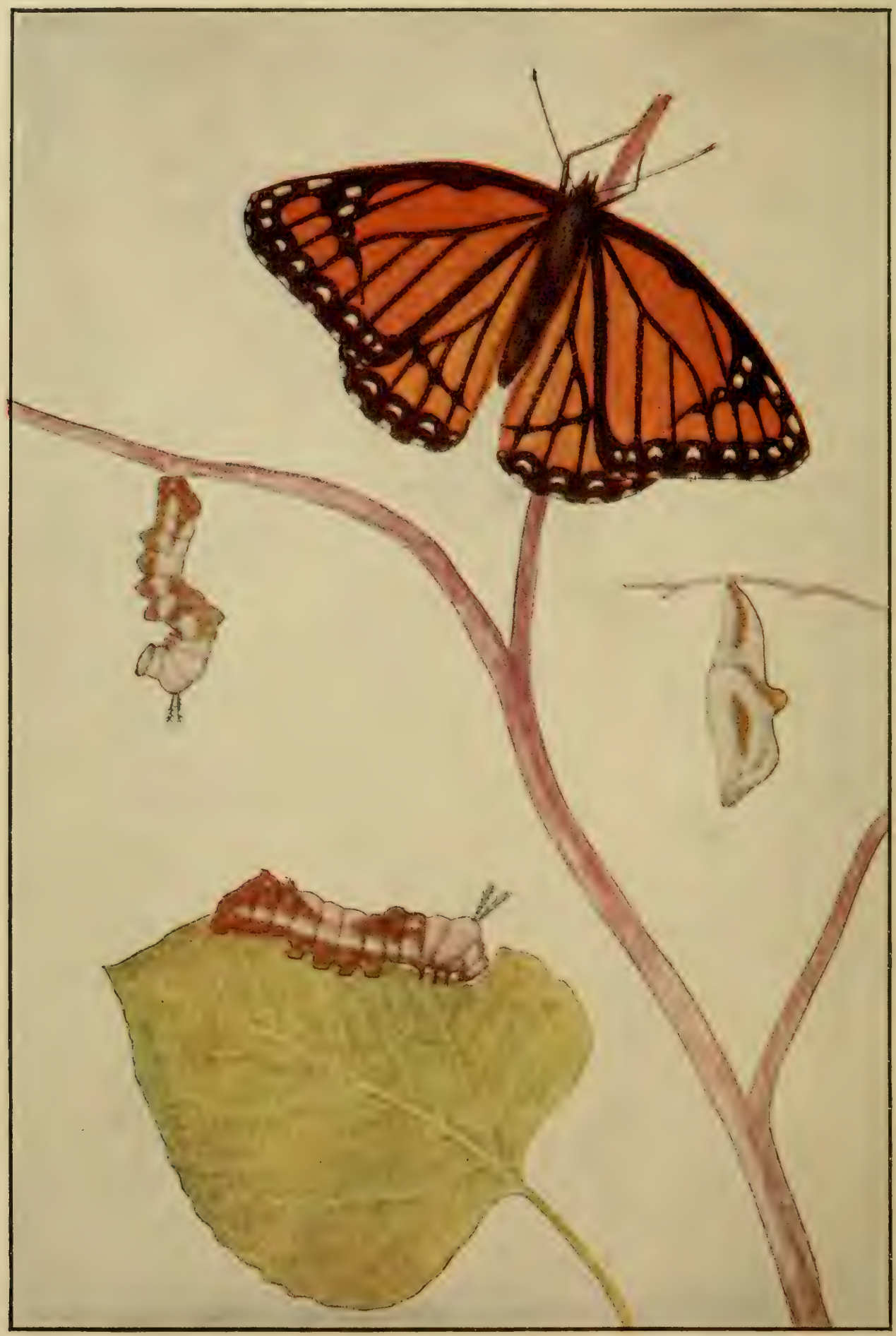

From a drawing by W. I. Beecroft

See pages 195-202

THE STAGES OF THE VICEROY

The butterfly freshly emerged; caterpillar hung up for pupation; the chrysalis; the caterpillar feeding 


\section{THE TRIBE OF THE SOVEREIGNS}

teresting points of view that it is a bit difficult to know which phases to emphasize. In general, there is a striking similarity in their structure and habits in the earlier stages. The eggs are very nearly alike; the caterpillars resemble one another so closely that even expert entomologists sometimes have to decide what species a collected caterpillar belongs to by seeing what plant it is feeding upon, and the chrysalids are also very similar.

Some of the more interesting phases in the development of these insects are discussed in connection with the lifestories of the different species. A phase which is characteristic to all of them may well be emphasized here. From the time the caterpillars hatch until they change to chrysalids they illustrate to a marked degree an adaptation through structure and habit which must very largely protect them from attack by birds and other enemies. Their structure and markings are almost grotesque. The body is covered with strange club-like appendages and it is colored with a curious mottling of tones of green, drab, brown, and white which is very difficult to describe but which suggests, as the caterpillar rests upon rough bark, simply a bit of bird dung or some natural excrescence. The caterpillars have the habit of feeding at night and remaining upon their perches by day, often assuming positions which are very unusual among insect larvae. Such positions, in which they remain motionless for hours at a time, are undoubtedly of protective value and help to conceal the insect. After the caterpillars are half grown they rest not upon the leaves upon which they feed, but rather upon the bark of twigs or branches where their peculiar structure is likely to make them inconspicuous.

The chrysalids of the Sovereigns are also curiously 
mottled in color tones that will probably lead to their eing overlooked.

Three distinct species of Sovereigns are found in eastern North America, namely:

The Viceroy, Basilarchia archippus.

The Banded Purple, Basilarchia arthemis.

The Red-spotted Purple, Basilarchia astyanax.

The first species, the Viceroy, has a much wider distribution than either of the others. It apparently is found in nearly all localities in which either of these occur, and so includes within its range almost the whole of the United States and much of Canada.

The second of these, the Banded Purple, is a northern form. It is found commonly at least as far north as the Mackenzie River region in British America and southward to central Massachusetts. It also occurs as far west as Nebraska so that it has a very wide distribution in northern regions. It is especially abundant in Canada and the White Mountains.

The third, the Red-spotted Purple, is the characteristic form south of latitude 42 degrees. Its range overlaps that of the Banded Purple for about one degree but it is seldom found north of latitude 42 degrees. It seems to range about as far west as the Banded Purple.

There are several other butterflies belonging to this genus which are rarely found and which occur only in certain limited regions. There has been much discussion in regard to these. Some entomologists have thought them simply varieties or dimorphic forms while others have considered them hybrids. An analysis of the conditions shows that these doubtful butterfies occur only in regions where the different species overlap. Thus in 
the boundary connecting the Banded Purple and the Redspotted Purple there are forms which resemble these two species in such a way as to suggest that these are the parents of the hybrid. In localities where the Viceroy and the Banded Purple occur there are other forms which seem to connect these two species, and in the locality where the Viceroy and the Red-spotted Purple occur there are still other forms which seem to suggest these as the parents. So the evidence seems pretty conclusive that where these butterflies overlap there are likely to be occasional crosses between the species which result in these natural hybrids.

In the far Western states there are certain other species of Basilarchia which take the place of the eastern form. One of the most abundant of these on the Pacific Coast is sometimes called Lorquin's Admiral (B. lorquini). In Florida there is another species, $B$. floridensis, which is found in the Southern states. It is the only one whose coloring resembles that of the Viceroy.

\section{The Viceroy}

\section{Basilarchia archippus}

The common name of this butterfly was probably given it in allusion to its resemblance to the Monarch butterfly. For the Monarch and the Viceroy have been closely associated in the minds of many observers ever since people began to study butterflies in America. These two insects have become famous as the most notable examples that we have of the mimicking of one butterfly by another. According to the theory which has been held by many naturalists, the Monarch is distasteful to birds and other ani- 
mals and it advertises the fact by its bright combination of brown and black. The Monarch is thus an example of what has often been called warning coloration. On the other hand, the Viceroy is commonly supposed to have no objectionable taste when eaten by birds, but it so closely resembles the Monarch in its color pattern and its habits of flight that it has been assumed that birds would not touch it because of its resemblance to the distasteful butterfly. There has, however, recently been a reaction among naturalists in regard to the validity of many supposed examples of warning coloration and the whole subject is still open to careful investigation. (See cover; and plate, page 145.)

Whether the Viceroy deserves its celebrity as an insect mimic or not, it is well worthy of study for other reasons. It is a common and attractive butterfly and it has most interesting habits in the larval state. It is found over a large part of North America and flies freely from spring until autumn over meadows, fields, and open glades.

\section{The Yearly Cycle of Life}

To trace the yearly cycle of this butterfly's life, let us begin with one of the mother insects flitting along a stream in early summer. She stops now and then to lay an egg on the tip of a leaf on a willow or poplar. She then continues on her way occasionally sipping nectar from any early flowers she may chance to find, and continuing her leisurely life perhaps for several weeks.

The egg thus laid upon the poplar leaf remains in position for a week or more, unless it should be devoured by some wandering ant or discovered by some tiny parasite. If it escapes these dangers, it hatches into a minute cater- 
pillar that escapes from the egg shell through a hole in its side. After it has come out it turns around and eats the remainder of the shell. It then begins feeding upon the tender tissue of the leaf it is resting upon, nibbling at the sides until its appetite is satisfied. Then it retires to the midrib on the lower surface where it remains quietly through the day and thereafter feeds chiefly at night. After about a week it becomes too large for the skin with which it was born, so it moults and immediately devours its cast skin. It continues these operations of feeding and moulting at occasional intervals for several weeks, finally becoming a rather large and curious looking caterpillar, mottled in greenish olive and light gray, with two large horn-like projections from the front of the body.

It finally becomes full grown in this larval state. Then it spins a web of silk upon the bark of the twig and entangles the hooked claws of its hind legs in the silken web. It thus hangs downward until the larval skin is shuffled off and the curious pupa with the conspicuous hump upon the middle of its back remains in its place. This chrysalis is of a mottled coloring, very similar to that of the caterpillar. A week or so later the chrysalis skin breaks open, and the butterfly comes out, catching hold of the twig with its legs and hanging quietly in position while its wings expand.

The butterflies of this brood are likely to appear late in summer. It is the second brood of adult butterflies for the season. These insects have the same leisurely habits as those that were on the wing earlier in the season. In a similar way the mother butterflies lay their eggs on the leaves of willows and poplars, and these eggs soon hatch into young caterpillars that look like those that hatched in 
early summer. The caterpillars, however, of this autum. nal brood have a most interesting habit which was entirely lacking in those of early summer. Soon after hatching they begin to make for themselves little houses in which to pass the winter. This is very cleverly done by utilizing part of the leaf upon which they are feeding. Each side of the leaf toward its tip is eaten off with the midrib remaining untouched; then the lower half of the leaf which has not been eaten is rolled into a tube and securely sewed together with silken threads. The stem of the leaf is also covered with a similar silken web and securely fastened to the twig in such a way that it is impossible for the leaf to fall off when the other leaves do. The little caterpillar thus cleverly provides itself with a safe winter home into which it retreats on the approach of cold weather to remain until spring. They enter these little cases head first, and apparently seldom emerge again until the warm spring sun brings them forth to feed upon the developing willow catkins or the unfolding leaves.

The caterpillars that thus pass the winter in these pitcher-like cases are perhaps a third grown. They develop rapidly in spring and are likely to use the cases for resting purposes when they are not feeding. After a few weeks they become full-grown caterpillars and change to chrysalids, to change again a little later into the butter. flies that appear in early summer. There are thus two broods of each stage of the insect during the year.

\section{Curious Caterpillar Habits}

This brief summary of the yearly history of the Viceroy is by no means adequate as a story of the many interesting things to be told about this insect, which has been carefully 


\section{THE TRIBE OF THE SOVEREIGNS}

studied by several eminent naturalists. One of these is the strange habit the very young caterpillars have of fastening a few bits of leaf together by means of silken threads and then tying the bunch to the denuded rib of the leaf. To explain this, allow me to quote from an admirable essay of the late Samuel H. Scudder, whose studies of butterflies have added so much to our knowledge of these beautiful creatures:

"Soon after birth," wrote Mr. Scudder, "when it has eaten but a very few swaths down the leaf, the little fellow constructs a small and loose packet from minute bits of leaf and other rejectamenta, loosely fastened to one another and to the midrib, close to but scarcely touching the eaten edge of the leaf; and as fast as the leaf is eaten, it removes this packet (continually added to until it becomes almost as big as a small pea) farther and farther down the midrib away from its perch, always keeping it near the eaten edge. It should be noted that it is so loosely attached(the bits of leaf at all possible angles) that it is moved by the least breath. Meanwhile, the caterpillar has been growing larger and more conspicuous, and thus in greater peril from its enemies. There are two possible services that this odd packet may render. A spider wandering over a leaf and observing its motion may seize it, and thinking it has a prize, hurry away with it and leave its architect unharmed. This seems to me rather a strained suggestion, for a wandering spider would probably proceed to investigate it on the spot. Another explanation seems more probable. It should be remembered that the leaves preferred by these creatures as food are mostly such as are easily shaken by the wind, and as the caterpillar moves with the leaf and with all the surround- 
ing leaves (in a continual fluttering in the case of the trembling aspen, and to a less degree in the other food plants), this of itself is a protection to it, as it would more readily escape observation as an object distinct from the leaves, all being in motion together; but on the more stable leaves, like the willow, the motion in a feeble wind would not be sufficient to be serviceable, and here, at least, the packet comes into play. An object in motion among others at rest is a noticeable thing; a fact well recognized among animals, as a host of them show when they fear being seen. This packet attached by loose silken threads moves, as stated, with a breath of wind, and so would distract attention from its architect near by, who has taken pains to place it at the farthest remove from his perch while still (to avoid undesirable steps) on his daily track. If this be really its object, it is surely one of the oddest devices in nature."

The curious winter cases of the Viceroy were first carefully described by the late Dr. C. V. Riley, in one of his classic reports on the insects of Missouri. It is one of the best accounts which has ever been written and is well worth quoting at some length:

"The larvae of the autumnal brood," wrote Doctor Riley, "when about one fourth or one third grown, build for themselves curious little houses in which they pass the winter. First and foremost - with wise forethought and being well aware through its natural instincts that the leaf which it has collected for its house will fall to the ground when the cold weather sets in unless it takes measures to prevent this - the larva fastens the stem of the leaf with silken cables securely to the twig from which it grows. It then gnaws of: the blade of the leaf at its tip 
end, leaving little else but the midrib. Finally it rolls the remaining part of the blade of the leaf into a cylinder, sewing the edges together with silk. The basal portion of the cylinder is of course tapered to a point as the edges of the leaf are nearly drawn together, not overlapped; and invariably the lower side of the leaf forms the outside of the house so as to have the projecting midrib out of the way of the larva as it reposes snugly on the inside. The whole, when finished, has somewhat the appearance of the leaf of a miniature pitcher-plant (Sarracenia), its length being .50-.65 inch, and its diameter .11-.14 inch.

"These curious little cases may be commonly found upon our willows and poplars in the winter time. I have examined hundreds of them and although they are invariably built upon this plan, they vary greatly in the degree of perfection which the architect attained; and this is especially the case where they have been built in confinement. The blade on the tip piece is sometimes gnawed off right down to the rib; at others it is left almost as broad as the tube. Sometimes it is bent over the orifice; at others not. They are also much more irregular and ungainly when made with broad leaves, such as those of the silver poplar, than when made from the more narrow leaves of the willow tree. These autumnal larvae have also another peculiar habit: they exhibit a tendency to build from the time they are hatched and will always eat the leaves from the side, gnawing large holes and cutting along the sides of the midrib. They commence at the tip, and as they work downward toward the base, they collect the débris into a little bunch which they fasten with silk to the midrib. When the hibernaculum is finished the seam is perfectly smooth and the hole inside is lined with 
silk. The larva, having completed its work, composes itself for the winter with the hind end toward the orifice. Here it remains till the catkins are in bloom the next spring when it retreats from its house and commences feeding. Not the least wonderful part of this phenomenon is that it is only the autumnal brood of larvae that form pitcherlike houses to live in during the inclement season of the year-the summer brood having no occasion to shelter themselves from cold." It is an interesting fact that in most northern regions these winter cases are nearly always made so near the ground that they are protected by snow during most of the winter.

When an insect has such a curious habit as that of making these winter cases it seems comparatively easy to explain it as an acquired instinct brought about through the conditions of life during the long period in which successive generations have been laid. But, as Doctor Riley seems to suggest above, it is much more difficult to explain this sort of phenomenon when it occurs only in one of two or more broods during the season.

\section{The Banded Purple}

\section{Basilarchia arthemis}

None of our common butterflies shows more striking color markings than the Banded Purple. A broad white stripe runs midway through the wings on both surfaces, the white making a strong contrast to the purplish or brownish black of the rest of the wings. This white band is supplemented by rows of fulvous and of blue dots, especially on both surfaces of the hind wings. 


\section{THE TRIBE OF THE SOVEREIGNS}

This butterfly is a northern form ranging to a large extent north of the regions occupied by the Viceroy. Its life-history is very similar to that of the latter insect. The caterpillars have the same curious habits and bear a close general resemblance to one another. The Banded Purple butterflies appear in June and lay their eggs in July upon the tips of the leaves of birches, especially the black birch. Almost all of these eggs are laid within two or three feet of the ground. They are of grayish green color. The caterpillars are greenish- or olive-brown.

About a week after the egg is laid it hatches into a small caterpillar that feeds upon the sides of the leaf and rests upon the midrib just as the Viceroy caterpillar does. It continues to feed through July and the early part of August, moulting once or twice before it begins to form the winter case. It usually goes into this during the latter part of August, when it is in the second or third caterpillar stage. From then on it remains quietly in its winter home, being covered by the deep snows during several months, and coming out about the middle of the following May, when the spring warmth starts the buds of its food plant. It then feeds for two or three weeks before it changes to a chrysalis to emerge in June as a butterfly. There seems to be normally but one brood each year although under exceptional conditions some of the eggs laid in July mature into butterflies the same season. But it is probable that these butterflies either do not lay eggs and perish as the cold comes on, or that if they do lay eggs the caterpillars that hatch from them do not get large enough to construct their winter cases. Consequently, it is doubtful if we can consider the insect really two-brooded even in part. 


\section{The Red-spotted Purple}

Basilarchia astyanax

Were it not for the wonderful iridescence of its wings the Red-spotted Purple would be one of the most plainly marked of the Sovereigns. But the upper surface of both pairs of wings is thickly covered with iridescent scales which give the insect a shimmering beauty that makes it conspicuous among northern butterflies, suggesting something of the marvelous coloring of the large tropical species. The general coloring is a purplish black with rows of white dots along the borders of the wings. The under surface shows much more of the fulvous brown which is so characteristic of the Viceroy, the brownish background being rather thinly overlaid with iridescent scales, but with a large number of spots and stripes, where the fulvous color alone shows.

The favorite food plants of this species belong to the great order Rosaceae which includes the apple, pear, cherry, rose, and many other common trees and shrubs. The egg is laid upon the extreme tip of the leaf, a characteristic habit of all the species of Basilarchia. It obviously must have decided advantages in preserving the eggs from attack by ants, spiders, Ichneumon flies, and other enemies. All of these creatures are constantly patrolling leaf surfaces in search of eggs and minute insects. They are much more likely to find their victims upon the broad general surface than upon the extreme tip of narrowly pointed leaves. The eggs of all these butterflies are small, and pitted much like a tiny little honeycomb with a large number of tiny hairs arising from the surface. These 


\section{THE TRIBE OF THE SOVEREIGNS}

hairs are very similar to the hairs upon the surface of many leaves and they probably assist in leading other insects to overlook the eggs. Yet, notwithstanding these devices for protection, it remains true that a large proportion of the eggs are attacked by tiny parasites and probably many others are eaten by ants and spiders. This very fact emphasizes the necessity of such protective features as the laying of one egg in a place upon the tip of a leaf and the hairy covering on the egg shells.

A few days after the eggs are laid each hatches into a small caterpillar that immediately begins feeding upon the green tissues beside it-first, however, devouring the empty egg shell. It does not eat the midrib of the leaf, but utilizes it as a perch, generally winding it more or less with silken threads, apparently to make it stronger and to prevent it from curling up. The caterpillar seems to feed chiefly at night, resting quietly by day. After a week or so it moults and then continues feeding as before. It continues to feed and grow for several weeks, moulting regularly until it becomes full fed as a caterpillar. It then spins a web of silk closely upon the bark of twig or branch or possibly upon some other object near at hand. In this web it entangles the hooked claws of its hind legs and hangs downward preparatory to the change to the chrysalis. Soon afterward the last larval skin is shed and the chrysalis hangs in place of the caterpillar. This chrysalis has the characteristic form of all the members of this limited group, the outer skin being well hardened and there being a very prominent projection on the middle of the back.

The chrysalis hangs thus, buffeted more or less by 
wind and rain for about ten days, then the skin breaks apart and the butterfly emerges.

Over a large part of its range there are two broods of this butterfly each year. The adults appear in early summer and lay eggs which develop into butterflies again during the latter part of summer. The life-history of this generation is the one described in the last paragraph. The eggs laid by these late summer butterflies, however, require a somewhat different story. They hatch in the same way as the others but when the caterpillars have moulted about twice they form a winter case or hibernaculum, in exactly the same way as the caterpillars of the Viceroy. They remain within these winter homes till the following spring, when they come forth and complete their development producing the early summer brood of butterflies with which our story began.

\section{The Vicereine}

\section{Basilarchia floridensis}

In Florida and some of the other Southern states there is a butterfly which looks almost like the Viceroy except that the brown coloring of the wings is very much darker. The species has been called the Vicereine as it is believed to mimic the Queen Butterfly, a species closely related to the Monarch and occurring in the Southern states. The Vicereine probably has a life-history very similar to that of its northern cousin.

\section{Synopsis of the Sovereigns}

Banded Purple (Basilarchia arthemis or Limenitis arthemis). Expanse $2 \frac{1}{2}$ inches. Ground color of upper 


\section{THE TRIBE OF THE EMPERORS}

surface of wings black with a distinct white band in bowlike form running across the middle of both wings. A row of six tawny spots just outside the white band on each hind wing and various sub-marginal blue spots outside of these. Under surface tawny brown with the white stripe distinct and many red-brown spots.

Red-spotted Purple (Basilarchia astyanax or Limenitis astyanax). Expanse $2 \frac{1}{2}$ inches. Ground color brownish black tinged with bluish, especially on the hind wings. No white band but various red and blue spots, especially near the outer margins of the upper surface of both pairs of wings.

Viceroy (Basilarchia archippus or Limenitis disippus).

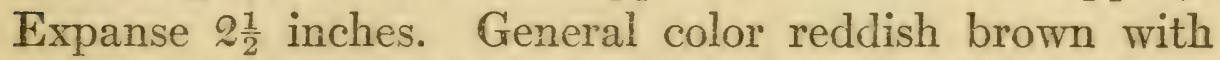
veins and margins blackish. A narrow black band running across the hind wings just beyond the middle. A series of white spots in all the marginal bands.

Vicereine (Basilarchia floridensis). Expanse $2 \frac{1}{2}$ inches. Similar to the Viceroy but much darker in the brown coloring of all the wings.

\section{THE TRIBE OF THE EMPERORS}

The members of this small group are distinguished from the closely related Sovereigns by the tailed hind wings in one species, by the eye-spots on the upper surface of the wings of the others, and by the fact that on the club of the antennae there are three instead of four longitudinal ridges. There is also a distinction in the arrangement of the veins of the hind wings.

This tribe is represented in our northern fauna by only two genera. In the genus Chlorippe the antennae are as long as the front wings are wide. In the genus Anoea the 
antennae are much shorter than the width of the front wings. Only two species of the former and one of the latter are sufficiently abundant to be considered here.

\section{The Goatweed Emperor}

Anoea andria

Comparatively few butterflies are confined so closely to the valley of the Mississippi River as the Goatweed Emperor. From southern Illinois south to the Gulf this insect is rather abundant in many localities where its food plant, the goatweed, is common. The life-history of the insect was carefully studied by Dr. C. V. Riley, and one of the best accounts was published in one of his early reports on the insects of Missouri. The excellent illustrations in that article first made the species familiar to many students.

Briefly summarized, the life-history runs something like this: the butterflies hibernate, coming forth in spring and visiting various spring and early summer flowers. The females deposit eggs singly upon the leaves of the young goatweed plants. In a week or less each egg hatches into a little caterpillar that feeds upon the tip of the leaf leaving the midrib and covering it with silk so that it may serve as a resting perch. Later each makes an excellent tent for itself by bending over and binding together the opposite margins of a leaf.* This bit of work is cleverly done, a hole being left at each end so that there is good ventilation and an opportunity for the caterpillar to go in and out. Quite frequently the nest is also lined with more or less silken webbing. This tent is used

* See next page. 


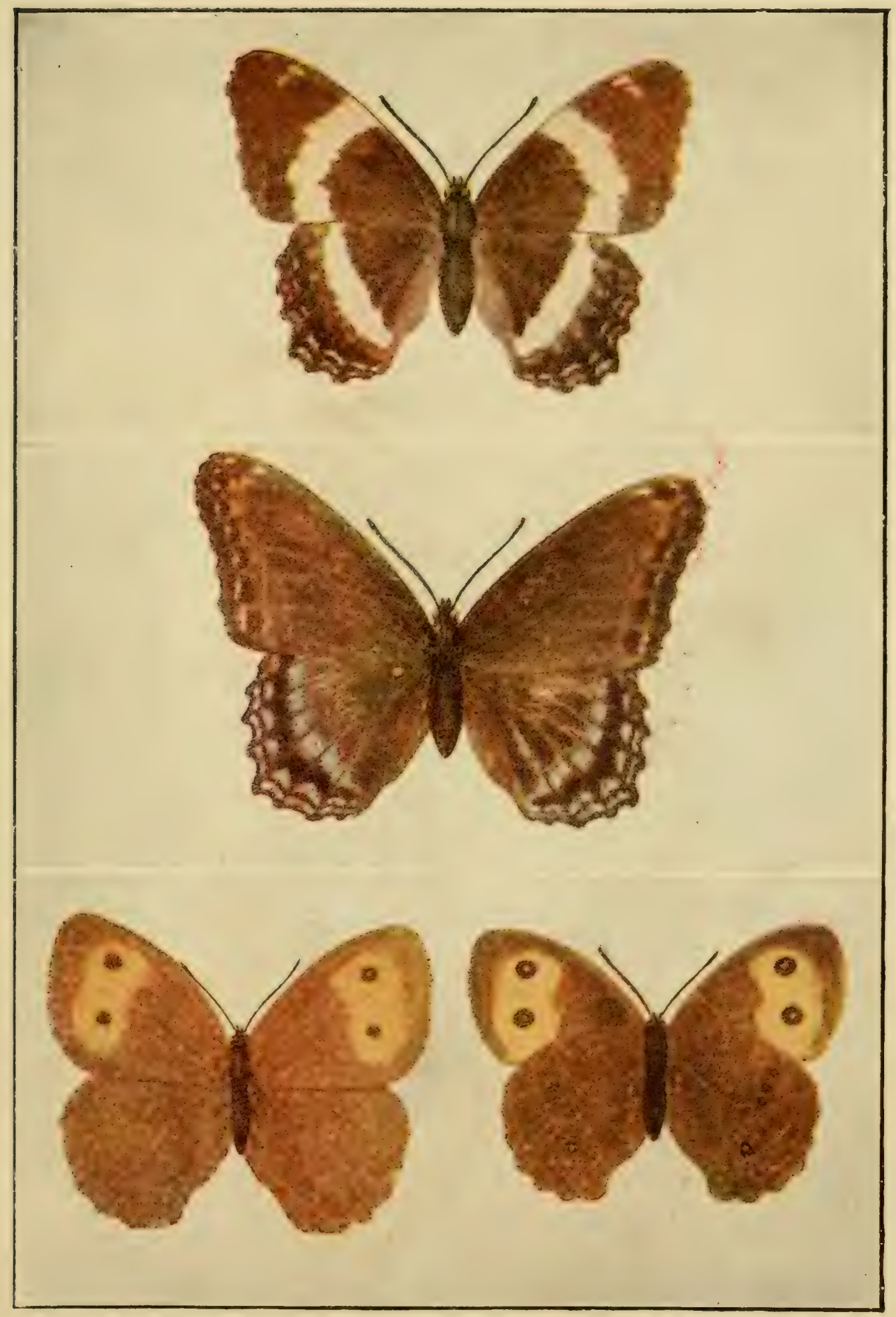

THE BANDED PURPLE (see page 202)

THE RED-SPOTTED PURPLE (see page 204)

THE BLUE-EYED GRAYLING OR COMMON IVOOD-NYMPH (Upper and lower surface) (see page 215) 


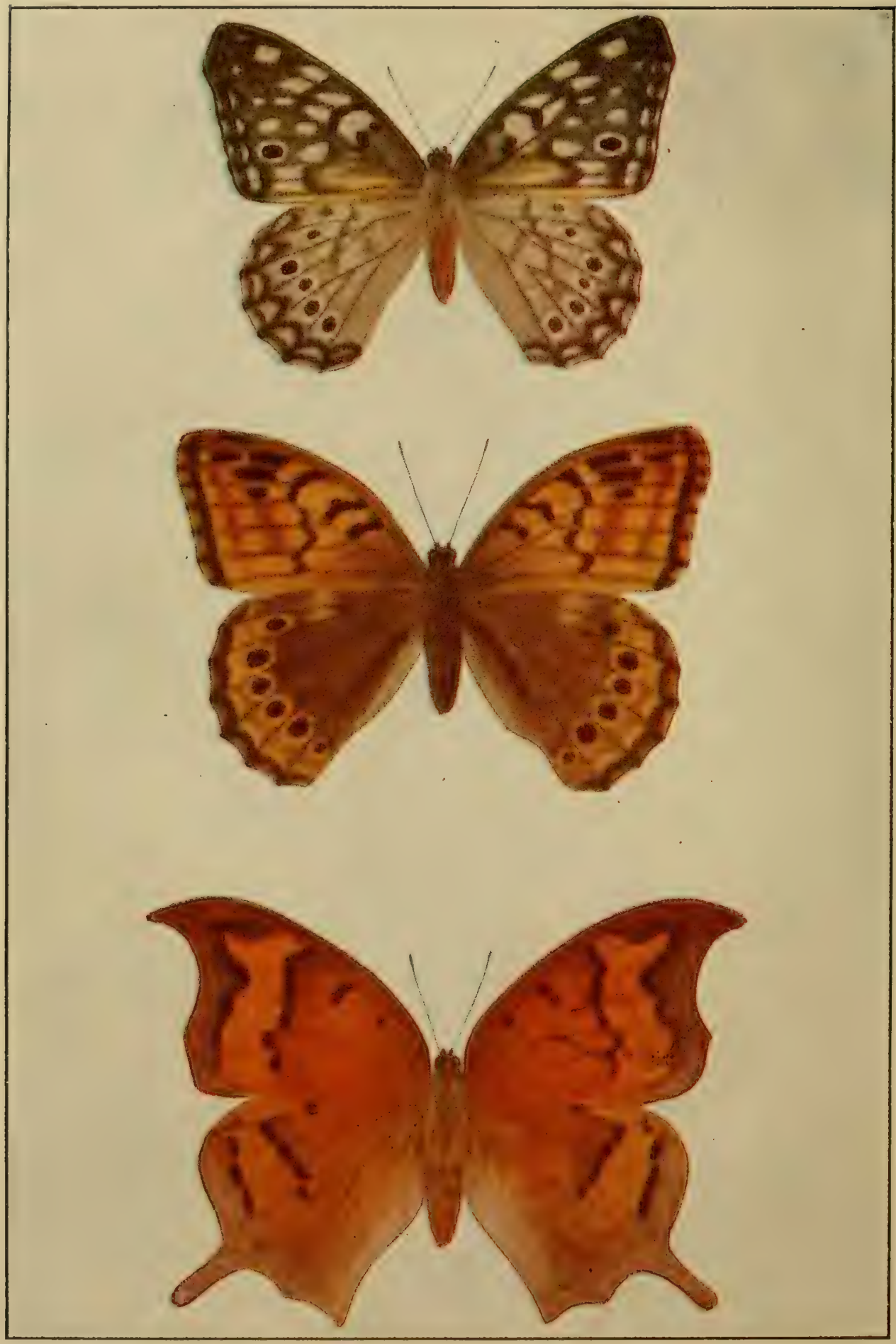

From drateings by W. I. Beecroft

See pages 207-214

THREE EMPEROR BUTTERFLIES

The Gray Emperor, female ( $t o p$ )

'The 'Tawny Emperor, female (middle)

The Goatweed Emperor, female (bottom) 


\section{THE TRIBE OF THE EMPERORS}

as a refuge from the heat of the sun and doubtless serves also in concealing the caterpillar from its many enemies. The larva goes out to neighboring leaves when it wishes to feed and only occasionally eats up the leaf of which its tent is made. When this is done it must of course construct another home.

After some weeks of this sheltered existence the caterpillar is ready to change to a chrysalis. It leaves the tent and commonly attaches a bit of silken web to the under side of a leaf or branch of its food plant

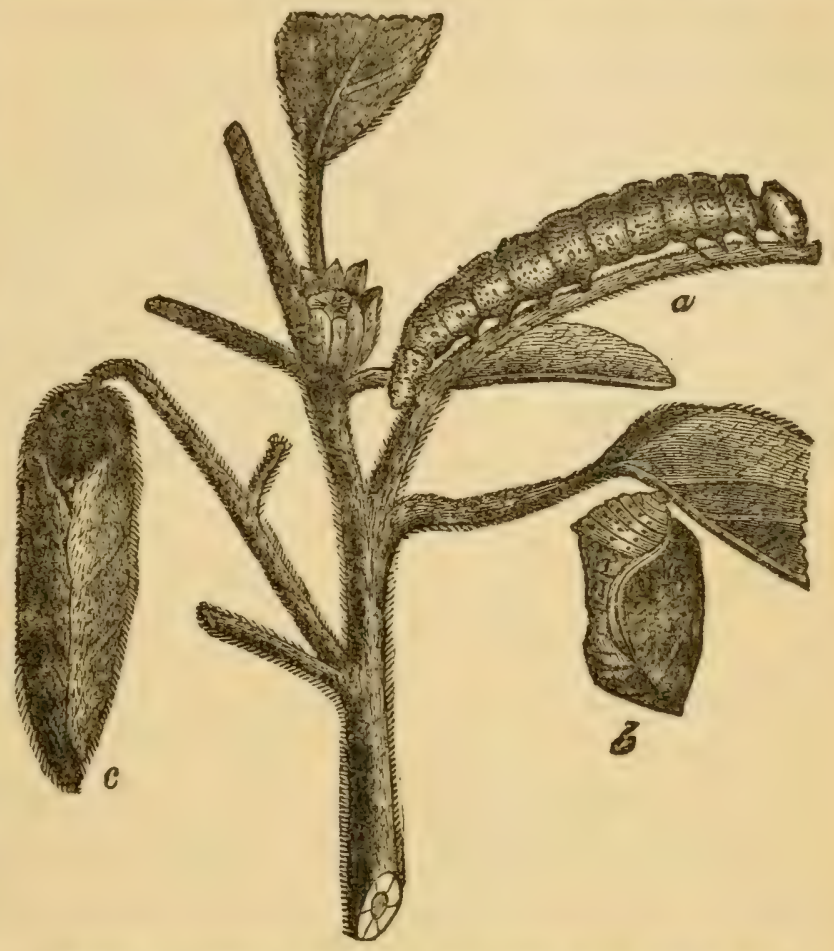

Goatweed Butterfly: $a$, larva; $b$, chrysalis; $c$, larval case. (After Riley) or some other kind of shelter. Here it changes to a chrysalis, to emerge a little later as the beautiful burntorange butterfly. There are said to be two broods each season, in some regions, although in others there seems to be but one. The butterflies hibernate in hollow trees or in such other shelters as they may find.

The full-grown caterpillar ( $a$ ) is an inch and a half long and of a general grayish color, dotted thickly with slightly elevated points. The chrysalis (b) is suggestive of that 
of the Monarch butterfly. It is light green covered with whitish granules.

The adult butterfly is remarkable for the falcate shape of the outer margin of each front wing and the broad tail at the hind outer angle of each hind wing. In the male the upper surface of all the wings is of a dark orange tone, with a rather narrow brown marginal marking. In the female this marginal band is broader and is nearly paralleled by another narrower band a little nearer the body. In bright sunshine there is a distinct purplish red iridescence over practically the whole upper surface. The under side of both wings is of a color to suggest a dead brown leaf, with a purplish iridescence in certain angles of light.

\section{The Gray Emperor}

Chlorippe celtis

This very distinctive medium-sized butterfly is found in the Southern states at least as far west as the Mississippi Valley. It extends north to Indiana and Ohio and probably occurs quite generally from Ohio eastward. This species is distinguished by the general gray-brown or olivebrown coloring of the wing surfaces, heavily marked with a much darker dusky brown and with many irregular white spots as well as one large eye-spot on each front wing near the border, and a row of seven more or less distinct eye-spots near the border of each hind wing.

Like the Tawny Emperor this species feeds in the larval state upon the leaves of hackberry. In Missouri the butterflies appear in June. A little later they lay eggs upon the under side of the hackberry leaves, commonly 
one in a place but sometimes several side by side. A few days later these eggs hatch into little yellow caterpillars that feed upon the leaves for about a month when they become full grown. They are then a little more than an inch long, of a general light green color with yellow spots along the middle of the back and three yellow lines along each side. The head has a pair of curious antlers much like those of the caterpillar of the Tawny Emperor. These caterpillars now spin a bit of silken web on the under side of the leaf or twig. They attach their hind legs into this web and hang downward for a day or two, before casting the last larval skin and changing to chrysalids. They change again to butterflies which are seen upon the wing early in August. These butterflies lay egos in turn on the hackberry leaves, the eggs soon hatching into small caterpillars which according to Riley's observations are less active than those of the earlier brood. These caterpillars feed for a few weeks until they become nearly half grown and have passed their second or possibly their third moult. 'They now stop eating and get ready for a long fast through the rinter. Apparently some of them at least attach themselves to the under side of the hackberry leaves and turn to a brownish color, remaining upon the leaves until the latter fall to the ground and presumably hibernating in the shelter thus provided. Whether or not all of the caterpillars have this rather curious habit seems to be doubtful. It has been suggested that some of them find shelter within the crevices in the rough bark of the tree. At any rate, the caterpillars remain in a sort of stupor until the following spring. Then they awaken, climb up the trees or bushes, and begin feeding upon the young leaves. They continue this until they become full 
grown in May when they change to chrysalids, to emerge as the first brood of butterflies the following month. Many of the caterpillars make a sort of nest for themselves by spinning a web of sill- upon the under surface of the leaf and drawing together slichtly the outer edges.

As is the case with so many other butterflies that hibernate as caterpillars, apparently the species is only partially double-brooded. Some of the earlier caterpillars become lethargic when half grown and remain in that condition throughout the later weeks of summer and all through the fall and winter.

\section{The Tawny Emperor}

Chlorippe clyton

This handsome butterfly is easily distinguished from the Gray Emperor by the general reddish color of the wings which are thickly marked with bands and eye-spots of darker brown or black. The eye-spots are especially marked on the hind wing, there being a row of five of these on each hind wing in both sexes. The females are decidedly larger than the male and generally of a distinctly lighter color.

This butterfly is a southern species found more or less abundantly from southern New York to northern Florida and across the country to a line drawn from Iowa to Texas. It seems to be more common in the Mississippi Valley than in other regions and its life-history was first thoroughly worked out in Missouri and published in one of Riley's classic reports on the insects of that state. It has sincs been studied by Edwards and others, but even now ihere 


\section{THE TRIBE OF THE EMPERORS}

seems to be some uncertainty in regard to many points in its development, notably the number of broods in different localities and the habits of the larvae when preparing for hibernation.

The principal points in the life-history of the species may be outlined as follows: some time in July the eggs are laid on the leaves of hackberry in dense clusters, each of which may contain from two hundred to five hundred eggs. These are usually deposited in two or more layers, one upon another. A little more than a week later these eggs hatch, each caterpillar eating through one end in a way to cut out the rim of a tiny cap which is pushed up as the larva escapes. The whole brood emerges at practically the same time and collects upon one or more leaves where they begin to feed upon the succulent green tissues. Like so many caterpillars that feed in companies each spins a silken thread wherever it goes.

The little larvae remain together until after the third moult, at which time they are about half grown. In the more northern regions where they are found they are now likely to scatter about in search of quarters for hibernation. Having found suitable shelter, they remain through the winter to come forth early the following spring and feed upon the developing leaves of the hackberry trees. They continue to do this for a few weeks before they become full grown. They are then smooth-bodied, greenish worms about an inch and a half long, striped longitudinally in yellow and brown. The hind end of the body is forked in a curious fashion and the head is even more remarkable for the strange pair of tiny antlers projecting from it.

These full-grown caterpillars soon change to pale green chrysalids, lightly striped with longitudinal lines of yellow, 
with a distinctly pointed head. From these chrysalids butterflies emerge early in summer.

Evidently in the more Southern states there are two broods of these butterflies each year but there is great need of more precise knowledge in regard to them.

As is the case with so many other butterflies there is a dimorphic form, called ocellata, in which the outer half of the hind wing is very dark brown, with the eye-spot showing as black with red-brown circles.

\section{Synopsis of the Emperors}

Goatweed Emperor (Anoea andria or Pyrrhanea andria). Expanse $2 \frac{1}{2}$ inches. Front outer angle of each front wing projecting into a falcate tip. Rear outer angle of each hind wing projecting into a distinct tail. General color burnt-orange with darker marginal bands, and in the female on the upper surface other sub-marginal markings.

Gray Emperor (Chlorippe celtis). Expanse 2 inches. General color grayish brown with numerous markings of white and blackish. A distinct brown eye-spot on the upper surface of each front wing near the outer hind angle.

Tawny Emperor (Chlorippe clyton). Expanse 2 inches. General color tawny brown with markings of black and yellowish white. No distinct eye-spot on upper surface of front wings.

\section{THE MEADOW-BROWNS OR SATYRS}

\section{Family Agapetidae}

The Meadow-browns form one of the most distinctive family groups among all the butterfly tribes. They are 


\section{THE MEADOW-BROWNS OR SATYRS 215}

characterized, at least so far as our eastern species are concerned, by their slender bodies and rather large wings, toned in various shades of brown, and marked chiefly with conspicuous and characteristic eye-spots. The larger veins of the front wings are swollen at the base. The caterpillars are rather slender and have a curious division of the last body segment into two parts, which gives them an appearance suggestive of the caterpillar of the Emperor butterflies, although the Meadow-brown caterpillars do not have, upon the head, the curious antlers borne by the Emperor larvae.

\section{The Common Wood-nymph or Grayling}

Cercyonis alope

In the development of our knowledge of both birds and mammals as found upon the American continent the experience in many cases has been essentially this: a bird or a mammal was first described from some well-known region of North America, commonly from specimens carried to Europe by early voyagers. Later other species of the same genus were brought to light by various explorers and given specific names. As each section was thus explored a new form differing markedly from the others was found and named. At a later period, when great collections were brought together so that one observer was able to make a careful survey of specimens from all parts of the continent, it was found that many of these species merged into each other through intergrading forms from regions between the localities of the original species. So it has come about that in the case of a large number of our birds 
and mammals we have geographical rares distinctly recognized instead of separate species.

While the study of butterflies has by no means received the degree of attention which has been given the birds and mammals, it is already evident that a similar condition prevails with reference to many species. As the size of collections has increased and more careful studies have been made of the various forms from different regions it has been found in numerous cases that they intergraded to so great an extent that it is impossible to distinguish many species which were formerly considered entirely distinct. One of the most striking examples of this is found in the case of our common Wood-nymph, which is sometimes called the Blue-eyed Grayling. The form which is one of our most abundant butterflies in southern New England and many of the Eastern states was described as Satyrus alope by the French naturalist Fabricius, who also described another species from the Southern states as Satyrus pegala, and a form found in northern Canada was described by the English entomologist Kirby as Satyrus nephele. Various other forms from isolated regions have been given specific names by other authorities. (See plate, page 81.)

During recent years many collectors have gathered these butterflies from all parts of North America and many specimens have been grouped together in the more important collections. When this occurred it became easy to see that this is essentially a variable species which under varying climatic conditions has assumed slightly different forms, so that we have a good illustration of well-developed geographical races. The more important of these are indicated in the synopsis of the Meadowbrowns on page 227 . 


\section{THE MEADOW-BROWNS OR SATYRS}

\section{The Similar Life-histories}

One good indication that these varying forms all have a common origin is found in the remarkable unity of their life-histories. It is essentially the same in all. The mother butterflies lay eggs late in summer upon the leaves of grasses and perhaps other plants. About three weeks later these eggs hatch into small caterpillars that immediately become lethargic and begin their hibernating condition without eating any vegetation. They remain thus fasting until spring when, after the weather warms up sufficiently, they begin to feed upan grasses and perhaps other herbage. But they have lots of time in which to complete their growth and they are very moderate in their eating and their movements. They grow slowly so that they do not become mature as caterpillars until June. They then change to chrysalids to emerge as butterflies during July and August. The female butterflies remain upon the wing for some weeks before they begin to lay their eggs. We thus have in this case an adaptation to single-broodedness in practically all stages of the insect's life. The twelve months of the year must be passed and egg, larva, chrysalis, and butterfly each seems to try to do its part in prolonging its period of life.

These butterflies are especially common along streams and near the borders of woods, as well as in upland pastures and meadows. They are interesting creatures with characteristic manner of flight. They are by no means so easy to capture as one might think who sees them apparently going with slow, erratic motions from flower to flower. Mr. S. F. Denton, a collector of long experience, has written this interesting paragraph upon this point: 
"As the flight of these insects is weak, they have been obliged to resort to a number of tricks to outwit their enemies. In capturing these butterflies the collector will very soon become acquainted with their modes of escape, which are very interesting and show, no small amount of cunning, scarcely to be looked for in an innocent little butterfly. Their first plan of escape on being disturbed is to make directly for a clump of bushes into the thickest part of which they dive and there remain until the danger is past. If one is startled from the grass at some distance from a safe retreat and the collector overtakes him, he will immediately dodge backward and forward, at one time high in air and again low down near the grass tops, and in spite of his slow flight keeping well clear of the net. If the net is at last brought very close to him he will try his last desperate scheme to elude his pursuer and shutting his wings quickly together will drop into the grass, disappearing as if by magic. If it were not for the cunning of the frail little creatures they would doubtless have gone to the wall long ago in the struggle for existence."

\section{The Southern Wood-nymph}

\section{Cercyonis pegala}

This large southern butterfly is sufficiently distinct from the other Wood-nymphs to rank as a separate species. The yellow blotch has expanded into a large band extending practically across the front wings. On its upper surface there is one eye-spot in the male and two in the female. It is abundant in the extreme Southern states and has occasionally been taken much farther north. 


\section{The Pearly Eye \\ Enodia portlandia}

Most butterflies are creatures of open country, basking freely in the sunshine and visiting flowers of many sorts for their nectar food. Some of them are found at times along the borders of woods and others seek the woods especially in autumn for the purpose of hibernation. This exquisite Pearly Eye, however, is distinctly a woodland species, being found only in little glades in the midst of woods and apparently seldom even seeking flowers for their nectar. It is commonly considered one of the rarest of American butterflies, but many collectors who have searched their regions carefully have been able to find small areas in which the butterfly is quite abundant. In such situations it may be looked for in all parts of the United States east of the western limits of the Mississippi Valley and south of Canada, except perhaps the lower part of Florida.

In northern regions this butterfly is single-brooded: the adults appear shortly before midsummer and continue on the wing through July and at least part of August. The eggs are laid some weeks after the butterflies emerge. The caterpillars feed upon grasses and apparently hibernate after they become well grown, changing to chrysalids the following spring in time to emerge as butterflies in early summer.

These Pearly Eyes have certain characteristics which are of especial interest. No other species presents such exquisite modulation of brown coloring arranged in beautiful circles upon both surfaces of the wings. The males 
possess, perhaps to a greater degree than any other of our native butterflies, the ability to give off a peculiar, pleasant aroma which is noticeable whenever the insects are collected and which at least one careful observer has been able to detect in the open air as the butterfly flew near.

For many years Mr. W. F. Fiske made a special study of the butterflies prevailing in the region of Webster, New Hampshire. His word picture of the haunts of the Pearly Eye is more adequate than any other which has been published and seems well worth quoting in this connection:

"I have found them in several localities, always in some numbers, but nowhere more abundant than in a little wooded glen in Webster. Here a scattering group of tall pines, a few thick hemlocks, and a young growth of miscellaneous deciduous trees fill up the space between two rather steep banks. A small trout brook follows close by one of these banks, and near the lower end of the glen, in a space kept clear of underbrush by the overshadowing influence of the pines and hemlocks, is a little spring, the overflow from which keeps the ground moist for some space on each side of the channel which it follows to the brook. This is the great meeting place of these butterflies; here they may be seen at almost any time in the day except in the early morning-when they seek the outskirts of the woods-until the shades of evening render their flitting forms indistinguishable. Half-way up the bank on one side, half shrouded in the dense growth of underbrush which is springing up around it, is an old apple tree upon which the sapsuckers work yearly. The wounded limbs, dripping with sap, are frequented by many forms of insect life, most noticeable among them 


\section{THE MEADOW-BROWNS OR SATYRS 221}

this butterfly, and such refreshment added to the moisture which they suck from the margin of the spring is all that I have ever seen them partake."

\section{The Eyed Brown}

\section{Satyrodes canthus}

For delicacy of gray-brown color tones few butterflies can compare with this exquisite creature. It seems indeed to have succeeded in a modest attempt to obliterate itself, for even when the spread wings are placed against a clear white background they can scarcely be called conspicuous and it is very probable that when the butterfly is at rest in its native haunts, with wings closed together so that only the very delicate light brown color-tones of the under surface are revealed, it actually becomes invisible.

The upper surface of the wings is broadly washed with a gray-brown color which runs into a suggestion of a lighter band near the outer margin of the front pair. The upper surface of the hind wings is almost uniformly washed with this same brown color which is interrupted only by very fine, double lines at the outer margin and a submarginal row of delicate ocelli which are larger than the somewhat similar sub-marginal row of eye-spots on the front wings. The under surface is much lighter in color, with distinct striations extending across the main surface of both wings from front to back and with some very attractive ocelli arranged as a sub-marginal series each with a central white eye.

This is distinctly a northern species, having rather a 
limited range in Canada and New England. It extends south to Pennsylvania and Ohio and westward to Wisconsin and Iowa. It is more abundant in northern than in southern New England but it is often overlooked by collectors who are not familiar with its haunts. It is especially likely to be found among the tall grass of swamps and brooks running through lowlands. One of the best ways to discover it is to beat the grasses in such situations.

The life-history of the Eyed Brown is fairly well known. The eggs are laid chiefly on grasses and probably at times upon the grass-like sedges. The larvae feed upon these plants and become nearly full grown before winter sets in. They then hibernate in this larval stage and the following spring complete their growth and change to chrysalids in time for the butterflies to emerge in June. There is but one brood a year.

\section{The White Mountain Butterfly}

\section{Oeneis norna semidea}

To appreciate the extraordinary distribution of this notable species one must let his fancy carry him back a million years or so until he reaches that old time when the whole northern part of the American continent was covered with an icy coating. Then he must follow the gradual retreating of the ice northward, carrying with it wonderful changes in climate and along with these climatic changes taking northward many plants and animals which were adapted to the cool temperature along the borders of the glacier. As the ice cap retreated most of these arctic forms retreated with it, and all along the 


\section{THE MEADOW-BROWNS OR SATYRS}

lower levels they were replaced by others migrating from the south so that gradually there came about the distribution of plants and animals as we find them to-day.

When, however, the glaciers left the higher elevations of the White Mountains and the Rocky Mountains there were at the summits small areas in which the climatic conditions were of very much the same aretic character as prevailed along the margin of the ice cap. Consequently conditions were here favorable for the continuation of many of the arctic species which had disappeared from the warmer, lower levels. It was as if we had a great sea of air of a certain warmth and rising above this the islands of the mountain tops, these islands retaining the same arctic features as otherwise are found much farther northward.

Among the animals thus left stranded iny the retreating ice cap this White Mountain butterfly has perhaps attracter the most attention from scientists. It is a butterfly of moderate size which shows in every phase of its structure and its life-history the results oi the long process of adaptation to its unique environment. It has been carefully studied by many observers and has been considered one of the most desirable trophies by every collector of insects. As a result, notwitnstanding its isolation and the difficulty of etudying it, its life-history is better known than that of many a common and widely distributed species.

To appreciate the facts in regard to the structure and life of this butterfly one must know that its habitat is confined to a thousand feet or so at the summits of the mountain, that in this area there are no trees or even shrubs worth mentioning, and that the surface of the 
mountain is covered with rocks between which grow a few stunted sedges and over which grows the ever-present reindeer moss. It is a bleak, bare, gray environment, constantly swept by terrific winds, where snow is seen in August and is likely to remain mintil June. So the summer season is of briefest duration and the climatic conditions are so severe that one can only wonder how a fragile creature like a butterfly is able to survive the twelve long months.

\section{Habits and Life-history}

From a first glance at the mottled gray-brown wings of these insects one would guess that here was a distinctive example of obliterative coloring, and it is true as all obser.... ers testify that when the butterfly lights upon the stones and turns sideways, as apparently it does habitually in deference to the force of the wind, it becomes very difficult to see, for the wings are closed and only the rounded, mottled under surface shows. It appears also to have the habit of some of t'xe Graylings when hard pushed of simply closing its wings and dropping to the ground feigning death. In deference also to the wirivis its flight is just above the surface. Doubtless if it rose high in the air it would be swept away to lower regions where evidently it is unable to survive for long periods.

These butterflies appear early in July and continue on the wing for -everal weeks. They lay their small eggs upon or near a species of sedge which is abundant on these alpine summits. About two weeks later the eggs hatch into sluggish little caterpillars which feed upon the sedge leaves, apparently eating only at night and hiding in crevices between stones by day. As one would expect 


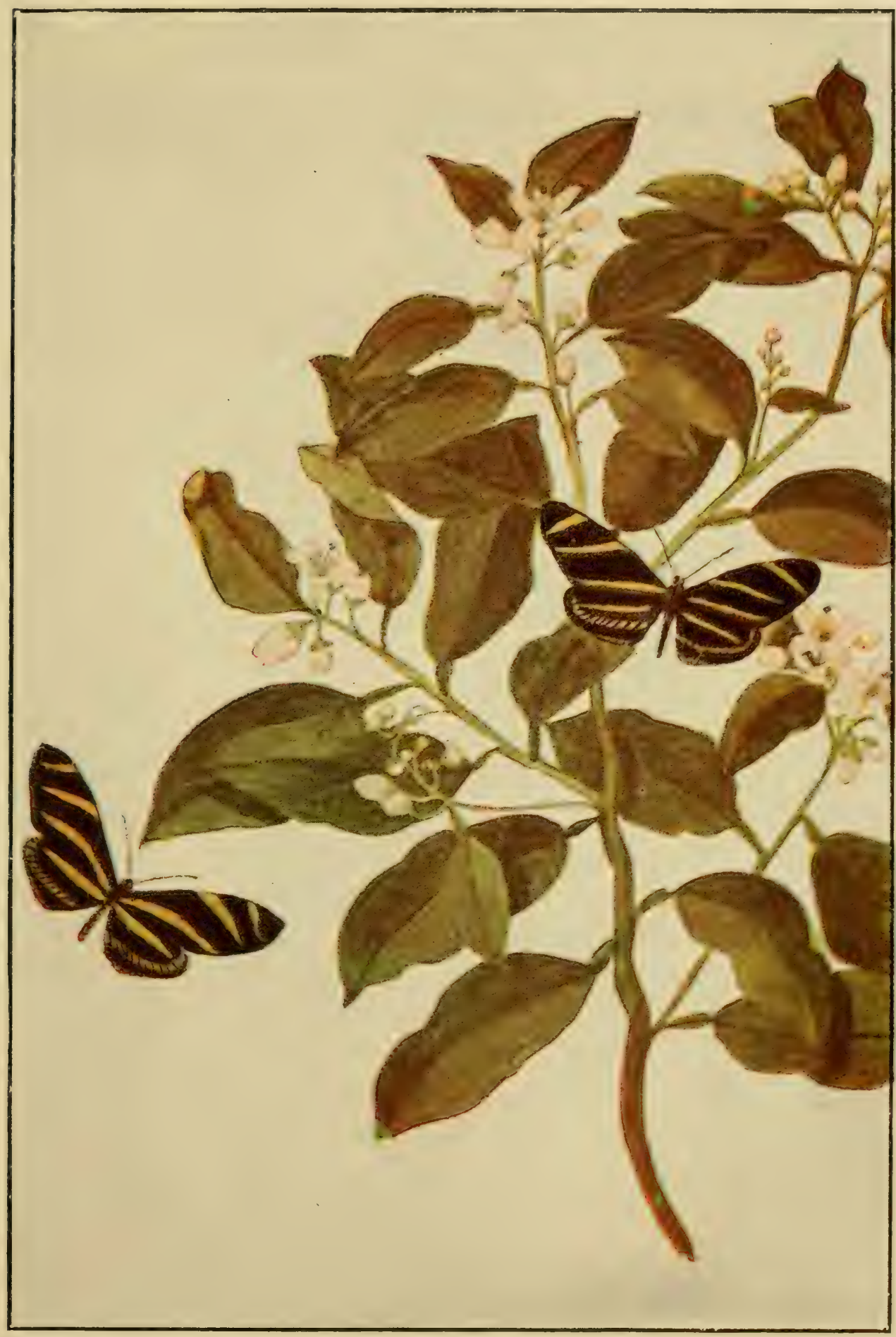

From a drawing by Mary E Walker

See prge???

THE ZEBRA BUTTERFLY

On orange leaves and blossoms. (Reduced) 


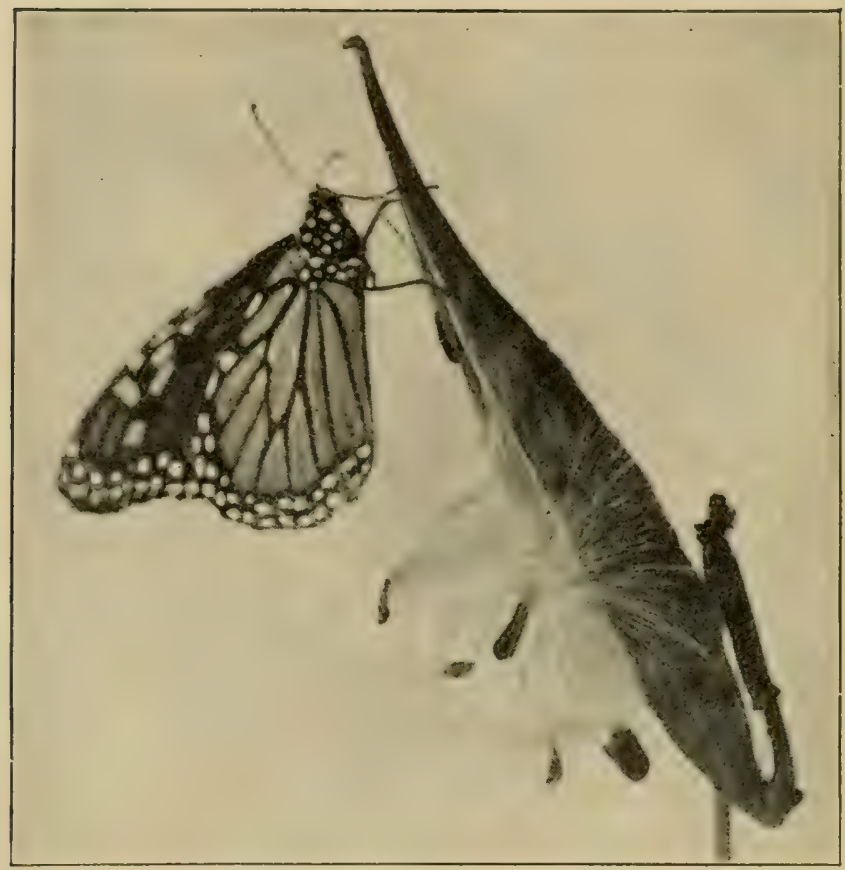

On a milkweed pod

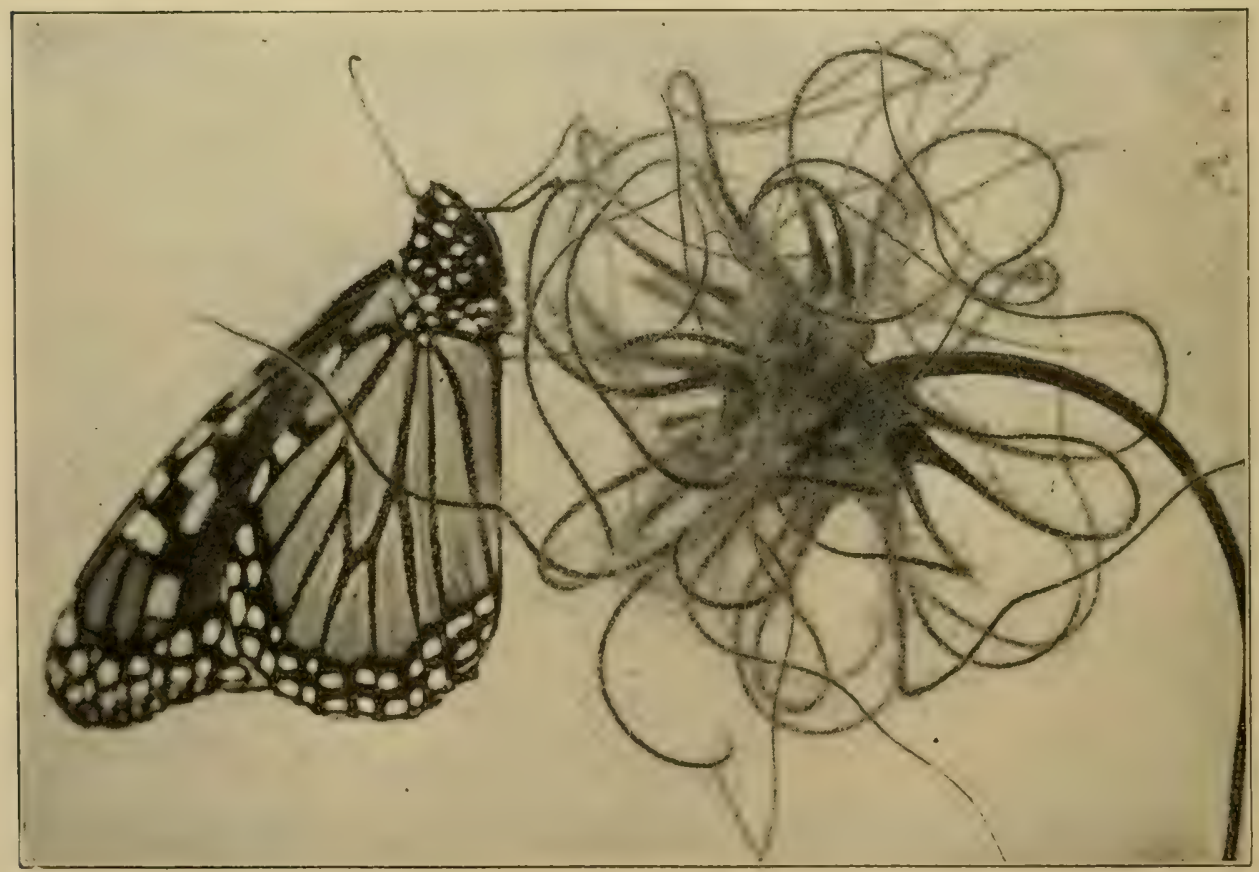

From "Seeing Nature First"

See pages 47, 235

On clematis seed-fruits

PHOTOGRAPHS OF A PET MONARCII BUTTERFLY 


\section{THE MEADOW-BROWNS OR SATYRS 295}

from the prevailing low temperatures these caterpillars grow very slowly and apparently a large proportion of them require two years to complete their development. There seems to be some uncertainty in regard to this phase of the insect's life-history, but most entomologists are of the opinion that some of the butterfiies mature in one year while others require two years: that is, the broods are both annual and biennial. There is no doubt that the insect hibernates as a caterpillar, and if this statement about the number of broods is correct some of the caterpillars hibernate when very small, and recently hatched from the egg, while others hibernate when nearly full grown.

The full-grown caterpillars change to chrysalids beneath the shelter of the small stones in practically the same sorts of situation which they have chosen for hiding at night or for hibernation through the winter. Here without any button of silk or silken loop and with scarcely a suggestion of a silken cocoon they change to chrysalids, generally about the first of June. They remain in this condition for perhaps three or four weeks when they come forth as butterflies.

\section{The Arctic Satyr}

\section{Oeneis norna jutta}

This is another butterfly of decided interest because of its geographical distribution. It is normally an inhabitant of the Far North, extending around the North Pole over parts of three continents. Apparently, the only place in the United States where it occurs is a bog a little north of 
Bangor, Maine. This locality is called the Orono. Stillwater bog and is the only place where collectors have been able to find this species.

An even more local insect is another of these mountain butterflies found by $\mathrm{H}$. H. Newcomb on Mount Katahdin, Maine. So far as known this species is confined to the higher portion of this mountain and so is even more distinctly localized than the White Mountain butterfly. It is called the Katahdin butterfly (Oeneis norna liatahdin).

\section{The Little Wood Satyr \\ Cissia eurytus}

This elfin creature has well been named the Little Wood Satyr, although under our modern conditions it is often found in fields and along hedgeroads rather than in the woods. It has, to a marked degree, the delicacy of structure of its allies and its small size serves to emphasize this appearance. It has also a rather general distribution west to the Mississippi Valley, extending from the corner of Dakota, south through Nebraska, Kansas, and central Texas, and north to Wisconsin, Michigan, and New England. It occupies the whole of the United States east and south of the lines thus indicated.

The life-history of this species is very similar to the Common Grayling. The butterflies appear in early summer, deposit their eggs upon grasses, and the resulting larvae feed upon the grasses and grow slowly through the weeks of summer. They become nearly full grown by autumn and hibernate in this condition in such shelter as 


\section{THE MEADOW-BROWNS OR SATYRS}

they can find at the soil surface. The following spring they come forth, probably feeding for a short time, and change to chrysalids in time to emerge as butterflies in May and early June. Practically all observers emphasize the fact that the butterflies are abundant only late in spring or early in summer, generally disappearing before the middle of July. There is thus but one brood a year.

\section{Other Meadow-browns}

The Gemmed Brown (Neonympha gemma) is a small southern species remarkable for the plainness of its graybrown wings which are marked on the upper surface only with two or three dark spots on the middle margin of each hind wing. There are two broods a year.

The Georgia Satyr (Neonympha phocion) is another small southern form, remarkable for the four elongated eye-spots on the lower surface of each hind wing. The shape of these spots distinguishes it at once from the Carolina Satyr (Cissia sosybius) in which the eye-spots are rounded.

\section{Synopsis of Meadow-browns}

Pearly Eye (Enodia portlandia or Debis portlandia). Expanse $2 \frac{1}{4}$ inches. Eyes hairy. Outer margin of hind wings projecting in a noticeable angle. Brown with many distinct eye-spots on both surfaces of wings.

Eyed Brown (Satyrodes canthus or Neonympha canthus). Expanse 2 inches. Eyes hairy. Margin of hind wings rounded, without an angle. Both surfaces of wings pale brown with four distinct blackish eye-spots on each front 
wing near the margin. Five or six such spots on each hind wing.

Common Wood-nymph or Grayling (Cercyonis alope). Expanse 2 inches. Eyes not hairy. Eye-spots on front wings, but not on upper surface of hind wings. The chief geographical races of this abundant species are indicated below, although in regions where the forms overlap many intermediate hybrids occur.

Blue-eyed Grayling (Cercyonis alope alope). A large yellowish-brown blotch near outer margin of each front wing, above and below, with two distinct eye-spots in middle spaces of the blotch. A southern race extending north to central New Hampshire, Michigan, and Wisconsin.

Dull-eyed Grayling (Cercyonis alope nephele). The yellowish brown blotch obsolete or nearly so, but eye-spots present. A northern race extenaing southward only to central New Hampshire, Michigan, and Wisconsin.

Maritime Grayling (Cercyonis alope maritima). Similar to the type form, but with the yellowish blotch tinged with redidish. A race found only near the seacoast.

Southern Wood-nymph (Cercyonis pegala). Expanse 3 inches. Eyes not hairy. General color brown with an orange-yellow blotch near outer margin of each front wing above and below with one eye-spot in middle space of the blotch on the male, and two on the female.

Little Wood-satyr (Cissia eurytus or Neonympha eurytus). Expanse $1 \frac{1}{2}$ inches. Eyes not hairy. General color fawn-brown with two eye-spots on upper surface of each front wing and several on each hind wing.

Gemmed Brown (Neonympha gemma). Expanse $1 \frac{1}{4}$ inches. Eyes not hairy. General color mouse-brown with 
no markings on upper wing surface except a rather indistinct pair or more of spots next the margin of the middle of each hind wing. Under surface indistinctly striped with rusty lines and a few brown and silvery spots on the hind wings directly beneath the spots on the upper surfaces. Occurs in Southern states.

Georgia Satyr (Neonympha phocion). Expanse $\mathbf{1} \frac{\mathbf{1}}{4}$ inches. Distinguished from the related species by the four distinct eye-spots on lower surface of each hind wing, these spots being transversely elongated rather than round. Occurs in Southern states.

Carolina Satyr (Cissia sosybius). Expanse $1 \frac{1}{4}$ inches. Distinguished by the row of round eye-spots near outer margins of lower wing surface. Occurs in Southern states.

\section{THE HELICONIANS}

\section{Family Heliconidae}

This is a tropical family with only a single species migrating northward to our Southern states. The butterflies of this group are characterized by having the wings so long and narrow that their length is usually twice as great as their width. The front legs in both sexes are so poorly developed that they are considered a modification approaching the complete dwarfing found in the Brushfooted butterflies.

\section{The Zebra Butterfiy}

\section{Heliconius Charitonius}

While the butterflies of temperate North America show many examples of marvelous beauty and coloring, one 
must go to the tropics to see the culmination of what nature has done in painting the outstretched membranes of butterfly wings with gorgeous colors. The great butterfly tribes that swarm in tropical forests seldom reach our temperate clime, and even when they do they are likely to show only a suggestion of the splendid size and rich coloring to be seen farther south. The Zebra butterfly (Heliconius charitonius) belongs to one of these tropical tribes. It shows its affinities by its coloring and the curious shape of its wings. In most of our northern butterflies, the wings are about as long as they are wide, but in the tropical family, Heliconidae, they are very much longer than wide. This gives the insect an entirely difierent look from our common forms so that one recognizes it at once as a stranger within our gates. Indeed, it does not penetrate far into our region, being found commonly only in Florida and one or two other neighboring states, its principal home being in tropical America.

The Zebra butterfly is well named, Across the brownish black wings there runs a series of yellow stripes, three on each front wing and one on each hind wing, with a submarginal row of white spots on each of the latter. The under surface is much like the upper, except that the coloring is distinctly paler. It is very variable in size: some specimens may be but two and a half inches across the expanded wings, while others are four inches. (See plate, page 224.)

The Zebra caterpillars feed upon the leaves of the passion flower. When full grown they are about an inch and a half long, whitish, more or less marked with brownish black spots arranged in transverse rows, and partially covered with longitudinal rows of barbed black spines. 
They change to chrysalids which are remarkable for their irregular shape, with two leaf-like projections on the head which the insect can move in a most curious fashion.

One of the most notable things about this insect is the fact that the male butterflies are attracted to the chrysalids of the females even before the latter emerge. Many observers have reported upon this curious phenomenon and have recorded experiments demonstrating that it is a general habit with the species.

\section{The Roosting Habits}

The adult butterflies flock together at night and rest upon the Spanish moss which festoons so many of the trees in the Far South, or upon dead branches. They take positions with heads upward and wings closed, many of them often flocking together to roost, and wandering out to the near-by fields when the morning sun gives them renewed activity. But these butterflies are essentially forest insects. Reliable observers have noticed that when one emerges from a chrysalis it flies up in the air and makes straight for the nearest woods. Others have noticed that when a butterfly in a field is alarmed it also makes for the woods. And in the regions where the species is abundant the butterflies are most likely to be found in paths and glades in the forest. Thus they show the influence of their ancestral habitat in the tropical wilderness.

There seems to be a certain amount of ceremony attending the flocking together at night for roosting purposes. A famous English naturalist, Philip Henry Gosse, saw the performance in the West Indies many years ago and described it in these words:

"Passing along a rocky foot-path on a steep wooded 
mountain side, in the Parish of St. Elizabeth (Jamaica), about the end of August, 184.5, my attention was attracted, just before sunset, by a swarm of these butterflies in a sort of rocky recess, overhung by trees and creepers. They were about twenty in number, and were dancing to and fro, exactly in the manner of gnats, or as Hepioli play at the side of a wood. After watching them awhile, I noticed that some of them were resting with closed wings at the extremities of one or two depending vines. One after another fluttered from the group of dancers to the reposing squadron, and alighted close to the others, so that at length, when only two or three of the fliers were left, the rest were collected in groups of half a dozen each, so close together that each group might have been grasped in the hand. When once one had alighted, it did not in general fly again, but a new-comer, fluttering at the group, seeking to find a place, sometimes disturbed one recently settled, when the wings were thrown open, and one or two flew up again. As there were no leaves on the hanging stalks, the appearance presented by these beautiful butterflies, so crowded together, their long, erect wings pointing in different directions, was not a little curious. I was told by persons residing near that every evening they thus assembled, and that $I$ had not seen a third part of the numbers often collected in that spot."

\section{THE MILKWEED BUTTERFLIES}

\section{Family Lymnadidae}

So far as the great majority of readers of this book are concerned, this family includes but one species-the familiar Monarch or Milkweed butterfly. In the Southern 


\section{THE MILKWEED BUTTERFLIES}

states there is another-the Queen-and in Florida, still a third. The distinguishing characteristics are found in the dwarfed, useless front legs and the absence of scales upon the antennae.

\section{The Monarch}

\section{Anosia plexippus}

From June until October one may often see the stately Monarch flitting leisurely about over fields and meadows. It is one of the largest and most distinctive of these "frail children of the air" and may be easily recognized by its resemblance to the picture opposite page 241 . The veins of the wings are heavily marked in black, with large white dots upon the black bands along the margin. The color of the rest of the wings both above and below is reddish brown.

These butterflies come from the South in spring or early summer. They find milkweed plants and lay their eggs upon the leaves. These eggs soon hatch into small white and black caterpillars that feed upon the milkweed leaves and grow rapidly. One is likely to find them throughout most of the summer, wherever a milkweed shows partially eaten leaves. Bring in the half-grown caterpillars, place them in an open vivarium, and furnish fresh leaves every day or two. The caterpillars will soon mature and change to beautiful green chrysalids with golden markings. This chrysalis has been called "the glass house with the gold nails." (See plates, pages 32-33, 241.)

About two weeks later the glass house will burst open and the butterfly emerge. It will rest an hour or two while its wings and body harden and then it will want to fly 
away. It is not so anxious to do this, however, as most butterflies. If one is kept beneath a good-sized bell-glass, or in a glass-covered box, or even in a closed room, and fed with sweetened water it will soon become so tame that it will perch on one's finger and suck nectar from a flower held in one's hand. On this account it is a particularly desirable butterfly for the amateur photographer to cultivate, because he can easily get many interesting and beautiful pictures by posing the butterfly on different flowers.

\section{The Change from Caterpillar to Butterfly}

The change from the caterpillar to the butterfly is easier to watch in this species than in most others. The full-grown caterpillar spins-sometimes on the under surface of the milkweed leaf, sometimes elsewhere-a little mat of silk in which it entangles the hooked claws of its hind feet. Then it lets go with its fore feet, and hangs downward with the front end of its body curled upward. In this position it remains for some hours-perhaps a day - the body juices gravitating downward and causing a swollen appearance on the lower segments. Then the skin splits apart and is wriggled off by the contortions of the body. When it finally drops away, there is left a strange-looking creature, broader below than above. This is a transition stage that lasts but a very short time: soon the form is entirely changed so that the broadest part is above instead of below. The definite outline of the chrysalis is soon taken on, the outer tissues hardening into a distinct covering. The insect is now a beautiful green with wonderful golden spots upon its surface and a few black spots just below the black "cremaster" by which the chrysalis is connected with the web of silk upon the leaf. 
In this quiet chrysalis the insect remains for nearly a fortnight. Then the structure of the forthcoming butterfly begins to show through the thin outer covering and you know that the period of the chrysalis is nearly ended. If you keep watch you will probably see the sudden bursting of the outer envelope and the quick grasping of its surface by the legs of the newly emerged butterfy. Its wings at first are short and crumpled, bearing little resemblance to those of the fully developed butterfly. But as it hangs there with one pair of legs holding to the empty chrysalis and the other to the leaf above, the wings rapidly lengthen, hanging limply downward, and the body juices penetrate the veins. A little later they expand in the other direction, the hind wings reaching full size before the front ones do. Finally both pairs of wings are fully expanded, and the butterfly is likely to walk to the top of the support, where it rests for an hour or two while its tissues harden, before it attempts to fly.

In early autumn out of doors these butterflies start southward on their long journey. They often gather in great flocks and roost at night on wayside shrubs and trees. At this season it is easy to catch them in an insect net and bring them indoors for pets. They live for a long while and lend interest and beauty to living room or window garden. To the photographer they offer opportunities for attractive indoor pictures. (See plates, pages 32-33, 160, 225.)

\section{The Queen}

\section{Anosia berenice}

The general form and color patterns of this fine butterfly show at once that it is related to the Monarch. Its gen- 
eral colors are chocolate-brown and black, dotted and spotted with white. The eggs are laid upon milkweed and the life-history is much like that of the Monarch. One of the most interesting facts in connection with this species is that it seems to be mimicked by the Vicereine butterfly in the same way that the Monarch is mimicked by the Viceroy.

\section{THE SNOUT BUTTERFLIES OR LONG-BEAKS}

\section{Family Libytheidae}

One has a suggestion of Hobson's choice in the common names of this unique family. If Snout butterflies does not seem sufficiently elegant as a descriptive phrase for such delicate creatures, he can call them the Long-beaks, until he sees that this also is inadequate. As a matter of fact both are misnomers, for the projection from the head that gives them these names is neither a snout nor a beak. It is simply a pair of palpi unusually developea, which perhaps in an early stage of butterfly history served a useful purpose. At present, however, they serve chiefly to set the few owners apart from the other butterflies in the system of classification; although possibly they may also serve the butterfly by helping to give the impression of a leaf attached to a twig. (See plate, page 240 .)

\section{The Snout Butterfy}

\section{Hypatus bachmani}

There is a peculiar interest in any form of animal life which can be definitely traced far back through the geologic ages. In nearly every group of living creatures 
there are certain types which scientists have found were once abundant but which now are on the wane. As a rule these are better represented in the museums through fossil species than by those now living. To a considerable extent also such forms are likely to present various features which mark their primitive condition and the living allies have peculiarities which set them off as distinct from those of their own relations which have been modeled in a more modern fashion. Among the mammals the curious marsupials, of which our southern opossum is an example, furnish good illustrations of this general truth. Among the birds the curious little Least Bittern is an example. Among the butterflies the strange Snout butterfly is by far the best example.

These Snout butterflies, of which only two species are now living in North America, are the sole representatives with us of the family Libytheidae or the Long-beaks. Only one of these species occurs to any extent at least north of Texas. It is the curious little creature called the Snout butterfiy. It has a strange appearance due to the angular outline of both front and hind wings and the long palpi which project forward from the head in a way to attract attention. The common name is due to these projecting palpi. Even the coloring is primitive, the general tone of the wings being blackish brown, distinctly marked with white and orange spots. The under surface is less primitive in its coloring, being toned in iridescent grayish brown in a way to suggest protective coloring, except in that part of each front wing which is not hidden when the insect is at rest. This shows the white and orange-brown markings.

Some years ago there were found in certain fossil de- 
posits in the West about a dozen species of fossil butterflies. It is strange indeed that these ethereal creatures should be fossilized at all. One would think it scarcely possible that they could be so preserved that a million years after they had died man should be able to study them, determine to what families they belonged, and even guess with a high probability of accuracy upon what leaves their caterpillars fed. This little collection of fossil butterflies was studied by one of the great American authorities on living butterflies, the late Samuel H. Scudder, who said of them: "They are generally preserved in such fair condition that the course of the nervures and the color patterns of the wings can be determined, and even, in one case, the scales may be studied. As a rule, they are so well preserved that we may feel nearly as confident concerning their affinities with those now living as if we had pinned specimens to examine; and, generally speaking, the older they are the better they are preserved."

A curious fact is that out of the comparatively few species of these fossil butterflies two were easily recognized as members of this Long-beak family. They were given special scientific names and undoubtedly were closely related to the Snout butterfly which is still flying every year in various parts of the United States. Our modern species lays its eggs upon the leaves of hackberry and in these geologic deposits of that far-gone era there have been found well-preserved leaves of old hackberry trees, upon which it is extremely probable that the caterpillars of these ancient Long-beaks fed. What an opportunity for a modern collector of butterflies to work his fancy, as he thinks of those old times when these fossil creatures were flying in the sunshine, depositing their eggs upon the 
leaves of trees that made up landscape pictures probably very different from those of to-day! And how he wonders what flowers these butterflies visited for their nectar food, what birds chased them from tree to tree, and what mammals wandered through those ancient forests. What a suggestion also it gives of the continuity of life upon our old earth to realize that these butterflies of to-day are carrying on their brief existence in practically the same way that these forbears of theirs did so many millions of years ago.

Another way in which these butterflies are peculiar is the fact that the females have six well-developed legs while the males have only four. As already indicated the caterpillars feed upon hackberry. When full grown they are about an inch long, dark green, striped with yellow, with two blackish tubercules on the second ring behind the head. They apparently pass the winter in the chrysalis stage. The butterflies are likely to be found along the borders of brooks or streams running through woods, or along the margins of the forest. Occasionally they become abundant in certain localities, but on the whole they are rare and highly prized by collectors.

\section{THE METAL-MARKS}

\section{Family Riodinidae}

This small family of very small butterflies contains five genera and a dozen species found in the United States and Mexico. Only two, however, occur in the eastern region and only one extends much north of the Gulf states. Aside from certain peculiarities of the wing-venation (a 
costal and a humeral vein on the hind wings) these Metalmarks may be known by their minuteness and the bright metallic markings on the brown wings.

Both our eastern species belong to the genus Calephelis. The Small Metal-mark (C. caenius) has been collected in Florida and Georgia. The wings are rusty red on both surfaces, brighter below than above, and marked with blackish spots that almost converge to form stripes; in addition to which there are, beyond the middle of each wing, two lines made by special scales that glisten with a steel glitter. The wings expand only about three quarters of an inch. So far as I can learn, the egg, larva, or pupa have never been described.

The Large Metal-mark is called by science Calephelis borealis, but it deserves the latter name only in the sense that it is more northern than its allies. It has been collected as far north as New York and Michigan, but it seems to be very seldom found, at least in eastern regions. It expands a little more than an inch. The general color of the wings is yellowish brown, marked with blackish dots and lines, together with rows of steely spots on the under surface. In this case also the life-history is unknown.

\section{THE GOSSAMER-WINGS}

\section{Family Lycaenidae}

The daintiest and most delicate of all our butterflies are included among the Gossamer-wings. Their bodies are small and slender, their antennae ringed with white and almost threadlike, their wings thin and of exquisite beauty. Many of them are marked with the slenderest of tailed 


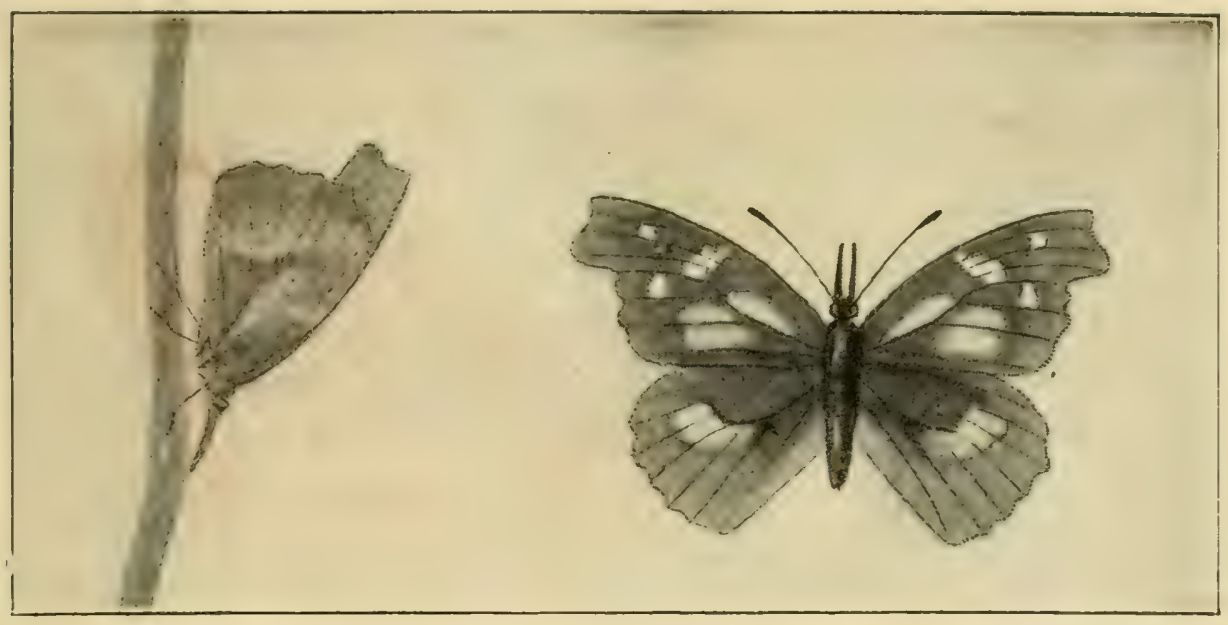

See page 236

THE SNOUT BUTTERFLY IN FLIGHT AND AT REST

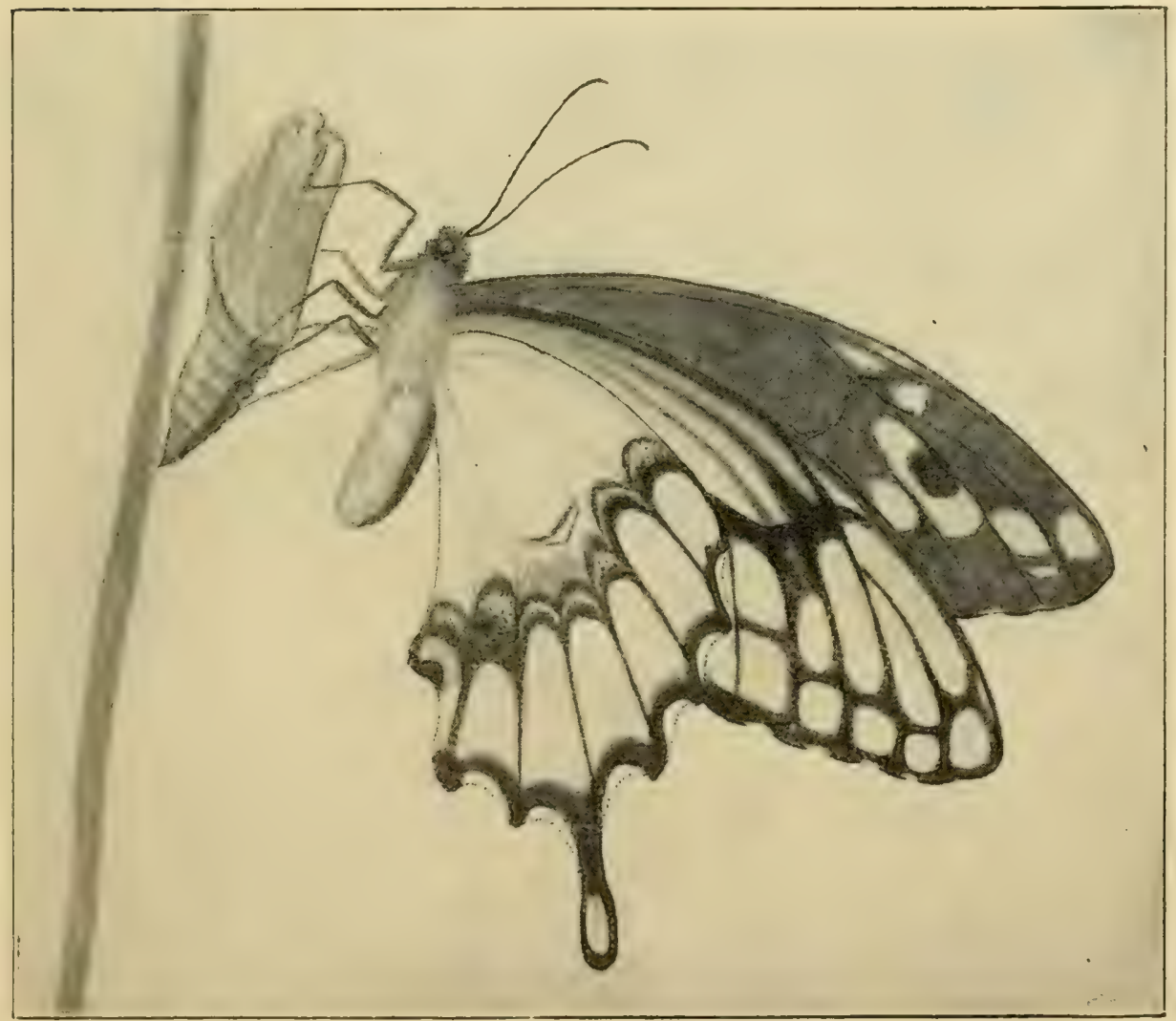

See page 62

GIANT SWALLOITAIL JUST OUT OF THE CIIRYSALIS 


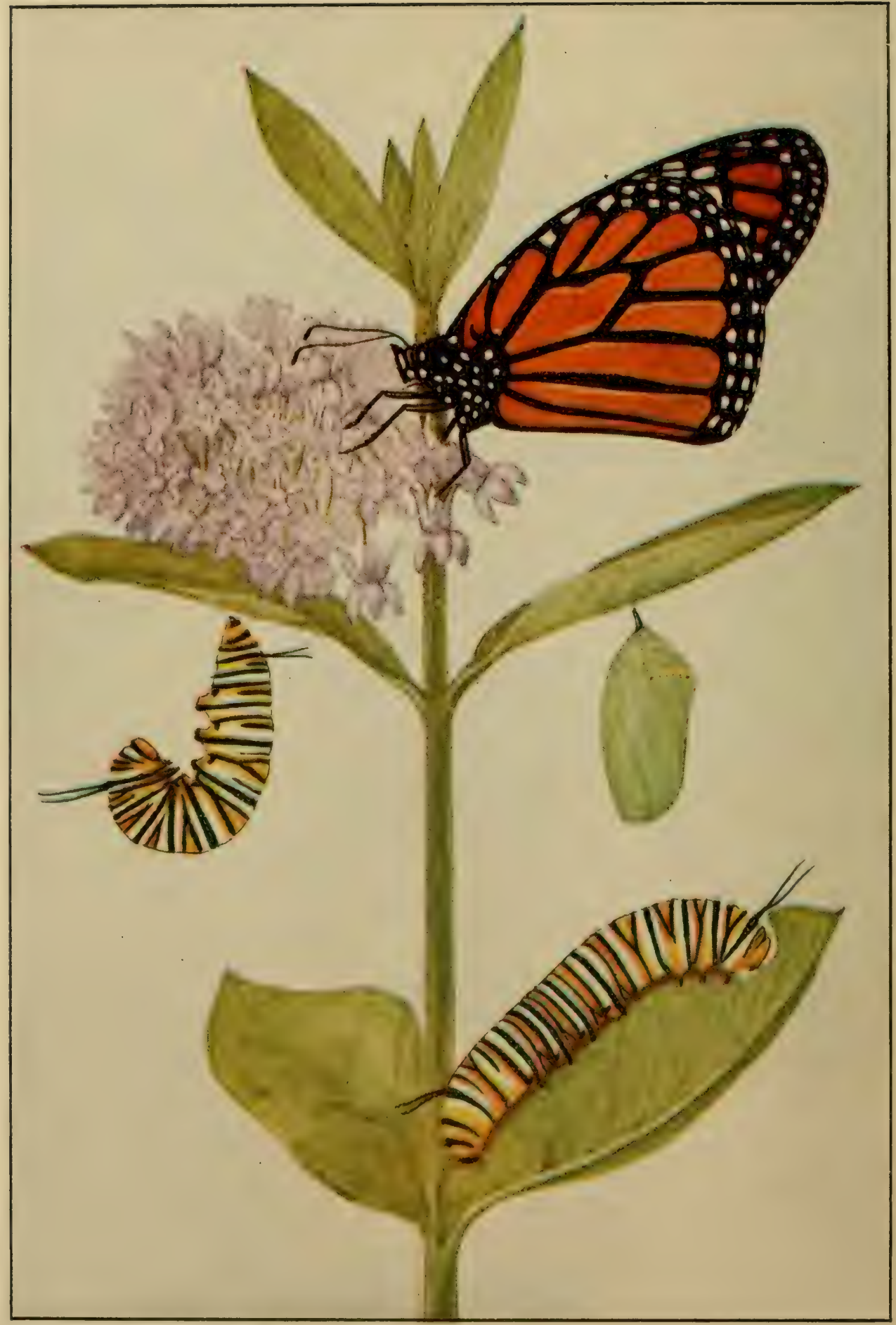

From a drazing by W.I. Beecroft

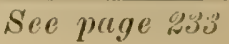

THE MONARCH BUT'PERFLY

Caterpillar feeding; caterpillar hung up for pupation; chrysalis, and adult 
projections from the hind wings. When the face is viewed from in front it is seen to be much narrower than its height. At the insertion of the antennae the eyes are notched, and they are also more or less surrounded with white scales. Most of the caterpillars have oval, slug-shaped, smooth bodies, with the under surface flattened, and very small heads, which in many species can be extended by means of an extensile neck. The chrysalids are held in place by silken threads both at the tail and over the middle. They are rounded, short, and stout.

Notwithstanding their small size, the Gossamer-wings are among the most spritely of all our butterfies. They seem indeed winged sprites, playing everywhere, in fields and open woods, along roads, lanes, and brooks, in dooryards and gardens-wherever, in fact, a bit of open space invites their presence. Not alone upon the wing but even when at rest does their liveliness appear. For most of these butterflies have the curious habit of keeping the hind wings in motion after alighting, rubbing them against each other in a vertical plane or "moving them backward and forward when half expanded." These habits are so fixed that when one sees a butterfly thus engaged one can pretty certainly conclude it is a member of this family.

The Gossamer-wings are commonly separated into three rather distinct tribes-the Hair-streaks, the Coppers, and the Blues. The characteristic features are these:

Three branches arising from the radius of each front wing. Under surface of hind wing commonly marked with threadlike streaks: the Hair-streaks.

Four branches arising from the radius of each front 
wing. Under surface of hind wing commonly marked with spots rather than lines.

Colors brownish red: The Coppers.

Colors blue: The Blues.

\section{THE TRIBE OF THE HAIR-STREAKS}

The Hair-streaks are small butterflies with the eyes notched to allow for the insertion of the bases of the antennae. The name is given on account of the fine, hair-like markings which extend across the under surface of the hind wings. In many species there is a tailed projection or two on the hind inner margin of the hind wing. The caterpillars are remarkable for the small head, so connected with the body that it can be pushed forward in a characteristic way.

The Hair-streaks are among the most exquisite and delicate of all our butterflies. A large proportion of them have the upper surface of the wings toned in beautiful hues of grayish brown and the under surface lighter gray, marked with dots and stripes, some of which are brilliant in coloring. A few of the larger species are brilliantly iridescent in purples, blues, and greens, marked with black. The males have well-developed scent-pockets in many species, these being commonly along the front border of the front wing.

A very interesting suggestion in regard to the possible function of the curious tail projections was made nearly a hundred years ago by some English entomologists and has since been discussed at considerable length in various publications. It is that the slender tails, together with the 


\section{THE TRIBE OF THE HAIR-STREAKS 243}

enlargement of the wing just back of them, give the impression of a false head. Along with this unusual development of the wing is to be considered the fact that these butterflies nearly always alight head downward so that the false head, furnished with what seem to be waving antennae, takes the place that would naturally be occupied by the true head. Instances have been reported in which this false head has apparently been nipped off by a lizard and much evidence has accumulated to indicate that this curious device may be a real protection in many cases. Of course, the loss of the tails and the part of the wings. adjacent would be comparatively insignificant. In most cases, these projections on the wings are held at right angles to the plane of the wing.

While nearly half a hundred species of Hair-streaks have been found in North America, only a few of these are sufficiently abundant to require discussion in this little book.

\section{The Great Purple Hair-streak}

\section{Atlides halesus}

It seems something of a reflection on the activities of American entomologists to say that, after the lapse of more than a century since Abbott studied the insects of Georgia, our knowledge of the early stages of two of the largest Hair-streak butterflies is still confined to the observations he made. Yet this is true, and one of themthe Great Purple Hair-streak-is the largest species of the group that occurs in the eastern United States. The other is the White-M Hair-streak. 
The Great Purple Hair-streak is a beautiful, iridescent blue creature, as seen from above, with blackish borders around the blue. As seen from below, the wings are dark brown, with red spots near the body. The two tail-like projections are quite long. It is very large for the group to which it belongs, measuring nearly two inches across the expanded wings. It is a tropical form, extending into our southern borders from California to Florida and occasionally occurring north as far as southern Illinois. The larvae feed on oaks. (See plate, page 256.)

\section{The White-M Hair-streak}

\section{Eupsyche M-album}

The White-M Hair-streak is about two thirds the size of the Great Purple species with less blue and more ick on the upper wing surface. The hind tail is slender and well developed, and the angle of the wing just back of it is rounded out in an unusual fashion. The lower surface of the wing is of a general grayish brown color, marked by a white stripe, which takes the form of the letter $\mathbf{M}$ : hence its name. This is also a southern species occurring at times as far north as Ohio and even Atlantic City, New Jersey. The caterpillars feed upon the leaves of oak and Astragalus or milk vetch.

There is also a third species of this group of whose history we are ignorant except for Abbot's observations. It is an exquisite little butterfly called the Least Purple Hair-streak (Calycopis cecrops) and is apparently a tropical form which has spread into our Southern states. It is especially heautiful because of the brilliant red and 
white lines running across the under surface of both wings. It occurs as far north as West Virginia and Kentucky and ranges westward at least to the Mississippi Valley.

\section{The Gray Hair-s'treak}

\section{Uranotes melinus}

This exquisite little creature is capable of surviving under a great variety of climatic conditions. It ranges from New Hampshire to Florida and Central America, but apparently occurs only rarely north of the United States. Perhaps the most distinctive feature in the female is the orange spot just in front of a pair of tiny tails on each hind wing, the rear one being curiously curved and about. three times as long as the other. In the male the shorter tail is absent. The general color of the upper surface is a dark bluish gray, relieved on the margin of each hind wing by a few white dots and the orange spot already mentioned. The under surface is much lighter gray, distinctly marked with two dark brown lines near the margin, the outer line little more than a row of spots and the inner line with a white edge. (See plate, page 25\%.)

These small butterflies lay tiny though beautiful eggs upon a variety of plants. The eggs hatch into curious little caterpillars that have the appearance of slugs with small heads which can be extended as if the little creature had really a rubber neck. The object of this extensile head is seen when one finds the larvae feeding upon the fruits or the seed-pods of its various food plants-hawthorn, hop, hound's-tongue, and St. John's-wort. The eaterpillar is able to thrust its jaws into the interior of the 
seed-pods and devour their contents. There seem to be generally two broods in a season, even in the more northern parts of its range, while toward the south there are probably at least three broods. The butterflies are found upon the wing almost any time in summer, especially from early June until late in August.

\section{The Banded Hair-streak}

\section{Thecla calanus}

This is one of the most familiar of the delicate little butterflies grouped in the genus Thecla. It occurs rather commonly in a great stretch of territory extending from Maine, west to Nebraska, south to New Mexico and Texas, and east to Alabama and Georgia. It also occurs in a limited area on the coast of California. The general color of the upper surface is a dark brown, which in the male is marked near the front edge of the fore wings with a distinct gray patch of scent scales. The under side is similar in color to the upper except that the outer half of the wing is marked by two series of broken lines in white, blue, and brown and a brilliant bit of coloring just in front of the tail projection of the hind wings; this coloring shows beautiful tones of red, blue, and black.

These little butterflies may often be seen visiting the midsummer flowers but are fully as likely to be found along the sides of a shady road, where they rest upon the leaves of trees, shrubs, and herbaceous plants. When disturbed, they fly up in small companies but soon settle back again into their previous positions. They are lovers of sunshine and may often be seen upon a leaf, with fully expanded 


\section{THE TRIBE OF THE HAIR-STREAKS}

wings, taking a sun-bath. There is but one brood a year, butterflies appearing early in summer and remaining for several weeks. They lay their tiny pale green eggs upon the leaves of various trees, especially oaks and hickories, and probably hawthorns. It is not known whether these eggs remain unhatched as a rule until the following spring, or whether they soon hatch and the young caterpillars hibernate without feeding. It is probable that both conditions occur. In spring the larvae eat holes in the leaves of their food plant and grow rather slowly, gradually becoming brown or green slug-like caterpillars about half an inch long. They finally change into greenish brown chrysalids from which the butterflies emerge in early summer.

\section{The Striped Hair-streak}

\section{Thecla liparops}

In the Eastern states the distribution of this species is almost the same as that of the Banded Hair-streak, but in the Central West the outline of its region moves northward extending into Canada, above North Dakota, and into Montana and Wyoming. It does not go so far south, however, extending practically only to the southern borders of Kansas and Missouri. The butterfly bears a striking general resemblance to the other species just named, differing chiefly in the fact that the under surface of the wings is much more thickly marked with broken lines that extend nearer to the body. As a rule, it is not common and consequently it is prized by collectors. Some good observers have noticed that it is more likely to be found 
only on flowers, instead of sunning itself on leaves. It is single-brooded, hibernating either in the egg state or in that of the young larvae. The food plants are varied, there being good evidence that the caterpillar feeds upon all of these: apple, plum, shadbush, blueberry, holly, chestnut, willow, thorn, and several kinds of oaks. Mr. W. F. Fiske found a chrysalis of this species in the deserted nest of a tent caterpillar in New Hampshire in early June, the butterfly emerging later in the month.

\section{The Acadian Hair-streak}

\section{Thecla acadica}

This is one of the numerous butterflies that offers some young student an opportunity to make real contributions to science. It is a beautiful little creature, expanding scarcely an inch across its outstretched wings, found from New England west to Montana along a rather restricted area, which coincides pretty closely with the southern part of the Transition Zone. There is a form on the Pacific Coast which is commonly considered to be this same species.

These butterflies appear during July and August. They visit various flowers but are especially likely to be found near willow thickets along the borders of brooks and swamps. It is supposed that the eggs are laid upon the willows and that they remain unhatched until the following spring. Then they develop into little caterpillars that feed upon the willow leaves and mature in time to form chrysalids early in June. These chrysalids in turn disclose the butterfly early in July. So far as I know the eggs 
themselves and the situation in which they are laid have never been described.

\section{The Olive Hair-streak}

\section{Mitoura damon}

Very few butterflies have the distinction of showing a clear case of protective resemblance to one kind of plant in both the adult and the larval stages. This is the case, however, with this Olive Hair-streak which is so intimately associated with our common red cedar, that where one is found the other is likely to occur, although both caterpillars and butterflies are seldom seen because they resemble the twigs of the cedar so closely.

Along the Atlantic Coast this little butterfly occurs from New Hampshire to Florida, and westward to a line drawn from Dakota to Texas. The upper surface of the wings is rather dark olive-brown and the under surface, so far as it is exposed when the butterfly is resting, is of a greenish hue that harmonizes with the green of the red cedar twigs. There are also, on the under surface, some irregular lines and dots of red, brown, and white which probably help in rendering the insect inconspicuous when it is resting among a cluster of twigs.

The yearly history of this beautiful little butterfly differs from that of most of its relatives. The species winters in the chrysalis state, the first brood of butterflies bursting forth early in May. These lay their eggs upon or between the scales of the red cedar twigs, especially those which bear flowers. About a week later the eggs hatch into tiny caterpillars that feed upon the scale-like leaves, 
continuing to eat and grow for nearly six weeks before they reach their full size. These caterpillars are so similar in color that they are difficult to see, and they have a remarkable protective device in that the first ring behind the head is developed into a shield which covers the head, hiding it so completely that the movement of the jaws in feeding is effectively concealed. Late in June they change to chrysalids, part of which appear to remain in this condition until the following spring, while most of them give forth a second brood of butterflies in July. These butterflies lay eggs for a second brood of larvae that mature into chrysalids during September, and hibernate in this condition until the following spring. Consequently, in the Northern states, the collector should look for fresh specimens in May and early June and again in July and early August.

These butterflies visit various flowers, apparently preferring rather small blossoms, such as those of the Mouseear Everlasting, which is in bloom when the first brood is flying, and the various members of the mint family, especially spearmint, as well as the sumacs, which are in bloom when the second brood is on the wing. The time between flower visits seems to be spent at rest upon the red cedar branches, and one of the surest ways to find the butterflies is to give these trees a sudden jar, which starts them into flight. In fact, they may often be seen flying around the tops of the cedars a score of feet from the ground.

\section{Synopsis of the Hair-streaks}

Great Purple Hair-sireals (Atlides halesus or Thecla halesus). Wing expanse $1 \frac{3}{4}$ inches. Upper wing surface 


\section{THE TRIBE OF THE HAIR-STREAKS 251}

bright blue with blackish margins, the blackish coloring extending nearly to the middle in the female. Two distinct tails on each hind wing. Under surface sepia brown with blue and red spots. Abdomen orange below.

White-II Hair-streak (Eupsyche m-album or Thecla $m$-album). Wing expanse $1 \frac{1}{3}$ inches. Upper wing surface blue with wide blackish margins in both sexes. Under surface marked with whitish lines suggesting the letter $\mathrm{M}$, with a reddish spot near it. Each hind wing with two small tails.

Least Purple Hair-streak (Calycopis cecrops or Thecla cecrops). Wing expanse 1 inch or less. Upper wing surface dark brown, more or less marked with blue, especially at base of front wings and inner half of hind wings. Under wing surface marked with a brilliant red line edged outside with white. Two very fine tails on hind wings with brightly colored spots near their base on lower surface.

Gray Hair-streak (Uranotes melinus or Thecla melinus). Wing expanse $1 \frac{1}{5}$ inches. Upper wing surface bluish gray with a brilliant red spot at base of tails on hind wing. Lower wing surface much lighter gray, each wing marked with a brown and white stripe and a row of dots nearer the margin.

Banded Hair-streak (Thecla calanus). Wing expanse $1 \frac{1}{5}$ inches. Upper wing surface dull dark brown, commonly without markings although sometimes there is an orange spot on each hind wing. Lower wing surface a little lighter than upper with bright red and blue spots at the base of the tiny tails, and with distinct narrow blue and white broken bands extending across the outer half of each wing. 
Striped Hair-streak (Thecla liparops). Wing expanse 1 inch. Very similar to the Banded Hair-streak, but having more white markings on the lower surface of the wings.

Acadian Hair-streak (Thecla acadica). Wing expanse $1 \frac{1}{3}$ inches. Upper wing surface blackish brown with a slaty tinge, and red spots at base of the single short tail on each hind wing. Lower surface bluish gray with many small blackish spots edged with white arranged in two principal rows on the outer half of each wing. Larger orange-red spots on each side of base of the tail on each hind wing.

Olive Hair-streak (Mitoura damon or Thecla damon). Wing expanse 1 inch or less. Upper wing surface olivebrown, more yellow in the male than the female. Tips of tiny tails on hind wing whitish. Lower surface green except where upper wing is covered by lower: this part is brown. The green is marked with a row of white spots on each front wing and two distinct rows of brown and white spots on each hind wing, with black spots between.

\section{THE TRIBE OF THE COPPERS}

The members of this tribe are well characterized by their name, for most of them show on the upper wing surface tones of coppery brown, more or less marked around the margin with darker shades. On the under side of the tarsi there are numerous spines in irregular clusters. In the chrysalis there are curious hair-like projections on the skin, which are short and shaped like tiny toadstools or mushrooms, 


\section{THE TRIBE OF THE COPPERS}

While some of the Coppers are very abundant, the majority are rather rare. Only a few species are sufficiently widely distributed to require description here.

\section{The Wanderer}

\section{Feniseca tarquinius}

In many orders of insects there are whole families whose larvae are habitually carnivorous, feeding entirely upon other kinds of insects. This is especially so in case of the beetles, the flies, the true bug's, and the great order to which the bees and wasps belong. Among the scalewinged insects, however, carnivorous caterpilicis are rare, seldom occurring among the moths and in hardly more than one species among the butterflies. This one exception is the modest-looking little butterfly fancifully called the Wanderer, perhaps because instead of frequenting the flowery fields where other butterflies congregate it wanders in and out among the alders by brooks and punds, alighting oftener upon a leaf or twig than upon a flowerthe latter apparently lacking for it the attraction it has for other butterflies.

If you watch one of these copper-hued creatures for awhile, however, you will soon see that its wandering is not aimless but has rather a method all its own. Perhaps you will see it alight upon an alder twig on or above which you are likely to notice curious woolly white excrescences. If you are close enough you will probably see the butterfly uncoil its tongue and sip up a liquid on twig or leaf-the exudations of the woolly aphids that make up the supposed excrescence and suck the sap from 
the bark. Much of this sap passes through the bodies of the aphids and collects in liquid globules on twigs and leaves, forming a sort of honey-dew which is much sought after by flies, wasps, and other insects. It seems to form the chief sustenance of these Wanderers.

But many of these butterflies have another purpose besides that of sipping the honey-dew. Should you watch one of the mother butterflies carefully you would be likely to see her alight on or near a colony of woolly aphids and run rather rapidly over them in a wasp-like manner, finally stopping long enough to lay a tiny, roundish, slightly flattened egg upon the twig, generally on the under side, and only one in a place. Then she may continue her way, wandering lazily along the alder-bordered stream.

Let us now centre our interest upon the egg. Three or four days later it hatches into a curious caterpillar. Instead of having mouth parts fitted for biting leaves as is the case with most butterfly larvae, it has one fitted for grasping, piercing, and sucking the juices of the plump bodies of the aphids, which it finds hard by its place of birth. It also has silk spinnerets connected with its mouth, so it is able to spin a web to shelter it from being run over by its intended victims.

The newly hatched larva is not slow to take advantage of the facilities with which it is provided. It at once begins to spin a web above and around itself, from the and of which it reaches out for the nearest aphids, sucking iheir life-blood and casting their empty skins to the discard of its protecting web. The skins thus serve as an additional shelter so that, as the caterpillar moves forward, increasing the number of its victims from day to day, it extends its web and the protection of the cast skins in- 
termingled with it, while through all-the cast skins, the silken web, and even the hairs on the body of the caterpillar-there runs a woof of the woolly excretion-effectually concealing the larva from sight.

The woolly aphids thus serve as the sole food of the caterpillar during its brief life as a larva. Perhaps because of the pre-digested nature of its food, it is able to mature much sooner than most butterfly larvae. In about eleven days after hatching it is ready to change to a chrysalis, having undergone during this period only three moults, instead of at least four as with other caterpillars. Each caterpillar then changes to a chrysalis which is remarkable because the form and color of its back bears a striking resemblance to the face of a miniature monkey. It remains in this condition nearly a fortnight and then emerges as a butterfly.

In New England and the Northern states the short life of the larva enables this insect to mature three broods each season. Farther south there are probably more, for this species is widely distributed in eastern North America, occurring from Nova Scotia to Georgia and west to the Mississippi Valley.

\section{The American Copper}

\section{Heodes hypophlaeas}

This little butterfly is one of the most generally abundant insects in the northern part of North America. It commonly occurs from ocean to ocean, from the Hudson Bay region to the latitude of Georgia, and it flies freely in city parks and village yards as well as in the more open 
spaces of field and forest. When seen through a lens it is very beautifully colored, the coppery red of the wings being overspread with conspicuous black dots and a touch of orange around the outer border. The expanded wings measure just about an inch, so that this is one of the smallest of our common butterflies.

The caterpillars of the American Copper feed upon sorrel, one of the commonest weedy plants of waste places everywhere. The rusty red blossoms of the sorrel harmonize in color with the color of the butterfly, which is frequently to be seen flying slowly above the plants, stopping now and then to lay its eggs singly upon the leaves or stems. Each egg soon hatches into a curious caterpillar, which looks more like a slug than the usual type of butterfy larva. It feeds upon the succulent tissue of the sorrel leaf, at first biting small holes in the under surface. As it gets larger it feeds more freely and is likely to make channels instead of holes. It matures in about three weeks, changing into a chrysalis under the shelter of a stone or board. A little later it again changes to a butterfly.

There is an interesting variation in the number of broods of this butterfly each season. In regions where it has been studied it has been found to be double-brooded in northern New England and triple-brooded in southern New England and the Atlantic states. It is probable that in its far northern home in the Hudson Bay territory it is only single-brooded. It is thought that the insect hibernates as a chrysalis.

These little butterflies are so small and fly so near the ground that they are likely to be overlooked by the casual observer. They frequently alight to sun themselves or to 


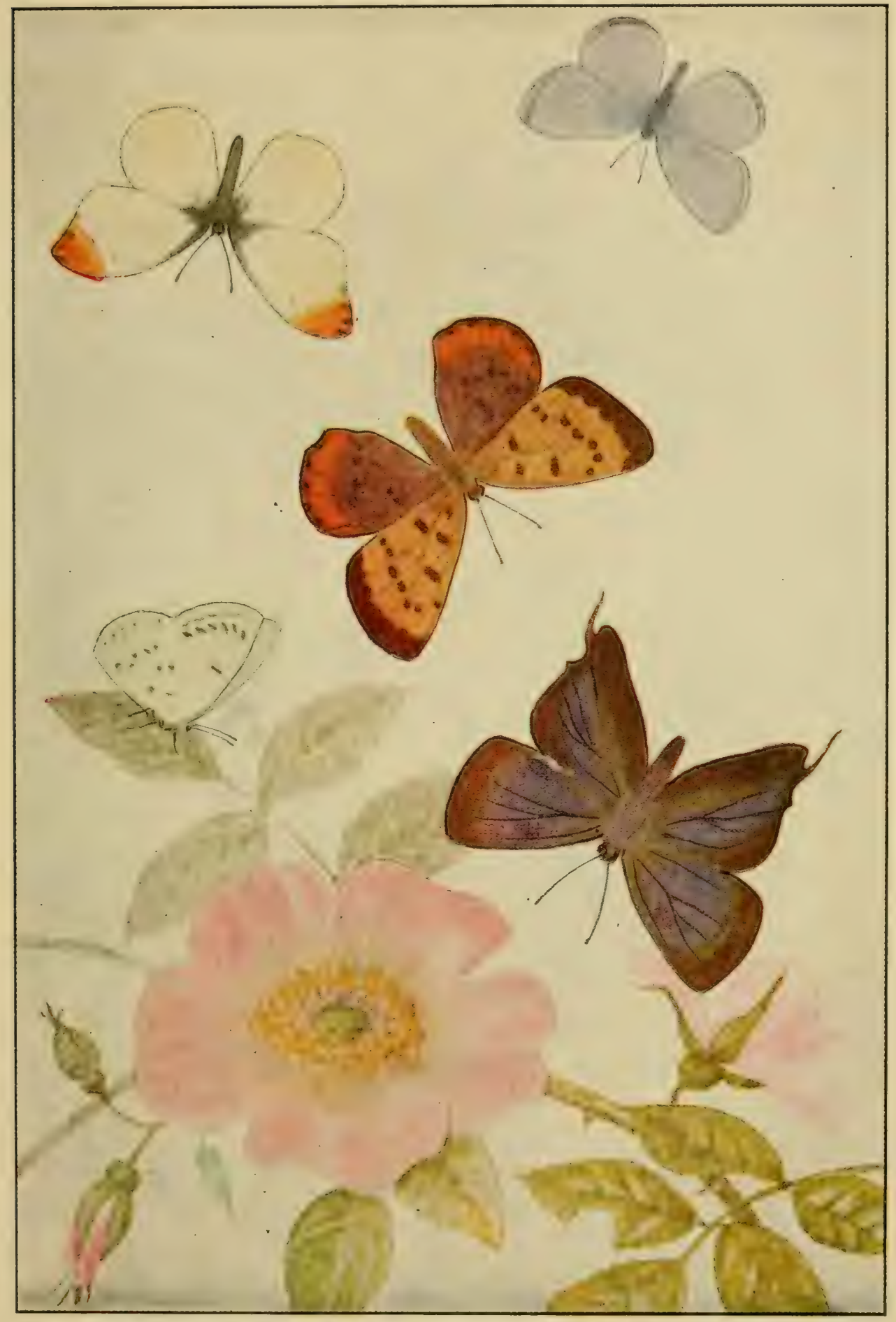

From a drazeing by W. I. Beecroft

FIVE INTERESTING BUTTERFLIES

The Spring Azure (p.2.58) at the top; the Falcate Orange-Tip (p. 9.4) next; the Bronze Copper ( $p .25 \%)$, female, next; the Spring Azure ( $p .58$ ) resting on a leaf, next; and the Great Purple Hairstreak (p. 243), female, below 


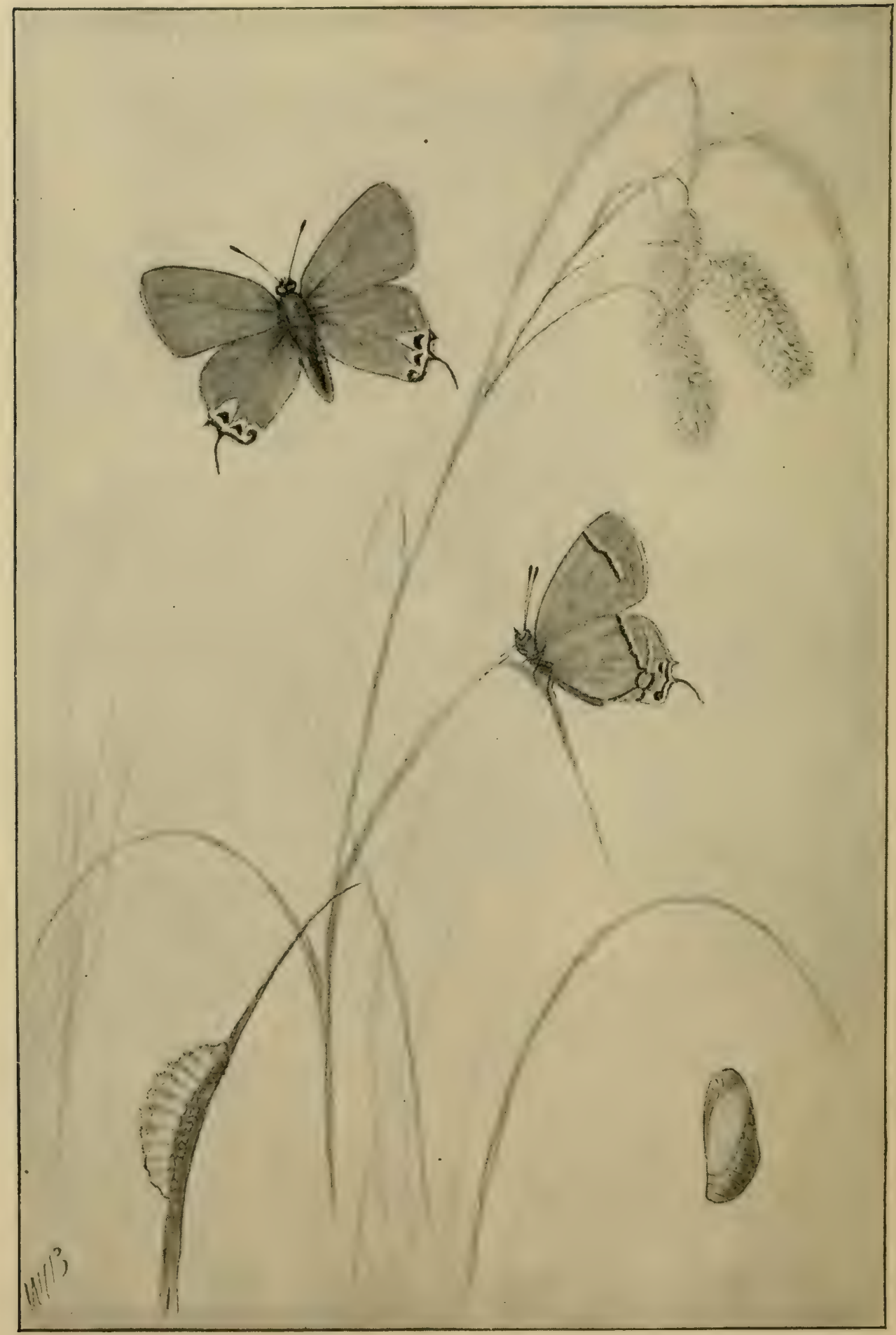

See page 245

STAGES OF THE GRAY IIAIR-STREAK 
sip nectar from many kinds of flowers. They begin their day's work early in the morning and continue well into the evening'. Then they find a roosting-place, head downward upon a blade of grass, where they sleep until wakened by the morning sunshine.

\section{The Bronze Copper}

Chrysophanus thoe

This butterfy is nearly twice as large as the American Copper to which the female of the present species bears a striking resemblance. The Bronze Copper is a rare species, occurring from New England nearly to the Rocky Mountains. The slug-shaped yellowish green caterpillar feeds upon dock and related plants. (See plate, page 256.)

\section{Synopsis of the Coppers}

The Wanderer (Feniseca tarquinius). Wing expanse $1 \frac{1}{4}$ inches. Upper wing surface tawny brown, each wing more or less marked with dark brown spots, the distinction between the colors being clear-cut, and the lines between having an angular effect. Lower surface of front wings similar in colors to upper with dark spots rectangular. Under surface of hind wings mottled with irregular spots of pale brown.

American Copper (Heodes hypophlaeas or Chrysophanus hypophlaeas). Wing expanse 1 inch. Upper surface of front wings tawny orange with margins and rectangular spots blackish. Upper surface of hind wings coppery red with a tawny orange band on outer margin. Lower surface of front wings much like upper surface; that of hind 
wings grayish marked with dark spots and an orange line near the margin.

Bronze Copper (Chrysophanus thoe). Wing expanse $1 \frac{1}{2}$ inches. Male. Upper wing surface coppery brown marked with dark spots and a tawny orange sub-marginal band along outer margin of hind wings. Under surface of front wings lighter orange with blackish spots and of hind wings grayish with blackish spots and an orange submarginal band. Female. Upper surface of front wings tawny orange with blackish spots.

\section{THE TRIBE OF THE BLUES}

These beautiful little butterflies are well named, for the majority of them are colored in exquisite tints of blue. They are distinguished from the Coppers by this blue coloring, as well as by the fact that the spines on the under side of the tarsi are arranged in rows rather than in clusters and are comparatively few in number. The body is rather slender and the under surfaces of the wings are generally dotted in a characteristic fashion. Most of the two score or more species found in North America occur on the Pacific Coast or in the Southwest, less than half a dozen being common in the eastern region.

\section{The Spring Azure}

Cyaniris ladon

For a wee bit of a gossamer-winged creature that expands scarcely an inch across its outstretched wings, the 
Spring Azure has caused American scientists an immense amount of patient labor. Over the vast territory from Labrador across to Alaska and south to the Gulf of Mexico, this little blue butterfly exists in so many different forms that it requires special analytical keys to separate them. Not only does it vary geographically so that in one locality we find one form and in another a different form, but it also varies seasonally to a marked degree. As one would expect there is a striking difference in its annual cycle between Labrador and the Gulf Coast. In the far northern region there is but one brood a year, while in the southern region there are at least two and perhaps more.

The variations in this butterfly are shown by the differences in the marking of both surfaces of the wings. These markings may run from a faint blackish border along the extreme margin and a few faint dots upon the under surface, to a wide black margin around the wings and a deep abundant spotting of the under surface. The markings of the various forms are so uniform that the varieties are easily distinguished. It is beyond the scope of this book to attempt to differentiate all these varieties but any reader interested will find an admirable summary of the conditions illustrated by an excellent plate in Comstock's "How to Know the Butterflies." The species as a whole may be known from the fact that the upper surface is blue, the lower surface ash-gray, more or less spotted with dark brown, and the wings are without tails. (See plate, page 256.)

\section{The Strange Structures of the Larvae}

A remarkable variation of the adults is sufficient to give this species a special interest, but the larvae also have a unique attraction for the naturalist. The mother butter- 
flies lay their eggs upon the flower buds of various plants, especially those which have clustered racemes of blossoms. These eggs hatch into minute slug-like larvae which feed upon the buds, commonly burrowing through the calyx lobes and devouring the undeveloped stamens and pistils inside. They finally change to chrysalids, which are more or less securely attached to a central flower stalk, from which in due time the butterflies emerge. So far there is nothing remarkable about this story of the life of the Spring Azure, but that is yet to come.

These little caterpillars are subject to attack by tiny parasitic flies which lay eggs in their bodies. Each egg hatches into a still more tiny maggot that lives at the expense of the tissues of the caterpillar and finally kills it. When one of these little caterpillars has its head buried in the round bai of a flower bud, about half of its body is exposed defenseless, so that the little fly that lights upon it to lay her egg cannot even be dislodged by the head of the caterpillar, as is often the case with other species. There is a very curious provision for defense, however. If you look carefully through a lens at the hind part of the body you will find a little opening on the back of the seventh abdominal ring. This opening leads to a sort of tiny pocket, a pocker which the caterpillar can turn inside out when it so desires. Now the curious thing about it is that the caterpillar, while this pocket is concealed in its body, is able to secrete in it a drop of liquid which we presume to be sweet to the taste. When the little pocket is partly filled with this drop of liquid the caterpillar turns it inside out in such a way that the liquid drop remains in position on top of the protruded pocket.

Perhaps you ask what is the good of all this complicated 
arrangement? If you could see what happens when the little drop of what-for lack of a better name-we shall call honey-dew is exposed, you would begin to guess the reason. Wherever these larvae are found you will also find many ants wandering round among them, and the moment the honey-dew appears these ants begin to sip it up. When it is all gone the little caterpillar draws in its pocket again and presumably begins to store up another bit of liquid. It is certainly a curious example of what the naturalists call symbiosis, which simply means a living together of two animals, each helping the other in some way. In this case it is easy enough to see how the caterpillar helps the ant, but perhaps you are wondering in what possible way the ant may help the caterpillar. I hardly dare give the most plausible explanation for fear some one will cry out, "Nature-faker!" But fortunately the explanation is based upon at least one precise observation by W. H. Edwards, one of the most careful and reliable naturalists America has produced, who lived before the recent era of Nature-fakers and was never accused of sensationalism. Mr. Edwards saw an ant drive away from one of these caterpillars a little parasitic fly which apparently was searching for a victim. Consequently, it would appear that the ants helped the caterpillars by protecting them from these arch enemies.

This is by no means an isolated example of the relations between ants and other insects. It has been known for hundreds of years that the ants use the aphids as a sort of domestic milk-producer, attending the aphids at all times $\varepsilon$ ad even caring for their eggs throughout the winter season. As the plant-lice live in colonies, sucking the sap of their host plant, they are attended by great numbers of 
ants that feed upon the honey-dew which passes through their bodies. In many cases the ants have been observed to stroke the aphids with their antennae in a way which seems to induce the aphid to give out a drop of the sweet liquid for the ant to lap up. In a similar way these ants seem sometimes to stroke these little caterpillars with their antennae and thus to induce them to turn their little pockets inside out with the drop of liquid at the tip. This is certainly an unusual and most interesting relation between two insects far separated by their structural characters.

The little pocket that I have thus described is situated upon the seventh segment of the abdomen. Just back of it there are two other openings which are even more curious in their structure. These are provided with some slender tentacles on which there are circles of hairy spurs. These structures are a great puzzle to naturalists. It is difficult to explain what they are for unless we assume that they relate in some way to the honey-dew pocket on the seventh ring. The only plausible explanation is that these serve to advertise to the ants, by giving off a distinctive odor, that there is nectar near at hand to be had for the asking. They would thus be analagous in a way to the fragrant scent of flowers which is for the purpose of advertising to the bee the fact that nectar or pollen or both are near at hand and may be had for the asking. In the case of these caterpillars, however, if this is the true explanation it is a most wonderful provision and one which would be likely to tax the ingenuity of man's mind for a long while before it was originated.

So this little butterfly which greets us in every spring, like "a violet afloat," to quote Mr. Scudder's happy phrase, 


\section{THE TRIBE OF THE BLUES}

is full of interest at all stages of its existence. It should lead one to a new respect for the familiar things in the natural world when one learns how baffling to the wits of the wisest scientist is this little creature with its protean forms and the wonderful structure of its caterpillars.

\section{Scudder's Blue}

\section{Rusticus scudderi}

This beautiful little butterfly is perhaps the most richly colored of all our northern Blues. The upper surface of the wings in the male is a nearly uniform hue, except for a narrow dark border around the margin. In the female there is, in addition, a series of black-centred orange spots inside of the black border, the series being more prominent on the hind wings than on the front ones. The under surface is very pale with distinct marks in black scattered over the basal two thirds, with a row of orange spots outside of these and another row of small blackish spots just inside of the blackish border stripe.

This butterfly is a northern species. It occurs in New England, New York, and Michigan, and thence extends far north into Canada. The caterpillar feeds upon blue lupine and apparently the butterfly is likely to be found in most places where this plant grows. The eggs are laid upon the leaves or stems and the little caterpillars come out of the shells through small holes which they have gnawed.

"The caterpillar," wrote Mr. Scudder, "has a very extensible head and flexible neck, and its manner of feeding 
immediately after birth is rather remarkable; it pierces the lower cuticle of the leaf, making a hole just large enough to introduce its minute head, and then devours all the interior of the leaf as far as it can reach-many times the diameter of the hole-so that when the caterpillar goes elsewhere, the leaf looks as if marked with a circular blister, having a central nucleus; the nearly colorless membranes of the leaf being all that is left, and at the central entrance to the blister the upper membrane only." Later in its life it often modifies this feeding habit somewhat, and as it approaches full growth it is likely to devour the entire blade of the leaf.

These larvae have the curious nectar-secreting glands on the seventh abdominal segment which are discussed in connection with the preceding species. Many ants are attracted by this secretion so that it often happens that the easiest way to find the caterpillars is to look for these attendants. In New England there are two broods of the butterfly, one appearing early in June and the other late in July.

\section{The Tailed Blue}

\section{Everes comyntas}

The tiny, thread-like, white-tipped tail projecting from the hind angle of the hind wings distinguishes this species at sight from any other found in eastern North America. The species, however, occurs clear to the Pacific Coast and ranges north and south over most of the northern continent. The small slug-like caterpillar feeds upon the flowers of various clovers and other legumes. 


\section{The Silvery Blue}

\section{Nomiades lygdamus}

It would be a distinct privilege to work out the lifehistory of this exquisite little butterfly. Although the adult was described as long ago as 1842, the early stages seem to be still unknown. The species occurs in the South Atlantic states, extending west as far as Wisconsin.

\section{Synopsis of the Blues}

Tailed Blue (Everes comyntas or Lycaena comyntas). Wing expanse 1 inch or less. A slender tail projecting from each hind wing. Upper wing surface of varying tones of blue, the males lighter than the females. Lower wing surface grayish white with scattered spots.

Scudder's Blue (Rusticus scudderi or Lycaena scudderi). Wing expanse 1 inch or less. No tails on hind wings. Eyes without hairs. Upper wing surface blue; female has dusky margins on front wings and an orange border with blackish spots near outer margin of the hind wings. Lower wing surface bluish gray with many small spots.

Silvery Blue (Nomiades lygdamus or Lycaena lygdamus). Wing expanse 1 inch. No tails on hind wings. Eyes hairy. Upper wing surface silvery blue with dusky margins which are broader in the female. Lower wing surface ashy gray with many darker spots.

Spring Azure (Cyaniris ladon or Lycaena ladon). Wing expanse 1 inch. No tails on hind wings. Eyes hairy. Upper wing surface azure blue with black border markings varying greatly, more pronounced in the female. Lower wing surface slaty brown with many darker spots. 


\section{PART III \\ THE SKIPPER BUTTERFLIES}

\section{SuPERFAMILY Hesperioidea}

The true butterflies are so distinct in their structure and many of their habits from the Skippers that the most careful students of the order are pretty well agreed in making the two great superfamilies-Papilionoidea, the true butterflies, and Hesperioidea, the Skipper butterflies. The latter includes these two families:

The Giant Skippers (Megathymidae).

The Common Skippers (Hesperiidae).

These insects as a whole are distinguished from the higher butterflies by their large moth-like bodies, small wings, hooked antennae (except in the Giant Skippers), by having five branches of the radius vein arising from the large central cell. The larvae spin slight cocoons in which to pupate and the pupae are rounded rather than angular.

The two families are readily distinguished by the differences in their size and the structure of the antennae. The Giant Skippers measure two inches or more across the expanded wings and have comparatively small heads, with the clubs of the antennae not pointed or recurved. The Common Skippers are smaller, and have very large heads with the antennal clubs drawn out and recurved. 


\section{THE GIANT SKTPPERS}

Family Megathymidae

Although large in size, the Giant Skippers are few in numbers. Only one genus and five species are listed for North America, and practically all of these are confined to the Southrestern states and Mexico. Some of them extend as far north as Colorado and as far east as Florida. So far as the story of its life is concerned, the best-

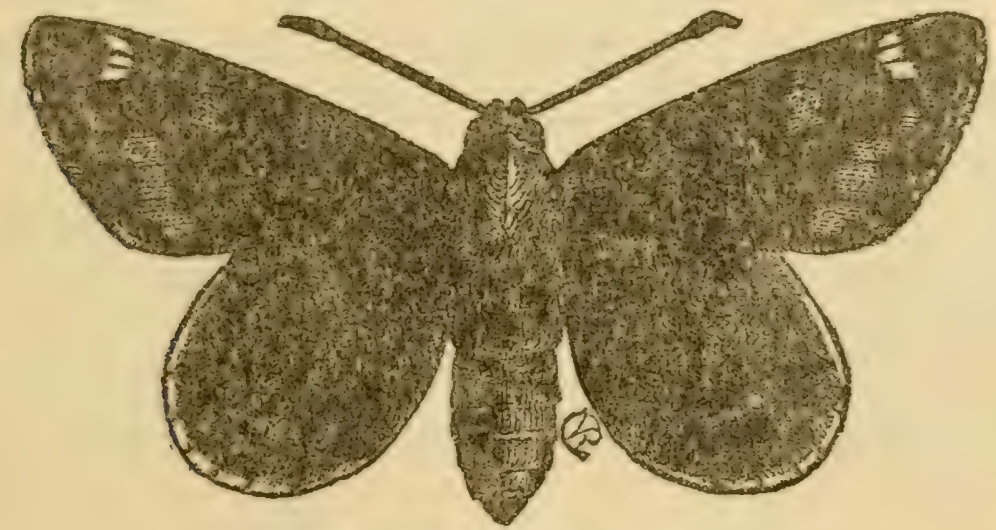

Megathymus yuccae. Female. (After Riley.)

known species is the Yucca-borer Skipper (Megathymus yuccae) which was carefully studied by the late Dr. C. V. Riley. As will be seen from the picture above which represents the adult, natural size, this skipper has a body so large as to suggest some of the heavy-bodied moths. The wings are dark brown, marked with redbrown spots and bands. They fly by day and when at rest hold the wings erect.

These adults lay eggs upon the leaves of Spanish needle or yucca. The eggs soon hatch into little caterpillars which at first roll parts of the leaves into cylinders, fas- 
tening the sides in place by silken threads, and later burrow into the stem and root, often making a tunnel a foot or more deep. Here the caterpillars remain until full grown. They are then nearly four inches long and half an inch in diameter. They now pupate in the top of their tunnel and in due season emerge as adults.

\section{THE COMMON SKIPPERS}

\section{Family Hesperiidae}

The Skippers are the least developed of the butterflies. They show their close relationship to the moths both by their structure and their habits. The larvae make slight socoons before changing to chrysalids, and these chrysalids are so rounded that they suggest the pupae of moths sather than those of butterflies. The common nameSkippers-is due to the habit of the butterflies-a jerky, skipping flight as they wing their erratic way from flower to flower.

In North America the Skipper family includes nearly two hundred species grouped in about forty genera. From. this point of view it is the largest family of our butterflies, but on account of the small size and limited range of most of the species it has by no means the general importance of such families as the Nymphs, the Swallow-tails, or the Pierids.

The Skippers are remarkable for the uniformity of structure in each stage of existence. The butterflies have small wings and large bodies. The broad head bears large eyes without hairs, but with a tuft of curving bristles overhanging each. The antennae are hooked at the end 


\section{THE TRIBE OF THE LARGER SKIPPERS 269}

and widely separated at the base. Each short palpus has a large middle joint and a small joint at the tip. The fore wings project out at the front angle and the hind wings are folded along the inner margin. There are six well-developed legs in both sexes. The colors are chieffy various tones of brown, dull rather than bright, and many of the forms resemble one another so closely that it is difficult to separate them.

The Skipper caterpillars have stout bodies and are easily known by the constricted neck. Most of these have the habit of making nests from the leaves of the food plants, weaving them together with silken threads. In a similar way each also makes a slight cocoon when it is ready to change to a chrysalis.

The Skippers found in eastern North America are commonly grouped into two types - the Larger Skippers and the Smaller Skippers. The characteristics are given in the paragraph immediately following and the one on page 278.

\section{THE TRIBE OF THE LARGER SKTPPERS}

The butterflies of this tribe have that part of the club of the antenna, which is recurved, about as long as the thicker part below it. As a rule, the abdomen is distinctly shorter than the hind wings. The caterpillars are rather short and thick, and the upper part of the head, when looked at from in front, is square or roundish rather than tapering. The chrysalids have the tongue case attached throughout its length and stopping short of the tips of the wing cases. 


\section{The Silver-spotted Skipper}

Epargyreus tityrus

One can seldom draw hard and fast artificial lines in nature. There are all sorts of intermediate conditions which disturb arbitrary classifications. It might seem simple enough to say that some insects are leaf-rollers and others are tent-makers, but as a matter of fact in the case of the Silver-spotted Skipper we have an insect which starts its larval life as a leaf-roller and finishes it as a tentmaker. Its life-history is rather interesting and easily observed, if one can find the larvae at work upon the leaves of locusts and other trees. (See plates, page3272-273.)

The Silver-spotted Skipper is one of the largest butterflies of the interesting group to which it belongs. It lays its eggs upon the upper surface of the leaflets of locusts and other plants of the legume family. In less than a week each egg hatches into a little caterpillar with a very large head and a comparatively large body, tapering rapidly toward the hind end. This little creature cuts out from one side of the leaf a small round flap which it turns over and binds in place by silken threads to make a home for itself. This little home shows considerable variation in its construction but it usually has an arched dome held in place by strands of silk running from the eaten fragment to the surface of the leaf. It remains an occupant of this home until after the second moult. About this time it becomes too large for its house and deserts it to make a new one generally by fastening together two adjacent leaves. These are attached along the edges by silken strands in such a way as to give con- 


\section{THE TRIBE OF THE LARGER SKIPPERS 271}

siderable room. It leaves one end open as a door out of which the caterpillar crawls to feed at night upon near-by leaves, returning to the house for shelter during the day. They continue to use this habitation until they are full grown as caterpillars and sometimes they change to chrysalids within it. More commonly, however, they crawl away both from the leafy case and the tree that bears it and find such shelter as they can upon the ground near by. Here they spin slight silken cocoons within which they change to chrysalids. In the more Northern states there is but one brood a year, so these chrysalids remain in position until early the following summer when they come forth as butterflies. Farther south there are two broods each summer, the second brood of butterflies appearing chiefly in August.

The Silver-spotted Skipper derives its name from the distinct silvery spots upon the under-wing surface against a background of dark brown. The butterflies appear in the Northern states early in June and remain upon the wing for several weeks, being found even in August. They fly very rapidly and are difficult to catch in an insect net except when they are visiting flowers.

This species is widely distributed, occurring from ocean to ocean over nearly the whole of the United States. It extends into Canada only in the eastern part and is not found in the Northwestern states.

\section{The Long-tailed Skipper}

\section{Eudamus proteus}

This is perhaps the most easily recognized of all the Skip - found in the United States for it is the only one 
that looks like a Swallowtail. Its hind wings project backward as long, broad tails in a way that marks the insect at once as different from anything else. It expands nearly two inches and when the front wings are spread at right angles, the distance from the apex of the front wing to the end of the tail of the hind wing just about equals the expanse. The general color is dark brown, with about eight more or less rectangular silvery spots on each front wing.

This is distinctly a tropical species which is common along the Gulf Coast from Mexico to Florida. It ranges north along the Atlantic Coast to New York City and even to Connecticut. In the South Atlantic states it is common, but toward the northern limits of its range it is very rare.

In the West Indies this butterfly is very common and has been observed to rest with its wings vertical, the front ones held far back between the hind ones and the tails of the latter held at right angles to the plane of the wings. Apparently, this curious fact was first noted by Dr. G. B. Longstaff. Of course in museum specimens the wings have been flattened into the same plane during the process of drying, so that this peculiarity would not be noticed.

\section{Juvenal's Dusky-wing}

Thanaos juvenalis

There are few trees which have so interesting a set of insects attacking them as does the oak. It would be a simple matter to find abundant material for a large volume by making a study of the life-histories of the various 


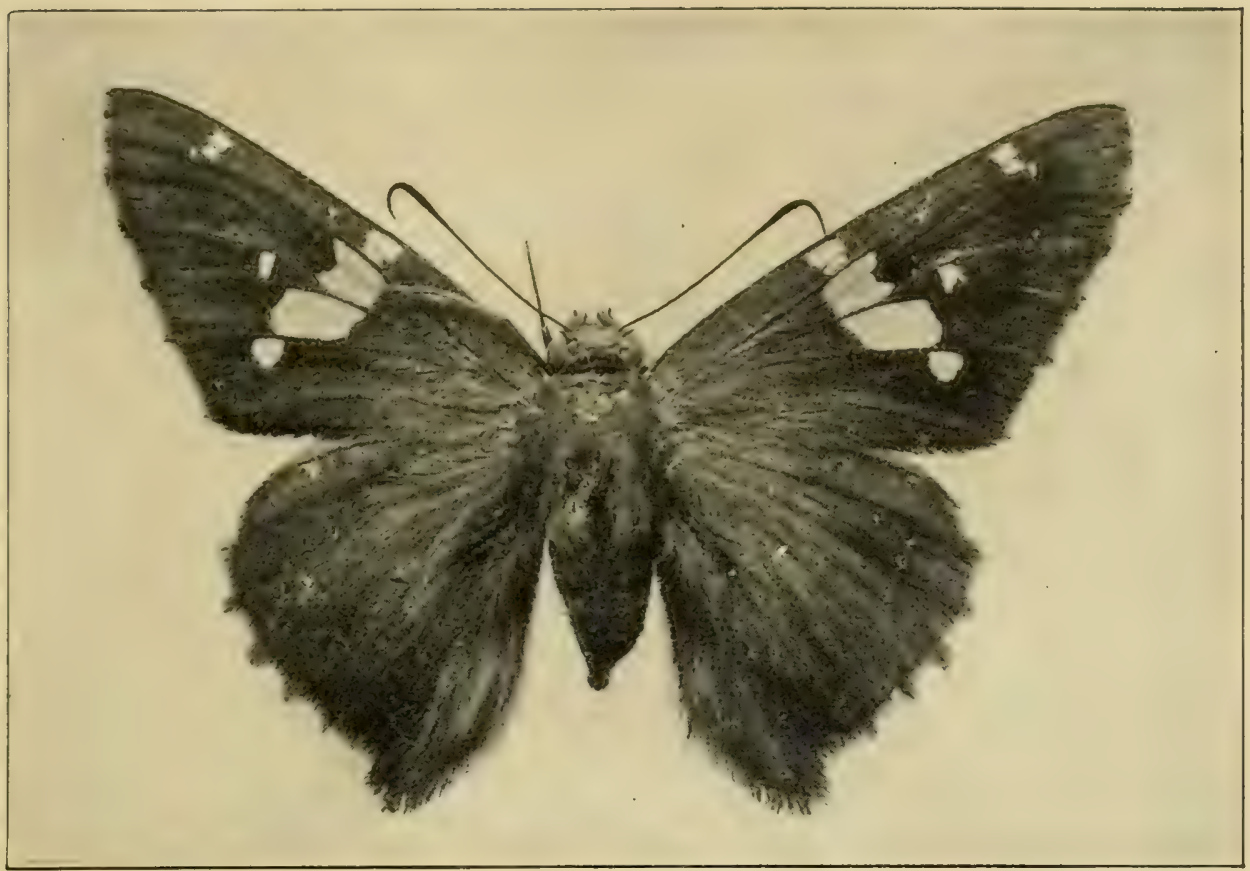

Upper Surface

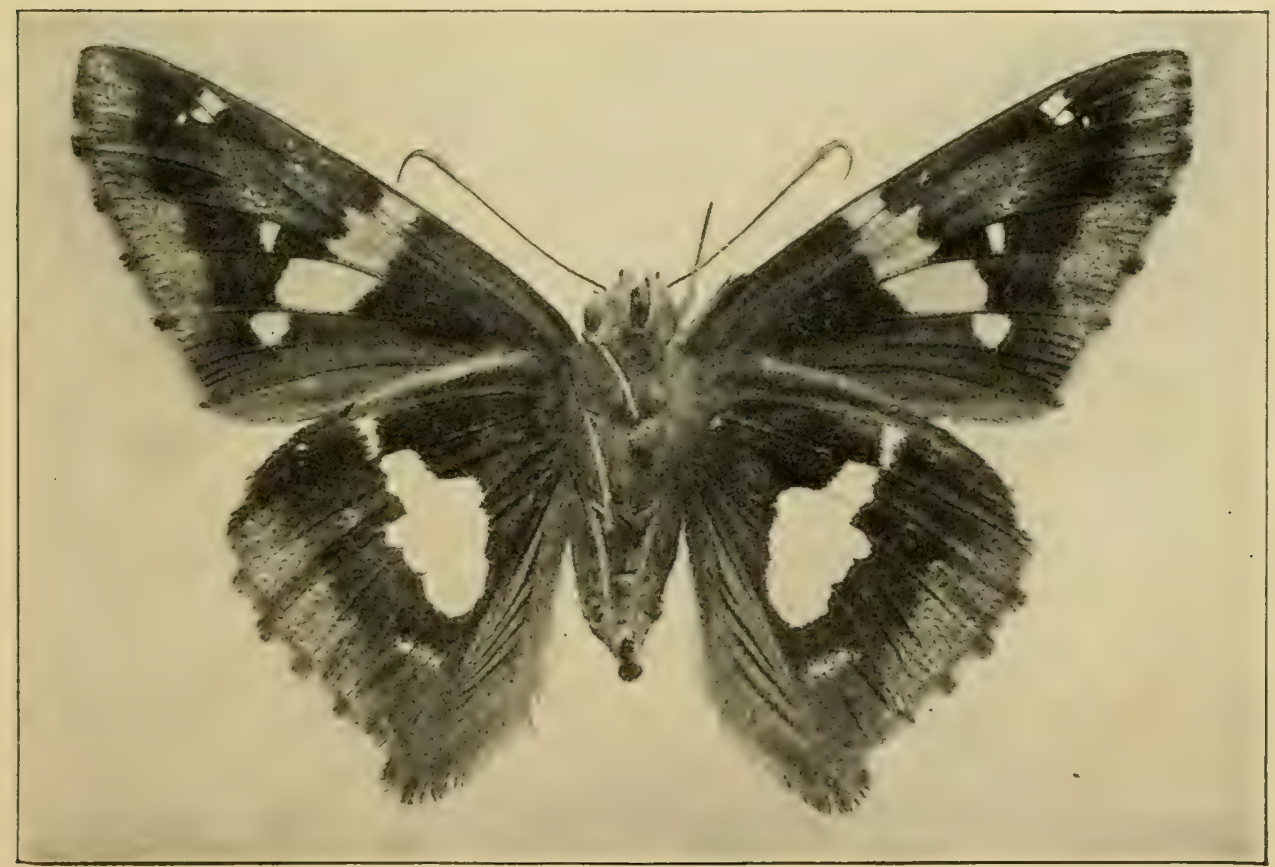

Photograph by A. H. Verrill

Lower Surface

See page 270

TIIE SILVER-SPOTTED SKIPPER

(About twice natural sizc) 


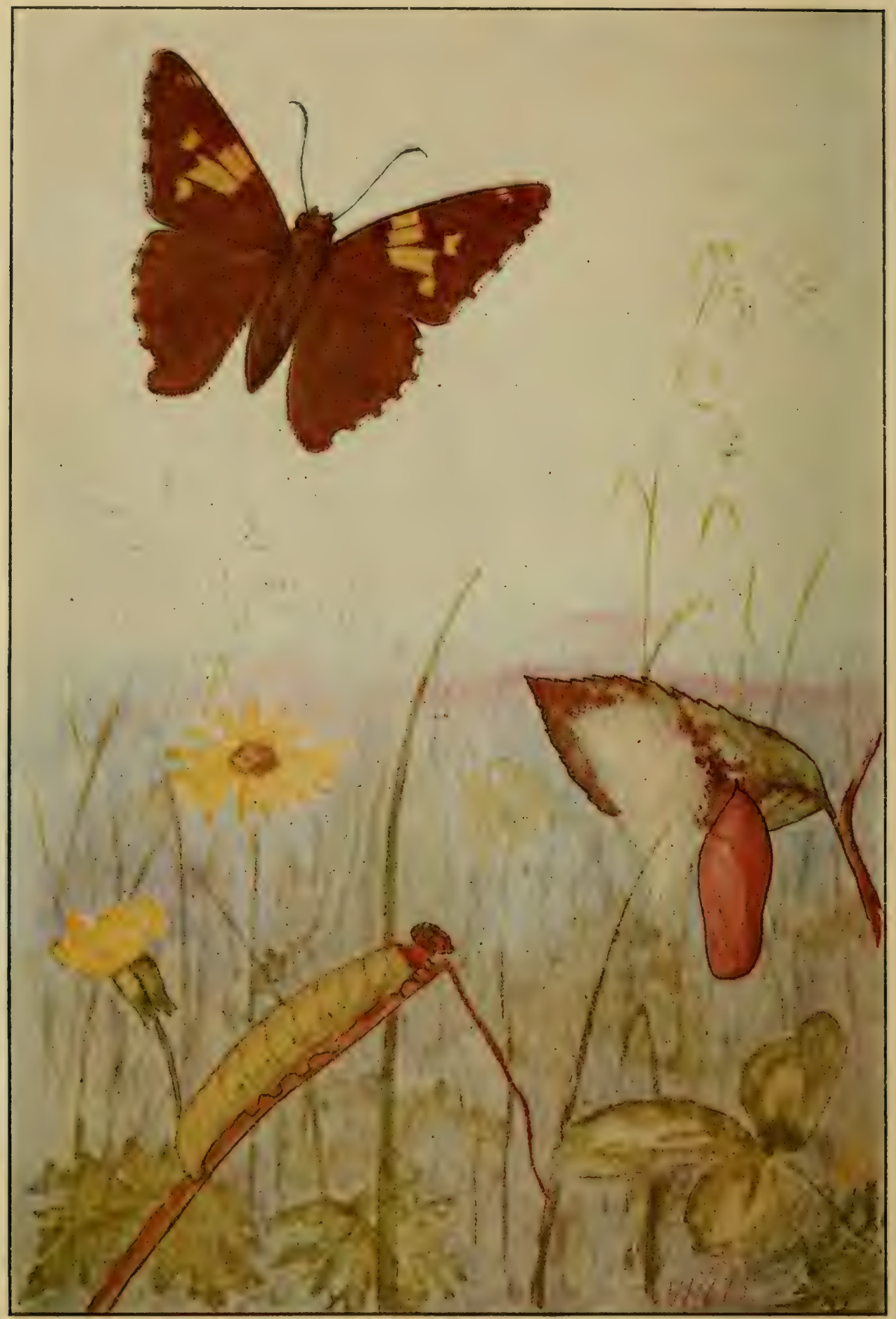

From a drawing by W. I. Beecroft

See page 270

THE SILVER-SPOTTED SKIPPER

Caterpillar, chrysalis and adult 


\section{THE TRIBE OF THE LARGER SKIPPERS 273}

insects that live upon or within the various tissues of this tree. The leaves alone provide a home for a remarkably large number of insect species scattered through a great many orders and families. The thickened blades seem to furnish an ideal opportunity for many larvae to get their living, and they are particularly useful to those which need to make a winter nest.

By a little searching almost any time after the middle of June, one is likely to find a curious caterpillar home upon some of the oak leaves. The margin of the blade has been turned over, generally from above downward but sometimes from below upward, and has been fastened down to the main expanse of the blade by means of golden threads; commonly this fastening is not continuous but is more or less intermittent, so that the turned-over margin is likely to have an irregular border where it joins the blade. Inside of this tubular construction a rather unusual looking worm-like caterpillar is probably to be seen. Late in the season it will probably be nearly an inch long, with a smooth greenish body and a head that may be a bit brownish and more or less marked on the sides with orange tones.

This is the larva of one of the most widely distributed Skippers-Juvenal's Dusky-wing. The species is found from southern New Hampshire west to the Great Plains and south to the Gulf of Mexico. In most localities it is seldom abundant but yet is so general that it may be found by almost every persistent collector. The wings expand about an inch and a half and are of a dull brownish color, more or less marked with darker and lighter spots. Toward the northern limits of its range there is but one brood a year but farther south there are two, although it 
is not improbable that some of the caterpillars of the first brood remain unchanged throughout the season, so that the insect is both single- and double-brooded in the same locality.

\section{The Yearly Cycle}

The yearly cycle in southern New Hampshire may be taken as an illustration of the life of the species in regions where there is but one brood. The butterflies appear in open woods and on cut-over lands in May and June. They lay eggs upon the twigs of oak trees, one egg in a place and generally near a leaf stem. The egg soon hatches into a little caterpillar that crawls upon a near-by leaf and begins the construction of its tubular nest by bending over the margin and sewing it with golden silk. It utilizes this nest chiefly as a tent for resting and sleeping and wanders away from it generally to another leaf when it is ready to feed. It grows very slowly, having before it all the weeks of summer to complete its caterpillar growth. As it gets larger it needs a new tent and is likely to desert its early one. When it does this some observers have noted a curious habit. It cuts loose all the silk that binds the margin of the leaf down upon the blade so that the flap is free to spring back to its original position. It would be difficult to suggest an adequate explanation for this habit.

When autumn comes our caterpillar is faced with the problem of passing through the winter successfully. It must shelter itself from birds, spiders, predaceous beetles, and many other enemies. It must find a means of keeping out of the reach of snow and rain, for while it can survive a great degree of cold as long as it keeps dry, it might easily 
be killed by freezing up with moisture. But the caterpillar is able to provide against these dangers. It has apparently an abundant supply of liquid silk to secrete from the silk glands in its head, so it lines its tubular tent with a dense silken web that effectually excludes enemies and moisture. It thus has on the outside of its nest the thick oak leaf and on the inside a dense soft lining that makes a most admirable winter protection. So it remains here throughout the winter, the leaf commonly staying on the tree until early spring. Then leaf, nest, and enclosed caterpillar are likely to drop to the ground to remain until spring arrives in earnest. Just what happens then seems to be a bit doubtful. The caterpillar changes to a chrysalis, but whether it first works its way out of its winter nest and makes a new and less dense covering seems not to be certainly known. Here is another good opportunity for some careful observations.

At any rate, the caterpillar changes to a chrysalis, and late in spring it changes again to an adult butterfly that flits about on "dusky wing for a few weeks before it dies.

\section{The Sleepy Dusky-wing}

Thanaos brizo

The appearance of this butterfly both as to size and marking is very similar to that of Juvenal's Dusky-wing except that the white spots are not present on the front wing of this species. The life-histories of the two species as well as their distribution seem to be closely parallel. The present butterflies are to be found early in summer in 
the same oak barrens as the other, the blueberry blossoms being freely visited for nectar by both species.

\section{Persius's Dusky-wing}

\section{Thanaos persius}

This is a rather small, dark brown Skipper, with a few white spots toward the apex of the front wing, but otherwise not marked except for a very pale transverse band which is almost obsolete. The butterfly is found from ocean to ocean along the northern tier of states. It also occurs in the Eastern states as far south as Florida as well as in the states along the Pacific Coast.

The food plants of the caterpillars differ from most of those of the other Skippers. The butterflies lay their yellowish green eggs, one in a place, upon the leaves of willows and poplars. These soon hatch into little caterpillars each of which cuts out a small flap along the margin of the leaf and folds it over, fastening it in place with silken threads. It thus forms a protecting nest within which it remains during the day, going forth at night to a neighboring part of the same leaf or to another leaf, and feeding upon the green surface tissues. In this first caterpillar stage it does not eat the veins to any extent. As it becomes larger it constructs a larger nest and feeds more freely upon the leaf tissues. When about half grown it has the curious habit of biting out small holes here and there in the blade so that the leaf takes on a very unusual appearance. The presence of these holes is generally the easiest way to find the caterpillars, for when the holes are seen, a 
little searching is likely to show one the characteristic tentlike nest.

After a few weeks the caterpillars become full grown. They then sew themselves in for the winter, fastening all of the crevices in the nest so securely with silken webbing that a very serviceable winter cocoon is formed. An interesting fact is that this sewing up for the winter is likely to take place about midsummer, the caterpillars remaining quiet from this time until the following spring. The nests of course fall in autumn with the leaves and the caterpillars remain unchanged until April or May, when they transform into chrysalids to emerge in May as butterflies. There appears to be normally but one brood a year although there is some evidence of a partial second brood.

\section{The Sooty Wing}

\section{Pholisora catullus}

This is one of the smallest of the blackish Skippers and may be known by its small size, expanding less than an inch, and the series of five white dots near the apex of the front wing, these dots being more distinct on the under surface. The species is widely distributed, occurring over practically the whole of the United States, except in the states along the Canadian border from Wisconsin westand in several of these it is found along their southern limits.

This butterfly is of particular interest because it is one of the comparatively few species that habitually occur in gardens and cultivated fields. The reason for this is that the eggs are laid upon white pigweed or lambs' quarter, 
the common garden pest of the genus Chenopodium. The eggs are laid singly, generally on the upper surface, and hatch in about five days into tiny caterpillars that make a little shelter for themselves by cutting out the edge of a leaf and folding over the blade, sewing it in place by a few silken threads. Here they remain and feed upon the green pulp of the succulent leaves either within the nest or near by outside. They remain in these cases until the time for the first moult, when they are likely to line the inside of the silken web before moulting. After this they make new cases for concealment and shelter, the cases as they grow older being generally made of two or more leaves securely bound together by silken web along their margin. When they become full grown, they spin a silken cocoon and change to yellowish green chrysalids from which the butterflies emerge a little more than a week later.

This species is supposed to be double-brooded in the north. The full-grown caterpillars of the second brood sew up their leafy cases very carefully, making them of such thick silken webbing that they are watertight. They remain in these coverings until the following spring, when each changes, still within the case, into a chrysalis from which the butterfly comes forth in April or May.

\section{THE TRIBE OF THE SMALLER SKIPPERS}

In the members of this tribe the tip beyond the club of the antenna is short and the abdomen is long enough to extend as far as or farther than the hind wings. The caterpillars have long and slender bodies with the upper part of the head, when looked at from in front, tapering 


\section{THE TRIBE OF THE SMALLER SKTPPERS 279}

rather than roundish or square. The chrysalids have the tongue-case free at the tip and projecting beyond the tips of the wing-cases.

\section{The Tawny-edged Skipper}

Thymelicus cernes

This is one of the commonest and most widely distributed of all our Skippers. It is found from Nova Scotia to British Columbia, south along the Rocky Mountains to New Mexico, Texas, and Florida. It is apparently absent west of the Rocky Mountains and along the Gulf Coast except in Florida. Its life-history was carefully worked out by Dr. James Fletcher, late entomologist to the Dominion of Canada, and in the north may be summarized thus: the butterflies come from the hibernated chrysalids in May or June. They remain upon the wing for several weeks so that worn specimens may be taken late in July or, rarely, even early in August. The females lay eggs upon grass blades. These eggs hatch about two weeks later, the larvae eating their way out of the shells so slowly that a whole day may be taken up by the operation. Each little caterpillar weaves a silken nest for itself, in which it remains concealed most of the time, reaching out to feed upon adjacent blades of grass but retiring into the nest at the least alarm. It is a sluggish little creature and grows so slowly that in the north it may require more than two months to become full fed as a larva. It is then abouf: an inch long and has the characteristic outlices of the other Skipper larvae, with a black head and a greenish brown body. It now spins a cocoon, possibly using its 
larval nest as a basis, and some time later, before cold weather surely, it changes to a chrysalis that winters over.

This is the story of the life of the butterfly in the more northern parts of its range. Even in New Hampshire there seems to be at least a partial second brood, and farther south there are probably two regular broods with the possibility that a small percentage of the first set of chrysalids remains unchanged until spring.

\section{The Roadside Skipper}

\section{Amblyscirtes vialis}

This little butterfly is found apparently in most parts of the United States, as it has been collected in New England, California, Texas, and many intermediate points. Over the northern part of its range there is but one brood a year. In New Hampshire the butterflies appear in May and early June and lay eggs upon the blades of various grasses. These hatch about ten days later into slender, silk-spinning caterpillars, each of which makes a nest for itself by sewing together the margin of one or more grass blades. When the larvae get larger, they make larger and denser nests with heavy linings of silken web. After the earlier moults, the thin skin is covered with very fine snow-white hairs, between which there is developed a curious whitish exudation, so that the caterpillars have a flocculent appearance. When full grown, they change to delicate green chrysalids which apparently in the North remain until the following spring before disclosing the butterflies. In more southern regions there are two broods each summer. 


\section{THE TRIBE OF THE SMALLER SKIPPERS 281}

\section{The Least Skipper}

\section{Ancyloxipha numitor}

The Least Skipper differs from the other Skippers both in structure and habits. Most of these butterflies have thick bodies and a distinct hook at the end of each antenna. This has a slender body and the antennae lack the hook. Most Skippers have strong wings and show their strength in their rapid, erratic flight. This has feeble wings that show their weakness in their slow, straight flight. But from the fact that it is about the smallest of all our butterflies, expanding little more than three quarters of an inch, it deserves our interested attention. The tawny wings are so marked with broad margins of dark brown that they show the tawny tinge chiefly in the middle spaces.

On account of its small size and its retiring habits this little butterfly is often overlooked by all but the most experienced collectors. It generally flies slowly just above the grass in sunny places in wet meadows and along the open margins of brooks and marshes. It rests frequently upon grasses, flowers, or bushes. Mr. Scudder noticed that when resting these butterflies have the curious habit of "moving their antennae in a small circle, the motion of the two alternating; that is, when one is moving in a forward direction, the other is passing in a reverse direction." This is the sort of observation that should challenge us all to sharper wits in watching living butterflies. It would be strange if no others thus twirled their feelers in their leisure moments. Who will find out?

The female butterflies at least have something to do besides sipping the nectar of flowers or idly twirling their 
feelers. They must lay their eggs and thus provide for the continuation of the species; to do this they find suitable blades of grass on which they deposit their tiny, halfround, smooth yellow eggs. A week or so later each egg hatches into a dumpy little yellow caterpillar with a black head and a body well covered with hairy bristles. This little creature is a silk spinner and makes a home instinctively by drawing together more or less the outer edges of a leaf blade and fastening them with transverse bands of silk. It then feeds upon the green tissues and as it grows larger it makes its nest more secure by thicker walls of silken web.

When full grown as a caterpillar it changes into a slender chrysalis generally of a grayish red color, thickly dotted with black. About ten days later it emerges as a butterfly.

The Least Skipper is one of the most widely distributed of all butterflies. It occurs from New England to Texas, south to Florida on the east coast, and west to the Rocky Mountains. 


\section{GENERAL INDEX}

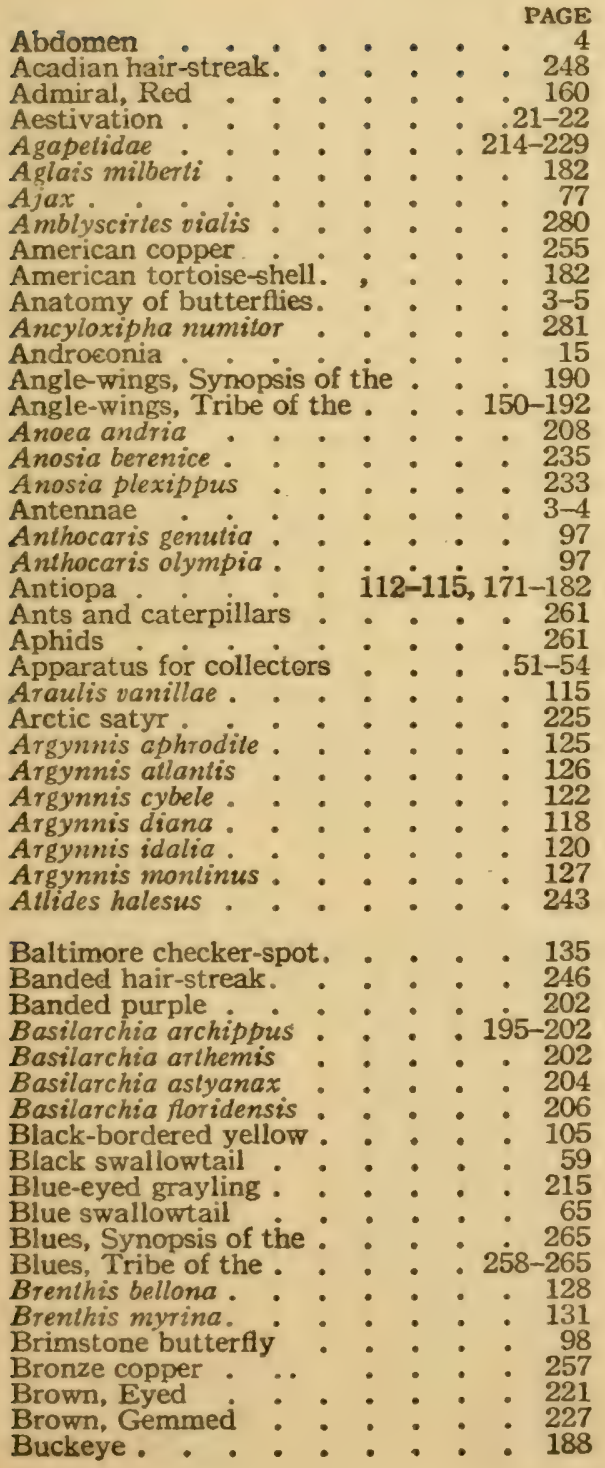

Butterflies, Aestivation of PAGE

Butterflies, Anatomy of : : 3-5

Butterflies and Moths, Difference be-

tween
Butterflies, Classification of : $\quad 13-14$

Butterflies, Collecting . : : .49-54

Butterflies, Coloration of : : .24-35

Butterflies, feigning death. $. .22-23$

Butterflies, General characteristics of 3-54

Butterflies, Hibernation of . . .17-21

Butterflies, Migrations of . . . .16-17

Butterflies, Parasites of . . . .40-43

Butterflies, Photographing. : . .47-48

Butterflies, Rearing of . . . .43-47

Butterflies, Scents of : : : 15

Cabbage butterfly, Southern . . 88

Cabbage butterfly, White or Impor ted 83

Callidrayas eubule . . . . . . 98

Calosoma scrutalor : : : : 181

Calycopis cecrops : : : 251

Camberwell beauty, see Mourningcloak

Carolina satyr . . . . . . 227

Caterpillar cages . . . . . . 44

Caterpillar collecting : . : . : 44

Caterpillar habits, curious. : . . 198

Caterpillar hunter . . : : : 181

Caterpillar parasites : . : . 260

Caterpillar to chrysalis. . . . . 8-10

Caterpillars . • . . 5-9

Catopsilia eubule, c. philea, or c. agari-

the 109

Cercyonis alope G. $^{\circ}$ : : : : : 215-228

Cercyonis pegala. : : : : 218

Chalcid flies . : . : : 42

Charidryas nycleis : : : : 141

Checker-spot, Baltimore $i \cdot$ : : 135

Checker-spot, Harris's . : : : 140

Checkered white . . . . . 88

Chlorippe cellis . : $: 0^{\circ} \quad 2_{210}$

Chlorippe clyton. : . : : $: 212$

Chrysalis.

Chrysalis to butterfiy: : : 10-13

Chrysophonus hypophloeus. : : 257

Chrysophanus thoë . • • • . 257

Cinclidia harrisii : : $:$ : $: 140$

Cissia eurytus : : : : 226

Cissia sosybius : . . . . 227

Classification of butterflies : : 55

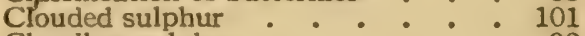

Cloudless sulphur : $: \quad: \quad$ : 98

Colias caesonia . . . • . . . 110

Colias eurytheme : • • : • 1110

Colios philodice . : : : : 110 
Collecting butterflies . . . 49-54

Color changes

Color sense, Selective

Coloration

Comma

Common skippers .

Common wood nymph.

Compton tortoise

Copper, The American.

Copper, The Bronze

Coppers, Synopsis of the

Coppers, Tribe of the .

Cosmopolite.

Counter-shading

Cremaster . . . . 8

Crescent-spots, Synopsis of the : 149

Crescent-spots, Tribe of the . . 135-150

Cyanide bottle ....... 51

Cyaniris ladon . . . . . . . 258

Cynthia alalanta . . . . . 191

Cynthia cardui . . . . . . . 191

Cynthia huntera. . . . . . . 191

Cynthia Moth . . . . . . . 14

Dainty sulphur .

Dazzling coloration. . . . . . 26-29

Death-feigning . . . . . .22-23

Debis porllandia. . . . . . 227

Diana fritillary . . . . . 118

Dog's-head butterfly : : . : 100

Drying box

Dull-eyed grayling . . . . . : 228

Dusky-wing, Juvenal's. . . . . 272

Dusky-wing, Persius's . : : : : 276

Dusky-wing, Sleepy

Eclipsing coloration

Eclosion .

Egg-laying

Emperors, Tribe of ${ }^{*}$

Encasement theory.

Enodia portlandica.

Envelopes for collector

Epargyreus tityrus - : : : 270

Euchloe genutia. . . . . . 97

Euchloe olympia.

Eudamus proteus . . . . . . 271

Eugonia J-album : • •

Euphydryas phacton : . . . 135

Eupsyche $M$-album . : : : : 244

Euptoiela claudia . . . . . . 116

Eurema euterpe : : : : : : 111

Eurema lisa. : 106

Eurema nicippe... . . . . 105

Eurymus eurytheme. . . . . . 102

Eurymus interior . . . . . . 104

Eurymus philodice . . . . . . 101

Euvanessa antiopa: : : : : : : 191

Everes comyntas. : : : : : : 264

Exuviae
Eyed brown: : : : : : : : 221

Falcate orange-tip . . . . . . 94

Fenisequa tarquinius : $: 0^{-} \cdot 253$

Fritillaries, Synopsis of the : : 133

Fritillaries, Tribe of the : : 115-135

Gemmed brown. . . . . . 227

Georgia satyr : : $: \vdots \vdots: 227$
Giant skippers

PAGE

Giant swallowtail

Goatweed emperor

Gossamer-wings. : . : 240-265

Gropta comma . . . . . . . 190

Grapta faunus : : • • • • 190

Grapta interrogationis : : : : 190

Grapta J-album . . . • . . . 192

Grapta progne : : : : : 191

Gray comma . • • • • • 158

Gray emperor . . . . . : 210

Gray hair-streak . . . . . 245

Gray-veined white . . . . : 86

Grayling, Blue-eyed : . : 215

Great purple hair-streak . : : : 243

Great southern white

Great spangled fritillary : : : : 122

Green-clouded swallowtail. : : : 67

Green comma . . . . . . 159

Gulf fritillary : : : : 115

Hair-streaks, Synopsis of the . . 250

Hair-streaks, Tribe of the . : 242-252

Harris's checker-spot

Heliconians

Heleconidae

Heliconius Charitonius.

Heliotropism

Heodes hypophlaeus.

Hesperiidae.

Hesperioidea.

Hibernation.

Honey-dew

Hop merchant

Hypatus bachmani :

$-232$

$229-232$

- 229

.35-37

255

268-282

$55,266-282$

$.17-21$

261

153

236

Ichneumon flies.

$.41-42$

Imago

Imported cabbage butterfly : : 83

Iphiclides ajax • • . : : : 76

Junonia coenia . • • • • . 188

Juvenal's dusky-wing : $: \vdots \quad: \quad 272$

Killing bottle . . . . . . 51

Laertias philenor . • . . . . 65

Larger Skippers, Tribe of the : : 269-278

Least purple hair-streak $: \vdots 251$

Least skipper . . . . . 281

Lepidoptera, see Butterfiles

Libytheidae

Limenitis arthemis

236-239

Limenitis astyanax

Limenitis disippus : $: \vdots 207$

List observations . $: .37-40$

Little sulphur : : : : : 106

Little wood nymph.

Little wood satyr

Locusts, Coloration of : : : 29

Long-beaks, The : : : 236-239

Long-tailed skipper.

Lycaena comyntas . . . . • . 265

Lycaena ladon . . : • . 265

Lycaena lygdamus : : : : $: 265$

Lycaena scudderi : : : : 265

Lycaenidae . . : : : 240-265

Lymnadidae : : : : : 232-236 
Marcellus $\quad$ PAGE

Maritime grayling : : : : : 228

Meadow-browns, The : : : 214-229

Meadow fritillary . . . . . 128

Meganostoma caesonia : : : : 100

Megathymidx . . . . . . 26ं7-268

Megathymus yuccae. . . . . 267

Melitaea harrisii, $M$. phaeton, $M$. nyc-

teis, or $M$. tharos . . . . . 149

Metal-marks, The . . . 239-240

Microgaster . . . . . . - 42

Migrations
Milkweed butterfies, The : : : 232-236

Mimicry . . . . 34-35

Mitoura damon . . . . . . 249

Monarch, The : : : : 12-233

Moths . . . . . . . .13-14

Moulting. : : : : : 6-7

Mountain silver-spot - . 126

Mourning-cloak. : : i12-115, 171-182

Nathalis iole. . . . . . . 109

Neonympha canthus. : : : : 227

Neonympha eurytus. . : : : : 228

Neonympha gemma . . . . . 227

Neonympha phocion. . . . . . 227

Net, Butterfly - . . . . . . 51

Nettle butterfly. . . . . . . 160

Nomiades lygdamus. . . . . . 265

Nymphalidae . . . . . . 111-214

Nymphs, The . . . . . . 111-214

Odors, see Scents of butterflies

Oeneis norna julla . . . . . 225

Oeneis norna semidea : : : : : 222

Olive hair-streak . . . : . : 249

Olympian orange-tip : : : : 96

"Orange dogs" . : : : : : 63

Orange sulphur . : : 102

Orange-tips, Synopsis of the . . 97

Orange-tips, Tribe of the . . . .92-97

Orientation, see Heliotropism

Painted beauty .

163

Painted lady.

Palamedes swallowtail :

Palpi .

Papilio asterias

Papilio brevicauda .

Papilio cresphontes.

Papilio glaucus.

Papilio palamedes

Papilio philenor.

Papilio polyxenes

Papilio thoas.

Papilio troilus

Papilionidae.

Papilionoidea

Parasites of the Mourning-cloak : . $170-43$

Parnassians . . . . . . 56-57

Parnassiidae. : : : : . . : $56-57$

Pearl crescent: : : : : 143

Pearly eye : : : : : : 219

Persius's dusky-wing : : : : 276

Pholisora calullus : : : : 277

Photographing butterflies: : :47-48

Phyciodes nycteis . : : : 149
Phyciodes tharos. PAGE

Pieridae : : : : : : $82-115$

Pieris napi: 86

Pieris phileta - . . . : . 92

Pieris protodice . $\quad . \quad$ : : : : 91

Pieris rapae . . . . . . 83

Pink-edged sulphur. . . . : : 104

Pins for collectors . . . . . 53

Polygonia comma . . . : 153

Polygonia faunus . . . . . 159

Polygonia interrogationis . . . . 150

Polygonia progne . . . . 158

Polygonias, Synopsis of : : : : 190

Pontia monuste. : . : : 90

Pontia protodice. - : : : 88

Protective coloration, see Coloration

Purple hair-streak, Great . . . 243

Purple hair-streak, Least : . : 251

Purples, Banded and Red-spotted 202-206

Pyrameis atalanta. . . . . 191

Pyrameis cardui. . . . . . . 191

Pyrameis huntera . . . . . . 191

Pyrrhanea andria . . . . . 214

Queen, The . . . . . . 235

Rearing butterflies . . . . . 43-47

Red Admiral : : : : : : 160

Red-horns, Tribe of the : : : 97-115

Red-spotted purple. . : : : . 204

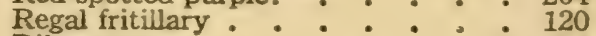

Riker mounts : . . : : : 54

Riodinidae : : : : : 239-240

Roadside skipper . . . . . . 280

Rusticus scudderi : • • • : 263

Satyr, Arctic. . . . . . 225

Satyr, Little wood . . . . . 226

Satyrodes canthus - . . . : 221

Satyrs, The . . . . 214-229

Satyrs, Georgia and Carolina . - $\quad 227$

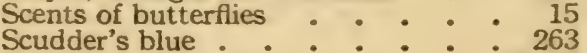

Selective color sense $: \quad: \quad: 32-33$

Setting board . . : : : . . . $52-53$

Shadow observations : $: .37-40$

Short-tailed papilio. : : : : 75

Silver-bordered fritillary : : : 131

Silver crescent . . : : : : 141

Silver-spot fritillary : : : : 125

Silver-spotted skipper . . . . : 270

Silvery blue. . : : : 265

Skippers . . . . . . 55, 266-282

Skippers, Common . . . 268-282

Skippers, Tribe of the larger : 269-278

Skippers, Tribe of the smaller. : 278-282

Sleepy dusky-wing . . . . 275

Smaller skippers, Tribe of the. : 278-282

Snout butterfies, The . . 236-239

Sooty wing, The $\quad$ - 277

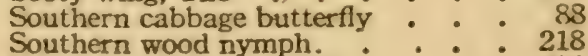

Southern wood nymph
Sovereigns, Synopsis of the $:$ : $: 206$

Sovereigns, Tribe of the : : $192-207$

Spring azure. . . : : • 258

Striped hair-streak - 247

Sulphur butterflies, 98-100, $101-105,106-109$

Swallowtails. . . . . . . $57-81$ 


\begin{tabular}{|c|c|c|c|c|c|c|c|}
\hline & & & & & & & \\
\hline Swallo & psis of & & & Vanessa huntera. & & - & $\begin{array}{ll}A G E \\
163\end{array}$ \\
\hline & & & 94 & Vanessa J-album & . & . & 192 \\
\hline T. & . & . & 96 & Vanessa milberti. & - & & 191 \\
\hline Tachina flies. & - & . & $42-43$ & Variegated fritillary & $\dot{.}$ & & \\
\hline & & - & & Vicereine. & - & & $\begin{array}{l}116 \\
206\end{array}$ \\
\hline $\begin{array}{l}\text { Tawny-edged skipp } \\
\text { Tawny emperor. }\end{array}$ & er . & . & . 279 & Viceroy. & - & & $195-202$ \\
\hline r. & - $\cdot$ & & - 212 & Violet-tip & . & & - 150 \\
\hline Terias lisa. & : & & $\begin{array}{r}77 \\
-\quad 110\end{array}$ & Wanderer. The & & & \\
\hline $\begin{array}{l}\text { Terias nicippe } \\
\text { Thanaos brizo }\end{array}$ & : & & $: 110$ & Warning coloration: & : & : & $\begin{array}{r}253 \\
.33-34\end{array}$ \\
\hline & - & & - 275 & Weismann's theory. & : & & \\
\hline nalis & - & & 272 & White cabbage butterfly & - & & \\
\hline ius. & & & 276 & White J butterfly & - & & 185 \\
\hline a calanus & & & 248 & White M hair-streak & & & - \\
\hline a calanus & • & & & White Mountain butter & & - & \\
\hline & - & - & 252 & $\begin{array}{l}\text { White Mountain fritinar } \\
\text { Whites, Synopsis of the }\end{array}$ & $\operatorname{ary}$ & - & \\
\hline non & & • & $\begin{array}{l}252 \\
: \quad 250\end{array}$ & $\begin{array}{l}\text { Whites, Synopsis of the } \\
\text { Whites, Tribe of the }\end{array}$ & : & : & $\begin{array}{r}91 \\
82-92\end{array}$ \\
\hline ops: & & : & $\therefore \quad 247$ & Wing expansion. & : & : & $.12-13$ \\
\hline & . & . & . . 251 & Wood nymph, Little & - & . & 8 \\
\hline melinus & : & : & : $166-171$ & Wood mymphs . & & $\cdot$ & \\
\hline Thora & - & - & . $\quad 4$ & Xanth & & & \\
\hline Ines & - & 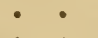 & - $\quad$ - 27 & Xanthidia nicippe & & - & \\
\hline $\begin{array}{l}\text { Tiger swallowtail } \\
\text { Tortoise-shell, Ames }\end{array}$ & erican & $: \quad:$ & $: \quad 182$ & & & & \\
\hline Transformations & .. & & : $5-13$ & Mourn & & loal & \\
\hline Uranotes melinus & - & & 24. & f the & - & & \\
\hline & & & & Iuced-Dorel skpph & & & \\
\hline & & : & .. & & & & \\
\hline anessa cardaui. & - & . & - 166-1' & ail & & : & \\
\hline anessa coenia. & - & - & & Zerene caesonia. & & & \\
\hline
\end{tabular}




